\title{
The Integration of Human Factors (HF) in the SAR Process Training Course Text
}

Thomas G. Ryan

Published March 1995

Idaho National Engineering Laboratory Applied Engineering and Development Lockheed Idaho Technologies Company Idaho Falls, Idaho 83415

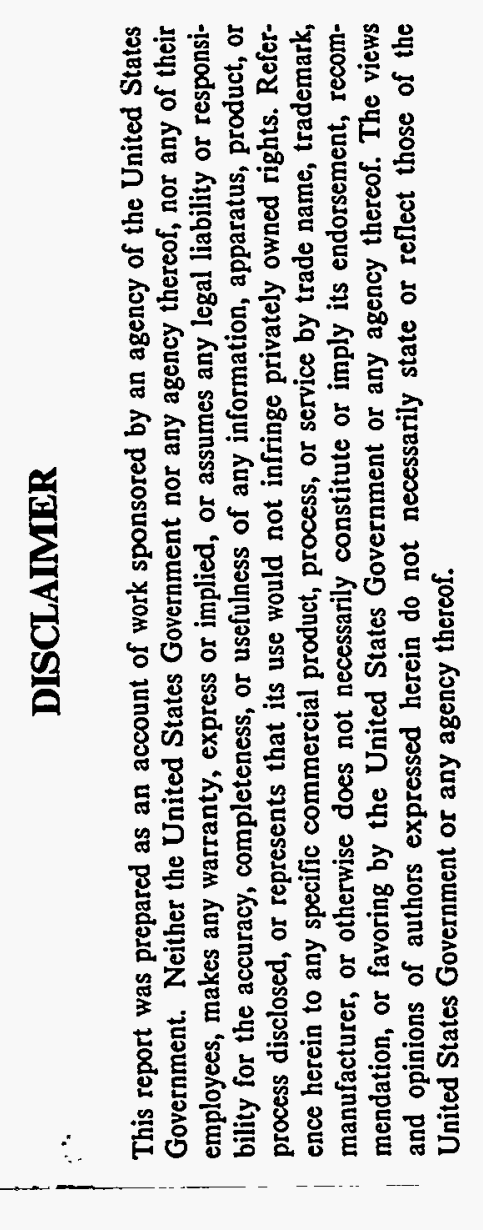

\section{MASTER}




\section{DISCLAIMER}

Portions of this document may be illegible in electronic image products. Images are produced from the best available original document. 


\section{TABLE OF CONTENTS}

LIST OF FIGURES $\ldots \ldots \ldots \ldots \ldots \ldots \ldots \ldots \ldots \ldots \ldots \ldots$ TOC-8

LIST OF TABLES $\ldots \ldots \ldots \ldots \ldots \ldots \ldots \ldots \ldots \ldots \ldots \ldots \ldots$ TOC-9

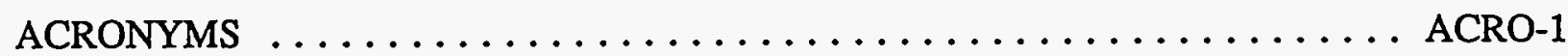

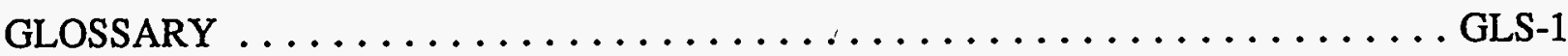

Introduction: Purpose of the Human Factors (HF) Course Text $\ldots \ldots \ldots \ldots$ INTRO-1

Introduction References $\ldots \ldots \ldots \ldots \ldots \ldots \ldots \ldots \ldots \ldots \ldots \ldots \ldots \ldots$ INTRO-2

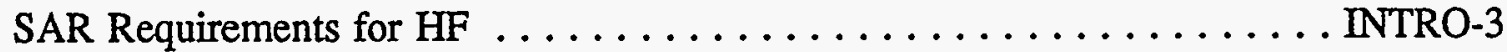

Technical Basis for Course Text $\ldots \ldots \ldots \ldots \ldots \ldots \ldots \ldots \ldots$ INTRO-7

DOE Requirements for HF $\ldots \ldots \ldots \ldots \ldots \ldots \ldots$ INTRO-8

Technical Basis for the General Contents of the HF SAR Course . . . . . . INTRO-11 Technical Basis for the Graded Approach Suggested in the HF SAR Course INTRO-14 Organization of Course Text . ................... INTRO-14

Chapter 1: Systems Approach to the SAR Process (hardware, personnel,

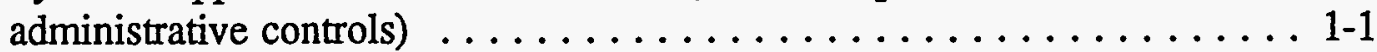

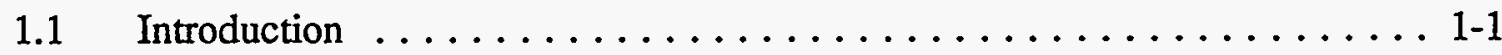

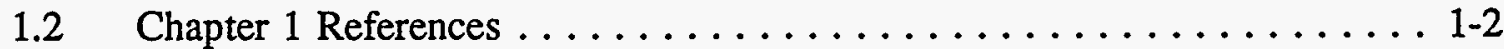

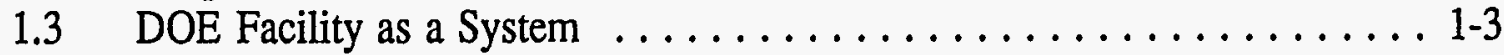

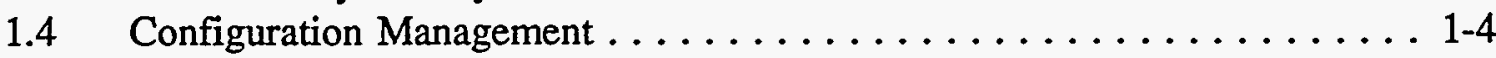

1.5 Total Quality Management (TQM) $\ldots \ldots \ldots \ldots \ldots \ldots \ldots \ldots \ldots \ldots$

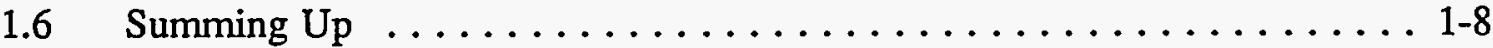

Chapter 2: $\quad$ HF as a Behavior-Centered Scientific Discipline $\ldots \ldots \ldots \ldots . \ldots 2-1$

2.1 Human-Machine Interactions and Performance $\ldots \ldots \ldots \ldots \ldots \ldots .2-1$

2.2 Chapter 2 References ........................ 2-3

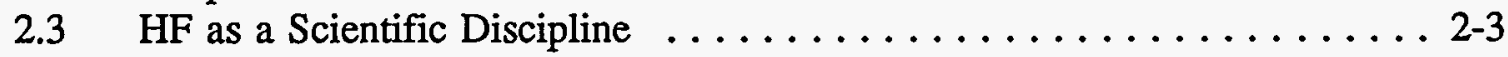

2.3.1 Human Error $\ldots \ldots \ldots \ldots \ldots \ldots \ldots \ldots \ldots \ldots \ldots \ldots \ldots \ldots . \ldots \ldots$

2.3.1.1 Three Mile Island (U.S. commercial nuclear plant) . . 2-4

2.3.1.2 Bhopal (U.S. designed chemical processing plant

2.3.1.3 Challenger (U.S. space shuttle) $\ldots \ldots \ldots \ldots \ldots 2-5$ 
2.3.1.4 Chernobyl (Soviet nuclear plant) $\ldots \ldots \ldots \ldots .2-5$

2.3.1.5 · Zeebrugge (Belgian/Dutch/English auto ferry) $\ldots .2-5$

2.3.1.6 King's Cross (London, England underground) . . . . 2-6

2.3.1.7 Summarizing TMI, Bhopal, Challenger,

Chernobyl, Zeebrugge, and King's Cross

Accidents .................... 2-6

2.3.1.8 Los Angeles Riots (Rodney King Verdict) . . . . . 2-7

2.3.1.9 Atlas Missile Program (U.S. Air Force) . . . . . 2-7

2.3.1.10 TWA Flight 514 (U.S. commercial airliner) . . . . 2-8

2.3.1.11 Procedure Violations ............... 2-8

2.3.2 $\mathrm{HF}$ as a Scientific Discipline for Reducing Human Error . . . . . . 2-9

2.3.2.1 Human Factors Engineering (HFE) . . . . . . . . 2-9

2.3.2.2 Human System Design (HSD) . . . . . . . . . . 2-9

2.3.2.3 Human Reliability Analysis (HRA) . . . . . . . 2 2-10

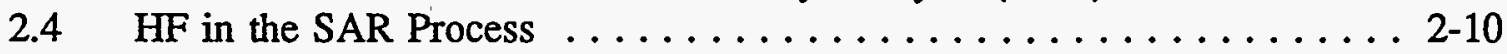

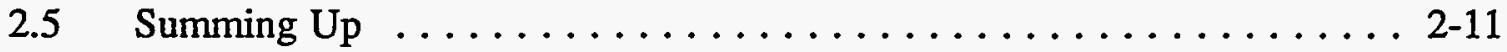

Chapter 3: HF at the U.S. Department of Energy (DOE) $\ldots \ldots \ldots \ldots \ldots \ldots$ 3-1

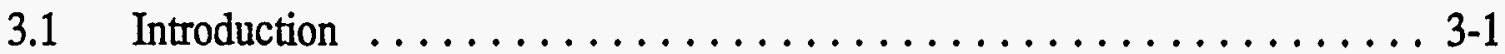

3.2 Chapter 3 References . . . . . . . . . . . . . . . . . . 3-1

3.3 Pre-1989 HF Requirements . . . . . . . . . . . . . . . . 3-2

3.4 HF Requirements 1989 to 1992 and Beyond . . . . . . . . . . . 3-3

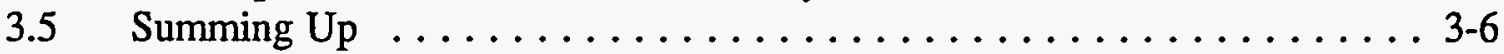

Chapter 4: HF Requirements and Guidance Established by DOE Order 5480.23, other DOE Orders and Standards, and DOE Provided and Referenced

Compliance Standards ...................... 4-1

4.1 Introduction $\ldots \ldots \ldots \ldots \ldots \ldots \ldots \ldots \ldots \ldots \ldots \ldots . \ldots . \ldots .1$

4.2 Chapter 4 References ...................... 4-1

4.3 Origins of HF Requirements $\ldots \ldots \ldots \ldots \ldots \ldots \ldots \ldots \ldots \ldots$ 4-2

4.4 Prioritized HF Requirements in the SAR .............. 4-3

4.5 Specific HF Requirements for SAR Topics $\underline{5}$ and $\underline{11}$ through $\underline{15} \ldots \ldots 4-5$

4.5.1 DOE Order 5480.23, Attachment 1 Topic $\underline{5}$ (Hazards Analysis and Classification of the Facility) ............... 4-5

4.5.2 DOE Order 5480.23, Attachment 1 Topic $\underline{11}$ (Analysis of Normal, Abnormal, and Accident Conditions) . . . . . . . . 4-6

4.5.3 DOE Order 5480.23, Attachment 1 Topic 12 (Management, Organization and Institutional Safety Provisions) . . . . . . . 4-7

4.5.4 DOE Order 5480.23, Attachment 1 Topic $\underline{13}$ (Procedures and 
Training) $\ldots \ldots \ldots \ldots \ldots \ldots \ldots \ldots \ldots \ldots$ 4-8

4.5.5 DOE Order 5480.23, Attachment 1 Topics 14a through $\underline{14 d}$

(Human Factors Engineering), and DOE Standard 3009-94,

Chapter 13, Human Factors . . . . . . . . . . . . . . . 4-9

4.5.5.1 DOE Order $5480.23 \ldots \ldots \ldots \ldots \ldots \ldots .4 .9$

4.5.5.2 DOE Standard 3009-94, Chapter $13 \ldots \ldots$. . . 4-10

4.5.6 DOE Order 5480.23, Attachment 1 Topic $\underline{15}$ (Initial Testing,

Internal Surveillance, and Maintenance) . . . . . . . . 4-12

4.6 Summing $U p \ldots \ldots \ldots \ldots \ldots \ldots \ldots \ldots \ldots \ldots \ldots \ldots \ldots \ldots$

Chapter 5: HF Concepts, Techniques, and Data Sources for a Human Safety

Analysis in Response to 5480.23 SAR and DOE Standard 3009-94

Requirements and Guidance .................. 5-1

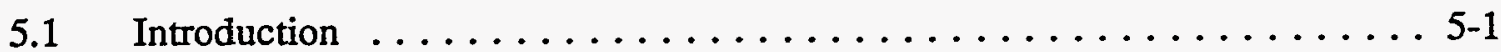

5.2 Chapter 5 References . . . . . . . . . . . . . . . . . $5-2$

5.3 Human System Analysis $\ldots \ldots \ldots \ldots \ldots \ldots \ldots \ldots \ldots \ldots . . \ldots \ldots$

5.3.1 Function Analysis (See Figure $5-1) \ldots \ldots \ldots \ldots \ldots \ldots \ldots$ 5-3

5.3.2 Task Analysis (See Figure $5-1$ ) $\ldots \ldots \ldots \ldots \ldots \ldots \ldots \ldots .6 \ldots \ldots$

5.3.3 Timeline Analysis (See Figure 5-2.) $\ldots \ldots \ldots \ldots \ldots \ldots \ldots$. 5-5

5.3.4 Link Analysis (See Figure 5-3) . . . . . . . . . . . 5-5

5.3.5 Human Vulnerability Analysis (See Figure 5-4) . . . . . . . 5-5

5.3.6 Human Failure Modes Analysis . . . . . . . . . . . 5-6

5.4 Human causal Factor Analysis $\ldots \ldots \ldots \ldots \ldots \ldots \ldots \ldots \ldots .7$

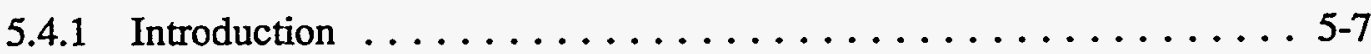

5.4.2 Characteristics for HCF Analysis $\ldots \ldots \ldots \ldots \ldots \ldots \ldots .6 \ldots \ldots$

5.4.2.1 Person-Centered . . . . . . . . . . . 5-13

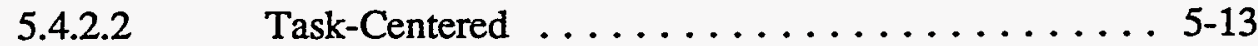

5.4.2.3 Environment-Centered .............. 5-13

5.4.2.4 Varying Impacts of HCFs on Performance ...... 5-14

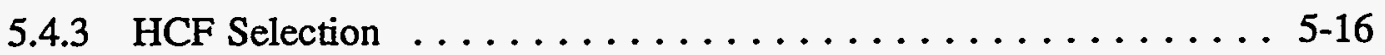

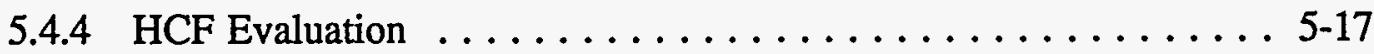

5.4.5 Uses of HCF Evaluation Results .............. 5-18

5.5 Human Performance Assessment . . . . . . . . . . . . . . . . 5-19 


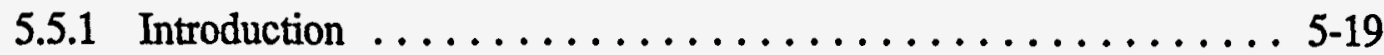

5.5.2 Qualitative Assessment .................. 5-20

5.5.3 Quantitative Assessment $\ldots \ldots \ldots \ldots \ldots \ldots \ldots \ldots \ldots . .5-20$

5.5.4 Probabilistic Assessment $\ldots \ldots \ldots \ldots \ldots \ldots \ldots \ldots \ldots . .6$ 5-21

5.5.5 Non-Probabilistic Assessment . . . . . . . . . . . . 5-22

5.5.6 Operational Experience Assessment . . . . . . . . . . 5-22

$5.6 \quad$ Summing $U p$

Chapter 6: Graded Approach to Human Safety Analysis for Facilities Classified as

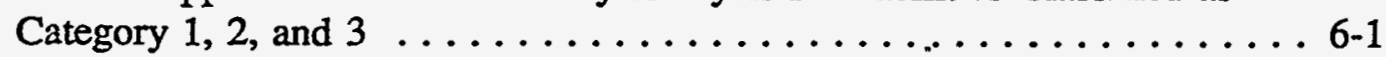

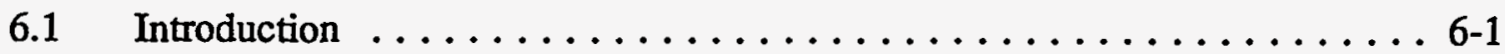

6.2 Chapter 6 References ....................... 6-1

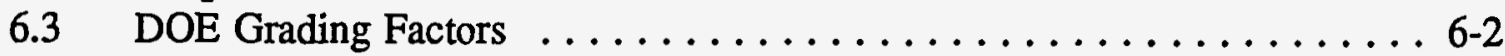

6.4 Quality Assurance Factors $\ldots \ldots \ldots \ldots \ldots \ldots \ldots \ldots \ldots \ldots .6 \ldots \ldots$

6.5 Graded Factors . . . . . . . . . . . . . . . . . 6-5

6.6 Graded Approach for Human System Analysis .............. 6-7

6.6 .1 Hazard Category $1 \ldots \ldots \ldots \ldots \ldots \ldots \ldots \ldots \ldots . \ldots .6 .6$

6.6 .2 Hazard Category $2 \ldots \ldots \ldots \ldots \ldots \ldots \ldots \ldots \ldots \ldots \ldots \ldots \ldots \ldots$

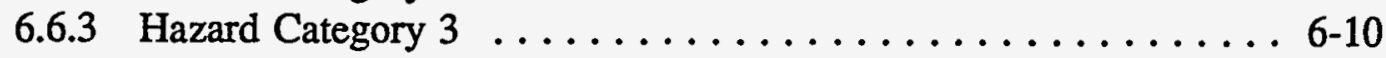

6.6.4 Application of Human System Analysis Results in the SAR ... 6 6-11

6.6.5 Products of the Human System Analysis . . . . . . . . . 6 6-12

6.6.5.1 Function/Task Description Analysis . . . . . 6 6-12

6.6.5.2 Function/Task Equipment Analysis . . . . . . . 6-12

6.6.5.3 Function/Task Human Failure Modes Analysis . . . 6 6-13

6.7 Graded Approach for the Human causal Factor (HCF) Analysis . . . . . 6-19

6.7.1 HCF Selection .................... 6-19

6.7.1.1 Hazard Category $1 \ldots \ldots \ldots \ldots \ldots \ldots 6.6 .20$

6.7.1.2 Hazard Category $2 \ldots \ldots \ldots \ldots \ldots \ldots .6 .6 .21$

6.7.1.3 Hazard Category $3 \ldots \ldots \ldots \ldots \ldots \ldots .6 .22$

6.7.2 HCF Evaluation $\ldots \ldots \ldots \ldots \ldots \ldots \ldots \ldots \ldots \ldots .6 .23$

6.7.2.1 Hazard Category $1 \ldots \ldots \ldots \ldots \ldots \ldots . . .6 .6 .23$

6.7.2.2 Hazard Category $2 \ldots \ldots \ldots \ldots \ldots \ldots \ldots 6.6 \ldots \ldots$

6.7.2.3 Hazard Category $3 \ldots \ldots \ldots \ldots \ldots \ldots .6 .26$

6.7.3 Application of HCF Analysis Results in the SAR ....... 6-28 
6.7.4 HCF Analysis Product $\ldots \ldots \ldots \ldots \ldots \ldots \ldots \ldots \ldots .6 .28$

6.8 Graded Approach for the Human Performance Assessment ... . . . . . 6-37

6.8.1 Introduction . . . . . . . . . . . 6.37

6.8.2 Bounding and Anchor Data Acquisition Step $\ldots \ldots \ldots \ldots \ldots 6-38$

6.8.2.1 Introduction . . . . . . . . . . . . 6-38

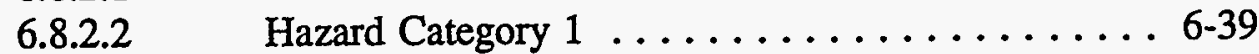

6.8.2.3 Hazard Category $2 \ldots \ldots \ldots \ldots \ldots \ldots \ldots .6 .40$

6.8.2.4 Hazard Category $3 \ldots \ldots \ldots \ldots \ldots \ldots .6 .41$

6.8.3 Results Indexing (Scoring) Step $\ldots \ldots \ldots \ldots \ldots \ldots \ldots .6-41$

6.8.3.1 Hazard Category $1 \ldots \ldots \ldots \ldots \ldots \ldots 6.43$

6.8.3.2 Hazard Category $2 \ldots \ldots \ldots \ldots \ldots \ldots \ldots 6.45$

6.8.3.3 Hazard Category $3 \ldots \ldots \ldots \ldots \ldots \ldots .6 .646$

6.8.4 Application of Human Performance Assessment in the SAR . . . 6-47

6.8.5 Human Performance Assessment Results . . . . . . . . . 6-47

6.9 Operational Experience Assessment $\ldots \ldots \ldots \ldots \ldots \ldots \ldots \ldots \ldots 6-58$

6.9.1 Hazard Category $1 \ldots \ldots \ldots \ldots \ldots \ldots \ldots \ldots .6 .58$

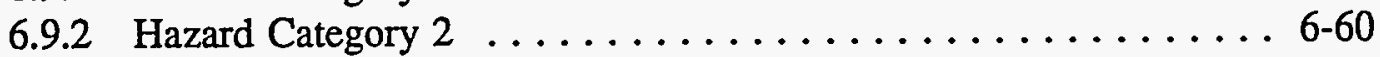

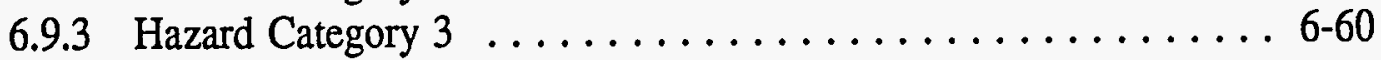

6.9 .4 Application of Results in the SAR ............. 6-60

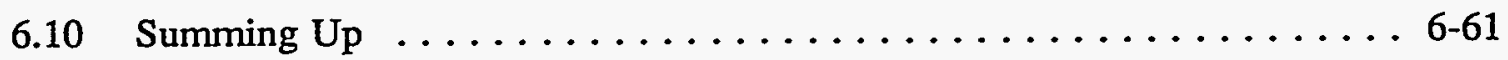

Chapter 7: Preparation of HF Documentation to Support the SAR Process . . . . . . 7-1

7.1 Introduction and Purpose $\ldots \ldots \ldots \ldots \ldots \ldots \ldots \ldots \ldots \ldots \ldots \ldots \ldots \ldots \ldots .1$

7.2 Chapter 7 References . . . . . . . . . . . . . . . . . $7-2$

7.3 Information Sources ...................... $7-2$

7.4 Human Factors Analysis Results and Findings Report .......... 7-3

7.5 Human Performance Assessment (HPA) Results and Findings Report . . . 7 7-5

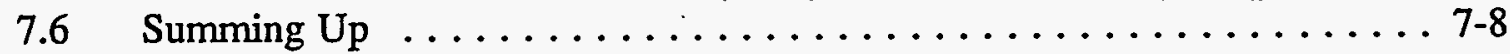

Chapter 8: Determination of Nuclear Safety Significance and Resolution of Deviations from HF Compliance Standards $\ldots \ldots \ldots \ldots \ldots \ldots .68$

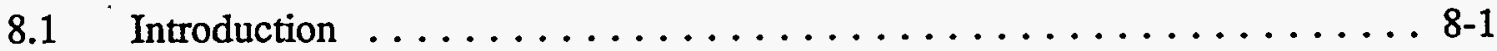

8.2 Chapter 8 References ..................... 8 .2 
8.3 Identification and Interpretation of Judged Deviations from Full Compliance with HF Standards, and Safety .............. 8-3

8.3.1 Safety Determination of Results and Findings Using the Hazards and Accident Analysis . . . . . . . . . . . . . . . 8-3

8.3.2 Safety Determination of Results and Findings Using the Defense in Depth and Worker Safety Concepts . . . . . . . . . . . . . 8-4

8.3.3 Safety Determination of Results and Findings Using the Operational Experience Analysis . . . . . . . . . . . . 8-5

8.3.4 Alternatives for Resolving Judged Deviations from Full Compliance with HF Standards . . . . . . . . . . . . 8-6

8.3.5 Administrative Control Interventions . . . . . . . . . . . . 8-7

8.3.6 Non-Intrusive Interventions . . . . . . . . . . . . . . 8 8-7

8.3.7 Intrusive Interventions $\ldots \ldots \ldots \ldots \ldots \ldots \ldots \ldots . \ldots \ldots$

8.3.8 Grandfathering ..................... 8-8

8.4 Summing $U p \ldots \ldots \ldots \ldots \ldots \ldots \ldots \ldots \ldots \ldots$

Chapter 9: Preparation of Human Factors Including Human Performance Assessment Sections of the SAR . . . . . . . . . . . . . . . 9-1

9.1 Introduction $\ldots \ldots \ldots \ldots \ldots \ldots \ldots \ldots \ldots \ldots \ldots \ldots \ldots \ldots \ldots$

9.2 Chapter 9 References . . . . . . . . . . . . . . . . . . . 9-2

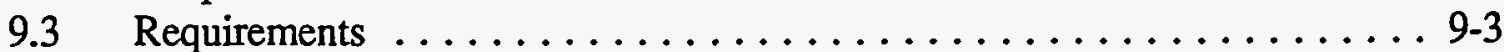

9.4 Organization of the Chapter . . . . . . . . . . . . . . . . 9-4

9.5 Suggested Guidelines and Examples ................. 9-4

9.5.1 Topics $\underline{5}$ and 11: Hazards Analysis and Accident Analysis . . . 9-5

9.5.1.1 Graded Technical Approach . . . . . . . . . . 9-5

9.5.1.2 Description of HPA Methodology and Results . . . 9 9-6

9.5.1.3 Demonstration of Safety Adequacy ...... . . . 9 9-6

9.5.2 Topic 12: $\quad$ Management, Organization, Institutional

Provisions and Controls . . . . . . . . . . 9-25

9.5.2.1 Technical Basis Using a Graded Approach . . . . 9-25

9.5.2.2 Description of Management and Organization

Provisions or Program . . . . . . . . . . . 9-25

9.5.2.3 Demonstration of Management and Organization Safety Adequacy ............... 9-25

9.5.3 Topic 13: $\quad$ Procedures and Training . . . . . . . . . . 9-30 
9.5.3.1 Technical Basis Using a Graded Approach ..... 9-30

9.5.3.2 Description of Management and Organization

Provisions or Program .............. 9-30

9.5.3.3 Demonstration of Procedures and Training Safety

Adequacy .................. 9-30

9.5.4 Topic 14: Human Factors Engineering (HFE) $\ldots \ldots \ldots \ldots$ 9-35

9.5.4.1 Introduction . . . . . . . . .

9.5.4.2 Technical Basis Using a Graded Approach ..... 9-35

9.5.4.3 Description of DOE HFE Requirements and HFE

Provisions or Programs for Responding to Those

Requirements .................. 9-35

9.5.4.4 Demonstration of Safety Adequacy ......... 9-35

9.5.5 Topic 15: Initial Testing, In-Service Surveillance, and

Maintenance $\ldots \ldots \ldots \ldots \ldots \ldots \ldots$. 9-60

9.5.5.1 Technical Basis Using a Graded Approach . . . . 9 9-60

9.5.5.2 Description of Management and Organization

Provisions or Program .............. 9-60

9.5.5.3 Demonstration of Testing, Surveillance and

Maintenance Safety Adequacy ........... 9-60

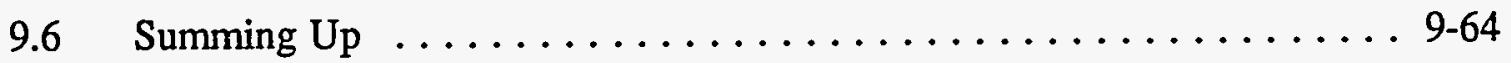

Chapter 10: Contribution of HF to the TSRs $\ldots \ldots \ldots \ldots \ldots \ldots \ldots \ldots \ldots \ldots \ldots$

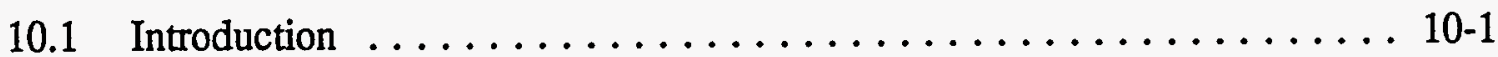

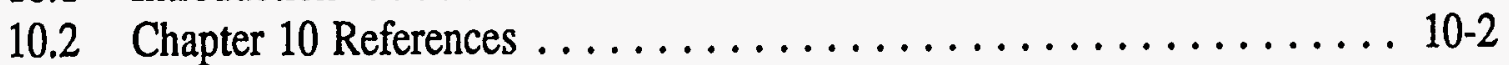

10.3 Action Statements . . . . . . . . . . . . . . . . . . 10-3

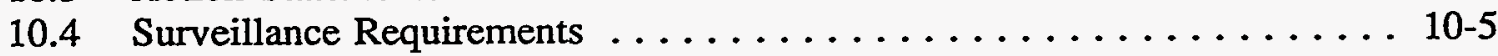

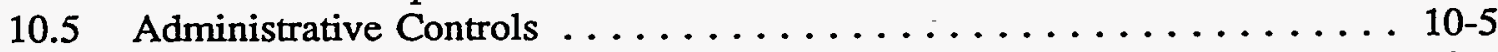

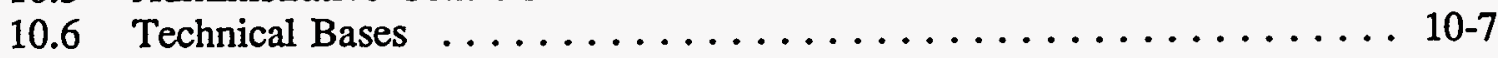

10.7 Summing $\mathrm{Up} \ldots \ldots \ldots \ldots \ldots \ldots \ldots \ldots \ldots \ldots \ldots \ldots \ldots \ldots \ldots \ldots \ldots$

SUBJECT INDEX

SUBJECT-1

APPENDIX A: $\quad$ Excerpts from NUREG/CR-4772, Accident Sequence Evaluation Program (ASEP) Procedure for Human Error Rate Screening . . . . A A-1

APPENDIX B: $\quad$ Excerpts from NUREG/CR-1278, Handbook of Human Performance Assessment with Emphasis on Nuclear Power Plant Applications: Application of THERP Methodology . . . . . . . B-1 
APPENDIX C: $\quad$ Explanations of THERP trees and Calculation Sheets Contained in Chapter 6, Figure 6-17 through Figure 6-20 . . . . . . C-1

C.1 THERP tree Results and Input Data Sheet $\ldots \ldots \ldots \ldots \ldots \ldots \ldots$ C-2

C.1.1 Human Event Designator and Title Section $\ldots \ldots \ldots \ldots \ldots \ldots$ C-2

C.1.2 Left or Results Side of THERP tree Data Sheet . . . . . . . C-2

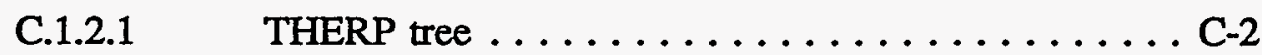

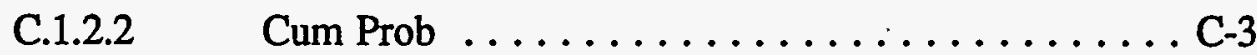

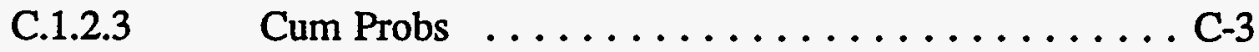

C.1.2.4 Median HEP $\ldots \ldots \ldots \ldots \ldots \ldots \ldots \ldots \ldots$ C-3

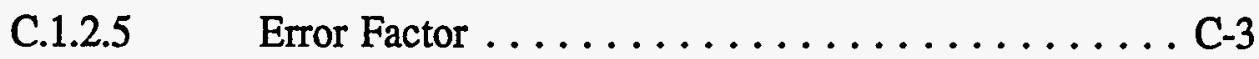

C.1.2.6 Main Paths TotalP(f) and TotalP(f) $\ldots \ldots \ldots \ldots$ C-4

C.1.2.7 $\quad \mathrm{EF} \ldots \ldots \ldots \ldots \ldots \ldots \ldots \ldots \ldots \ldots \ldots \ldots \ldots \ldots$

C.1.3 Right (or Input) Side of THERP tree Data Sheet . . . . . . . C-5

C.1.3.1 Basic HEP . . . . . . . . . . . . . . 5

C.1.3.2 Basic EF . . . . . . . . . . . . .

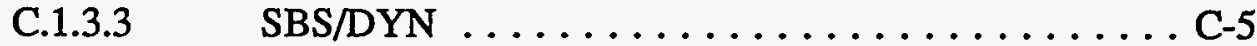

C.1.3.4 HCF Modifier . . . . . . . . . . . C-5

C.1.3.5 Source ................... C-6

C.1.3.6 HCF Method .................. C-6

C.1.3.7 Dependency ................. C-6

C.2 Failure Path Calculation Sheets $\ldots \ldots \ldots \ldots \ldots \ldots \ldots \ldots \ldots$ C-6

C.2.1 Failure Path $\ldots \ldots \ldots \ldots \ldots \ldots \ldots \ldots \ldots \ldots \ldots \ldots \ldots \ldots \ldots$

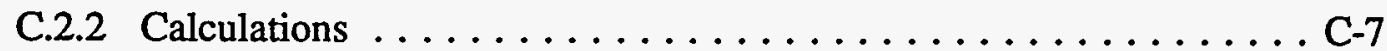

C.2.3 Median/Mean ........................ C-7 


\section{LIST OF FIGURES}

Figure 1

Figure 2

Figure 3

Figure 4

Figure 1-1

Figure 1-2

Figure 5-1

Figure 5-2

Figure 5-3

Figure 5-4

Figure 6-1

Figure 6-2

Figure 6-3

Figure 6-4

Figure 6-5

Figure 6-6

Figure 6-7

Figure 6-8

Figure 6-9

Figure 6-10

Figure 6-11

Figure 6-12

Figure 6-13

Figure 6-14

Figure 6-15

Figure 6-16

Figure 6-17

Figure 6-18

Figure 6-19

Figure 6-20

Figure 6-21

Figure 6-22

Figure 6-23

Figure 6-24

Figure 7-1

Figure 7-2

Figure 9-1
SAR Role in DOE System Acquisition . . . . . . . . . . INTRO-5 DOE Facility Acquisition Phases with PSAR \& FSAR . . . . . . . INTRO-6 Human Factors in the SAR process (DOE Standard 3009-94) . . . . . INTRO-9 Human System Design versus Human Safety Analysis . . . . . . . . . INTRO-10 Systems Approach to HF and the SAR . . . . . . . . . . . 1-5 The Systems Approach Cycle . . . . . . . . . . . . . . . . . 1-6 Function/Task Analysis $\ldots \ldots \ldots \ldots \ldots \ldots \ldots \ldots \ldots$. . . . . . . . . . . . Timeline Analysis . . . . . . . . . . . . . . . . . . . . 5-10 Link Analysis . . . . . . . . . . . . . . . . . . . 5 5-11

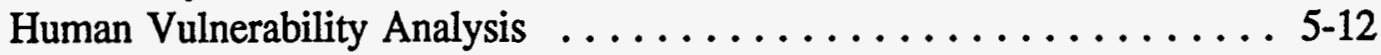
Matrix of DOE Facility Classifications and Human System Analysis Graded Approach . . . . . . . . . . . . . . . . . . . . 6-14 Human Safety Analysis: Human Safety Analysis . . . . . . . . . . . . . 6-15 Human System Analysis: Description Analysis . . . . . . . . . . . . 6 6-16 Human System Analysis: Equipment Analysis . . . . . . . . . . . . 6-17 Human System Analysis: Human Failure Modes Analysis . . . . . . . . 6 6-18 Matrix of Facility Classifications and HCF Selection Graded Approach . . 6-30 Matrix of Facility Classifications and PSF Evaluation Graded Approach 6-31 Matrix of DOE Facility Classifications and HCF Evaluation Graded

Approach . . . ......................... 6-32

Human Causal Factor Analysis Graded Approach . . . . . . . . . 6 6-33

HFE Communications Checklist .................. 6-34

HFE Instrumentation/Control Checklist .............. 6-35

HFE Environment Checklist . . . . . . . . . . . . . . . 6-36

Matrix of DOE Facility Classifications and Human Performance

Assessment Graded Approach . . . . . . . . . . . . . . . . . 6 6-48

ASEP Question Sheet . . . . . . . . . . . . . . . . . . . . 6-49

ASEP Data Sheet $\ldots \ldots \ldots \ldots \ldots \ldots$. . . . . . . . . . . . . . . . . . . .

Human Performance Assessment Using THERP . . . . . . . . . . . . 6-51

THERP Tree (Base Case) . . . . . . . . . . . . . . . . . . . 6-52

THERP Tree (Best Case) . . . . . . . . . . . . . . . . . . 6-53

THERP Calculation Sheets (Base Case) . . . . . . . . . . . . 6-54

HRA Calculation Sheets (Best Case) . . . . . . . . . . . . . 6-55

Matrix of DOE Facility Classifications and Human Performance

Assessment Graded Approach . . . . . . . . . . . . . . . . 6-56

Human Initiator Composite Sequences and HEPs . . . . . . . . . 6-57

Operational Data for the Graded Approach . . . . . . . . . . . . . . . . 6-59

Facility-Comparison Group ORPS Data Table ... . . . . . . . . . 6-61

Human Factors Analysis Report Annotated Outline . . . . . . . . . . . . 7-9

Human Performance Assessment Report Annotated Outline . . . . . . . 7-20

Human Performance Assessment Technical Approach ........... 9-8 
Figure 9-2 Human Initiator Performance Assessment $\ldots \ldots \ldots \ldots \ldots \ldots \ldots$ 9-12

Figure 9-3 Human Accident Mitigator HRA .................. 9-17

Figure 9-4 Management and Organizational Provisions and Safety ......... 9-27

Figure 9-5 Procedures, Training and Safety $\ldots \ldots \ldots \ldots \ldots \ldots \ldots \ldots . \ldots \ldots$ 9-32

Figure 9-6 Introduction and Technical Approach $\ldots \ldots \ldots \ldots \ldots \ldots \ldots \ldots . . \ldots \ldots$

Figure 9-7 DOE Requirements . . . . . . . . . . . . . . . . . . .

Figure 9-8 NFF Human Factors Program ................. 9-44

Figure 9-9 Design Optimization of Human-Machine Interfaces . . . . . . . . . 9 9-51

Figure 9-10 Initial Testing, In-service Surveillance, and Maintenance . . . . . . . 9 9-62

Figure 10-1 Technical Safety Requirement (Example) . . . . . . . . . . . . . . . . 10-6

Figure 10-2 Facility Training and Procedures (Example) $\ldots \ldots \ldots \ldots \ldots \ldots \ldots$ 10-8

\section{LIST OF TABLES}

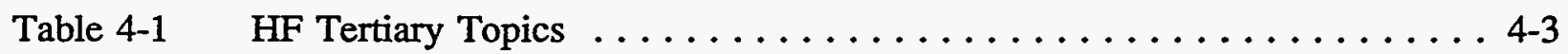

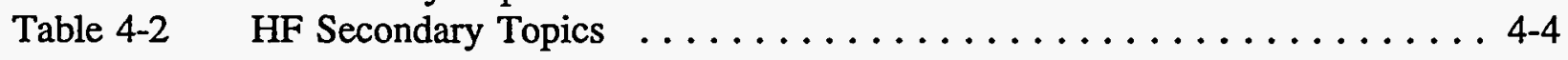

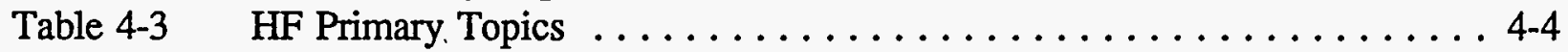




\section{ACRONYMS}

AIT

ANSI

ASEP

BNL

CFR

DOE

DOP

ESF

FAA

FMEA

FSAR

$\mathrm{HCF}$

HCR

HEP

HEPGen

HF

HFE

HFS

HPA

HSD

IIT

LCO

LCS

MAUD

NRC
Augmented Investigation Team

American National Standard Institute

Accident Sequence Evaluation Program

Brookhaven National Laboratory

Code of Federal Regulations

U.S. Department of Energy

Detailed Operating Procedure

Engineered Safety Feature

Federal Aviation Administration

Failure Modes and Effects Analysis

Final Safety Analysis Report

Human Causal Factor

Human Cognitive Reliability Model

Human Error Probability

Human Error Probability Generation Code

Human Factors

Human Factors Engineering

Human Factors Society (currently the Human Factors and Ergonomics Society)

Human Performance Assessment

Human System Design

Incident Investigation Team

Limiting Condition of Operation

Limiting Control Setting

Multiattribute Utility Decomposition

U.S. Nuclear Regulatory Commission (also referred to as USNRC) 
NUCLARR Nuclear Computerized Library for Assessing Reactor Reliability

NUREG U.S. Nuclear Regulatory Commission Internally Written Technical Report

NUREG/CR - U.S. Nuclear Regulatory Commission Contractor Written Technical Report

ORNL Oak Ridge National Laboratory

ORPS Occurrence Reporting and Processing System

OSR Operating Safety Requirement

PORV Power Operated Relief Valve

PSAR Preliminary Safety Analysis Report

RAM Remote Area Monitor

SAR Safety Analysis Report

SL Safety Limit

SLIM Success Likelihood Index Method

SR Surveillance Requirement

TEEM Team-Enhanced Evaluation Method

TMI Three Mile Island

TQM Total Quality Management

TSR Technical Safety Requirement

UCRL University of California Research Laboratory

USQ Unresolved Safety Question 


\section{GLOSSARY}

Acronyms are included in this Glossary within the term definition and are cross referenced with the most prominent chapters of this Course Text in which they are discussed.

\section{Action Statements (Chapter 10)}

Contain instructions to the operator for taking remedial or compensatory actions and a time limit for completing the actions to restore the facility to its original configuration should the facility enter a TSR condition. Action Statements should be justified on the basis of programmatic and/or analysis-based information.

\section{Administrative Controls (Chapter 10)}

Provisions relating to organization and management, procedures, training, staffing, other operational aids, recordkeeping, reviews and audits necessary to ensure the safe operation of the facility.

\section{Administrative Control Interventions (Chapter 8)}

Involve changes in training, written procedures, staffing, and direct oversight, or any combination capable of compensating for most HF deviations, including some HFE deviations. These interventions are especially valuable for resolving HFE deviations since they do not impact the current equipment design and configuration. For example, improper positioning of displays and controls relative to one another that preclude individual workers from operating the equipment can often be overcome by adding a second participating worker. Marginal labeling can often be overcome

\section{GLS-1}


through additional training of workers or expanded written procedures for operating equipment associated with the marginal labeling.

\section{Auditability (Chapter 6)}

Graded approach principle stating that a human safety analysis must be welldocumented and traceable for the results to be practical and defensible. All steps, assumptions, information, and methods relevant to the analysis must be presented in detail to allow a reviewer to understand the origin, understand the specific context, and assess the meaning of the results. Appropriate and well-documented analyses define much of the basic information acquired and used to perform the human safety analysis. The information from the earlier human system analysis and human causal factor (HCF) analysis, become part of the Human Performance Assessment, and are linked to assessment results through complete documentation of the process, assumptions, and methods used to generate quantitative estimates or qualitative assessments. The human safety analysis is not traceable when the human system and HCF analyses are not done, or are not well-documented. Auditability of the human safety analysis, including these analyses, is essential to support further assessments of factors contributing to risk, and to allow comparison with other human safety analyses.

\section{Base Case Error Probability (Chapters 6, 7, and 9)}

Computed taking into account the actual conditions that exist for performing a task. HCFs are scored according to their actual ability to support performance. 


\section{Best Case Error Probability (Chapters 6, 7, and 9)}

Computed on the basis that all HCFs are optimized. A best case estimate indicated the degree that performance can be enhanced on a human task action or human task action sequence.

\section{Configuration Management (Chapter 1)}

Systems approach to control of the design, development, implementation, and changes to the facility/activity physical configuration through documentation, records, and data. Focus is intended to be on the documentation, records, and data. The physical configuration is expected to conform. Good configuration management is built around: (1) a rigorous definitional system, (2) a well-documented change process, and (3) strict adherence to a "no-documentation = no-implementation" philosophy.

\section{Credibility (Chapter 6)}

Graded approach principle stating that defensible human safety analysis results require an experienced HF practitioner carefully using accepted HF techniques. Techniques that have demonstrated reliability and validity are essential. Reliability requires reasonable consistency of results across time and analysts. Validity requires results consistent with actual human performance. The large number and complex context specific interactions of variables influencing Human Performance Assessment and the scarcity of human error data can result in significant uncertainty if not dealt with systematically and completely by the HF technique used. 


\section{Dependency (Chapters 6, 7, 9, and Appendices A, B, and C)}

Influence on performance of a second task based on the success or failure in performing the first task.

\section{Direct Comparison (Chapter 5)}

Evaluation technique that involves comparing a HCF with a DOE or DOE referenced standard, or a content analysis usually associated with Hazard Category 1 facilities. For example, such an instrument probes the contents of the factors and provides an algorithm for assessing technical adequacy. In evaluating operating procedures, such an instrument would usually focus on completeness, technical accuracy, and comprehensibility. The human system analysis results (function, task, human vulnerability, and human failure modes analyses) should be used to the extent possible as a standard for this process.

\section{Direct Observation (Chapter 5)}

Evaluation technique that involves verifying the availability of a HCF. The HF practitioner scores the HCFs based on reviews of facility records, observes the same or similar functions and tasks being performed, and talks to the people who perform and supervise these same or similar functions and tasks. This approach is usually associated with Hazard Category 2 facilities, and is usually limited to verifying, for example, that provisions for formal training, written procedures, and direct oversight are available and implemented by the facility. Judgments concerning their technical accuracy, completeness, and comprehensibility are limited. 
Extrinsic characteristics of the institution (organization), administrative control (supervision and management), habitability (heat, light, noise, radiation), and the task context. Of particular interest to DOE in the SAR for operations and maintenance are:

- Institutional and administrative controls, that is, organization and management analyzed primarily for SAR Topics $\underline{11}, \underline{12}$, and $\underline{15}$;

- Habitability analyzed primarily for SAR Topics $\underline{11}$ and $\underline{14}$; and,

- Task context factors such as dependency that influence performance on an earlier or later task. Also recoverability means that task settings allow subtasks to be attempted more than once without failing the entire tasks.

\section{Final Safety Analysis Report (FSAR) (Introduction Chapter)}

Documents the adequacy of the safety analysis of the current operating configuration of a nuclear facility to ensure that the facility can be operated, maintained, shut down, and decommissioned safely and in compliance with applicable laws and regulations.

\section{Function Analysis (Chapters 5 and 6)}

Primarily system-centered, focuses on tasks performed by personnel within the context of general operations of the facility (e.g., producing an alloy using reactor energy). It is a step-by-step representation of a function or activity using flow charts and narrative descriptions. As such, it is analogous to a systems analysis used to understand the functioning of facility equipment. The focus of the analysis is the facility operation. 
Equipment and human tasks (e.g., activate pump, open/close valve) and conditions under which the human tasks are performed are described in the sequence in which they occur. There is no attempt to break down human actions below the task level. The function analysis is part of the larger systems analysis done to support the SAR. Therefore, it should involve all members of the safety analysis team including the HF practitioners working together. The primary outcome of this system-centered analysis is the operating and accident sequences that will be the focus of the remainder of the SAR effort. Therefore, the accuracy with which the system hardware, personnel, administrative controls, and their interactions are defined in the function analysis will, in large measure, determine the overall credibility of the safety analysis, and subsequent SAR and TSR commitments to DOE.

\section{Graded Approach (Chapter 6)}

Systematic variation in the scope, detail, and rigor of the safety analysis of a nuclear facility based on the hazard consequences, complexity of the facility operating configuration, life cycle status of the facility, its missions, and any other factors that might impact safety.

\section{Graded Factors (or Factors Graded) (Chapter 6)}

Systematically varied to achieve a human safety analysis graded approach. Scope, detail, rigor, and HF techniques are varied to achieve the graded approach.

\section{Grandfathering Interventions (Chapter 8)}

Not so much intervention as exclusions from change. Most DOE facility structures, systems, components, and their upgrades were completed prior to 1989. Given a good operating history, a classification below a Hazard Category 1 facility, and current and 
anticipated missions, consideration might be given to excusing HF deviations from full compliance especially where they involve low potential for hazard or accident or Best Case analysis suggests that something less than optimal performance can be achieved by introducing any or all of the previous interventions.

\section{Human Error Probability (HEP) (Chapters 5 and 6, and Appendices A and} B)

Likelihood of a human succeeding or failing to perform a task action or action sequence based on a comparison of anticipated errors with anticipated opportunities.

\section{Human Factors (HF) (All Chapters, and Appendices A, B, and C)}

As a scientific and engineering support discipline, HF is directed toward applying behavioral and social sciences principles developed over the past century, to system settings in order to control, channel, monitor, and optimize human and ultimately system performance. Similarly, DOE Order 5480.23, Attachment 1, Section 3.b(1)(b) defines human factors safety to include: "allocation of control functions to humans and machines, staffing and qualifications of personnel, personnel training, written procedures to guide operations and maintenance, and design of human-machine interfaces." Chapter 3 of this text presents an expanded discussion of HF at DOE.

\section{Human Factors Analysis Results and Findings Report (Chapter 7)}

Reports the background, methodology, and findings of a human factors analysis of the facility, to support its SAR (PSAR or FSAR) in responding to the requirements of Department of Energy (DOE) Order 5480.23 and DOE Order 5480.22. Depending on the type of facility, the analysis should focus on general building areas, workstations, handling devices, and human factors controls (e.g., procedures, training, HFE, 
management controls), involved in or directly supporting the administrative and/or technical operations of the facility. These technical operations include testing, surveillance, and preventive and recovery maintenance activities required to support technical operations.

\section{Human Factors Engineering (HFE) (Chapter 2)}

Human factors subdiscipline sometimes referred to as simply human engineering or as ergonomics. HFE is directed primarily toward person-machine issues such as equipment design (e.g., displays, controls, and their juxtaposition); workspace layout and accessibility; and habitability (e.g., temperature, light, noise, and radiation). For example, HFE provides the technical basis for creating a physical work environment that is user friendly and therefore enhances operator safety performance. HFE is the subject of SAR Topic 14, Human Factors Engineering.

\section{HF Technique (Chapter 6)}

Refers to credible procedural and mathematical processes used to gather human safety analysis information and analyze the safety impact of HF. For example, function and task analyses as procedural techniques that provide the context for judging human performance. They are used as basic tools for Hazard Category 1, 2, and 3 human safety analyses. However, their scope, level and detail, and level of rigor vary between categories. The Technique for Human Error Rate Prediction (THERP) is a modeling structure for describing task actions and action sequences as well as a mathematical method for estimating human error likelihood. It is used as a scoring technique for Hazard Category 1 and 2 facilities which require quantitative results, and also to a lesser degree, level of detail and level of rigor of input data for Hazard Category 2 facilities. THERP is described further in Section 6.8 of this course text, and in Appendix B to this Course Text. 


\section{Human Failure Modes Analysis (Chapters 5 and 6)}

Extends the human vulnerability analysis. It lists, for each human action and action sequence identified in the human vulnerability analysis, ways (modes) by which the action or sequence can be failed. For example, the breaching of a waste container by a forklift operator may be the action identified in the human vulnerability analysis. The human failure modes analysis asks: how can the operator precipitate the breach? The human failure modes analysis may answer, in part, that the operator can drop the container because he/she does not: (1) clear surface obstacles, (2) doesn't seat the load, (3) ignores rough driving surfaces, (4) inadvertently activates the vertical load control, (5) inadvertently activates the side-shift control, and/or (6) exceeds forklift load capacity. It is these latter human failure modes that become the focus of the HRA supporting Topic 5 , hazards analysis, and Topic 11 , accident analysis, and in turn, HF considerations for other topics of the SAR. Finally, the human failure modes analysis provides the human failure paths for a hazards and accident analysis for Category 1, 2, and 3 facilities.

\section{Human Initiator (Chapter 7)}

Action of a human that starts or contributes to the start of a normal, abnormal, or accident sequence.

\section{Human Mitigator (Chapter 7)}

Action of a human in response to, or contributing to, a normal, abnormal, or accident sequence. 


\section{Human Performance Assessment (HPA) (Chapters 5 and 6, and Appendices A, B, and C)}

Human factors subdiscipline directed toward both person-machine and person-person issues pertaining to qualitative or quantitative human performance measurement, including probabilistic analysis. For example, in the case of probabilistic analysis, HPA results are expressed as human error or human success likelihoods. That is, an operator failing to or successfully activating/deactivating a säfety class or safety significant system or component. Primarily, HPA is a subject of SAR Topic 11

- (Accident Analysis). HPA is also considered in SAR Topics $\underline{5}$ (Hazard Classification) and 16 (Derivation of Technical Safety Requirements).

\section{Human Performance Assessment (HPA) Results and Findings Report (Chapter 7)}

Reports the background, methodology, results and findings of the HPA for accident scenarios capable of being initiated and/or mitigated by human means, near to and within the facility. The results of this HPA are integrated into the larger hazards and accident analyses, which in turn serve as the safety basis for the human factors segments of the SAR. More specifically; the HPA document in this report responds to the requirements of DOE Order 5480.23, Section $8 \mathrm{~b}(3)(\mathrm{k})$ and Attachment 1, Topic 11 , requiring an analysis of normal, abnormal, and accident conditions. (including design basis accidents), assessments of risk; assessment of contributory and causal events (both hardware and human), mechanisms, and phenomena; and if appropriate beyonddesign-basis accidents. 


\section{Human Safety Analysis (Chapters 5 and 6)}

Involves three sequential (sometimes iterative) steps:

1. Human System Analysis which provides the context for judging human performance from radiological, chemical, and industrial safety perspectives.

2. Human causal Factor (HCF) Analysis which provides causal factor information for indexing human performance, and;

3. Human Performance Assessment which provides indexing of human performance using qualitative or quantitative measures, or both.

\section{Human System Analysis (Chapters 5 and 6)}

Contributes human performance inputs to logic or facility models used as a general framework for estimating overall human vulnerabilities. It also serves as the technical basis for judging the adequacy of the HCFs (e.g., staffing, oversight, training, operating procedures, human factors engineering) selected for inclusion in the analysis.

\section{Human System Design (HSD) (Chapter 2)}

Human factors subdiscipline directed primarily toward person-person issues directed at allocation of duties and responsibilities, staffing, qualifications, personnel selection, training, operating procedures, and technical and administrative management and organizational controls. As an example, HSD provides the technical basis for assigning operators to specific safety tasks. HSD also provides the technical basis for 
training (to accomplish the safety task), written procedures (where necessary to increase the level of assurance that the safety task will be completed correctly), and direct oversight (to verify that the safety task is completed successfully). Primarily, HSD is a subject of SAR Topics $\underline{12}$ (Management Organization and Institutional Controls), 13 (Procedures and Training), and 15 (Initial Testing, In-service Surveillance and Maintenance). Human system analysis is also considered in SAR Topics $\underline{17}$ (Operational Safety), 18 (Quality Assurance), and 19 (Emergency Preparedness).

\section{Human Vulnerability Analysis (Chapters 5 and 6)}

Similar to an equipment failure modes and effects analysis (FMEA). It uses the results of function, task, timeline, and link analyses to screen (rank order) human actions and action sequences listed therein for their relative likelihoods of precipitating a human error. The range of human actions analyzed, for example in subsequent phases of the HPA, depends on relative error likelihood (less than, equal to, greater than). Vulnerabilities are categorized as potential accident initiators or mitigators. Their potential types of consequences (radiological, chemical, industrial) are also identified. No attempt is made to assign human error probability estimates to individual vulnerabilities. The human vulnerability analysis provides the human failure paths for doing a hazard analysis in lieu of an accident analysis for Category 3 facilities. The human vulnerability analysis also helps the HF practitioner identify (screen) tasks from the set developed as part of the task analysis for inclusion in subsequent steps of the safety analysis. Finally, the human vulnerability analysis provides information to procedure writers, trainers, and managers, alerting them to segments of tasks that require special emphasis because of the tasks' susceptibility to error. 


\section{Intrusive Interventions (Chapter 8)}

Involve primarily fixes to Human Factors engineering (HFE) deviations, and require actual changes to the equipment. They are used when administrative controls and nonintrusive interventions cannot be demonstrated to achieve acceptable performance levels. They may be necessary in all cases of equipment involved in dominating accident sequences.

\section{Knowledge-Based Tasks (Chapter 5)}

Require new response patterns (or variations of existing response patterns) which are rarely performed, are primarily influenced by person-centered factors such as experience, reasoning ability, and decisionmaking ability. These tasks are also influenced by environment-centered factors such as organizational culture, management philosophy, and decision aids.

\section{Level of Detail (Chapter 6)}

Units of behavior that are analyzed, and the range of factors included in the human safety analysis. For example, for Hazard Category 1 facilities, task analyses could include hierarchies of subtasks and subtasks broken into elements. Hazard Category 3 facilities task analyses, on the other hand, would usually end at the subtask level without organizing subtasks into hierarchies. Additionally, human safety analyses of Hazard Category 1 facilities could include a wide range of HCFs. For Hazard Category 2 and 3 facilities HCFs would be limited to those prescribed by DOE which include training, procedures, oversight, experience, staffing, qualifications, and human factors engineering (HFE). 


\section{Link Analysis (Chapters 5 and 6)}

Organizes a function or task analysis as a network diagram showing interfaces between and among tasks or lower units of analysis, and the frequency with which those interfaces occur. A link analysis is usually completed as part of the function and task analysis. Finally, the link analysis provides the analyst with information to determine how dependency should be modeled as a human causal factor in the Human Performance Assessment.

\section{Non-Intrusive Interventions (Chapter 8)}

Involve primarily fixes to Human Factors Engineering (HFE) deviations, that is, changes in equipment operating configurations without changing the equipment itself-. For example, higher wattage light bulbs can usually be added without modifying the electrical system or electrical fixture. Individual pieces of equipment and furniture making up a workstation can be physically rearranged to achieve compliance. Tape and marking pens can cover poorly labelled or mislabelled equipment and relabel equipment to achieve compliance.

\section{Operational Experience Analysis (Chapters 5 and 6)}

Analysis of existing data maintained at the facility or by DOE which represents error likelihood on recurring events, self-awareness programs, and the Occurrence Reporting and Processing System (ORPS) mandated by DOE Order 5000.3B. These data are used to verify the results of hazard and accident analysis, and to further demonstrate that facility programs are capable of fully supporting the safety mission of the facility, including its SAR and TSR commitments to DOE. 


\section{Operating Limit (Chapter 10)}

An operating limit is a safety limit, limiting control setting, or limiting condition and its associated action statement and time limit. An operating limit is established for each TSR developed for the results of the safety analysis.

\section{Human causal Factor (HCF) (Chapter 5)}

Influences human performance. That is, human performance on a given task, including likelihood of error, is a product of a variety of intrinsic and extrinsic factors. Included among these intrinsic factors, for example, are the human's own physical ability, attitudes toward and motivation for performing well on the task, amount of stress felt, and experience. Performance is also influenced by performance aids available to the human. Included among these extrinsic factors, for example, are formal training, written procedures, co-workers, and supervisor oversight. Finally, human performance is influenced by extrinsic physical environment factors such as heat, light, noise, temperature, and larger environmental factors such as management policies. All of these factors, which are pertinent to human performance on a given task, must be analyzed as part of the Human Safety Analysis if credible estimates of safety significance are to be achieved. HCFs directly impact human performance. HCFs impact local, onsite and offsite consequences of an accident. The HCF impact results from an earlier human action that could be the precursor, initiator, or mitigator of the hazard or accident.

\section{Human causal Factor (HCF) Analysis (Chapters 5 and 6)}

Second step of a human safety analysis during which human causal factors are selected and evaluated. The HCF analysis provides: (1) bounding values for the remaining Human Performance Assessment step of the HF safety analysis process, and 
(2) causal factors information that will systematically impact Human Performance Assessment results.

\section{Person-Centered HCFs (Chapter 5)}

Intrinsic characteristics that are brought to the task by the individual. Some are stable or slowly changing such as experience, aptitude, and physical strength. Others are situational such as fatigue, stress, and emotional upset. Worker qualifications are of particular interest to DOE in the SAR for operations and maintenance including experience, and are analyzed primarily for SAR Topics $\underline{11} \underline{12}$ and $\underline{15}$.

\section{Preliminary Safety Analysis Report (PSAR) (Introduction Chapter)}

Documents the adequacy of the safety analysis of the proposed operating configuration of a nuclear facility to ensure that the facility can be constructed, operated, maintained, shut down, and decommissioned safely and in compliance with applicable laws and regulations.

\section{Primary HF Topics (Chapter 4)}

SAR topics which use HF information as the primary source for demonstrating the adequacy of human performance subject matter. These latter SAR Topics are the primary focus of this SAR course. These include SAR Topics:

$5 \quad$ Hazards Analysis and Facility Classification

11 Accident Analysis (Human Performance Assessment segments)

12 Management, Organization, and Institutional Controls

13 Procedures and Training

14 Human Factors Engineering

15 Initial Testing, In-service Surveillance, and Maintenance 


\section{Qualitative Human Performance Assessment (Chapter 5)}

Uses a measure of error or success likelihood estimate (probabilistic), deviation score, or measure of central tendency (non-probabilistic) derived judgmentally from information and data developed earlier in the Human Safety Analysis. The result is obtained primarily through a reasoning process, relying to some extent on the insights of the analyst. One emphasis is on explaining relationships between human performance outcomes and associated root, direct, and contributing causal factors, individually and in combination. Another emphasis is on deriving remedial (get well) options due to their linkages with the earlier root, direct, and contributing causal factors.

\section{Quantitative Human Performance Assessment (Chapter 5)}

Uses a measure of error or success likelihood estimate (probabilistic), deviation score, or measure of central tendency (non-probabilistic) derived computationally from information and data developed earlier in the Human Safety Analysis. Emphasis is on an objective measure or snapshot of human performance. The result is obtained through application of a transparent algorithm (capable of being audited). A qualitative result obtainable from the quantitative result is also needed to apply HF findings to facility improvement.

Recovery (Chapters 6, 7, 9, Appendices A, B, and C)

Correcting an error in sufficient time to avoid an adverse effect from the initial error. 


\section{Rigor (Chapter 6)}

Means by which human safety analysis information is gathered and performance is scored. For Hazard Category 1 facilities, each HCF has a comparison made between discrete standards and content analyses. For example, human-machine interface equipment is analyzed for compliañce with DOE or DOE referenced standards. Formal training and procedures are examined for their technical accuracy, completeness, and comprehensibility. For Hazard Category 2 facilities, the existence of formal training materials and written procedures is checked. No content analysis is done of the training materials or procedures. For both Hazard Category 1 and 2 facilities quantitative Human Performance Assessments are done to estimate the impacts of human performance on safety. For Hazard Category 3 facilities these estimates are arrived at qualitatively using consensus expert judgment.

\section{Rule-Based Tasks (Chapter 5)}

Involve under-learned response patterns which are performed on less than a regular basis and are primarily influenced by task-centered factors such as training, procedures, and direct oversight.

\section{Safety Analysis Report (SAR) (Introduction Chapter, Chapter 4)}

Documents the adequacy of the safety analysis for a nuclear facility to ensure that the facility can be constructed, operated, maintained, shut down, and decommissioned safely and in compliance with applicable laws and regulations. 


\section{Scope (Chapter 6)}

Physical area of the facility which is the subject of the human safety analysis. For Hazard Category 1 facilities the site boundary usually provides the limit of the analysis; for Hazard Category 2 facilities it is usually the facility boundary; and for Hazard Category 3 facilities it is usually the immediate work area up to 100 meters from ground zero.

\section{Secondary HF Topics (Chapter 4)}

SAR topics which use HF information, combined with information on facility structures, systems, and components, as secondary sources, to demonstrate the adequacy of the SAR topic subject matter. These include SAR Topics:

$\begin{array}{cl}4 & \text { Facility Description } \\ 6 & \text { Health and Safety Criteria } \\ 16 & \text { Derivation of Technical Safety Requirements } \\ 17 & \text { Operating Safety } \\ 18 & \text { Quality Assurance } \\ 19 & \text { Emergency Preparedness }\end{array}$

\section{Skill Based Tasks (Chapter 5)}

Involve over-learned responses which are performed on a regular basis and are primarily influenced by person-centered factors such as coordination, concentration and motivation. 


\section{Subject Matter Expert Judgment (Chapter 5)}

Evaluation technique which involves polling of the experts on the adequacy of the HCFs based on their general knowledge of the facility and the functions and tasks being analyzed. This approach is usually associated with Hazard Category 3 facilities.

\section{Surveillance Requirements (SRs) (Chapter 10)}

Relate to test, calibration, or inspection to ensure that the necessary operability and quality of structures, systems, components, and their support systems that are required for safe operation of the facility are maintained.

\section{Systems Approach (Chapter 1)}

The safety analysis takes into equal consideration the roles and interactions among hardware, human, and administrative controls that make up the system or organization.

\section{Task Analysis (Chapters 5 and 6)}

Primarily human-centered and is a step-by-step representation of a human task action sequence using flow chart diagrams and narrative descriptions. The focus of the analysis is human tasks derived from the function analysis. Each task is broken down into sub-tasks, and in some cases into hierarchical elements of those sub-tasks. The human tasks identified in the function analysis are used as the starting point for the task analysis. The task analysis is performed by the HF practitioner and involves frequent coordination with other members of the safety analysis team. The task analysis provides the HF practitioner with descriptions of human actions, many of which will be analyzed later as part of the hazards and accident analysis. The task analysis - enhanced by later timeline, link, human vulnerability, and human failure 
modes analysis-represents our best description of how human actions and action sequences are actually performed by facility personnel. The task analysis therefore becomes the basis for developing and evaluating a wide range of human factors controls such as: allocation of responsibilities, qualification requirements, training, procedures, and HFE.

\section{Task-Centered HCFs (Chapter 5)}

Extrinsic characteristics of the human-machine interface such as design, workspace layout, staffing, training, and written procedures. Of particular interest to DOE in the SAR for operations and maintenance are:

- $\quad$ Staffing analyzed primarily for SAR Topics $\underline{11} \underline{12}$, and $\underline{15}$;

- $\quad$ Procedures and training analyzed primarily for SAR Topics $\underline{11}, \underline{13}$ and $\underline{15}$

- Human-machine interface and workspace layout analyzed primarily for SAR Topics $\underline{11}$ and 14 .

\section{Technical Bases (Chapter 10)}

Document the rationale for the Action Statement and Time Limits, and the Surveillance Requirements and Intervals contained in the TSR document. As with other sections of the TSR document, the information in the Technical Bases appendix should be traceable back to the PSAR/FSAR and its supporting documentation. 


\section{Technical Safety Requirement (TSR) (Chapter 10)}

Defines the conditions, safe boundaries, and the management or administrative controls necessary to ensure the safe operation of a nuclear facility and to reduce the potential risk to the public and facility workers from uncontrolled releases of radioactive or chemical materials, or for enhancing defense in depth or worker safety.

\section{Tertiary HF Topics (Chapter 4)}

SAR topics that use HF information as third level sources, to demonstrate the adequacy of SAR topic subject matter. These include SAR Topics:

$\begin{array}{cl}1 & \text { Introduction and Summary } \\ 2 & \text { Codes and Standards } \\ 3 & \text { Site Characteristics } \\ 7 & \text { Waste Management } \\ 8 & \text { Inadvertent Criticality } \\ 9 & \text { Radiation Protection } \\ 10 & \text { Hazardous Materials Protection } \\ 20 & \text { Decontamination and Decommissioning } \\ 21 & \text { Applicable Facility Design Codes and Standards }\end{array}$

\section{Timeline Analysis (Chapters 5 and 6)}

Organizes a function or task analysis along a time grid (including plant response times) to highlight sequential and parallel ordering of tasks or lower level units of analysis (e.g., subtasks, elements of subtasks), and timing between those units of analysis. A timeline analysis is usually done as part of a function and task analysis. A timeline analysis also provides information on hardware utilization in conjunction with and parallel to human actions. Finally, the timeline analysis provides the analyst 
with information to determine whether time stress and/or recovery should be modeled as human causal factors in the Human Performance Assessment.

\section{Total Quality Management (TQM) (Chapter 1)}

Approach to quality assurance which stresses four absolutes: (1) high pay-off of conformance to requirements, (2) quality is prevention, (3) zero defects, and (4) high cost of nonconformance to requirements. 


\section{Introduction}

\section{Purpose of the Human Factors (HF) Course Text:}

This text provides the technical basis for a two-day course on human factors (HF), as applied to the Safety Analysis Report (SAR) process. The primary objective of this text is to be a ready reference for U.S. Department of Energy (DOE) facility managers, SAR preparers, SAR reviewers, and DOE regulators responsible for implementing the HF requirements of DOE Order 5480.23, Nuclear Safety Analysis Reports and as further defined by DOE Standard 3009-94 (DOE 1992a 1994). Its secondary objective is to be a ready reference for implementing the human factors requirements of DOE Order 5480.22, Technical Safety Requirements (DOE 1992b).

The overall objective of this text and course is to:

provide the participant with a working knowledge of human factors-related requirements, suggestions for doing a human safety analysis applying a graded approach, and an ability to demonstrate using the results of the human safety analysis, that human factors elements as defined by DOE (human factors engineering, procedures, training, oversight, staffing, qualifications), can support wherever necessary, nuclear safety commitments in the SAR.

More specifically, the objectives of the text and course are:

(1) To provide the SAR preparer with general guidelines for doing HF within the context of a graded approach for the SAR;

INTRO-1 
(2) To sensitize DOE facility managers and staff, safety analysts and SAR preparers, independent reviewers, and DOE reviewers and regulators, to DOE Order 5480.23 requirements for HF in the SAR;

(3) To provide managers, analysts, reviewers and regulators with a working knowledge of HF concepts and techniques within the context of a graded approach for the SAR, and

(4) To provide SAR managers and DOE reviewers and regulators with general guidelines for monitoring and coordinating the work of preparers of HF inputs throughout the SAR process, and for making decisions regarding the safety relevance of HF inputs to the SAR.

As a ready reference for implementing the human factors requirements of DOE Order 5480.22 and DOE Standard 3009-94, this course text and accompanying two-day course are intended for all persons who are involved in the SAR. In summary, the text and course are directed especially toward persons who have: (1) completed the DOE five-day SAR Course, (2) prior experience with the 5480.23 and DOE Standard 3009-94 SAR process, or (3) experience as an HF practitioner.

\section{Introduction References:}

Code of Federal Regulations (CFR), 1993, "Procedural Rules for DOE Nuclear Facilities." Title 10 Part 820.

Department of Energy (DOE), 1989, "General Design Requirements for Nonreactor Facilities, " Order 6430.1A, April.

DOE, 1991, "Unreviewed Safety Questions," Order 5480.21, December.

DOE, 1992a, "Nuclear Safety Analysis Reports," Order 5480.23, April.

DOE, 1992b, "Technical Safety Requirements," Order 5480.22, September. 
DOE, 1992c, "Project Management Plan," Order 4700.1B, June.

DOE, 1992d, "Writer's Guide for Technical Procedures," Standard 1029-92, December.

DOE, 1993, "Nuclear Reactor Safety Design Criteria," Order 5480.30, January.

DOE 1994, "Preparation Guide for U.S. Department of Energy Nonreactor Nuclear Facility Safety Analysis Reports," Standard 3009-94, July.

\section{SAR Requirements for HF:}

In April 1992, DOE Order 5480.23 established explicit requirements for demonstrating the adequacy of the human factor to fully support the nuclear safety missions of DOE facilities classified as Hazard Category 1, 2, and 3 (DOE 1992a). More specifically, DOE requires that individually and collectively all human-centered provisions and controls instituted at DOE facilities in response to the design and programmatic requirements of other DOE orders and DOE adopted government regulations must be fully capable of supporting the facility safety mission. Included among these human-centered provisions and controls for facility operations, surveillance, and maintenance mandated by DOE are: "allocation of duties and responsibilities, personnel qualification and certification, staffing, management oversight, training, operating procedures, and human-machine interfaces" (DOE 1992a). It is also necessary to demonstrate, by means of the hazards and accident analyses and operating experience, that these provisions and controls can support safety given the facility hazard classification, mission, complexity, life cycle status, and other factors germane to the facility safety envelope.

This text and its companion course recognize the SAR process does not exist in a vacuum. As suggested in Figure 1, the SAR influences and is influenced by a variety of other requirements and considerations of facility design and authorization. 
- In Figure 1, DOE Orders 6430.1A and 5480.30 establish HF design requirements for nonreactor and reactor nuclear facilities respectively (DOE $1989,1993)$. Implemented within the context of DOE Order 4700.1B, system acquisition program, HF work conducted in response to $6430.1 \mathrm{~A}$ or 5480.30 requirements forms the technical basis for responding to 5480.23 in the Preliminary Safety Analysis Report (PSAR) and initial Final Safety Analysis Report (FSAR) (DOE 1992c, 1993). Figure 2 shows the PSAR and initial FSAR embedded in the 4700.1B acquisition process (DOE 1992c).

- The SAR must be viewed in combination with the Unreviewed Safety Question (USQ) and Technical Safety Requirements (TSR) established by DOE Orders 5480.21 and 5480.22 respectively (DOE 1991, 1992b). SARs written to 5480.23 are required to be "living". This means that they must be capable of being revised as needed to reflect changes in the facility operating configuration, and must demonstrate that these changes do not degrade the ability of facility safety features to fully support the nuclear safety mission of the facility including its SAR and TSR commitments to DOE.

- The USQ process is an important mechanism in establishing technical justifications for changing the SAR, and

- the SAR is an important mechanism in establishing technical justifications for changing the TSRs. 
Figure 1 SAR Role in DOE System Acquisition

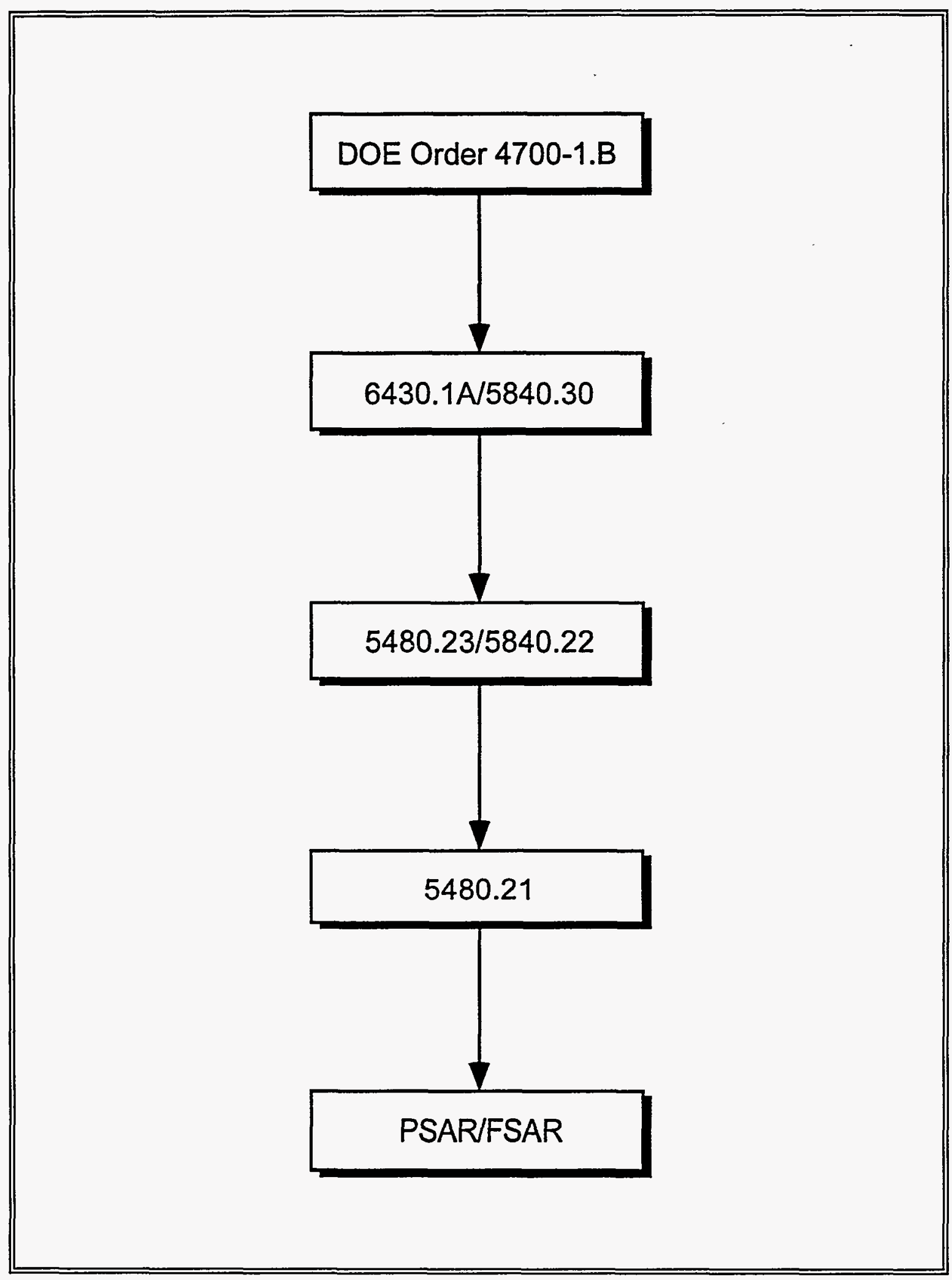

INTRO-5 
Figure 2 DOE Facility Acquisition Phases with PSAR \& FSAR

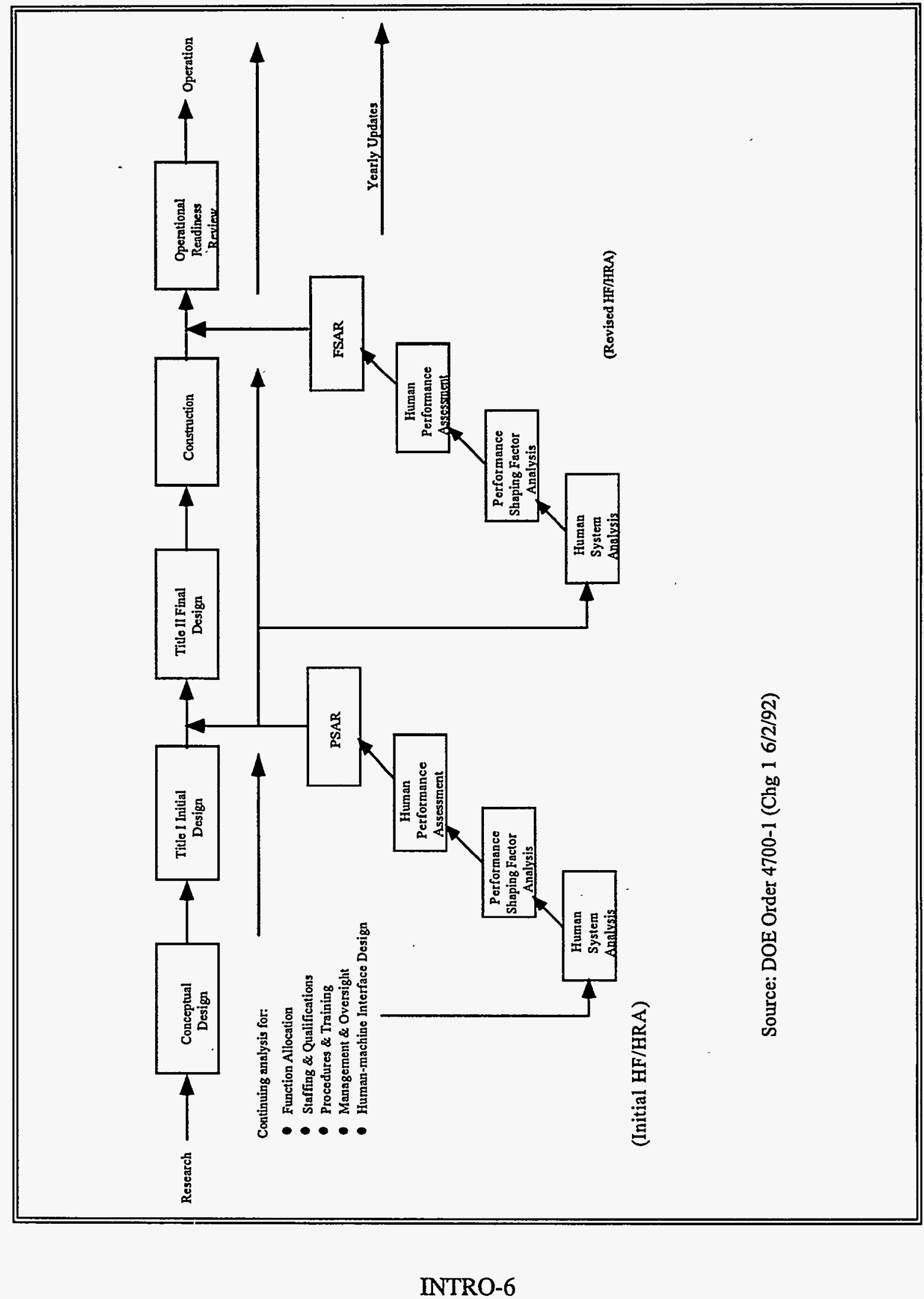


Figure 3 shows the integration of HF into the SAR development process as portrayed in DOE Standard 3009-94 (DOE 1994). The left side of Figure 3 lists the major steps in the SAR development process; the right side shows the human safety analysis development steps and their continuing interactions with the SAR development process. This text and its companion two-day course are directed toward a credible human safety analysis fully integrated into other SAR activities, and fully responding to the requirements of DOE Order 5480.23 and, for non-reactor facilities as further defined by DOE Standard 3009-94 (DOE 1992a, 1994).

Figure 4 makes a distinction between human system design which is mandated by DOE Orders 6430.1A and 5480.30, and human safety analysis for the SAR which is mandated by DOE Order 5480.23 and as further defined by DOE Standard 3009-94. Human system design begins with consideration of safety and progresses toward aesthetics. For example, if one wishes to sell automobiles in a highly competitive market, it is necessary that the vehicle design emphasize comfort and appearance, as well as being safe, efficient, and cost competitive. The same may be true of DOE facilities attempting to break into commercial markets. The human safety analysis for the SAR, on the other hand, is directed toward parsing out the human factors that are relevant to safety, from the other design factors, and toward determining the degree to which the human safety factors are capable of supporting the facility's SAR commitments to DOE commensurate with the facility's classification as Category 1,2 , or 3 .

\section{Technical Basis for Course Text:}

DOE has established requirements for human factors (HF) in SAR Order 5480.23a for all its facilities that are classified as Hazard Category 1, 2, or 3 (DOE 1992a). DOE has further defined HF requirements in the SAR for nonreactor Hazard Category 2 and 3 facilities in DOE Standard 3009-94 (DOE 1994). To date, specific HF guidelines for responding to these requirements have not yet been promulgated by DOE, nor have specific analytic tools

\section{INTRO-7}


been developed or formally endorsed by DOE for responding to these SAR requirements. In lieu of such guidance, the HF SAR course relies on commonly held interpretations of the requirements, lessons learned to date doing $\mathrm{HF}$ within the context of the SAR process, feedback from DOE on SARs submitted to date, and feedback from organizations with an interest in the DOE SAR process. More detailed discussions of the technical bases for the course are presented in the following paragraphs.

\section{DOE Requirements for HF.}

The contents of the course are directed toward a credible demonstration that the human factors elements making up DOE's concept of human factors safety, are capable of supporting the nuclear safety commitments being made to DOE, by the facility, in its SAR and accompanying TSRs. Contents of the course derive from the fact that such commitments made by the facility in its SAR and TSRs come under the liability provisions of 10 CFR 820, Appendix A, referred to as "Price Anderson" (CFR 1993). Therefore, nuclear safety must be a clearly discernible issue for every commitment that is made, including those relying on human factors elements for their accomplishment.

Human factors including Human Performance Assessment elements that are the domain of the course are taken directly from DOE Order 5480.23 (DOE 1992a). DOE Order 5480.23, Attachment 1, Section 3.b(1)(b) defines human factors safety to include: "allocation of control functions to humans and machines, staffing and qualifications of personnel, personnel training, written procedures to guide operations and maintenance, and design of human-machine interfaces."

Similarly, DOE Order 5480.23, Attachment 1 Topic 11 (Analysis of Normal, Abnormal, and Accident Conditions) requires that: "Safety analyses include the application of methods such as deterministic safety analysis, risk assessment, reliability engineering, common cause failure analysis, Human Performance Assessment, and

\section{INTRO-8}




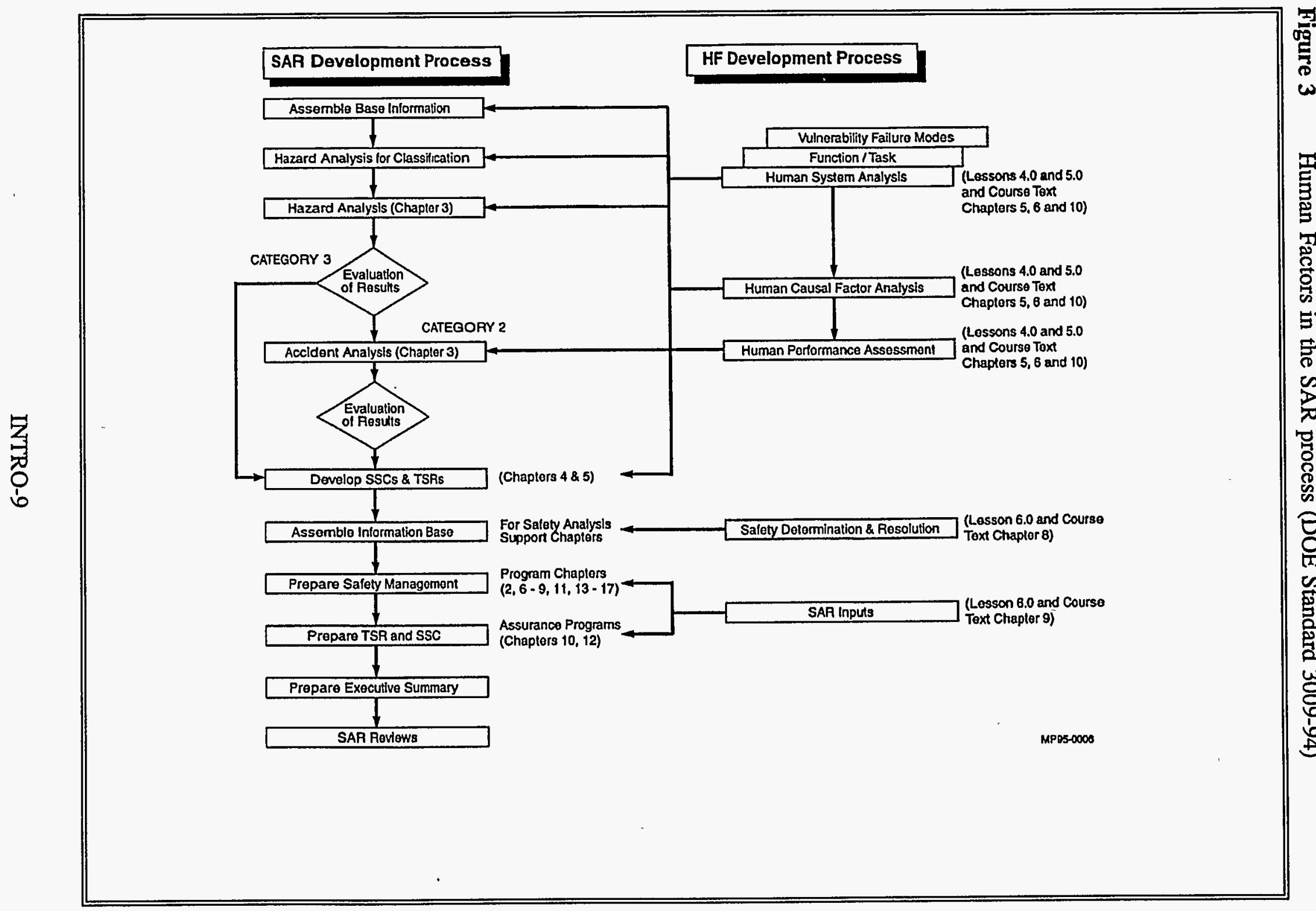




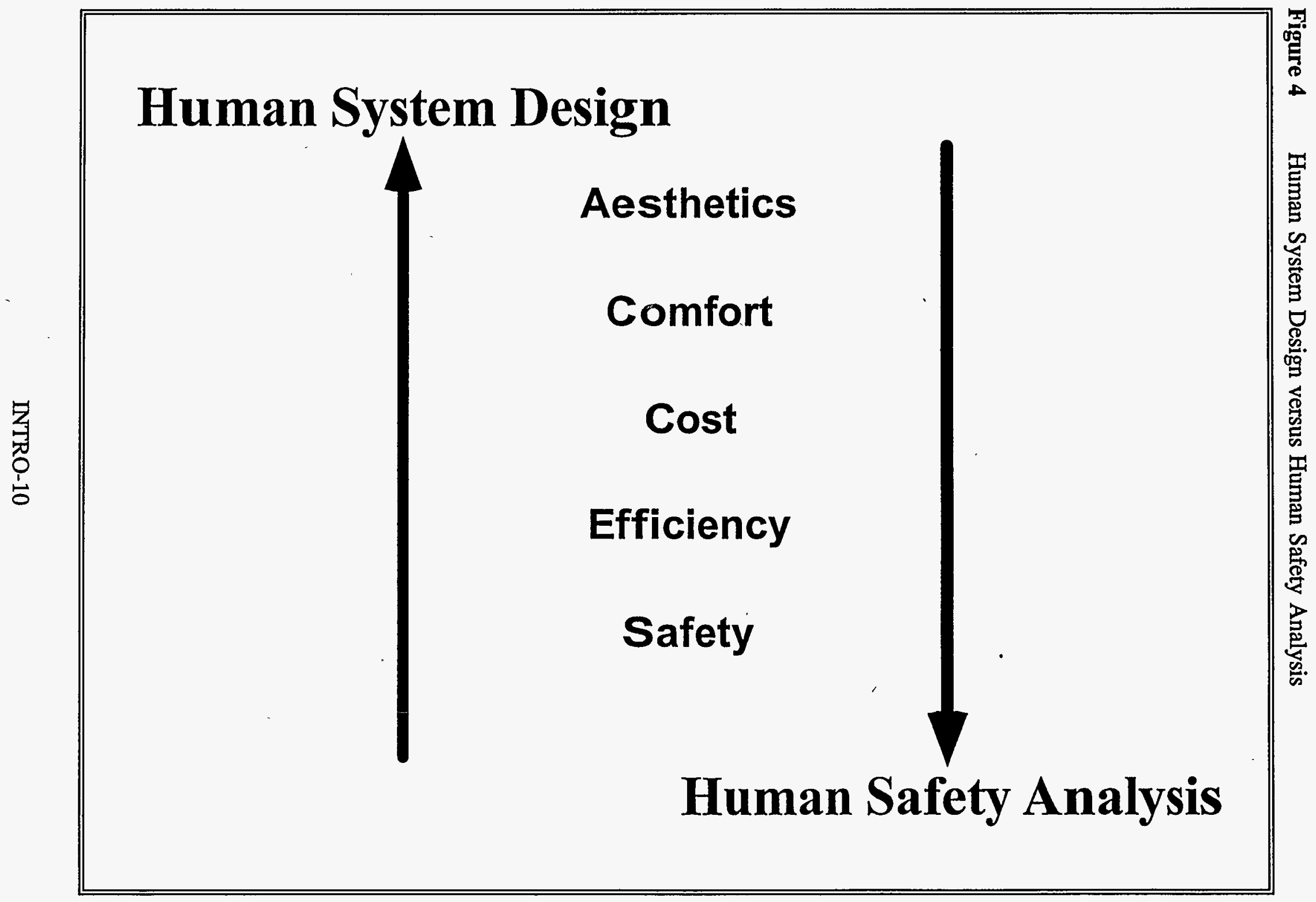


human factors safety analysis techniques as appropriate in the identification, investigation, elimination, mitigation, or control of vulnerabilities of the facility to accidents and accidental releases."

\section{Technical Basis for the General Contents of the HF SAR Course:}

The HF SAR course contents recognize that the SAR, along with its companion TSR document, make a legal commitment. They further recognize that nuclear safety is at issue, not general design requirements or other larger programmatic requirements that may be imposed on the facility by DOE and its field offices, other Federal government agencies, and state and local agencies. The course contents also recognize that DOE intends the SAR to play an active role in the daily operation of the facility. Finally, the course contents recognize that DOE intends the SAR to be a "living" document requiring systematic updating and coordination with DOE by means of the Unresolved Safety Question (USQ) process. More specifically:

1. The contents of the course start with DOE's definition of human factors safety and requirements for HF in the SAR stated above.

2. The contents of the course focus on nuclear safety. That is, the elements making up human factors, as defined by DOE, are demonstrated to be fully capable of supporting the SAR nuclear safety commitments to DOE as derived from the hazards and accident analysis, concerns about defense-in-depth and worker safety, operational experience, and any other nuclear safety issues as might be raised in other documentation that make up the authorization basis for the facility. 
3. The course agenda emphasizes a hands-on approach. Five mini-exercises are integrated into the presentation/discussion segments of the course. SAR preparation and SAR review exercises make up the practicum segments of the course.

4. The goal of the course is a credible, cost-effective and timely process, guided by a systems approach, for demonstrating that human factors elements are capable of supporting facility SAR nuclear safety commitments to DOE.

5. The primary guiding principle of the course is that the SAR must demonstrate a safe operating configuration, not just describe programs and processes. SARs often are too long and don't resolve the safety question. This is especially true when it comes to the programmatic topics which make up about $80 \%$ of the SAR contents.

6. The human safety analysis process, presented in Chapters 5 and 6 of this text and Lessons 4.0 and 5.0 of the course, rely on a systems approach, using good configuration management principles, as a means to Total Quality Management (TQM).

7. The human safety analysis processes suggested in the course are directed at using the results of the DOE facility human factors program, to the extent they exist and are current.

The contents of the course come from a wide variety of sources going back to publication of DOE Order 5480.23 in April 1992.

1. DOE Standard 3009-94, other DOE standards (e.g., 1029-92, Writer's Guide for Technical Procedures), and DOE referenced standards pertaining to human 
factors engineering (HFE) (DOE 1994, 1992d). In addition, the course references specific publications of DOE labs developed to support HF in the SAR (e.g., Savannah River Human Error Data Manual, Oak Ridge National Laboratory [ORNL] Accident Sequence Evaluation Program [ASEP] Implementation Procedure).

2. Lessons learned by the authors and others from doing SARs to 5480.23 and 3009-93, 3009-YR, and currently 3009-94 (DOE 1992a, 1994).

3. Feedback from DOE on SARs responding directly to 5480.23 for Hazard Category 1 facilities, to 3009-93/YR/94 for Hazard Category 2 and 3 nonreactor facilities, and to other guidance provided by DOE field offices on a site-by-site basis (DOE 1992a, 1994).

4. Feedback on the proposed concepts and materials from DOE and managing contractor representatives.

5. Feedback from current DOE SAR course participants on an overview of the concepts and processes proposed for the HF SAR course.

6. Feedback from a wide variety of reviewers (DOE staff, other government experts, human factors community, non-human factors SAR managers and writers). 


\section{Technical Basis for the Graded Approach Suggested in the HF SAR Course:}

Chapter 6 of the Course Text and Lesson 5.0 of the course suggest a graded approach for human safety analysis to support the SAR process. The graded approach is directed toward:

1. Retaining the credibility and auditability of the HF SAR inputs,

2. Responding to the grading factors established by DOE: hazard consequence, complexity, life cycle, mission, and other unique facility factors that might affect safety,

3. Applying a systems approach at all grade levels to minimize cost, time, and other resources, and

4. Reducing scope, level of detail, and rigor when moving from a Hazard Category 1 through Hazard Category 3 facility.

\section{Organization of Course Text:}

This text takes a systems approach to HF in that human-centered functions are viewed from the perspective of their integration with hardware and the administrative control elements of the facility operating configuration. Although treated as separate topics in the SAR Order, this text views human performance as dependent on the collective adequacy of the allocation of duties and responsibilities, personnel qualification and certification, staffing, management oversight, training, operating procedures, and human-machine interfaces. Therefore, this text is divided into 10 chapters accompanied by numerous illustrations to 
emphasize important points and provide examples to the reader. The text also contains an Acronym List, a Glossary, and a Subject Index.

\section{Chapter 1: Systems approach to the SAR process (hardware, personnel, administrative controls)}

The overall objective of Chapter 1 is to sensitize the reader to system elements, each of which needs to be considered as an integrated whole, if the safety analysis is to be credible and auditable.

\section{Chapter 2: HF as a behavior-centered scientific discipline}

The overall objective of Chapter 2 is to provide the reader with knowledge of the origins of $\mathrm{HF}$ in the behavioral, social, and engineering sciences, and as a scientific discipline in itself.

\section{Chapter 3: HF at the U.S. Department of Energy (DOE)}

The overall objective of Chapter 3 is to sensitize the reader to HF initiatives at $\mathrm{DOE}$, as they pertain to general design requirements, operating requirements, and regulatory requirements such as the HF requirements posed by the Safety Analysis Report (SAR) order.

Chapter 4: HF Requirements and Guidance established by DOE Order 5480.23 , other DOE Orders and Standards, and DOE-provided and referenced compliance standards

The overall objective of Chapter 4 is to provide explicit and implicit $\mathrm{HF}$ requirements from DOE, guidance that is DOE-provided and referenced, and compliance standards for responding to these requirements, within the context of the SAR. 
Chapter 5: HF Concepts, techniques, and data sources for human safety analysis, to respond to 5480.23 and DOE Standard 3009-94 SAR requirements and guidance

The overall objective of Chapter 5 is to provide HF concepts, techniques, and processes for responding to SAR requirements. The human safety analysis process includes three sometimes iterative steps (human system analysis, human causal factor analysis, and Human Performance Assessment).

Chapter 6: Graded approach to human safety analysis for facilities classified as Category 1,2, and 3

The overall objective of Chapter 6 is to provide one approach for achieving a graded HF analysis commensurate with facility classification, while retaining credibility and auditability.

\section{Chapter 7: Preparation of HF Documentation to support the SAR process}

The overall objective of Chapter 7 is to provide guidance on documenting the results of the HF analysis for making safety relevance determinations, for serving as a technical basis for the HF segments of the SAR process, and for supporting future HF activities of the facility.

\section{Chapter 8: Determination of nuclear safety significance and resolution of judged deviations from HF compliance standards}

The overall objective of Chapter 8 is to provide a means for: (1) determining from the hazards and accident analyses which of the HF judged compliances and non-compliances are nuclear safety significant, and (2) resolving nuclear safety significant deviations that are judged not in compliance with $\mathrm{HF}$ standards. 


\section{Chapter 9: Preparation of Human Factors including Human Performance Assessment sections of the SAR}

The overall objective of Chapter 9 is to provide a strategy for using the human safety analysis information (generated by means of Chapters 1 through 8), to demonstrate in the SAR that the human factors element(s) are fully capable of supporting the current facility nuclear safety SAR commitments to DOE.

\section{Chapter 10: Contribution of HF to the TSRS}

The overall objective of Chapter 10 is to sensitize the reader to the potential role of HF in selecting and developing Action Statements, Surveillance Requirements, and Administrative Controls for the Technical Safety Requirements (TSRs).

\section{Appendix A: $\quad$ Accident Sequence Evaluation Program (ASEP) Procedure:} Excerpts from the U.S. Nuclear Regulatory Commission Report NUREG/CR-4772

This appendix provides additional information on the ASEP screening procedure for Human Performance Assessment. ASEP is a subject of Chapters 4,5 , and 6 of this Course Text.

Appendix B: $\quad$ Technique for Human Error Rate Prediction (THERP): Excerpts from the U.S. Nuclear Regulatory Commission Report NUREG/CR-1278

This appendix provides additional information on the THERP procedure for detailed Human Performance Assessment. THERP is a subject of Chapters 4, 5 , and 6 of this Course Text. 


\section{Appendix C: $\quad$ Explanation of Human Performance Assessment. (HPA) Tree Entries Contained in Chapter 6, Fiqure 6-17 and Figure 6-18}

This appendix provides explanations for HEPGen generated HPA Tree entries that appear in Chapter 6, Figure 6-17 and Figure 6-18. HEPGen is a computer code for drawing and solving HPA trees using the THERP methodology. 


\section{Chapter 1}

\section{Systems Approach to the SAR Process (hardware, personnel, administrative controls)}

The overall objective of Chapter 1 is to sensitize the reader to system elements, each of which needs to be considered as an integrated whole, if the human safety analysis is to be credible and auditable.

\subsection{Introduction}

The purpose of this chapter is to sensitize the reader to the fact that the Department of Energy (DOE) community is very hardware-oriented. Until recently this orientation has carried over to Preliminary and Final Safety Analysis Report (PSAR/FSAR) preparation, and subsequent development of Technical Safety Requirements (TSRs) [formerly called Operating Safety Requirements or OSRs]. Traditionally, we talk about facilities in terms of their structures, systems, and components. A comparison between the operating records of similar DOE facilities, however, will indicate that differences are primarily the result of non-hardware factors. DOE Orders 5480.23 (pertaining to the PSAR/FSAR), and 5480.22 (pertaining to the TSRs) recognize this fact, and have established several new requirements focusing on the non-hardware side of the system (DOE 1992a, 1992b).

The remaining sections of this chapter address the DOE facility as a living system comprised of interacting hardware, personnel, administrative controls, and institutional controls. The remaining sections also address issues of configuration management and total quality management, concepts that are increasingly important if PSAR/FSAR and TSR preparers are to achieve and maintain credible documentation on their ever-changing operating configurations. 


\subsection{Chapter 1 References}

Code of Federal Regulations (CFR), "Procedural Rules for DOE Nuclear Activities," 10 CFR 820, August 1993.

Cartin, T. J. (1993), Principles and Practices of TQM, ASQC Quality Press, Milwaukee, WI.

Crosby, P. B. (1984), Quality without Tears: The Art of Hassle-Free Management, Penguin Books, New York

Department of Defense (DOD), 1992, "Configuration Management," MIL-STD-973, June.

Department of Energy (DOE), 1991, "Unreviewed Safety Questions," Order 5480.21, December.

DOE, 1992a, "Nuclear Safety Analysis Reports," Order 5480.23, April.

DOE, 1992b, "Technical Safety Requirements," Order 5480.22, September.

DOE, 1993, "Guide for Operational Configuration Management Program including Design Reconstitution and Material Condition and Aging Management," DOESTD-1073-93, November.

Feigenbaum, A. V., (1991), Total Quality Control, 3rd ed. Revised, McGraw Hill Co., New York.

Guess, V. C. (1979), Engineering: The Missing Link in Materials Requirements Management Systems, Vanard Lithographers, San Diego, CA. 


\subsection{DOE Facility as a System}

For several decades, systems theorists and practitioners have recognized that systems-regardless of complexity-involve three interactive elements: (1) the structures, systems and components that make up the hardware subsystem, (2) the humans that comprise the personnel subsystem, and (3) the procedures and other controls that make up the administrative subsystem. These elements are shown in Figure 1-1. Together, these three elements make up the system operating configuration. The relative-impact each of these elements has on system safety and efficiency depends upon the complexity of the system and its daily mission. Complexity and mission notwithstanding, considerable evidence from over the past few decades within a variety of industry and government settings indicates that nonhardware factors, especially human performance, dominate likelihood of success or failure of the system. Chapter 2 of this text discusses several examples of the human's impact on reallife safety-related events.

Recognizing the importance of non-hardware factors to the safe and efficient operations of its facilities, DOE has recently issued Orders 5480.23 and 5480.22, which are directed toward more systems-oriented approach to assessing the operating safety of its facilities (DOE 1992a, 1992b). For example, DOE Order 5480.23, concerning nuclear safety analysis reports, requires that 21 topics be addressed (DOE 1992a). Of the 21 topics, all but two (i.e. Site Characteristics and Facility Description) give equal if not primary emphasis to non-hardware elements of the system. Likewise, DOE Order 5480.22, concerning technical safety requirements, focuses on non-hardware requirements except for equipment safety limits and limiting control settings (DOE 1992b).

Given the DOE requirement that the PSAR/FSAR demonstrate the capability of all elements of the system to support fully the safety mission of the facility, and the mandate to develop TSRs that are capable of ensuring that safety commitments can be achieved, maintained, and recovered if necessary, a system-centered safety analysis is required. Chapters 4 through 10 of this text focus on a technical approach for achieving system- 
centered results for the human factors (HF) segments of the SAR and TSR process. As suggested in Figure 1-2, a systems approach begets good configuration management that precedes Total Quality Management (TQM).

\subsection{Configuration Management}

It is DOE's intention that the SARs be prepared so they can be readily accessed by facility management and staff as a means of ensuring that safety commitments to DOE are being maintained. To that end, DOE Order 5480.23, Section 8.c., and Attachment 1, Section 4.f(11) and 4.f(12) require that the SAR be maintained up-to-date and be controlled (DOE 1992a). Section 8.c also requires that the Unreviewed Safety Question (USQ) provisions of DOE Order 5480.21 be implemented to judge the safety significance of anticipated changes on the operating configuration of the facility (DOE 1991). Achieving a document that is usable in an operational setting, and judging the necessity of and making timely changes to the document, require good configuration management. While this text and accompanying course do not have configuration management as their primary objective, both recognize the concern of Vince Guess, the Department of Defense (DOD) MIL-STD-973, and the DOESTD-1073-93 (Guess 1979, DOD 1992, DOE 1993), all of whom consider configuration management to be the missing link for achieving goals such as DOE has set for the SAR and TSR process.

Good configuration management is built around: (1) a rigorous definitional system, (2) a well-documented change process, and (3) strict adherence to a no-documentation=noimplementation philosophy. Chapter 7 of this text is directed toward a process by which HF analyses and their results can be documented and maintained so they fully support DOE's usefulness, updating and control objectives. As suggested in Figure 1-2, configuration management begets TQM. 


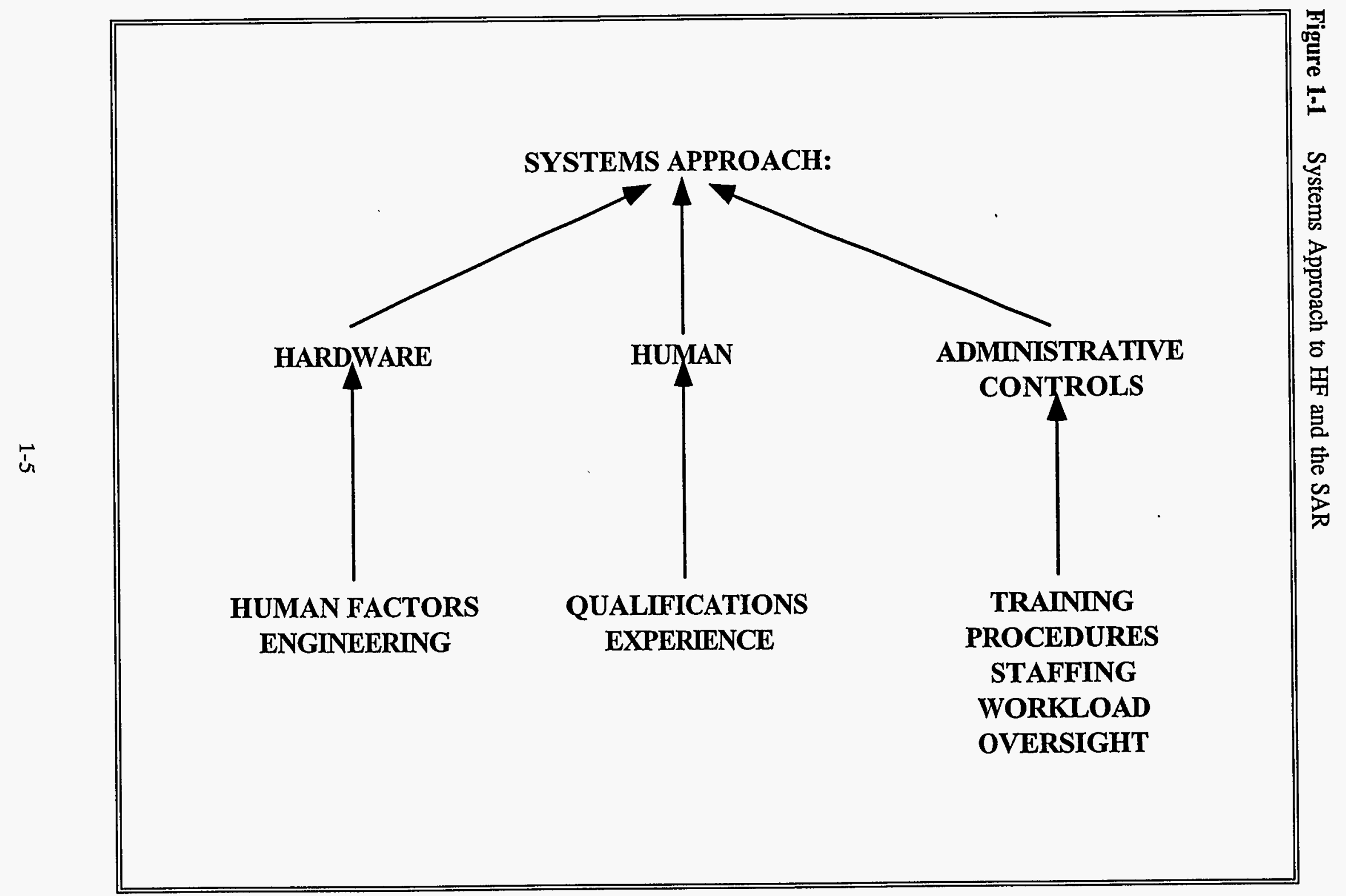




\subsection{Total Quality Management (TQM)}

Total Quality Management (TQM) is a philosophy being embraced by DOE as a means for achieving high quality SARs and maintaining quality throughout the SAR and TSR life cycles. TQM is a working system or structure, documented in procedures, which coordinates people and information, practically, to assure internal and external customer satisfaction (Feigenbaum, 1991). In the case of the SAR process, there are several identified internal and external customers. Certainly, DOE is an external customer of the SAR process. Additionally, the general public is an external customer. Internal customers consist of the facility contracting to produce the SAR. Within the facility are several people and organizations that will benefit from the development of the SAR, both now and in the future. Internal customers also include SAR preparers responsible for other sections of the SAR impacted by HF results and analysis. Finally, another internal customer is the HF SAR section preparer. Lessons learned from performing an analysis at one facility can be used to improve the analysis of another facility. This process of continuous improvement is an essential ingredient of TQM (Cartin, 1993).

Figure 1-2 The Systems Approach Cycle

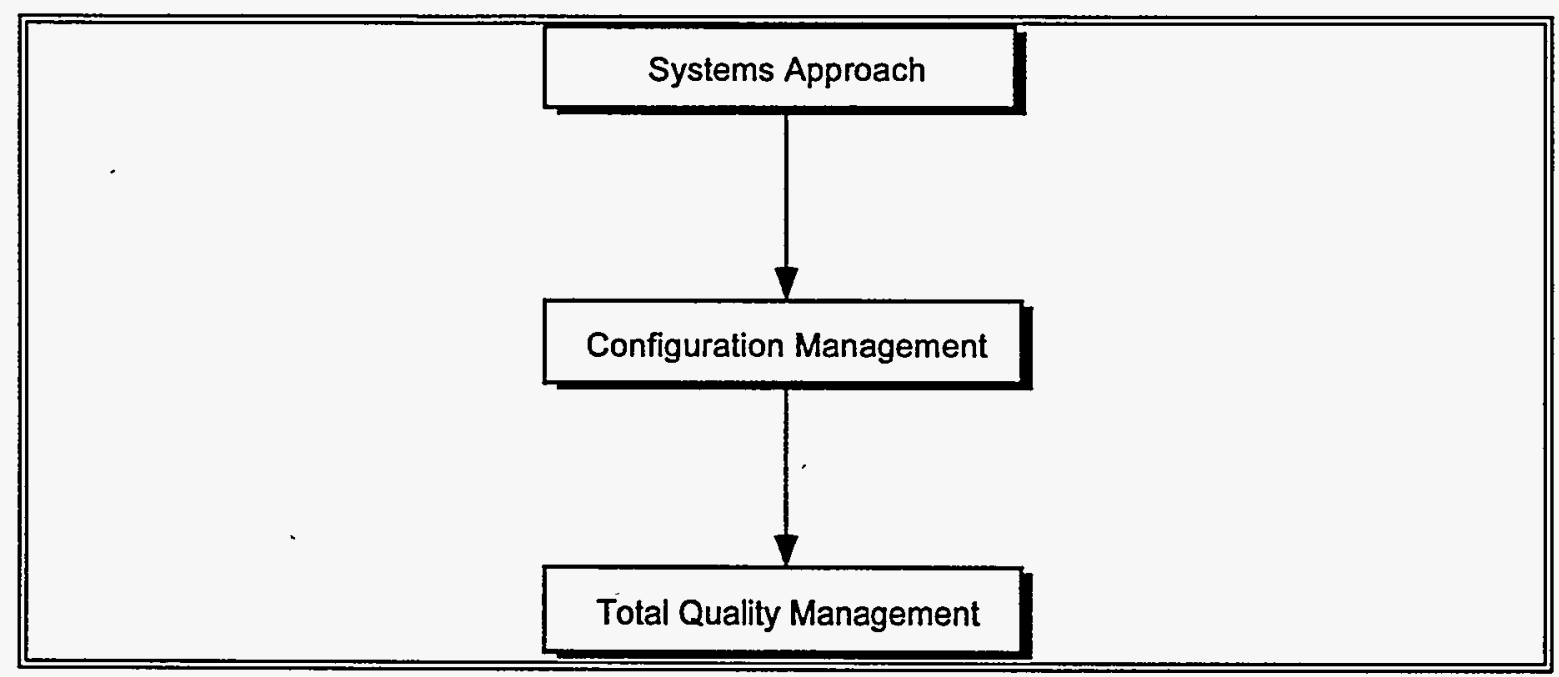


Crosby states that TQM stresses four absolutes: (1) a high pay-off gained from conformance to requirements, (2) quality as prevention, (3) zero defects, and (4) a high cost associated with non-conformance to requirements (Crosby, 1993). The conformance to requirements means that the SAR preparer should meet the requirements of the facility and of DOE, although DOE's requirements are paramount. Quality being prevention means that the SAR preparer should focus on preventing any internal or external failures while preparing the chapter. Internal or external failures are evidenced in the number of times the chapter or findings report must be revised or in lack of depth of analysis. Zero defects and prevention are closely related.

Other TQM experts have taken the approach that conformance to requirements is not enough (Cartin, 1993). In any process, service or manufacturing, there is process variability. The preparation of the SAR is no exception. The variability is often found in interpreting Orders and regulations and in professional judgments made during the analysis. Other sources of variability are found in the data collection process due usually to missing documentation, changing facility configurations, or lack of complete analysis. While the SAR may conform to the requirements specified by DOE, the document may still not be as useful as high quality as practically possible.

One of the basic tools for applying TQM to the SAR process is "configuration management", defined as a systems approach to the control of the design, development, implementation, and changes through documentation, records, and data. Focus is on the documentation, records, and data. Good configuration management is built around: (1) a rigorous definitional system, (2) a well documented change process, and (3) strict adherence to a "no-documentation = no-implementation" philosophy. A good configuration management process ensures that the SAR development process achieves its goals and remains a living document. Another basic tool in the application of TQM to the SAR process is "simultaneous engineering", representatives from all the affected organizations act as a team to produce the SAR document. With all members of the SAR process acting together as a team, the document will be produced more quickly, cheaply, and be of higher quality. 
Two processes can benefit from the application of TQM principles, including a systems approach. The first process is the analysis of the human, hardware, and administrative controls existing at the facility which is producing the SAR. The second process is the production of the SAR. The systems approach must be applied to each of these processes and acts as the foundation for the application of configuration management which in turn acts as a foundation for TQM. The systems approach during the analysis consists of accounting for the interactions between the human, hardware, and administrative controls while performing the HF analysis at the facility. The systems approach during production of the SAR document consists of merging the results of the HF analysis into the analysis and the findings supporting the other chapters of the SAR as well as merging the results of the analysis and the findings supporting the other chapters of the SAR into the HF analysis. In other words, all members of the SAR team must work together to produce the document while incorporating the interactions between the human, hardware, and administrative controls.

TQM recognizes that not only must the SAR process embrace good configuration management principles and processes, it must demonstrate to all parties ranging from facility operators to DOE regulators that such an approach is in everyone's best interest, especially in view of civil and criminal penalties accompanying codification of DOE Orders 5480.21, 5480.22, and 5480.23, as 10 CFR 820 (DOE 1991, 1992b, 1992a, CFR 1993). This Course Text and the accompanying Participant Workbook and Exercise Booklet are designed to define the role of the HF analyst in the preparation of the SAR document. Following the principles outlined in these documents will ensure that the HF analyst will produce a quality product and function well as an important member of the team developing the SAR document.

\subsection{Summing Up}

The purpose of this chapter has been to raise the reader's level of awareness of DOE's goals for the current SAR process, i.e., useful, credible, and up-to-date documentation for 
maintaining the subject facility's safety envelope. In order to achieve these goals, a systems approach to the process is needed as the linchpin for achieving good configuration management and TQM. Chapter 2 of this text introduces the reader to human factors including Human Performance Assessment as a scientific discipline and how it fits into DOE's concept of a systems approach to the SAR process. 


\title{
Chapter 2
}

\section{HF as a Behavior-Centered Scientific Discipline}

\author{
The overall objective of Chapter 2 is to provide knowledge of the \\ origins of human factors (HF) in the behavioral, social, and engineering sciences, \\ and as a scientific discipline.
}

\subsection{Human-Machine Interactions and Performance}

The collection of human performance data under controlled conditions began in the late 1870 s, primarily in Germany. Subjects. were asked to respond to a variety of contrived situations under varying control factors (e.g., time limit). Responses usually took two forms. First, the subject would describe the process by which he/she arrived at an intended action (verbal data); second, the subject would implement the intention (performance data). Later in the mid-1890s, primarily in England, the formulation of descriptive and inferential statistics began such that human performance data might be analyzed, inferences drawn, and human performance principles proposed.

Just prior to World War I, Henry Ford opened an assembly line at his Willow Run, Michigan, automobile assembly plant. For the first time, humans and machines were brought together to optimize time and minimize motion. Starting with the Willow Run assembly line and continuing up to the late 1930s, the prevailing attitude among the various engineering disciplines was that humans were extensions of machines. Time and motion studies performed on assembly line operations (e.g., Western Electric), subsequent to the Willow Run experience, helped to foster this belief. 
During, and immediately following World War II, however, with the introduction of new human-machine technologies, a recognition slowly emerged that machines are really extensions of humans. No matter their complexity and dexterity, machines are designed, built, maintained, and remain under the operational control of humans.

Along with this shift in perceptions regarding the relationship between humans and machines, the science of human factors, which includes Human Performance Assessment, emerged. Therefore it should come as no surprise that questions pertaining to human performance in the complex, high-reliability system making up Department of Energy (DOE) reactor and nonreactor nuclear facilities primarily involve behavioral and social issues, rather than engineering issues. This is true because of at least three uniquely human characteristics:

- We humans have free will, therefore, we are capable of behaving in ways that go beyond our specified roles in the system. We may be motivated to engage in heroic behavior to maintain operating safety and efficiency (recover equipment failures), or we may be motivated to behave in ways which might compromise operating safety and efficiency (sleeping on the job).

- We humans are social beings. We influence and are influenced through our interactions with one another (group culture, management oversight).

- We humans are capable of cognition (e.g., forming intentions, solving problems, making decisions). We form perceptions and make value judgments about the organizations and systems of which we are a part, and we often act on these perceptions and value judgments.

The reason for the Chernobyl accident, for example, had little to do with the operators' knowledge of system operating characteristics or engineered safety features (ESFs), rather it was the product of person-machine and person-person factors that permeated the organizational cultures in which plant personnel worked. Three managers who later received 
prison terms were able to convince some $20-24$ knowledgeable technicians to willingly violate safety rules.

\subsection{Chapter 2 References}

Reason, J. 1990, Human Error, Cambridge University Press, New York.

Trager, E. A. 1985, "A Case Study Report on Loss of Safety System Function Events," AEOD/C504, U.S. Nuclear Regulatory Commission, November.

Department of Energy, 1992, "Nuclear Safety Analysis Reports," Order 5480.23, April.

\subsection{HF as a Scientific Discipline}

\subsubsection{Human Error}

Human error is believed to be involved in $50 \%$ to $90 \%$ of all accidents in complex, high-reliability system settings. In the commercial nuclear arena, for example, the U.S. Nuclear Regulatory Commission estimates that human error is involved in about $65 \%$ of abnormal occurrences as a direct, indirect, or contributing cause (Trager 1985). Reason (1990), in a study of a dozen prominent accidents over the past 15 years (e.g., Three Mile Island, Chernobyl, Bhopal, London subway fire), concludes that at least $80 \%$ of these system failures were human driven, especially by inadequate management oversight. As suggested by these accidents, a wide range of person-machine and person-person factors enter the human error equation (e.g., misallocation of duties and responsibilities, technically inaccurate and/or incomplete training or operating procedures, poor management or organizational controls, or a poorly designed work environment). 
The following are some examples of human error involvement in contemporary accidents involving complex, high-reliability systems, including nuclear settings. compiled by J. Reason (1990) in Human Error.

\subsubsection{Three Mile Island (U.S. commercial nuclear plant) In March} 1979, a pressure transient was experienced during which the power operated relief valve (PORV) opened to relieve system pressure. Unknown to the operators, it failed to reseat and allowed the coolant pressure to drop to the saturation pressure of the coolant. Boiling within the core created a steam bubble, which allowed the core to overheat when a safety system was turned off. It was turned off because the operators were locked in on a reading that under normal circumstances indicated the coolant system was full. Experience of this crew was limited, and they failed to remember the basic principles of thermal hydraulics given during their earlier training. A more experienced operator arrived approximately 4 hours into the event, and he quickly diagnosed the problem. Unfortunately, it was too late. The investigation of the accident indicated that in-plant communication was not readily available between experienced operators and inexperienced operators or plant management. Additionally, it was discovered that the U. S. Nuclear Regulatory Commission (NRC) had several reports of PORVs sticking open, however, this information had not been communicated to other plants via Generic Letter, word of mouth, or other form of public announcement. A total of nine causal factors were identified, eight attributable to human error. Fortunately, there was no loss of life.

\subsubsection{Bhopal (U.S. designed chemical processing plant in India) In} December 1984, a gas leak occurred at a chemical plant in Bhopal, India. A total of 2500 persons were killed and over 100,000 were known to be injured. The United States (U.S.) based Union Carbide Company, operator of the Bhopal plant, had failed to make safety improvements in the plant, despite 
several leaks and explosions at its similar plants in the U.S. and around the world. The investigation identified 30 causal factors, 26 attributable to human error, primarily those of middle and upper-level management.

\subsubsection{Challenger (U.S. space shuttle) In January 1986, an O-ring} failed during the ascent of Challenger causing an explosion which destroyed the vehicle and killed all eight crew members on board. The O-ring problem had been identified in 1977. High-pressure air testing of O-rings began in February 1984, but data from those tests had not been fully disseminated, therefore the data were apparently not used in crucial decision-making throughout 1985 leading up to the accident. The investigation identified a total of 28 causal factors for the accident, all attributable to human error.

2.3.1.4 Chernobyl (Soviet nuclear plant) In April 1986, during a test of the coast-down capacity of a turbine generator, a melt-down occurred reportedly killing 1000 persons and injuring at least 10,000 fatally. Approval for the test had not been secured from a Safety Technical Group as was required. Rather it was approved by an electrical engineer, not a specialist in nuclear plant operations. Approximately two-dozen managers and operators of the plant circumvented a variety of safety rules in order to perform the test. The investigation identified 15 causal factors, 14 attributable to human error. Since the accident, at least three managers have received prison terms for dereliction of their duties.

\subsubsection{Zeebrugge (Belgian/Dutch/English auto ferry) In March 1987,} the Herald of Free Enterprise, an auto ferry of the Townsend-Thorsen Line, sunk just beyond the breakwater at the Belgium port of Zeebrugge. The bow door had been left open upon departure. A total of 150 passengers were killed, and over 100 are known to have been injured. The bow door was not closed because the assistant bowson mate, who should have closed the bow doors, was 
asleep after many hours of special duty (maintenance and clean-up). There had been no replacement scheduled. The Chief Officer, who usually checked the bow doors, did not make that check because he was required on the bridge 15 minutes before departure and, due to heavy traffic from Dover, England, arrived at Zeebrugge too late. Loading was allowed up to 5 minutes before departure. The investigation identified 16 causal factors, 12 attributable to human error.

\subsubsection{King's Cross (London, England underground) In November} 1987, a fire in the London King's Cross Underground Station of the Piccadilly line killed 31 persons and injured at least 70 others. Smoking material had been dropped in the operating mechanism of the wooden escalator leading to the street level. There were no smoke detectors in King's Cross Station or its approaches. The water fog equipment could not be used because it was rusted. There was no evacuation plan, and personnel discovering the fire did not have access to the public address system. The investigation found that $45 \%$ of all fires occurring in the underground over the past 20 years had involved wooden escalators. The investigation also identified five major causal sequences, four of which were attributable to human error.

\subsubsection{Summarizing TMI, Bhopal, Challenger, Chernobyl, Zeebrugge,} and King's Cross Accidents Summarizing the above accidents, despite no loss of life from the Three Mile Island accident, the following grim statistics were established:

- $\quad 3798$ dead resulting in a cost of $\$ 1.4$ Billion $(\$ 300,000$ per death)

- 200,000 injuries resulting in a cost of $\$ 200$ Million (1000 per injury)

- $\quad$ Out of 110 errors, 97 (88\%) were identified as human errors 
The following incidents reinforce the notion that human error can be expected to play a major role in the design, operation, and oversight of complex, high-reliability systems such as those found at many of the DOE facilities for which Safety Analysis Reports (SARs) are prepared.

\subsubsection{Los Angeles Riots (Rodney King Verdict) Early in 1992, riots} occurred in South Central Los Angeles which were immediately attributed to a lack of preparation on the part of the Los Angeles Police Department. A total of 13 persons were killed and over 100 known injured. Larger blame was attributed to society's failure to deal with the inner city problems that spawned the riots. Having launched the Great Society program in 1964, and having spent in excess of 3 trillion dollars in the succeeding 28 years, society was at a loss as to the causes of the riots and measures that might to taken to ensure that they would not occur again. The investigation identified some 25 immediate and societal causal factors for the riots, all of which were attributable to human error, especially poor configuration management of the Great Society program.

\subsubsection{Atlas Missile Program (U.S. Air Force) During the late 1950s} and early 1960s, Atlas missiles were deployed at Vandenberg AFB, California, and other sites throughout the U.S. It was soon discovered that a single set of technical manuals was not adequate to service and operate all 250-260 of the missiles that had been and were being produced. Due to a lack of configuration management of missile production, missiles with differing hardware and operating configurations were being delivered to user sites. Therefore, technical manuals, or portions thereof, unique to each missile had to be prepared onsite. The eventual cost of preparing these unique manuals rivaled the cost of producing the missiles themselves. The investigation identified several causal factors, all of which were attributable to human error, primarily poor configuration management. 


\subsubsection{TWA Flight 514 (U.S. commercial airliner) In December of}

1974, on its approach to Dulles International Airport outside Washington, D.C., the TWA aircraft hit a mountain-side killing 110 passengers and crew. The investigation identified ambiguous air/ground communicating procedures. It also found that three other aircraft had experienced near misses during the previous few months. Pilots of those aircraft had written letters to the Federal Aviation Administration (FAA) that were found in an FAA In-Box but never processed. The investigation identified several errors leading up to the accident attributable to human error, especially involving poor communications and procedures, inadequate dissemination of important safety information, and a lack of management oversight.

2.3.1.11 Procedure Violations Finally, of immediate concern to DOE (as well as other regulatory agencies such as the $\mathrm{NRC)}$ ) are unavoidable procedures violations. These are instances where existing procedures do not address the situations. Complex, high-reliability systems are procedures driven. Four of the NRC's major incident investigations (IITs), and over 20 of its augmented site investigations (AITs) since Three Mile Island, reported unavoidable procedures violations. An operator or supervisor had information the organization did not because of poor configuration management of the procedure development and change process. That is, there either was no easily accessible communications channel for making this information known to the procedures writers, or necessary operations in the plant ran ahead of the documentation change process. Operators and supervisors were confronted with either taking a corrective action (using their new information) and violating a regulation, or following existing procedures and increasing the likelihood of an accident. 


\subsubsection{HF as a Scientific Discipline for Reducing Human Error}

As a scientific discipline, HF dates back to World War II, during which complex sociotechnologies in aviation, radar, and weapons control were introduced and advanced. The behavioral and social sciences body of knowledge from which HF emerged dates well back into the last century.

As a scientific and engineering support discipline, $\mathrm{HF}$ is directed toward applying behavioral and social sciences principles to system settings in order to control, channel, monitor, and optimize human and ultimately system performance. There are three overlapping sub-disciplines within HF.

\subsubsection{Human Factors Engineering (HFE) HFE or simply human} engineering, is also sometimes referred to as ergonomics. HFE is directed primarily toward person-machine issues such as equipment design (e.g., displays, controls, and their juxtaposition), workspace layout and accessibility, and habitability (e.g., temperature, light, noise, and radiation).

For example, HFE provides the technical basis for creating a physical work environment that is user-friendly and therefore enhances operator safety performance. HFE is the subject of SAR Topic 14, Human Factors Engineering.

2.3.2.2 Human System Design (HSD) HSD is focused primarily toward person-person issues directed at allocation of duties and responsibilities, staffing, qualifications, personnel selection, training, operating procedures, and technical and administrative management and organizational controls.

As an example, HSD provides the technical basis for assigning operators to specific safety tasks. The HSD technical basis is also used to 
provide training (to accomplish the safety task), written procedures (to increase the level of assurance that the safety task will be completed correctly), and direct oversight (to verify that the safety task is completed successfully).

Primarily, HSD is a subject of SAR Topic 12 (Management Organization and Institutional Controls), Topic $\underline{13}$ (Procedures and Training), and Topic 15 (Initial Testing, In-service Surveillance and Maintenance). HSD is also considered in SAR Topic 17 (Operational Safety), Topic 18 (Quality Assurance), and Topic 19 (Emergency Preparedness).

\subsubsection{Human Reliability Analysis (HRA) HRA is directed toward} either person-machine and person-person issues pertaining to qualitative or quantitative human performance measurement, including probabilistic analysis. For example, in the case of probabilistic analysis, HRA results are expressed as human error or human success likelihoods.

Primarily, HRA is a subject of SAR Topic 11 (Accident Analysis). HRA is also considered in SAR Topic $\underline{5}$ (Hazard Classification) and Topic $\underline{16}$ (Derivation of Technical Safety Requirements).

\subsection{HF in the SAR Process}

DOE Order 5480.23, Attachment 1, Section 3.b(1)(b) defines human factors safety to include: "allocation of control functions to humans and machines, staffing and qualifications of personnel, personnel training, written procedures to guide operations and maintenance, and design of human-machine interfaces" (DOE 1992).

DOE Standard 3009-94, Chapter 13, Purpose, (p. 109), states that .... "Human factors consists of 
- Human factors engineering that focuses on designing facilities, systems, equipment, and tools so they are sensitive to the capabilities, limitations, and needs of humans, and

- Human Performance Assessment that quantifies the contribution of human error. to risk, (DOE 1994).

\subsection{Summing Up}

The object of this chapter has been to review the origins of the behavioral sciences of which HF is a part, the pervasiveness of human error as a causal factor in accident events, HF as a scientific discipline, and DOE's conception of human factors safety for consideration in the SAR and TSR process. Chapter 3 now turns to a more detailed presentation of HF as a more general interest of DOE. 


\section{Chapter 3}

\section{HF at the U.S. Department of Energy (DOE)}

The overall objective of Chapter 3 is to sensitize the reader to human factors (HF) initiatives at the U.S. Department of Energy (DOE), as they pertain to general design requirements, operating requirements, and regulatory requirements such as the HF requirements posed by the Safety Analysis Report (SAR) order and DOE Standard 3009-94.

\subsection{Introduction}

HF requirements imposed by the SAR Order restates earlier requirements imposed by the DOE on its reactor and nonreactor nuclear facilities. This chapter traces explicit HF requirements imposed by DOE up to publication of the SAR Order 5480.23, in April 1992, and subsequent to the publication of the SAR Order such as DOE Order 5480.30 concerning reactor facilities, and DOE Standard 3009-94 for preparing nonreactor SAR documentation (DOE 1992a, 1993, 1994). Section 3.2 lists (with full citations) documents that are the subject of this chapter. Section 3.3 briefly discusses HF at DOE prior to publication of DOE Order 6430.1A, in April 1989 (DOE 1989). Section 3.4 presents DOE's current HF requirements leading up to and following publication of the SAR Order in 1992. Chapter 4 of this text presents a detailed discussion of specific HF requirements contained in the SAR Order. Section 3.5 sums up current DOE HF requirements, and presents important points regarding these requirements.

\subsection{Chapter 3 References}

DOE, 1987, "Safety Analysis and Review System," Order 5481.1B, May. 
DOE, 1989, "General Design Criteria (Nonreactor Facilities)," Order 6430.1A, April.

DOE, 1991a, "Accreditation of Performance-Based Training for Category A Reactors and Nuclear Facilities," Order 5480.18A, July.

DOE, 1991b, "Personnel Selection, Qualification, Training, and Staffing Requirements at DOE Reactor and Nonreactor Nuclear Facilities", Order 5480.20, June.

DOE, 1992a, "Nuclear Safety Analysis Reports," Order 5480.23, April.

DOE, 1992b, "Conduct of Operations Requirements for DOE Facilities," Order 5480.19 , May.

DOE, 1992c, "Writer's Guide for Preparing Technical Procedures," DOE Standard 1029-92, December.

DOE, 1993, "Nuclear Reactor Safety Design Criteria," Order 5480.30, January.

DOE, 1994a, "Maintenance Management Program," Order 4330.4B, February.

DOE, 1994b, "Preparation Guide for U. S. Department of Energy Nonreactor Nuclear Facility Safety Analysis Reports," Standard 3009-94, July.

U. S. Nuclear Regulatory Commission, 1981, "Standard Review Plan: Review of Safety Analysis Reports for Nuclear Power Plants," NUREG-0800, June.

\subsection{Pre-1989 HF Requirements}

DOE's definition of human factors is presented in Chapter 2 of this text. DOE Order 5480.23, Attachment 1, Section 3.b(1)(b) defines human factors safety to include: "allocation of control functions to humans and machines, staffing and qualifications of personnel, personnel training, written procedures to guide operations and maintenance, and design of human-machine interfaces" (DOE 1992a). Prior to April 1989 (when DOE Order 6430.1A was published), DOE facilities were required to staff and train their personnel, and to provide 
them procedures and oversight sufficient to maintain a safe operation (DOE 1989). DOE Order 5481.1B and Nuclear Regulatory Commission NUREG-0800 provided general requirements and guidance to a facility operator for establishing and maintaining programs and activities falling under DOE's definition of human factors influence on safety (DOE 1987, NRC 1981). Among these were requirements for management oversight, staffing, operating procedures, and the training program and activities. Prior to 1989 , no DOE published order or guidelines made explicit reference to human factors, NUREG-0800 included as its Topic 18: Human Factors Engineering (NRC 1981). Despite the fact that human factors is not explicitly cited by DOE publications prior to 1989 , reviews of individual facility documentation beginning in the early 1980s indicates that several facilities were formally considering human factors in their upgrade programs and activities. Searches, reviews, and referencing of such documentation by HF practitioners involved in SAR preparation is encouraged.

\subsection{HF Requirements 1989 to 1992 and Beyond}

On April 6, 1989, DOE published Order 6430.1A concerning general design requirements for nonreactor facilities (DOE 1989). Section 1300-12 is titled Human Factors Engineering (HFE). Section 1300-12.1 states that the DOE policy regarding HFE is...

"to ensure that appropriate human factors technology is considered in the design, operation, and maintenance of Departmental nonreactor nuclear facilities. The criteria and requirements provided in this section are applicable to the design of the work environment and human-machine systems at DOE facilities. These criteria shall apply to new construction and to retrofitting of existing facilities. These criteria shall be considered for upgrading existing facilities where cost-benefit or risk-tradeoff analyses indicate justification for such expenditures."

Section 1300-12 goes on to specify which human-machine interactions shall be covered including: communications, equipment design and positioning, and environmental factors such as heat, light, and noise, all of which could impact performance. These 
requirements raise two important questions for the HF practitioner involved in preparing an SAR to Order 5480.23 .

- Is existing documentation available at the facility on HFE design studies for new construction or other upgrades since 1989 ?

- Do existing risk-tradeoff studies exist such as probabilistic risk assessments or hazards and accident analyses, which demonstrate that HFE involving pre-1989 safety features of the facility is impacting human performance?

If the answer to the first question is yes, any current HFE documentation recovered from the facility should be used to support the HF SAR effort. If the answer to the second question is yes, HFE involving pre-1989 safety features of the facility should be a subject of the human safety analysis described in Chapters 5 and 6 of this Course Text; that is the SAR Order requiring applicability of HFE criteria to the design of the work environment for all structures, systems, and components determined to be safety related, regardless of how long they have been a part of the facility operating configuration. Chapter 4 of this text describes DOE Order 5480.23 HFE requirements for the SAR (DOE 1992a). From 1990 through 1992, a series of human factors requirements were published under the general heading of conduct of operations. In 1990 and in its Change dated 1992, DOE Order 5480.19 (Conduct of Operations) established general requirements in 18 areas with varying degrees of relation to human factors (DOE 1992b). In some human factors areas, 5480.19 itself is the primary source of HF requirements. For example, Chapters I, II, III, XII, and XV of 5480.19 address organization, administration, and control which are included in Topic 12 of the SAR. In other instances, conduct of operations chapters related to human factors have been supplemented by other orders further defining requirements. For example:

- Chapters IV, IX, XVII, and XVII of 5480.19 address HFE (Topic 14 of the SAR). HFE has been supplemented by Orders $6430.1 \mathrm{~A}$ for nonreactor facilities and 5480.30 for reactor facilities (DOE 1989, 1993). 
- Chapter V of 5480.19 addresses training (Topic 13 of the SAR). Training, along with staffing and personnel qualifications, has been supplemented by Orders 5480.18A and 5480.20 for operations and 4330.4B for maintenance (DOE 1991a, 1991b, 1994a).

- $\quad$ Chapter XVI of 5480.19 addresses operating procedures (Topic 13 of the SAR). Procedures are supplemented for maintenance activities by Order 4330.4B (1994a). Both operations and maintenance technical procedures are supplemented by DOE Standard 1029-92 (DOE 1992c).

DOE Order 5480.30 concerning HFE for reactor facilities was published in January 1993 (DOE 1993). It is intended as a corollary to 6430.1A for reactor facilities (DOE 1989). Section 8.c(9) of 5480.30 regarding HFE states...

"HFE shall be considered per 5480.23 in the design of nuclear reactors or nuclear reactor systems that have a human interface for operating or maintenance. The formality and extent of the HFE program shall be graded on the basis of the extent of the human interaction, the overall design effort, and the risk associated with human performance failures."

Later in Attachment 2 of 5480.30, DOE defines human factors as...

"those biomedical, psychosocial, workplace environment, and engineering considerations pertaining to people in a human-machine system. Some of these considerations are allocation of functions, task analysis, Human Performance Assessment, training requirements, job performance aiding, personnel qualification and selection, staffing requirements, procedures, organizational effectiveness, and workplace environmental conditions."

DOE Standard 3009-94 was published in July 1994. It alluded to HF as follows...

Chapter 3, Worker Safety, Section 3.3.2.3.3, Figure 3-2 (p. 47) cites "job task analysis" and an input to Hazard identification. 
Chapter 3, Accident Analysis, Section 3.4, (p. 55) states... "All assumptions made in the accident analysis (i.e., defining points in scenario progression) are to be validated as part of the accident analysis activity. For example, if an operator is supposed to push Button $Z$ to stop an accident's progression, the accident analysis needs to make it clear that the operator can actually do so."

Chapter 13, Purpose (p. 109), states that.... "Human factors consists of

- Human factors engineering that focuses on designing facilities, systems, equipment, and tools so they are sensitive to the capabilities, limitations, and needs of humans, and

- Human Performance Assessment that quantifies the contribution of human error to risk.

Later in the next paragraph, the Standard states... "This chapter demonstrates that human factors are considered in facility operations where humans are relied upon for preventive actions (e.g., surveillance and maintenance activities during normal operations), and for operator mitigative actions during abnormal and emergency operations. In this respect, the human-machine interface is an integral part of facility safety, and, thus, requires special treatment in the SAR. The emphasis is on humanmachine interfaces required for ensuring the safety function of SSCs that are important to safety and on the provisions made for optimizing the design of this human-machine interface to enhance reliable human performance.

Section 13.5, Optimization of Human-Machine Interfaces, (p. 112) regarding design element includes:

". Staffing considerations (e.g, minimum staffing levels, allocations of control functions, overtime restrictions, facility status turnover between shifts, procedures, training, etc.)."

\subsection{Summing Up}

This chapter has attempted to provide the reader with DOE's perception of and policy toward HF. It is a prelude to focusing on HF in Chapter 4 of this text, as a subject of the SAR and TSR process. Before proceeding on to Chapter 4, however, several points need to be made regarding human factors at DOE. These points are based on a review of the Orders, lessons learned preparing SARs to 5480.23, and feedback from DOE on SARs submitted for approval. 
1. DOE defines HF broadly to cover all aspects of the human in facility design and operation (e.g., HFE, procedures, training, staffing, management oversight), and in Human Performance Assessment.

2. DOE does not expect operating configurations in place prior to April 1989 (nonreactor facilities) and January 1993 (reactor facilities) to meet DOE and DOE referenced HF standards, except where human factors impact nuclear safety, as determined by risk tradeoff studies employing HPA. In this latter instance, DOE expects compliance with its own or referenced HF standards, regardless of how long the affected operating configuration has been in place.

3. DOE expects HF conducted at its nonreactor and reactor facilities to be programmatic such that it is cost-effective. A systems approach, configuration management, and Total Quality Management (TQM) discussed in Chapter 1 of this text, apply to $\mathrm{HF}$ as to any other activity in which the facility engages.

4. DOE expects that safety-related HF deviations from full compliance with its own standards or those it references to be resolved as part of the SAR process such that the resulting operating configuration is fully capable of supporting the facility's SAR commitments to DOE.

5. DOE expects that HF information developed by the facility prior to or independent of the SAR will be used to the extent possible in the SAR process. 


\section{Chapter 4}

\section{HF Requirements and Guidance Established by DOE Order 5480.23, other DOE Orders and Standards, and DOE Provided and Referenced Compliance Standards}

The overall objective of Chapter 4 is to sensitize the reader to the U.S. Department of Energy (DOE) explicit and implicit human factors (HF) requirements, DOE provided and referenced guidance, and compliances standard for responding to these requirements, within the context of the $S A R$.

\subsection{Introduction}

This chapter focuses on specific HF requirements of DOE Order 5480.23 and DOE Standard 3009-94, and the origins of these requirements (DOE 1992, 1994). Documents listed in this chapter carry their full citation at the locations where they are cited or listed in Section 4.2. Section 4.3 briefly restates earlier HF requirements leading up to the SAR Order. Section 4.4 prioritizes the 21 topics of the SAR Order according to their tertiary, secondary, and primary relatedness to HF. Section 4.5 presents a detailed discussion of the primary HF topics. Section 4.6 sums up the chapter as a bridge to Chapter 5 which focuses on a human safety analysis approach for responding to the primary HF topics of the SAR Order.

\subsection{Chapter 4 References}

U. S. Department of Energy (DOE), 1989, "General Design Criteria," Section 1300-12, "Human Factors Engineering," Order 6430.1A, April. 
DOE, 1992, "Nuclear Safety Analysis Reports," Order 5480.23, April.

DOE, 1993, "Nuclear Reactor Safety Design Criteria," Section 8.c.(9) and Attachment 3 Section 3.a.(9), Order 5480.30, January.

DOE, 1994, "Preparation Guide for U.S. Department of Energy Nonreactor Nuclear Facility Safety Analysis Reports," Standard 3009-94, July.

All other documents listed in this chapter carry their full citations at the location where they are cited.

\subsection{Origins of HF Requirements}

As described in Chapter 3 of this text, human factors requirements were formalized for DOE nonreactor facility design by DOE Order 6430.1A, General Design Requirements for Nonreactor Facilities, and for reactor facilities by DOE Order 5480.30, General Design Requirements for Reactor Facilities (DOE 1989, 1993). Human System Design (HSD) requirements for all DOE nuclear facilities were formalized by DOE Orders 5480.19 (Conduct of Operations including procedures) and $\mathbf{5 4 8 0 . 2 0}$ (staffing, qualifications, and training). Human Performance Assessment (HPA) requirements, as well as those for human factors engineering (HFE), were established for all DOE nuclear facilities by the SAR DOE Order 5480.23 (DOE 1992).

In order to respond appropriately to the various HF requirements of the aforementioned DOE Orders in the SAR, the HF practitioner must first answer the following questions by means of facility documentation, managing contractor decision and DOE decision:

- What HF requirements of $6430.1 \mathrm{~A}$ or 5480.30 apply to the facility, given its era of construction, authorization to operate, and other contractual agreements existing between DOE and the managing contractor (DOE 1989, 1993)? 
- What level of HF analysis is required to demonstrate that the facility is operating, or is capable of operating, within its nuclear safety envelope?

NOTE: It is critical in determining the scope and content of the SAR that the HF practitioners be clear about the degree to which the subject facility is required to conform to the HF segments of DOE Order 6430.1A in the case of nonreactors, and DOE Order 5480.30 in the case of reactors (DOE 1989, 1993).

\subsection{Prioritized HF Requirements in the SAR}

$\mathrm{HF}$ is required, in a general sense, to support all of the topics of an SAR prepared in compliance with DOE Order 5480.23, since all of its safety analysis information has a human component. Nevertheless, some SAR topics are more directly impacted by HF, and in turn, impact HF. The 21 SAR topics have been divided into three categories.

First are those SAR topics that use HF information as tertiary sources, to demonstrate the adequacy of topic subject matter. In Table 4-1, these include SAR Topics:

Table 4-1 HF Tertiary Topics

\begin{tabular}{||cl||}
\hline \hline Number & \multicolumn{1}{c|}{ Title } \\
1 & Introduction and Summary \\
2 & Codes and Standards \\
3 & Site Characteristics \\
7 & Waste Management \\
9 & Radiation Protection \\
10 & Hazardous Materials Protection \\
20 & Decontamination and Decommissioning \\
21 & Applicable Facility Design Codes and Standards \\
\hline
\end{tabular}


Second are those SAR topics which use HF information, combined with information on facility structures, systems, and components, as secondary sources, to demonstrate the adequacy of chapter subject matter. In Table 4-2, these include SAR Topics:

Table 4-2 HF Secondary Topics

\begin{tabular}{||cl||}
\hline Number & \multicolumn{1}{c|}{ Title } \\
4 & Facility Description \\
6 & Health and Safety Criteria \\
8 & Inadvertent Criticality \\
16 & Derivation of Technical Safety Requirements \\
17 & Operating Safety \\
18 & Quality Assurance \\
19 & Emergency Preparedness \\
\hline
\end{tabular}

Third are those SAR topics which use HF information as the primary source for demonstrating the adequacy of human performance subject matter. These latter SAR Topics are the primary focus of this self-study handout. In Table 4-3, these include SAR Topics:

Table 4-3 HF Primary Topics

\begin{tabular}{||cl||}
\hline Number & \multicolumn{1}{c|}{ Title } \\
5 & Hazards Analysis and Facility Classification \\
11 & Accident Analysis (human reliability segments) \\
12 & Management, Organization, and Institutional Controls \\
13 & Procedures and Training \\
14 & Human Factors Engineering \\
15 & Initial Testing, In-service Surveillance, and Maintenance \\
& \\
& \\
\hline
\end{tabular}




\subsection{Specific HF Requirements for SAR Topics $\underline{5}$ and $\underline{11}$ through $\underline{15}$}

DOE Order 5480.23 Attachment 1 topics establishing HF requirements, other DOE orders establishing HF requirements relevant to the SAR, and DOE developed and referenced standards for complying with HF requirements are listed below for preparing SAR Topics $\underline{5}$ and $\underline{11}$ through $\underline{15}$ (DOE 1992). A distinction is made between a requirement and a compliance standard.

- DOE Orders state requirements usually as a qualitative goal (e.g., internal and external communications shall support nuclear safety and efficiency).

- DOE developed and referenced standards provide criteria for judging compliance with DOE requirements. For example, these latter standards, rather than the Orders, specify control panel layout, label positioning and size, and physical access dimension criteria to meet DOE requirements.

\subsubsection{DOE Order 5480.23, Attachment 1 Topic $\underline{5}$ (Hazards Analysis and Classification of the Facility)}

Topic $\underline{5}$ requires that: "The energy sources and release processes (human actions?) shall be specified and assessed in terms of the hazards of the facility, and the bounding analysis of potential accidents associated with each type of hazard shall be documented." Other DOE Orders and standards that apply to the hazards analysis and hazards classification include:

DOE 1992, "Hazard Categorization and Accident Analysis Techniques for Compliance with DOE Order 5480.23, Nuclear Safety Analysis Reports," DOE Standard 1027-92, December. 
DOE 1994, "Preparation Guide for U.S. Department of Energy Nonreactor Nuclear Facility Safety Analysis Reports," Section 3, "Hazard and Accident Analysis," DOE Standard 3009-94, July.

NOTE: $\quad$ DOE referenced compliance standards listed throughout this chapter do not necessarily represent all those that might be used to prepare the SAR. They have been chosen because they are referenced in DOE documentation, andlor they directly relate to the requirements of the DOE SAR Order.

DOE Referenced Compliance Techniques include:

U.S. Nuclear Regulatory Commission, NUREG/CR-2254, "A Procedure for Conducting a Human Performance Assessment for Nuclear Power Plants," May 1983.

U.S. Nuclear Regulatory Commission, NUREG/CR-1278, "Handbook of Human Performance Assessment with Emphasis on Nuclear Power Plant Operations," August 1983.

U.S. Nuclear Regulatory Commission, NUREG/CR-4772, "Accident Sequence Evaluation Program Human Performance Assessment Procedure," February 1987.

\subsubsection{DOE Order 5480.23, Attachment 1 Topic 11 (Analysis of Normal, Abnormal, and Accident Conditions)}

Topic 11 requires that: "Safety analyses should include the application of methods such as deterministic safety analysis, risk assessment, reliability engineering, common cause failure analysis, Human Performance Assessment, and human factors safetv analysis techniques as appropriate in the identification, investigation, elimination, mitigation, or control of vulnerabilities of the facility to accidents and 
accidental releases." Other DOE Orders and standards that apply to the accident analysis include:

DOE 1992, "Hazard Categorization and Accident Analysis Techniques for Compliance with DOE Order 5480.23, Nuclear Safety Analysis Reports," DOE Standard 1027-92, December.

DOE 1994, "Preparation Guide for U.S. Department of Energy Nonreactor Nuclear Facility Safety Analysis Reports," Section 3, "Hazard and Accident Analysis," DOE Standard 3009-94, July.

DOE Referenced Compliance Techniques include:

U.S. Nuclear Regulatory Commission, NUREG/CR-2254, "A Procedure for Conducting a Human Performance Assessment for Nuclear Power Plants," May 1983.

U.S. Nuclear Regulatory Commission, NUREG/CR-1278, "Handbook of Human Performance Assessment with Emphasis on Nuclear Power Plant Operations," August 1983.

U.S. Nuclear Regulatory Commission, NUREG/CR-4772, "Accident Sequence Evaluation Program Human Performance Assessment Procedure," February 1987.

\subsubsection{DOE Order 5480.23, Attachment 1 Topic 12 (Management, Organization and Institutional Safety Provisions)}

Topic 12 requires that: The safety analysis demonstrates that the contractor organization responsible for design, construction, and operation of a DOE-owned facility is capable of maintaining the safety envelope. This includes its structure, staffing, operational aids such as written procedures and training, internal and external interfaces and controls, and operating configuration management. Other DOE Orders 
and Standards that apply to management, organization and institutional safety provisions include:

DOE 1994, "Preparation Guide for U.S. Department of Energy Nonreactor Nuclear Facility Safety Analysis Reports," Section 17, DOE Standard 3009-94, July.

DOE, 1990, "Conduct of Operations Requirements for DOE Facilities," (Chapter 1) Order 5480.19, July.

DOE, 1991, "Personnel Selection, Qualifications, Training, and Staffing Requirements at DOE Reactor and Nonreactor Nuclear Facilities," Order 5480.20, February.

DOE, 1993, "Occurrence Reporting and Processing of Operations Information," Order 5000.3B, January.

DOE Referenced Compliance Techniques include:

U.S. Nuclear Regulatory Commission, NUREG/CR-5538, "Influence of Organizational Factors on Performance Reliability," July 1992.

\subsubsection{DOE Order 5480.23, Attachment 1 Topic 13 (Procedures and Training)}

Topic 13 requires that the safety analysis demonstrates that programs and processes employed by the facility result in:

- written procedures that are technically accurate, complete, and comprehensible, and 
- training that is technically accurate, complete, and comprehensible, and qualifies facility personnel to fully respond to their responsibilities during normal, abnormal and emergency operations.

Other DOE Orders and Standards that apply to procedures and training include:

DOE 1994, "Preparation Guide for U.S. Department of Energy Nonreactor Nuclear Facility Safety Analysis Reports," Section 12, "Procedures and Training," DOE Standard 3009-94, July.

DOE, 1990, "Conduct of Operations Requirements for DOE Facilities," (Chapter 16) Order 5480.19, July.

DOE, 1991, "Personnel Selection, Qualifications, Training, and Staffing Requirements at DOE Reactor and Nonreactor Nuclear Facilities," Order 5480.20, February.

DOE Referenced Compliance Techniques include:

DOE, 1992, "Writer's Guide for Technical Procedures," Standard 1029-92, December.

\subsubsection{DOE Order 5480.23, Attachment 1 Topics $14 a$ through 14d (Human Factors Engineering), and DOE Standard 3009-94, Chapter 13, Human Factors}

\subsubsection{DOE Order 5480.23 Topic 14 requires that: "A systematic} inquiry be conducted into the importance to safety of reliable, correct, and effective human-machine interactions, including the effectiveness of surveillance, maintenance, and normal, abnormal and emergency operations. In those contexts in which reliable, effective human performance by the operating crew is important to safety, and in proportion to the importance-to-safety, 
safety analyses should document a systematic inquiry into the optimization of the design of the human-machine interface to enhance reliable human performance." Human-machine design considerations should include:

14a communication and operational aids

14b layout of controls and instrumentation and labelling

14c work environment factors such as heat, light, noise, physical access, protective clothing, and breathing apparatus.

14d demonstrated ability of personnel to accomplish their responsibilities under normal, abnormal, and accident conditions.

\subsubsection{DOE Standard 3009-94, Chapter 13 This chapter focuses} exclusively on human factors engineering. Use of the term human factors in this Standard does not connote an expectation or requirement for Human Performance Assessment.

This chapter demonstrates that human factors are considered in facility operations where humans are relied upon for preventive actions (e.g., surveillance and maintenance activities during normal operations), and for operator mitigative actions during abnormal and emergency operations. In this respect, the human-machine interface is an integral part of facility safety and, thus, requires special treatment in the SAR. The emphasis is on humanmachine interfaces required for ensuring the safety function of safety SSCs that are important to safety and on the provisions made for optimizing the design of those human-machine interfaces to enhance reliable human performance. 
A complete discussion of human factors without application of the graded approach includes:

- Description of the human-factors process for systematically inquiring into the importance of human factors in facility safety.

- Description of human-machine interfaces with safety-significant SSCs and safety-class SSCs that are important to safety.

- Description of the systematic inquiry into the optimization human-machine interfaces with safety-significant SSCs and safety-class SSCs to enhance human performance.

Other DOE Orders and Standards that apply to human factors engineering (HFE) include:

DOE 1994, "Preparation Guide for U.S. Department of Energy Nonreactor Nuclear Facility Safety Analysis Reports," Section 13, "Human Factors," DOE Standard 3009-94, July.

DOE, 1993, "Occurrence Reporting and Processing of Operations Information," Order 5000.3B, January.

DOE Referenced HFE Compliance Techniques include:

ANSI/HFS (American National Standard Institute/Human Factors Society), 1981, "Practices for Respiratory Protection," Standard Z88.2-1980, March.

ANSI/HFS (American National Standard Institute/Human Factors Society), 1988, "Human Factors Engineering of Visual Display Terminal Work Stations," Standard 100-88, February.

CFR (Code of Federal Regulations), 1992, "Personal Protective Equipment," 29 CFR 1910.132 - 134, Office of Federal Registry, February. 
DOD, 1985, "Human Engineering Guidelines for Management Information Systems," DOD-HDBK-761A, June.

DOD, 1987, "Human Engineering Procedures Guide," DOD-HDBK-763, February.

DOD, 1989, "Human Engineering Design Criteria for Military Systems, Equipment, and Facilities," MIL-STD-1472D, March.

DOE, 1993, "Human Factors Engineering Design Criteria: Volume 1 General Criteria," Draft Standard 1062-93, August.

IEEE (Institute of Electrical and Electronic Engineers), 1988, "Guide for the Application of Human Factors Engineering to Systems, Equipment, and Facilities of Nuclear Generating Stations," Standard 1023, October.

USNRC (U.S. Nuclear Regulatory Commission), 1981, "Guidelines for Control Room Design Reviews," NUREG-0700, September.

USNRC, 1985, "Human Engineering Guidelines for the Evaluation and Assessment of Video Display Units," NUREG/CR-4227, July.

UCRL (University of California Research Laboratory), 1985, "Human Factors Design Guidelines for Maintainability of Energy Nuclear Facilities," UCRL 15673, June.

\subsubsection{DOE Order 5480.23, Attachment 1 Topic 15 (Initial Testing, Internal Surveillance, and Maintenance)}

Topic 15 requires: that the safety analysis demonstrates that the contractor initial testing, surveillance, and maintenance programs are fully supportive of maintaining the safety envelope. This includes its staffing, operating aids such as written procedures and training, internal and external interfaces and controls, and 
operating configuration management. Other DOE Orders and Standards that apply to initial testing, in-service surveillance, and maintenance include:

DOE 1994, "Preparation Guide for U.S. Department of Energy Nonreactor Nuclear Facility Safety Analysis Reports," Section 10, "Initial Testing, In-service Surveillance and Maintenance," DOE Standard 3009-94, July.

DOE, 1994, "Maintenance Management Program," Order 4330.4B, February.

Topic $\underline{15}$ is governed by the standards applicable for Topics $\underline{13}$ and 14 especially:

DOD, 1989, "Human Engineering Design Criteria for Military Systems, Equipment, and Facilities," MIL-STD-1472D, March.

DOE, 1992, "Writer's Guide for Technical Procedures," Standard 1029-92, December.

UCRL (University of California Research Laboratory), 1985, Human Factors Design Guidelines for Maintainability of Energy Nuclear Facilities, UCRL 15673, June.

\subsection{Summing Up}

Chapter 4 briefly restated the origins of HF requirements at DOE, to the SAR Order. Tertiary, secondary and primary HF topics of the SAR Order were nominally grouped. Primary topics were described in detail. Other DOE orders and Federal government requirements that apply to each primary topic were listed. Finally, DOE referenced techniques that might be used to respond to each primary topic were also listed. Chapter 5 of this text presents concepts and techniques for conducting a human safety analysis the results of which are used to respond to the primary HF topics of the SAR. 


\section{Chapter 5}

\section{HF Concepts, Techniques, and Data Sources for a Human Safety Analysis in Response to 5480.23 SAR and DOE Standard 3009-94 Requirements and Guidance}

The overall objective of this chapter is to provide human factors (HF) concepts, techniques, and processes for responding to Safety Analysis Report (SAR) requirements. The human safety analysis process includes three sometimes iterative steps (human system analysis, human causal factor analysis, and Human Performance Assessment).

\subsection{Introduction}

The human safety analysis process described in this chapter is applicable, in varying degrees, to the analysis of the 200 plus DOE facilities that make up the DOE community. Therefore, in applying the process to a particular facility, the analyst should apply the grading factors described in Chapter 6 of this text. The analyst should also take advantage of human safety analysis information as might already exist for the facility. In summary, the human safety analysis process presented in this chapter, should be viewed as a road map and checklist. In instances where human factors information/data already exist, and are determined adequate for fulfilling one or more information needs of the human safety analysis, they should be used in lieu of doing additional information gathering. In instances where necessary information/data do not exist, the human safety analysis process should be used as a guide for acquiring that information/data. With the above in mind, the human safety analysis involves three sequential (sometimes iterative) steps: 
1. Human system analysis which provides the context for judging human performance from radiological, chemical, and industrial safety perspectives.

2. Human causal factor ( $\mathrm{HCF}$ ) analysis which provides causal factor information for indexing human performance, and

3. Human Performance Assessment which provides indexing of human performance using qualitative and/or quantitative measures.

The remaining sections of this chapter describe each step of the human safety analysis. Following Section 5.3 (describing the human system analysis) is a series of illustrations to enlarge on the text material. Section 5.4 describes the HCF analysis involving both HCF selection and HCF evaluation. Section 5.4 emphasizes differing impacts of HCFs when considered in the analysis individually and in combination, and difficulties attending the selection of HCFs for a particular task action sequence. Section 5.5 describes the Human Performance Assessment using the results of the human system and HCF analyses as inputs. It also describes quantitative and qualitative approaches to the assessment.

\subsection{Chapter 5 References}

U.S. Department of Energy (DOE), 1987, "Project Management System," Order 4700.1, March.

DOE, 1992, "Nuclear Safety Analysis Reports," Order 5480.23, April.

DOE, 1993, "Occurrence Reporting and Processing System (ORPS)," Order 5000.3B, January.

DOE 1994, "Preparation Guide for U.S. Department of Energy Nonreactor Nuclear Facility Safety Analysis Reports, " 3009-94, July. 


\subsection{Human System Analysis}

The human system analysis contributes human performance inputs to logic or facility models used as a general framework for estimating overall human error probabilities. It also serves as the technical basis for judging the adequacy of the HCFs (e.g., staffing, oversight, training, operating procedures, human factors engineering) selected for inclusion in the analysis. The human system analysis is made up of each of the analyses described in 5.3.1 through 5.3.6 below.

NOTE: Wherever possible, existing documentation of facility function/task analysis should be used to replace or supplement one or more of the analyses below. Potential sources are facility acquisition documents prepared to DOE Order 4700.1, or a recent SAR (DOE 1987). The HF analyst should verify, however, that existing documentation represents the current operating configuration of the facility.

\subsubsection{Function Analysis (See Figure 5-1)}

A function analysis (primarily system-centered) focuses on tasks performed by personnel within the context of general operations of the facility (e.g., producing an alloy using reactor energy). It is a step-by-step representation of a function or activity using flow charts and narrative descriptions. It is analogous to a systems analysis used to understand the functioning of facility equipment. The focus of the analysis is the facility operation. Equipment, human tasks (e.g., start the pump, open/close valve), and conditions under which the human tasks are performed are described in the sequence in which they occur. There is no attempt to break down human actions below the task level.

The function analysis is part of the larger systems analysis which supports the SAR. Therefore, it should involve all members of the safety analysis team, including 
the HF practitioners, working together. The primary outcome of this system-centered analysis is the operating and accident sequences that will be the focus of the remainder of the SAR effort. Therefore, the accuracy with which the system hardware, personnel, administrative controls, and their interactions are defined in the function analysis will, in large measure, determine the overall credibility of the safety analysis, and subsequent SAR commitments to DOE.

\subsubsection{Task Analysis (See Figure 5-1)}

A task analysis (primarily human-centered) is a step-by-step representation of a human task action sequence using flow charts and narrative descriptions. The focus of the analysis is human tasks derived from the function analysis. Each task is broken down into sub-tasks, and in some cases into hierarchical elements of those sub-tasks. The human tasks identified in the function analysis are used as the starting point for the task analysis. The task analysis is performed by the HF analyst and involves frequent coordination with other members of the safety analysis team. The task analysis provides the HF analyst with descriptions of human actions, many of which will be analyzed later as part of the hazards and accident analysis. The task analysis - enhanced by later timeline, link, human vulnerability, and human failure modes analysis-represents our best description of how human actions and action sequences are actually performed by facility personnel. The task analysis therefore becomes the basis for developing and evaluating a wide range of human factors controls, such as allocation of rèsponsibilities, qualification requirements, training, procedures, and HFE. Refer to Figure 5-1 at the end of this section for a pictorial example of the output of a function and task analysis.

NOTE: $\quad$ Timeline and link analyses, described below and portrayed in Figure 5-2 and Figure 5-3, are prepared in order to organize the function and task analysis to account for critical timing and 
interfacing of person-person and person-equipment actions respectively.

\subsubsection{Timeline Analysis (See Figure 5-2.)}

A timeline analysis organizes a function or task analysis along a time grid (including equipment response times) to highlight sequential and parallel ordering of tasks or lower level units of analysis (e.g., subtasks, elements of subtasks) and timing between those units of analysis. A timeline analysis is usually done as part of a function and task analysis. A timeline analysis also provides information on hardware utilization in conjunction with and parallel to human actions. Finally, the timeline analysis provides the analyst with information to determine whether time stress and/or recovery should be modeled as human causal factors in the Human Performance Assessment. Refer to Figure 5-2 at the end of this section for a pictorial example of a function or task analysis presented along a timeline.

\subsubsection{Link Analysis (See Figure 5-3)}

A link analysis organizes a function or task analysis as a network diagram showing interfaces between and among tasks or lower units of analysis, and the frequency with which those interfaces occur. A link analysis is usually completed as part of the function and task analysis. Finally, the link analysis provides information to the analyst in determining how dependency should be modeled as a human causal factor in the Human Performance Assessment. Refer to Figure 5-3 at the end of this section for a pictorial example of a function or task analysis linking functions and tasks.

\subsubsection{Human Vulnerability Analysis (See Figure 5-4)}

A human vulnerability analysis is similar to an equipment failure modes and effects analysis (FMEA). It uses the results of function, task, timeline, and link 
analyses to screen (rank order) human actions and action sequences listed therein for their relative likelihoods of precipitating a human error. The range of human actions analyzed in subsequent phases of the HPA depends on relative error likelihood (less than, equal to, greater than). Vulnerabilities are categorized as potential accident initiators or mitigators. Their potential types of consequences (radiological, chemical, industrial) are also identified. No attempt is made to assign human error probability estimates to individual vulnerabilities. The human vulnerability analysis provides the human failure paths for a hazard analysis in lieu of an accident analysis for Category 3 facilities. The human vulnerability analysis also provides a starting point for the HF practitioner to eliminate sub-tasks from the set developed as part of the task analysis, and from inclusion in subsequent steps of the human safety analysis. Finally, the human vulnerability analysis provides information to procedure writers, trainers, and managers, alerting them to segments of tasks that require special emphasis because of their susceptibility to error. Refer to Figure 5-4 at the end of this section for an example of a human vulnerability analysis format.

\subsubsection{Human Failure Modes Analysis}

A human failure modes analysis extends the human vulnerability analysis. It eliminates low probability sub-tasks from further analysis, and it then lists, for each human action and action sequence, ways (modes) by which the action or sequence can be failed. For example, the breach of a waste container by a forklift operator may be the action identified in the human vulnerability analysis. The human failure modes analysis asks: how can the operator precipitate breaching the container? The human failure modes analysis may answer, in part, that the operator can drop the container because he/she does not: (1) clear surface obstacles, (2) doesn't seat the load, (3) ignores rough driving surfaces, (4) inadvertently activates the vertical load control, (5) inadvertently activates the side-shift control, and/or (6) exceeds forklift load capacity. It is these latter human failure modes that become the focus of the HPA supporting Topic $\underline{5}$ (Hazards Analysis) and Topic 11 (Accident Analysis) and in turn, HF 
considerations for other topics of the SAR. - Finally, the human failure modes analysis provides the human failure paths for a hazards and accident analysis for Category 1,2, and 3 facilities.

\subsection{Human causal Factor Analysis}

\subsubsection{Introduction}

The HCF concept is central to HF work. Human performance on a given task, including likelihood of error, is a product of a variety of intrinsic and extrinsic factors. Included among these intrinsic factors, for example, are the human's own physical ability, attitudes toward and motivation for performing well on the task, amount of stress experienced, and experience performing the task. Performance is also influenced by performance aids available to the human. Included among these extrinsic factors are formal training, written procedures, co-workers, and supervisor oversight. Finally, human performance is influenced by extrinsic physical environment factors such as heat, light, noise, temperature, and larger environmental factors such as management policies. All of these factors, as they pertain to human performance on a given task, should be analyzed as part of the human safety analysis if credible estimates of nuclear safety significance are to be achieved.

HCFs directly impact human performance. HCFs impact local, onsite and offsite consequences of an accident to the degree that an earlier human action could be the precursor, initiator, or mitigator of the hazard or accident.

The HCF analysis provides: (1) bounding values for the remaining Human Performance Assessment step of the human safety analysis process, and (2) causal factors information that will systematically impact Human Performance Assessment results. 
NOTE: Throughout the remainder of this text, the terms $\underline{H C F}$, human factors element, and SAR topic are used interchangeably. HCF is usually used when referring to the Human Performance Assessment step of the human safety analysis. Human factors element is usually used when referring to DOE's definition of human factors or human factors safety. SAR topic is usually used when referring to a specific chapter or section of that document. The six human factors elements of particular interest to DOE in the SAR are: staffing, qualifications, procedures, training, oversight, and human factors engineering.

NOTE: Wherever possible, existing facility HCF documentation should be used to replace or supplement one or both of the HCF selection and evaluation steps below. Potential sources are facility acquisition documents prepared to DOE Order 4700.1 , or a recent $S A R$. The HF analyst should verify, however, that existing documentation represents the current operating configuration of the facility. 


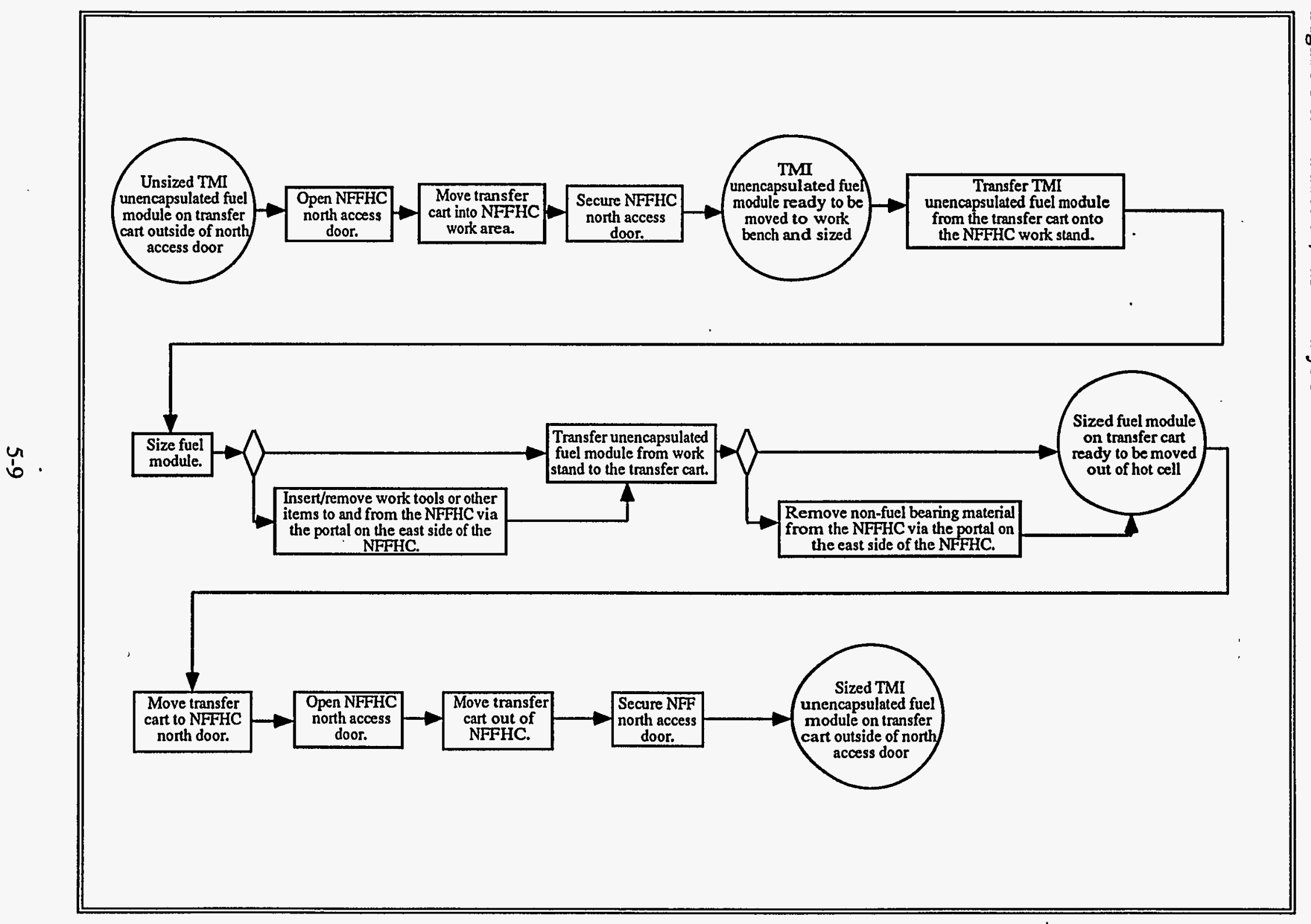

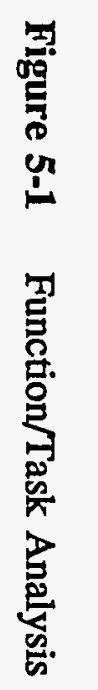




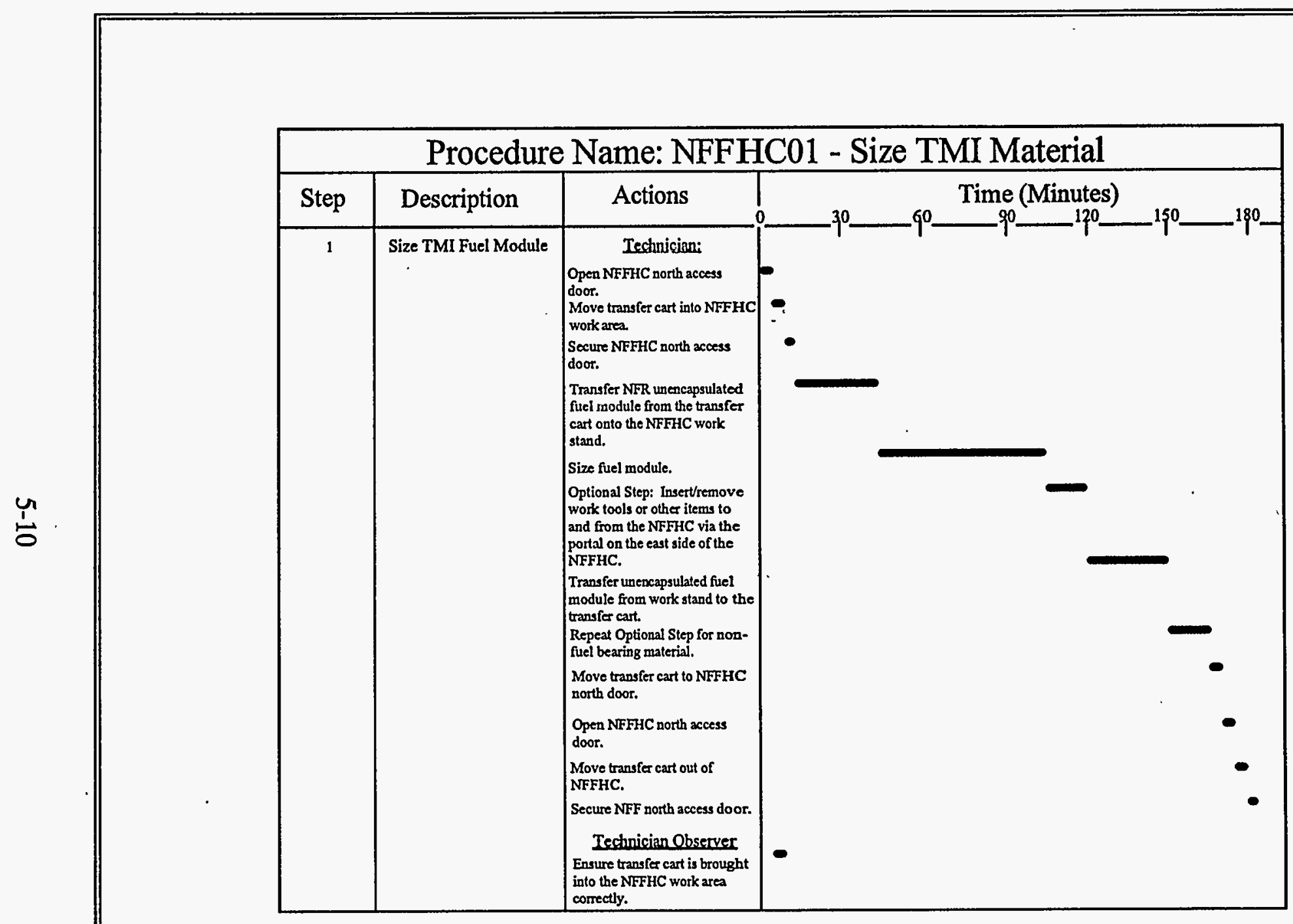


Figure 5-3 Link Analysis

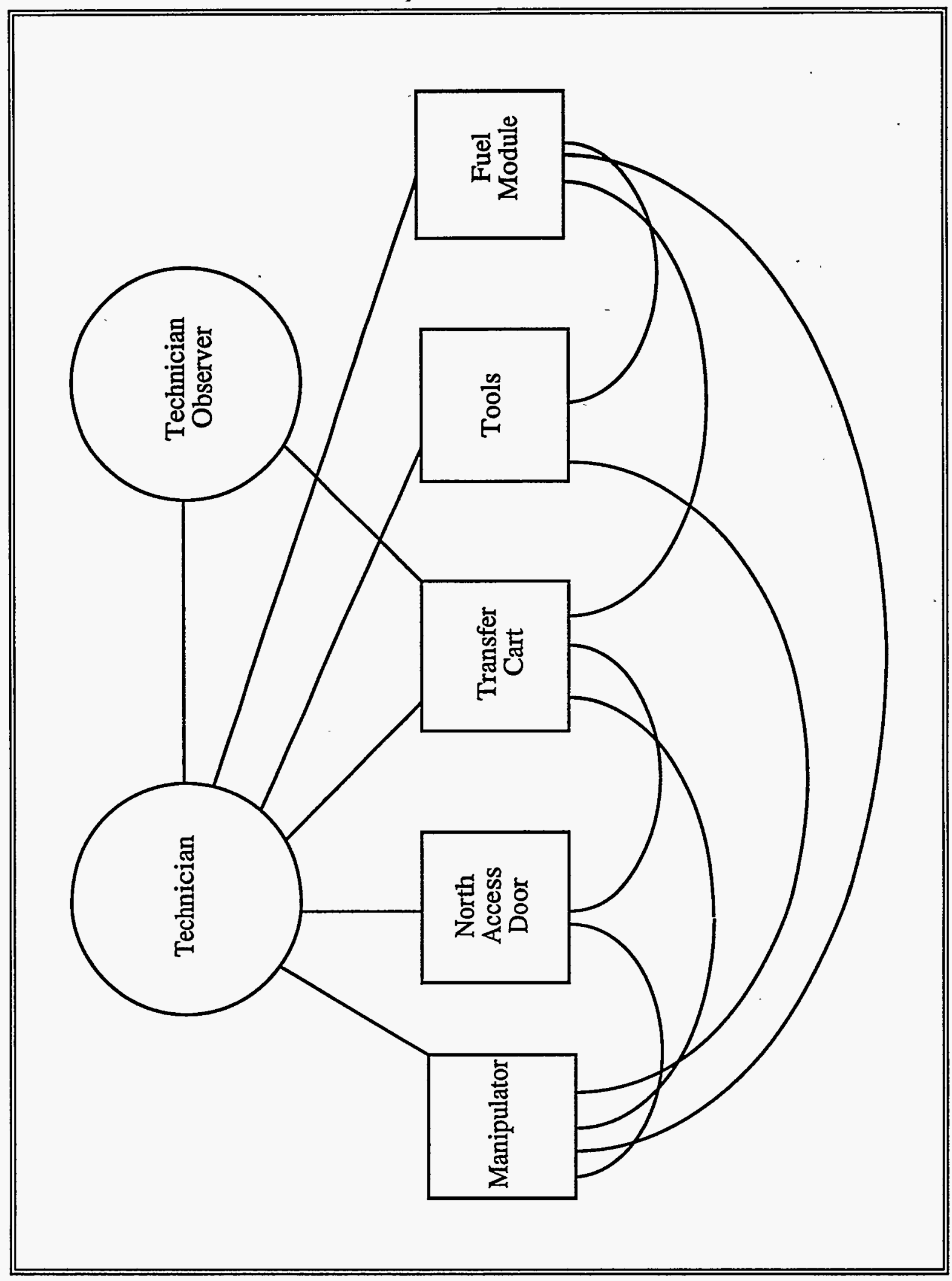




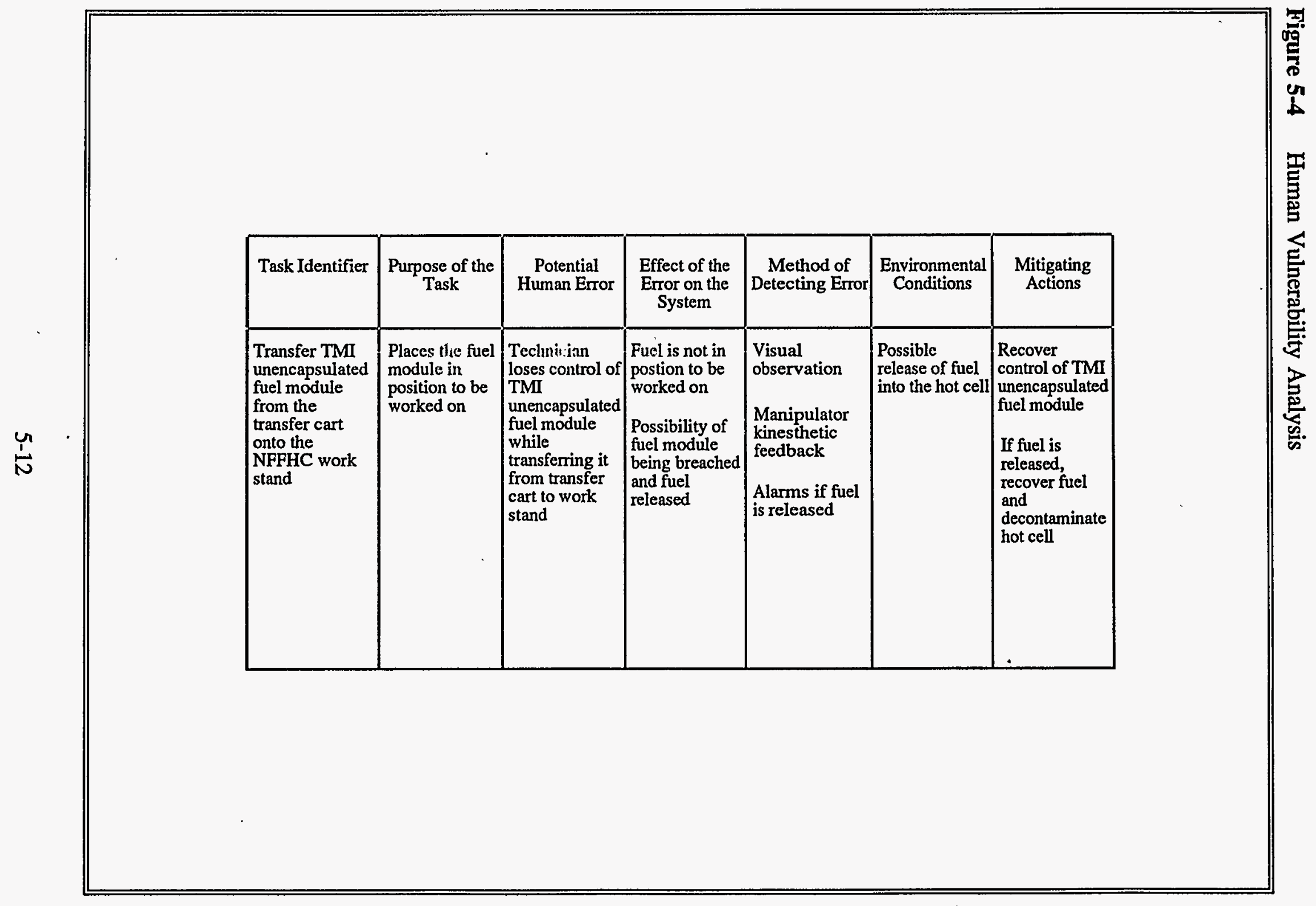




\subsubsection{Characteristics for HCF Analysis}

HCFs are usually divided into three categories: person-centered, task-centered, and environment-centered.

5.4.2.1 Person-Centered These are intrinsic characteristics brought to the task by the individual. Some are stable or slowly changing such as experience, aptitude, and physical strength. Others are situational such as fatigue, stress, and emotional upset. Of particular interest to DOE in the SAR (for operations and maintenance) are worker qualifications, including experience, which are analyzed primarily for SAR Topics $\underline{5}, 11, \underline{12}$ and $\underline{15}$.

5.4.2.2 Task-Centered These are extrinsic characteristics such as the human-machine interface design, workspace layout, staffing, training, and written procedures. Of particular interest to DOE in the SAR for operations and maintenance are:

- $\quad$ Staffing analyzed primarily for SAR Topics $\underline{5}, \underline{11}, \underline{12}$, and $\underline{15}$;

- $\quad$ Procedures and training analyzed primarily for SAR Topics $\underline{5}$, $\underline{11}, \underline{13}$ and $\underline{15}$

- Human-machine interface and workspace layout analyzed primarily for SAR Topics $\underline{5}, \underline{11}$ and $\underline{14}$.

5.4.2.3 Environment-Centered These are extrinsic characteristics of the institution (organization), administrative control (supervision and management), habitability (heat, light, noise, radiation), and the task context. Of particular interest to DOE in the SAR for operations and maintenance are: 
- Institutional and administrative controls, that is, organization and management analyzed primarily for SAR Topics $\underline{5}, \underline{11}, \underline{12}$, and $\underline{15}$.

- Habitability analyzed primarily for SAR Topics $\underline{5} \underline{11}, \underline{14}$ and $\underline{15}$.

- Task context factors such as dependency (i.e., the influence of earlier task performance on a later task). Also recoverability (task settings that allow subtasks to be attempted more than once without failing the entire task).

HCFs identified by DOE as important for the SAR should be analyzed, at a minimum, for Hazard Category 1, 2, or 3 facilities. These include oversight, staffing, and qualifications (SAR Topics 12 and 15 ), procedures and training (SAR Topics $\underline{13}$ and 15), and HFE, including communications, operational aids, instrumentation and controls, and physical environment factors (SAR Topic 14). This should not, however, limit analysis of other HCFs believed by the HF practitioner to measurably impact performance on the function or task being analyzed. The first substep is a task-by-task identification or selection of the HCFs, which have the greatest potential for impacting human performance. The second substep involves evaluating each HCF for its availability and competence for supporting human performance on the tasks being analyzed.

\subsubsection{Varying Impacts of HCFs on Performance Critical in selecting} and evaluating HCFs is an understanding of how and to what degree particular HCFs individually and in combination affect human performance in a positive or negative way. A popular belief is that there is a linear relationship between intensity and performance level for most HCFs, the more or less of the HCF present, the better the performance. In the case of some HCFs this is true up to a point, for other HCFs it is not true. 
- It is well documented that stress, whether psychological or time related, shows a curvilinear relationship with human performance. That is, low levels of stress enhance performance, high levels of stress degrade performance.

- Dependency, causing enhanced or degraded performance on a second task as determined by success or failure on an earlier task, can represent two sides of the same coin. For example, in problem solving tasks or infrequently performed action response tasks, performance on a second task is usually degraded.

However, when an earlier task involves feedback to the performer from the human-machine interface and/or management oversight, performance on a second task can be enhanced even if the earlier task is failed since the earlier task provides a learning experience.

- The impact of a high level-or even the presence of one-HCF interacting with a second HCF can degrade performance. For example, a detailed operating procedure combined with microoversight can often overload the task performer, create divided attention, and result in degraded performance. Individually, detailed operating procedures or micro-oversight may be good things. Together, they may become a distractor.

In the SAR, DOE wants to know the degree to which certain HCFs can support the nuclear safety commitments. Included among these are procedures, training, HFE, oversight, staffing and qualifications. One approach, therefore, is to include all of these HCFs in every human action and action sequence analyzed. However, experience over the past two years suggests this is a questionable approach. Tasks performed at many DOE facilities have a failure likelihood high enough to have a 
significant impact on safety. Yet, success likelihood on some of these tasks cannot necessarily be enhanced by a collection of the HCFs listed above. For example, at DOE processing, waste handling, and storage facilities, errors in transport of waste containers and encapsulated source material from one location to another by handcart or forklift have high human error probabilities. In most cases, the equipment operators who transport these materials are not given task-specific training or written procedures. In the case of most handcarts there is little human-machine interface design. Analysis of this type of task suggests that providing or increasing the level of training, procedures, and HFE will not necessarily enhance performance. The problem for the equipment operator is negotiating the load around comers, up/down ramps, along congested corridors, and positioning the load at a precise location. It turns out that the quality of direct oversight (two-person rule) alone can enhance performance by 2-3 magnitude. In reporting on HCFs of interest to DOE in the SAR, attention should be given to demonstrating the relevance and non-relevance of these factors, as well as demonstrating their adequacy in supporting the nuclear safety commitments. In summary, HCFs can enhance or degrade performance in a variety of ways given their individual natures, their interactions with other HCFs, and the context in which they appear.

\subsubsection{HCF Selection}

There are no straightforward checklist approaches for selecting HCFs. This requires an in-depth understanding of the context in which the function or task is being performed, and knowledge of the scientific literature concerning general relationships between human performance and individual HCFs. This is achieved by the HF practitioner reviewing: (1) the function, task, human vulnerability, and human failure modes analyses, (2) operating experience of the facility and/or similar facilities, (3) scientific evidence, and (4) using a skill, rule, and knowledge based task approach as follows: 
- $\quad$ Skill-based tasks which involve over-learned responses and which are performed on a regular basis are primarily influenced by personcentered factors such ás coordination, concentration and motivation.

- $\quad$ Rule-based tasks which involve under-learned response patterns and which are performed on less than a regular basis are primarily influenced by task-centered factors such as training, procedures, and direct oversight.

- $\quad$ Knowledge-based tasks which require new response patterns, or variations on existing response patterns and which are rarely performed, are primarily influenced by person-centered factors such as experience, reasoning ability, and decisionmaking ability. These tasks are also influenced by environment-centered factors such as organizational culture, management philosophy, and decision aids.

\subsubsection{HCF Evaluation}

We evaluate and scale each human causal factor selected above for its actual potential to increase or decrease the likelihood of human error by using information on facility personnel, equipment and environment. Qualitative and quantitative assessments of factors that affect human performance in the HCF selection step above are crucial for achieving the overall performance assessment objectives of the SAR. These factors can be evaluated for that purpose at any of three levels in descending order of rigor and precision.

- The first involves a direct comparison of a human-machine interfacing piece of equipment with a DOE or DOE referenced standard, or a content analysis usually associated with Hazard Category 1 facilities. For example, such an instrument probes the contents of the factors and 
provides an algorithm for assessing technical adequacy. In evaluating operating procedures, such an instrument would usually focus on completeness, technical accuracy, and comprehensibility. The human system analysis results (function, task, human vulnerability, and human failure modes analyses) should be used to the extent possible as a standard for this process.

- The second involves a direct observation (verification of availability) approach in which the analyst familiarizes himself- or herself- with and scores these factors. These factors are based on reviews of facility records, on observations of the same or similar functions and tasks being performed, and on conversations with the people who perform and supervise the same or similar functions and tasks. This approach is usually associated with Hazard Category 2 facilities, and is usually limited to verifying, for example, that provisions for formal training, written procedures, and direct oversight are available and implemented by the facility. Judgments concerning procedures, training or oversight, and the technical accuracy, completeness, and comprehensibility are limited.

- The third involves polling subject matter experts on the adequacy of these factors based on general knowledge of the facility as well as the functions and tasks being analyzed. This approach is usually associated with Hazard Category 3 facilities.

\subsubsection{Uses of HCF Evaluation Results}

The results of the HCF analysis provides scores on each HCF for use in the Human Performance Assessment, and causal factors information supporting the HCF scores. 


\subsection{Human Performance Assessment}

\subsubsection{Introduction}

Both qualitative and quantitative assessments are made using the information and data developed in the human system and HCF analyses described in Sections 5.3 and 5.4 above. The relative degree to which qualitative and quantitative assessments are made for a specific facility will depend primarily on its hazard classification. For Category 1 and 2 facilities, quantitative assessments will dominate; for Category 3 facilities qualitative assessments will dominate.

For purposes of supporting the HF segments of the SAR, human system and HCF analyses information and data should be entered into a probabilistic analysis to derive inputs for the facility hazards and accident analysis. Other operational experience data maintained by the facility and DOE should supplement the human system and HCF analyses information and data in the hazards and accident analysis, and with the results of the hazards and accident analysis be used to demonstrate the safety adequacy of the HCFs for supporting the nuclear safety SAR and TSR commitments to DOE.

NOTE: $\quad$ Throughout this text the term "Human Performance Assessment" is used to refer to indexing of data collected during the human system and HCF analyses steps of the human safety analysis. This includes a wide variety of indexing ranging from probabilistic to descriptive. The term "Human Performance Assessment" (HPA) is used in a more narrow sense, to refer only to probabilistic analysis. 


\subsubsection{Qualitative Assessment}

A qualitative assessment is a human performance error or success likelihood estimate (probabilistic), deviation score, or measure of central tendency (mean, median, mode) derived iudgmentally from information and data developed earlier in the human safety analysis. The result is obtained primarily through a reasoning process, relying to some extent on the insights of the analyst. One emphasis is on explaining relationships between human performance outcomes and associated root, direct, and contributing causal factors, individually and in combination. Another emphasis is on deriving remedial (get well) options due to their linkages with the earlier root, direct, and contributing causal factors.

\subsubsection{Quantitative Assessment}

A quantitative assessment is a human performance error or success likelihood estimate (probabilistic), deviation score, or measure of central tendency (mean, median, mode) derived computationally from information and data developed earlier in the Human Safety Analysis. Emphasis is on an objective measure or snapshot of human performance. The result is obtained through application of a transparent algorithm (capable of being audited). A qualitative result obtainable from the quantitative result is also needed to apply HF findings to facility improvement.

NOTE: $\quad$ Wherever possible, existing facility Human Performance Assessment documentation should be used to replace or supplement the Human Performance Assessment steps below. Potential sources are facility acquisition documents prepared to DOE Order 4700.1, or a recent SAR. The HF practitioner should verify, however, that existing documentation represents the current operating configuration of the facility. 


\subsubsection{Probabilistic Assessment}

DOE Order 5480.23 requires that a thorough hazards and accident analysis be performed to demonstrate that the facility operating configuration, including its safety features and administrative controls, is fully capable of supporting nuclear safety (DOE 1992). The primary technique for demonstrating this adequacy is a likelihood and consequence analysis guided in scope and content by the facility hazard classification. Important inputs to this analysis are credible human error probabilities (HEPs). The task for the HF practitioner is to apply quantitative and/or qualitative techniques to derive the necessary HEP inputs commensurate with the hazard classification of the facility.

HEPs are usually derived from any of three sources: (1) operational experience data from the facility, that is, errors divided by opportunities, (2) nominal error probabilities adjusted to reflect the impacts of the HCFs for a particular facility and task, and (3) consensus expert judgment. Seldom is sufficient operational experience data available to serve as the sole basis for a probabilistic analysis. In almost all cases nominal HEP adjustment and consensus expert judgment techniques are used.

A HEP acquired from any of these sources can be labelled quantitative or qualitative depending on how it is stated. If it is stated as a specific error rate (e.g., 1E-03) it is considered quantitative since it resulted from a calculation formula and represents a point estimate. If it is stated as an adjective (e.g., anticipated, likely, highly unlikely) it is considered to be qualitative since it represents a likelihood class rather than a specific point estimate.

Probabilistic estimates, whether quantitative or qualitative, should be derived for all human tasks involved in the operating and accident sequences selected for the hazards and accident analysis. Chapter 6 presents specific guidelines for deriving HEPs as a part of the HF graded approach. 


\subsubsection{Non-Probabilistic Assessment}

Throughout the SAR, analysts are required to demonstrate adequacy by means other than probabilistic analyses. For example, numeric standards (i.e., materials limits) are established by authorization basis documentation, and comparison scores are derived from facility inventories. Data on a variety of facility activities are combined and a mean or median computed to reflect a best facility estimate. Percentage scores relating operational event frequency with specific causal factors are used to compare facility and population norms. Finally, counts such as minimum staffing levels are used to demonstrate the ability of the facility to operate safely under a variety of conditions. As described in Chapter 6 of this Course Text, the facility hazard classification significantly influences the degree to which non-probabilistic analysis is used.

\subsubsection{Operational Experience Assessment}

Section 5.4 suggests that operational experience data are seldom sufficient for supporting probabilistic assessments. However, these data are still a valuable source of information for the HF practitioner. Probabilistic data discussed in Section 5.4 are essentially hypothetical in the sense that they are derived through modeling or simulating real events. SAR reviewers and DOE regulators often ask the question: to what degree do the probabilistic results reflect actual experience? Operational experience should be assessed in order to establish this relationship, and to demonstrate that HCFs are in place to adequately support the nuclear safety commitments.

Three possible sources of operational experience data are available through DOE facilities. The HF practitioner should make a thorough inquiry into what operational experience data the facility and DOE are maintaining. 
- The first possible source is numeric information on specific recurring events. For example, waste management facilities often keep records on the number of waste containers that are moved per day, week, month and/or year. Drop information is also kept, that is, how many of these moves resulted in a drop. Based on these data a drop error rate can be calculated and compared with the modeling or simulation rate established by the probabilistic assessment. If the model and the operational experience rates do not generally agree, the former needs to be reconsidered to bring it into general agreement with actual facility experience.

- The second source is facility internal data management systems. DOE mandates that its facilities establish programs and recording systems for assessing and monitoring their operating effectiveness. These selfawareness programs result in compilations of incidents and events requiring action, but are not necessarily reportable to DOE. In some instances, incident and event data are appended causal factor information. The HF practitioner should review the facility's selfawareness data systems for data attributable to any of the HCFs included in the human safety analysis. The question is, to what degree are error rate estimates (derived from the probabilistic assessment) in general agreement with rates derived from facility self-awareness data?

The third source is the DOE mandated Occurrence Reporting and Processing System (ORPS) program that is sustained by DOE Order 5000.3B (DOE 1993). The ORPS data store compiles reports starting in March 1990 up to the present. DOE Order 5000.3B requires that events meeting the ORPS reporting threshold be documented, including their causal factors and resolution strategies, and reported to DOE. The DOE-wide ORPS data store is accessible to legitimate users, especially 
contractors managing DOE facilities. The ORPS data store includes a personnel error category, along with cause codes for the human factors topics discussed in the SAR. As with recurring event and selfawareness data, the ORPS data store should be interrogated to reconcile probabilistic assessment results with operational experience. A second use of the ORPS data is to respond directly to the DOE Order 5480.23 , Attachment 1, Section $14 \mathrm{~d}$ requirement regarding human performance optimization under abnormal conditions (DOE 1992). For this purpose, trending and comparative analyses using the ORPS data are suggested.

- Trend percentages of total ORPS reports attributable to human error yearly starting with 1990 . Is the percentage decreasing, remaining essentially the same, or increasing? If the percentage is increasing or is steady at a high percentage level -- what is the reason? This question can be answered by interrogating the ORPS data store for the human factors SAR topics as causal factors in the ORPS reports attributable to human error. What proportion of the ORPS reports attributable to personnel error cite each of the human factors controls as causal factors? Do these proportions increase or decrease yearly from 1990 to the present?

- Compare the facility ORPS reports and a mean score for a representative group of similar DOE facilities. How does the facility compare on the percentage of total ORPS reports attributable to human error for the period 1990 to the present? How does the facility compare on each of the human factors SAR topics? 


\subsection{Summing Up}

This chapter has described concepts and techniques for conducting a human safety analysis to support the SAR process. Human safety analysis includes the following steps: 1) The human system analysis defines the scope of the efforts by identifying and describing functions and tasks that will be the focus of the SAR hazards and accident analysis. 2) The HCF analysis identifies and evaluates the adequacy of the HCFs that are believed to influence performance on each of the functions and tasks identified from the earlier human system analysis. 3) The Human Performance Assessment derives quantitative and qualitative measures of human performance so that nuclear safety determinations can be made.

Chapter 6 will present a graded approach for implementing the HF concepts and techniques described in this chapter. 


\section{Chapter 6}

\section{Graded Approach to Human Safety Analysis for Facilities Classified as Category 1, 2, and 3}

The overall objective of this chapter is to provide an approach for achieving a graded human safety analysis commensurate with facility classification, while retaining credibility and auditability.

\subsection{Introduction}

The purpose of this chapter is to present a graded approach for human safety analysis commensurate with the facility's hazard classification, and fully responding to DOE Orders 5480.23 and 5480.22 Safety Analysis Report (SAR) and Technical Safety Requirements (TSR) expectations respectively (DOE 1992a, 1992b). The chapter is divided into nine technical sections (6.2 through 6.10), describing quality assurance and grading factors for the approach, and application of the approach to each step of the human safety analysis process.

\subsection{Chapter 6 References}

U.S. Department of Energy (DOE), 1992a, "Nuclear Safety Analysis Reports," Order 5480.23, April.

DOE, 1992b, "Technical Safety Requirements," Order 5480.22, September.

DOE, 1993, "Occurrence Reporting and Processing System (ORPS)," Order 5000.3B, January. 
Other references are presented with full citations in the sections of the chapter where they are used.

\subsection{DOE Grading Factors}

The graded approach presented in this chapter, addresses as follows the three grading factors (consequence, complexity, life cycle status) established by DOE Order 5480.23.

Consequence The human system. human causal factor, and human performance assessment grading factors imposed in this chapter are directed primarily at consequence. The greater the judged consequence, the greater the scope, level of detail, and rigor required of the human safety analysis. A reactor release with potential offsite consequences would be expected to elicit a more expansive analysis that a release from a low-level waste drum with local consequences.

Complexity This factor is judged by the numbers and diversity of structures, systems, and components (SSCs) that make up the facility, along with the number and diversity of missions that the facility is tasked to perform. The greater the number and diversity of SSCs and facility missions, the greater the complexity. For purposes of this chapter, complexity is not necessarily considered a corollary with consequence. For example, a waste management facility (Category 2) with lesser numbers and diversity of SSCs and missions might not achieve a level of complexity achieved by a Tritium storage and processing facility (also Category 2) where the numbers and diversity of SSCs and missions exceed those of the waste management facility. For the purpose of this chapter, complexity is considered to be a natural grading factor. The difference in complexity between the waste management and Tritium facilities would be expected to dictate a difference in the scope, detail, and rigor of the human safety analysis even if the analyst were never told that there was such a thing as a graded approach. Therefore, human safety analyses done on facilities within the same classification level (Category 1,2, or 3) would be expected to differ naturally on the basis of relative complexity. 
Life Cycle Status For the purpose of this chapter, life cycle status is considered an administrative issue rather than a technical issue. In instances where the DOE determines that a facility requires a SAR prepared to DOE Order 5480.23 and DOE-STD-3009-94, the imposed grading factor (consequence) and the naturally occurring grading factor (complexity) would be expected to determine the scope, detail, and rigor of the human safety analysis. In instances where the DOE determines that a SAR prepared to DOE Order 5480.23 and DOESTD-3009-94 is not required (substituting a DOE Order 5481.1B SAR or a Basis for Interim Operation [BIO]), the graded approach for a human safety analysis is mute.

\subsection{Quality Assurance Factors}

Introduction of a graded approach to the human safety analysis in no way relaxes the requirement for technically defensible human factors analysis, which includes the Human Performance Assessment (HF) segments of the SAR and its companion TSRs. In order to retain technical defensibility, the human safety analysis graded approach described in the following pages is directed toward the following four quality criteria.

- $\quad$ Credibility - Defensible results require an experienced HF practitioner to use carefully accepted HF techniques. Techniques that have demonstrated reliability and validity are essential. Reliability requires reasonable consistency of results across time and analysts. Validity requires results consistent with actual human performance. The large number and complex context-specific interactions of variables influencing Human Performance Assessment and the scarcity of human error data can result in significant uncertainty if not dealt with systematically and completely by the HF technique used.

- $\quad$ Auditability - A human safety analysis must be well-documented and traceable for the results to be practical and defensible. All steps, assumptions, information, and methods relevant to the analysis must be presented in detail, to allow a reviewer to understand the origin, understand the specific context, 
and assess the meaning of the results. Appropriate and well-documented analyses define much of the basic information acquired and used to perform the human safety analysis. The information from the earlier human system analysis and human causal factor (HCF) analysis become part of the Human Performance Assessment, and are linked to assessment results through complete documentation of the process, assumptions, and methods used to generate quantitative estimates or qualitative assessments. The human safety analysis is not traceable when the human system and HCF analyses are not done, or are not well-documented. Auditability of the human safety analysis, including these analyses, is essential to support further assessments of factors contributing to risk and to allow comparison with other human safety analyses.

- Support analysis of contributing factors to risk - The results of the human safety analysis must provide some level of information on the technical accuracy and thoroughness of the HCFs included in the analysis. This information is obtained through formal evaluations of each HCF, observation of the HCF supporting documentation used (e.g., operating procedures), or from subject matter experts familiar with the activities being focused on in the safety analysis. This HCF information becomes the basis for making changes in the operating configuration of the facility to ensure that the HCFs, individually and in combination, are fully capable of supporting the safety mission of the facility, including its SAR and TSR commitments to DOE.

- $\quad$ Results comparable with other analyses - The value of the human safety analysis results, quantitative or qualitative, is enhanced if the results can be compared to results from other human safety analyses. Such comparisons facilitate examination of human safety analysis related issues of possible relevance across systems or facilities not originally included in a single analysis, but careful, standardized, and meticulously documented use of accepted HF techniques is necessary for valid comparisons of results from 
separate human safety analysis efforts. Analysis results are very contextspecific, therefore any valid combining or comparison of results must include rigorous comparisons and matching of the variables and influences identified and used to estimate the human safety analysis results. The process, assumptions, and methodologies employed must also be carefully considered to determine valid comparisons of human safety analysis results.

\subsection{Graded Factors}

The graded approach presented in this section varies four factors: the scope of the analysis, level of detail, level of rigor, and HF techniques used to index the information.

- $\quad$ Scope refers to the physical area which is the subject of the human safety analysis. For Hazard Category 1 facilities the site boundary usually provides the limit of the analysis; for Hazard Category 2 facilities it is usually the facility boundary; and for Hazard Category 3 facilities it is usually the immediate work area up to 100 meters from ground zero.

- Level of detail refers to the units of behavior that are analyzed, and the range of factors included in the human safety analysis. For example, in Hazard Category 1 facilities task analyses could include hierarchies of subtasks and subtasks broken into elements. Hazard Category 3 facility task analyses, on the other hand, would usually end at the subtask level without organizing subtasks into hierarchies. Additionally, human safety analyses of Hazard Category 1 facilities could include a wide range of HCFs. For Hazard Category 2 and 3 facilities HCFs would be limited to those prescribed by DOE which include training, procedures, oversight, experience, staffing, qualifications, and human factors engineering (HFE). 
- Level of rigor refers to the means by which human safety analysis information is gathered and performance scoring is done. For Hazard Category 1 facilities comparisons with discrete standards and content analyses are done on each HCF. For example, human-machine interface equipment is analyzed for compliance with DOE or DOE referenced standards. Formal training and procedures are examined for technical accuracy, thoroughness, and comprehensibility. For Hazard Category 2 facilities a determination is made that formal training materials and written procedures exist. Analysis of the training materials or procedures is not done. For both Hazard Category 1 and 2 facilities, quantitative Human Performance Assessments are made to estimate the impact of human performance on safety. For Hazard Category 3 facilities these estimates are made qualitatively using consensus expert judgment.

- $\quad$ HF techniques refer to credible procedural and mathematical processes used to gather human safety analysis information and analyze the safety impact of HF. For example, function and task analyses as procedural techniques provide the context for judging human performance. They are used as basic tools for Hazard Category 1, 2, and 3 human safety analyses. However, their scope, level and detail, and level of rigor vary between categories. The Technique for Human Error Rate Prediction (THERP) is a modeling structure for describing task actions and action sequences as well as a mathematical method for estimating human error likelihood. It is used as a scoring technique for Hazard Category 1 and 2 facilities which require quantitative results, and also to a lesser degree, level of detail, and level of rigor of input data for Hazard Category 2 facilities. THERP is described further in Section 6.8 of this chapter, and in Appendix B to this Course Text.

Sections 6.5. through 6.7 of this chapter suggest a graded approach for Hazard Category 1,2 , and 3 facilities on each of the three steps of the human safety analysis (human system analysis, HCF analysis, Human Performance Assessment). Each section is broken 
down by hazard category suggesting guidelines for implementing the graded factors, and suggesting technical references to assist in implementing the graded factors. Graded factors for each step are summarized in figures at the end of its section. Section 6.8 suggests a graded approach for doing an operational experience assessment. Section 6.8 is organized similar to Sections 6.5 through 6.7. Finally, Section 6.9 is a summary of the chapter.

\subsection{Graded Approach for Human System Analysis}

The graded approach for human system analysis is summarized in Figure 6-1 at the end of this section, for Hazard Category 1, 2, and 3 facilities, and is described in Sections 6.6.1 through 6.6.5.

\subsubsection{Hazard Category 1}

\section{Guidelines}

For Hazard Category 1, site-wide analysis of function, task, timeline, link, human vulnerability, and human failure modes are performed. These analyses also include facility-wide and local work area functions and tasks. Local work area is defined as a radius of $100 \mathrm{~m}$ from ground zero. The second column of Figure 6-1 at the end of this section, provides a summary of the graded approach for a Category 1 facility.

- $\quad$ Functions and tasks as part of operational and accident sequences should be considered on a site-wide basis. These functions and tasks could also extend beyond the site boundary for post-accident sequences involving off-site entities such as public fire departments and rescue squads. 
- All major technical and administrative activities performed by the facility should be screened as potential sources of support to the nuclear safety commitments.

- Task element level of detail should be pursued since individual human actions often have potential for initiating or mitigating an accident situation.

- All of the process steps listed at the bottom of Figure 6-1 should be performed to achieve human system analysis results of sufficient detail to support other Hazard Category 1 SAR analysis dependent on HF input. These process steps include:

1. reviewing pertinent facility documents, including training materials and operating procedures, earlier SARs, Operational Safety Requirements (OSRs) and TSRs,

2. conducting non-directed/open-ended interviews (interviewee picks the topics) with subject matter experts,

3. conducting walkdowns of the function or task with job incumbents (e.g., operators),

4. directly observing the function/task being performed, and

5. resolving documentation, interview, walkdown, and observation discrepancies, if applicable, and organizing the information in a consistent, usable fashion. 


\section{Hazard Category 1 Suggested References}

NUREG/CR-1278, "Handbook of Human Performance Assessment with Emphasis on Nuclear Power Plant Operations." U.S. Nuclear Regulatory Commission, Washington, DC: 1983.

NUREG/CR-2254, "A Procedure for Conducting a Human Performance Assessment of Nuclear Power Plants." U.S. Nuclear Regulatory Commission, Washington, DC: 1983.

NUREG/CR-5538, "Influence of Organizational Factors on Performance Reliability." U.S. Nuclear Regulatory Commission, Washington, DC: 1992.

\subsubsection{Hazard Category 2}

\section{Guidelines}

For Hazard Category 2, facility-wide function, task, timeline, link, human vulnerability, and human failure modes analyses are performed. All major technical activities performed by the facility should be considered. These analyses also include local work areas. The third column of Figure 6-1 at the end of this section provides a summary of the graded approach for a Category 2 facility.

- Functions and tasks as part of operational and accident sequences should be considered on a facility-wide basis. These functions and tasks could also extend beyond the facility boundary for post-accident sequences involving on-site and off-site entities such as fire departments and rescue squads. 
- All major technical activities performed by the facility should be screened as potential sources of support to the nuclear safety commitments.

- Sub-task level of detail should be pursued since even limited concatenations of individual human actions often have potential for initiating or mitigating an accident situation.

- The first three process steps, listed at the bottom of Figure 6-1 and described in Section 6.5, can be combined and still achieve human system analysis results of sufficient detail to support other Hazard Category 2 SAR and TSR analyses dependent on HF input.

\section{Hazard Category 2 Suggested References}

The suggested references are the same as for a Category 1 facility. The procedures for function and task analyses presented in the references allow for differing scopes, levels of detail, and rigor.

\subsubsection{Hazard Category 3}

\section{Guidelines}

For Hazard Category 3, a selected or representative set of function, task, timeline, link, human vulnerability, and human failure modes analyses should be considered for technical activities: (1) internal to the facility (local work areas), and (2) believed to be related to safety. These analyses could extend beyond the local work areas since hazard and accident scenarios are analyzed for their potential consequences facility-wide. The right column of Figure 6-1 at the end of this section provides a summary of the graded approach for a Category 3 facility. 
- Functions and tasks as part of operational and accident sequences should be considered on a local work-area basis. These functions and tasks could also extend beyond the local work-area (100 meters from ground zero) for post-accident sequences involving on-site and off-site entities such as fire departments and rescue squads.

- A representative set of technical activities performed by the facility should be screened as potential sources of support to the nuclear safety commitments.

- Task level of detail should be pursued since extensive concatenations of individual human actions are required for initiating or mitigating an accident situation.

- The first three process steps, listed at the bottom of Figure 6-1 and described in Section 6.5, can be combined and the observation step realized and still achieve human system analysis results of sufficient detail to support other Hazard Category 2 SAR analysis dependent on HF input.

\section{Hazard Category 3 Suggested References}

The suggested references are the same as for a Category 1 facility. The procedures for doing function and task analyses presented in the references allow for differing scopes, levels of detail, and rigor.

\subsubsection{Application of Human System Analysis Results in the SAR}

Figure 6-2 at the end of this section provides a summary of the analysis and the application of its result in the SAR. The first step of the human safety analysis, 
the human system analysis, is the heart of the analysis process just as the systems analysis is for an equipment engineering analysis. The results obtained in this step provide the context for the remaining HCF analysis and subsequent Human Performance Assessment steps of the human safety analysis process.

\subsubsection{Products of the Human System Analysis}

The products of the human system analysis include a series of flow diagrams and narratives, as described in Chapter 5, and accompanying function and task summaries provided in Figure 6-3 through Figure 6-5 at the end of this section. Note that the function/task portrayed in Figure 6-3 through Figure 6-5 is the same one that was used in Chapter 5, that is Sizing a Three Mile Island (TMI) Assembly.

6.6.5.1 Function/Task Description Analysis The function/task description presented in Figure 6-3 provides the following information:

- function/task designator and title, location within the site, facility or work area boundaries within which the task is performed,

- $\quad$ function/task start and stop conditions.

- numbered actions required to carry out the task along with an indication of who is responsible for carrying out the task.

6.6.5.2 Function/Task Equipment Analysis The function/task equipment analysis presented in Figure 6-4 at the end of this section provides the following information:

- function/task designator and title, location within the site, facility or work area boundaries within which the task is performed, 
- list of equipment involved in the function/task which also involve human-machine interactions,

- $\quad$ numbered actions to which each piece of equipment applies along with a YES or NO indication as to whether the equipment will be a subject of the HFE evaluation. The original action numbers are retained throughout the human safety analysis for cross-referencing and configuration management.

\subsubsection{Function/Task Human Failure Modes Analysis The} function/task human failure modes analysis presented in Figure 6-5 at the end of this section provides the following information:

- function/task designator and title, location within the site, facility or work area boundaries within which the task is performed,

- numbered actions identical with those provided in the description and equipment analysis illustrations,

- numbered actions converted into human failure statements. 
Figure 6-1 Matrix of DOE Facility Classifications and Human System Analysis Graded Approach

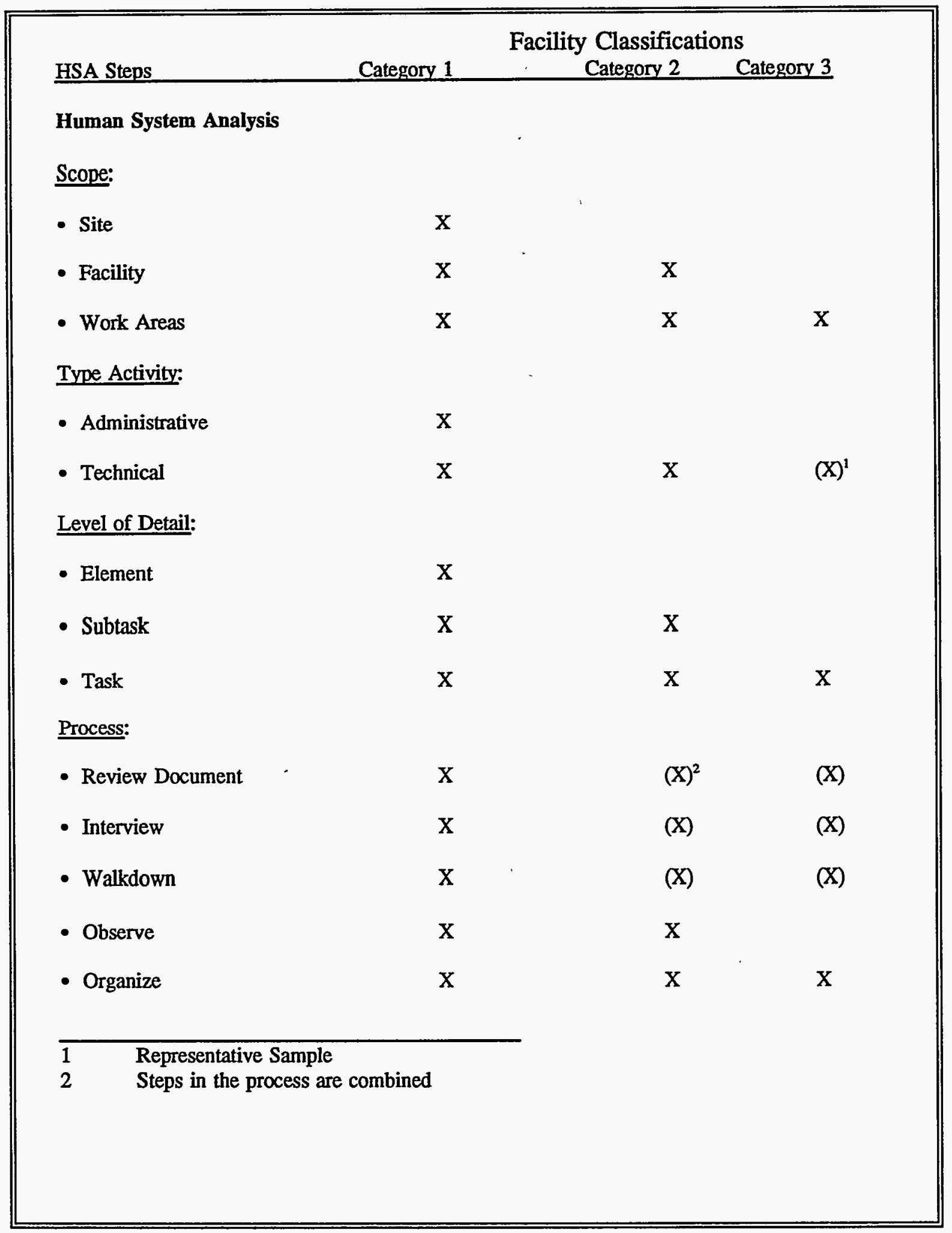


Figure 6-2 Human Safety Analysis: Human Safety Analysis

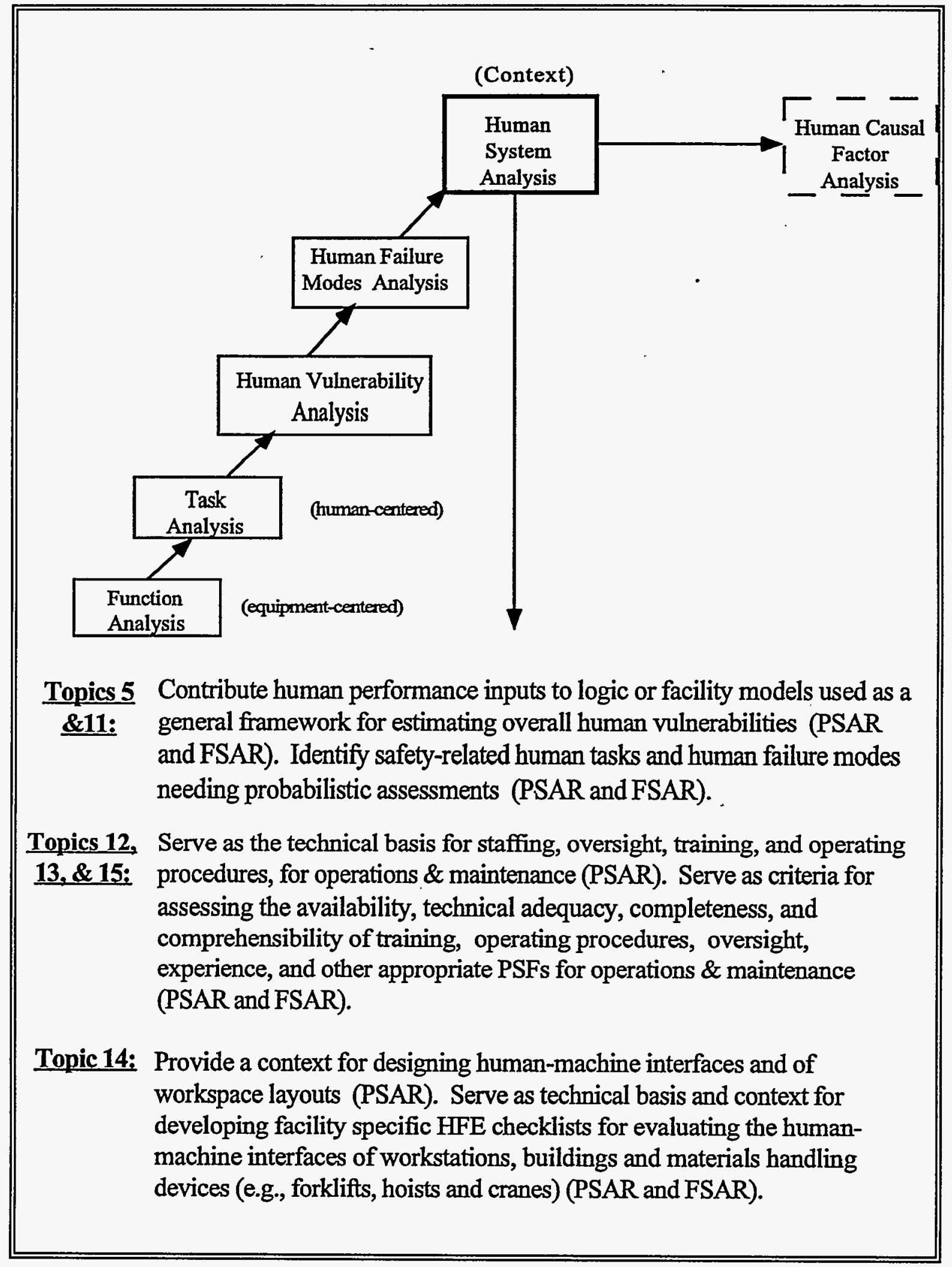


Figure 6-3 Human System Analysis: Description Analysis

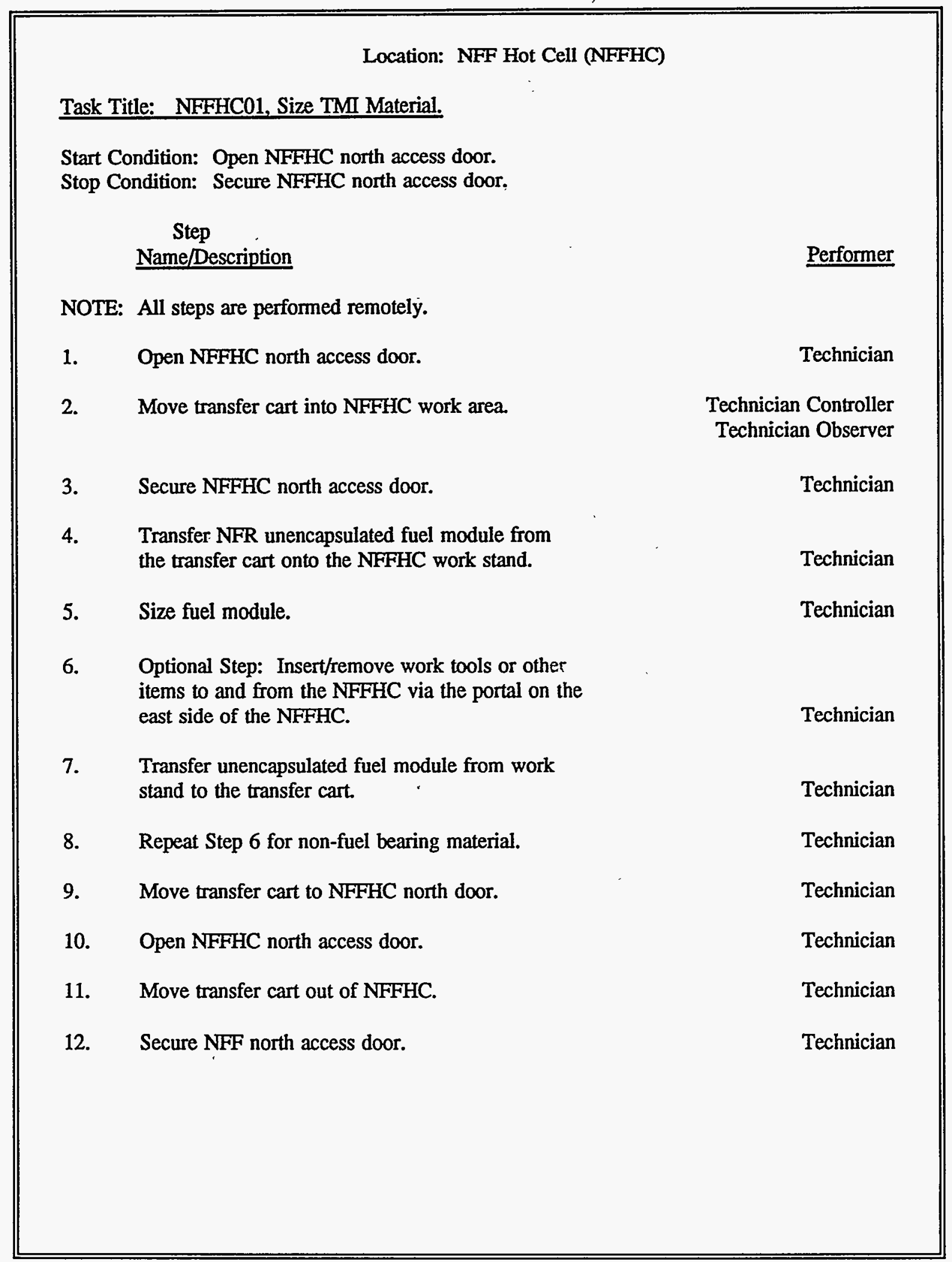


Figure 6-4 Human System Analysis: Equipment Analysis

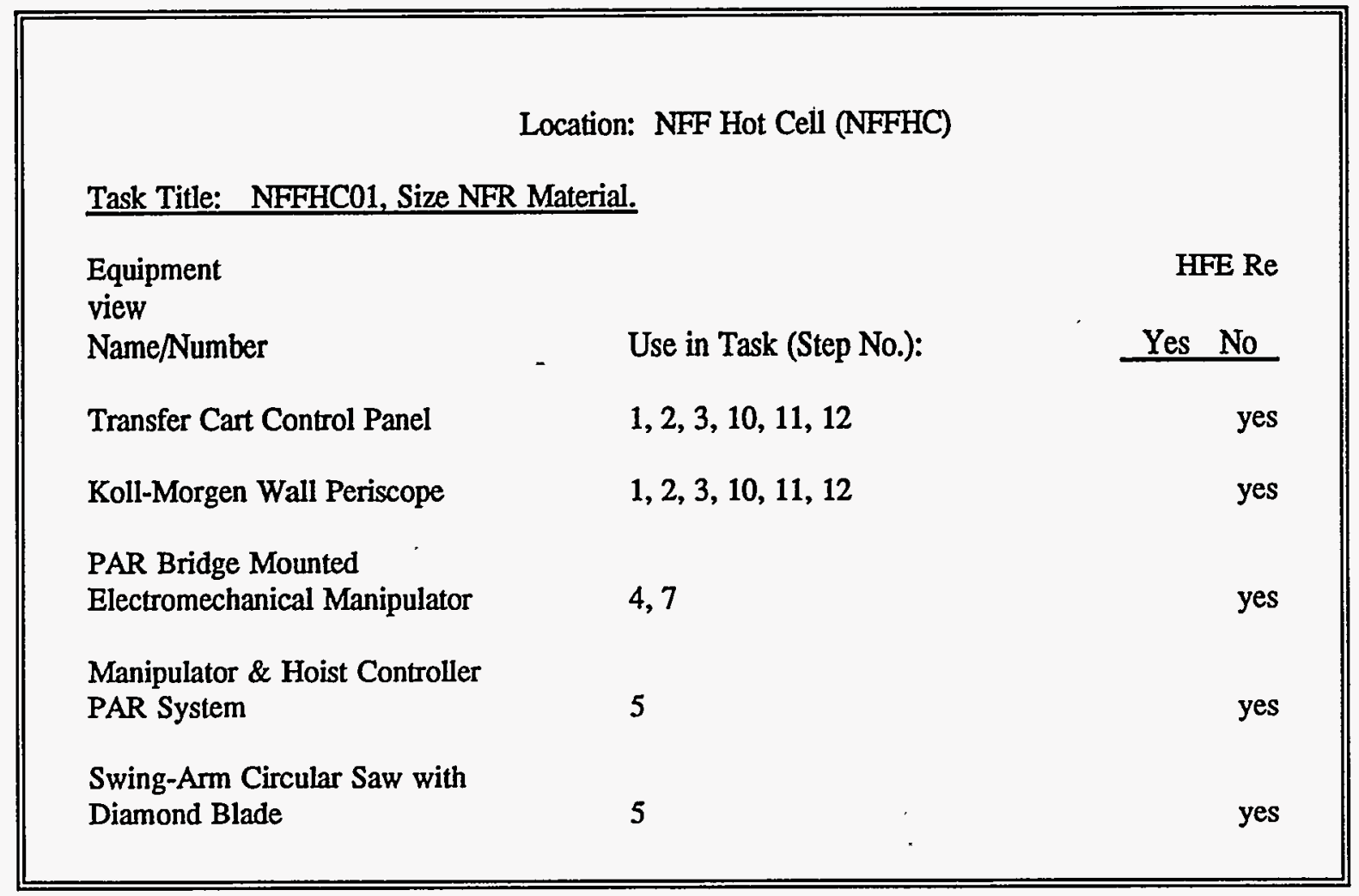


Figure 6-5 Human System Analysis: Human Failure Modes Analysis

Location: NFF Hot Cell (NFFHC)

Task Title: NFFHC01, Size TMI Material.

Human failure modes for each human step, that is, how can it be failed?

$\underline{\text { Step }}$

\section{Failure Modes}

1. Technician fails to open NFFHC north access door enough to clear transfer cart.

2. Technician loses control of transfer cart while moving it into the NFFHC work area.

3. Technician fails to secure NFFHC north access door.

4. Technician loses control of TMI unencapsulated fuel module while transferring it from the transfer cart onto the NFFHC work stand.

5. Technician breaches the fuel while sizing the fuel module.

6. Technician opens NFFHC norti access door to Hot Shop or NFFHC ports while unencapsulated fuel is in the NFFHC.

7. Optional Step: Technician fails to secure inner or outer portal door when inserting or removing material from the NFFHC interior.

8. Technician loses control of the unencapsulated fuel while moving it from work stand to the transfer cart.

9. Technician loses control of transfer cart while moving it from the NFFHC work area to the NFFHC north access door.

10. Technician fails to open NFFHC north access door enough to clear transfer cart.

11. Technician loses control of transfer cart while moving it through the NFFHC north access doorway.

12. Technician fails to secure NFFHC north access door. 


\subsection{Graded Approach for the Human causal Factor (HCF) Analysis}

The graded approach for the HCF analysis is summarized in Figure 6-6 and Figure 6-7 at the end of this section for Hazard Category 1,2, and 3 facilities, and is described in Sections 6.7.1 and 6.7:2. Analysis of HCFs involves two substeps. The first substep identifies or selects HCFs, on a task-by-task basis, which have the greatest potential for impacting human performance. The second substep evaluates each HCF for its availability and competence in supporting human performance on the task, or tasks, being analyzed.

NOTE: $\quad$ Throughout the remainder of this text, the terms $\underline{H C F}$, human factors element, and SAR topic are used interchangeably. HCF is usually used when referring to the Human Performance Assessment step of the human safety analysis. Human factors element is usually used when referring to DOE's definition of human factors or human factors safety. SAR topic is usually used when referring to a specific chapter or section of that document. The six human factors elements of particular interest to DOE in the SAR are: staffing, qualifications, procedures, training, oversight, and human factors engineering.

\subsubsection{HCF Selection}

The graded approach for HCF Selection is summarized in Figure 6-6 at the end of this section for Hazard Category 1, 2, and 3 facilities. 


\subsubsection{Hazard Category 1}

\section{Guidelines}

The following considerations pertain to HCF selection for facilities classified as Hazard Category 1, as indicated in the second column of Figure 6-6.

- Select person-centered, task-centered, and environment-centered factors appropriate for site-wide analysis of functions and tasks. Include where appropriate HCFs specified by DOE for inclusion in the SAR. These include staffing, qualifications, procedures, training, oversight, and HFE. Also include others where appropriate, especially person-centered HCFs such as stress and experience.

- There may be cases where one or more of the HCFs specified by DOE for the SAR do not apply to a given human action or action sequence. In such a case it or they should not be included in the analysis, however, an explanation of why it or they are not included should be documented.

- Weight each HCF against the others selected for the analysis, that is, rank order HCFs according to their potential for affecting human performance. More than one HCF can be given the same weight. Weighting allows for modeling varying degrees of influence in the Human Performance Assessment. 


\section{Hazard Category 1 Suggested References}

Gertman, D. I., and Blackman, H. S. (1994) Human Performance Assessment and Safety Analysis Data Handbook, John Wiley \& Sons, Inc., New York.

Rasmussen, J., "Skills, Rules, Knowledge: Signals, Signs, and Symbols and other Distinctions in Human Performance Models," IEEE Transactions: Systems, Man, and Cybernetics, 1983, SMC-13-257-267.

\subsubsection{Hazard Category 2}

\section{Guidelines}

The following considerations pertain to HCF selection for facilities classified as Hazard Category 2, as indicated in the middle column of Figure 6-6.

- Select person-centered, task-centered, and environment-centered factors appropriate for facility-wide analysis of functions and tasks from the topics specified by DOE for the SAR.

NOTE: There may be cases where one or more of the HCFs specified by $D O E$ for the SAR do not apply to a given human action or action sequence. In such a case it or they should not be included in the analysis, however, an explanation of why it or they are not included should be documented.

- Limit choices to HCFs specified by DOE for inclusion in the SAR. These include staffing, qualifications, procedures, training, oversight, and HFE. Include other HCFs only if they are crucial to performance. 


\section{Hazard Category 2 Suggested References}

(The suggested references are the same as for a Category 1 facility.)

6.7.1.3 Hazard Category 3

\section{Guidelines}

The following considerations pertain to HCF selection for facilities classified as Hazard Category 3, as indicated in the right column of Figure 6-6.

- $\quad$ Select person-centered, task-centered, and environment-centered factors appropriate for local area analysis of functions and tasks from the topics specified by DOE for the SAR.

NOTE: $\quad$ There may be cases where one or more of the HCFs specified by DOE for the SAR do not apply to a given human action or action sequence. In such a case it or they should not be included in the analysis, however, an explanation of why it or they are not included should be documented.

- Limit choices to HCFs specified by DOE for inclusion in the SAR. These include staffing, qualifications, procedures, training, oversight, and HFE.

\section{Hazard Category 3 Suggested References}

(The suggested references are the same as for a Category 1 facility.) 


\subsubsection{HCF Evaluation}

The graded approach for HCF Evaluation is summarized in Figure 6-7 at the end of this section, for Hazard Category 1, 2, and 3 facilities.

\subsubsection{Hazard Category 1}

\section{- Guidelines}

For Hazard Category 1, as indicated in the second column of Figure 6-7, use the standard evaluation instrumentation (content analysis) approach appropriate for site-wide, facility-wide, and local work area functions and tasks. Each HCF should undergo a content or direct comparison analysis of the type described in Chapter 5. Once each HCF has been evaluated, scores should be weighted in accordance with the rankings developed as part of the HCF selection process, and final scores computed.

\section{Hazard Category 1 Suggested References}

Function/task analysis results derived from the human system analysis.

Gertman, D. I., and Blackman, H. S. (1994) Human Performance Assessment and Safety Analysis Data Handbook, John Wiley \& Sons, Inc., New York.

Human system analysis results described in Section 6.6 above.

NUREG/CR-1278, "Handbook of Human Performance Assessment with Emphasis on Nuclear Power Plant Operations." U.S. Nuclear Regulatory Commission, Washington, DC: 1983.

BNL-38585, "Team-Enhanced Evaluation Method (TEEM) Procedures: An Enhanced Human Performance Assessment Process." Brookhaven National Laboratory, Upton, NY: 1986. 
NUREG/CR-5538, "Influence of Organizational Factors on Performance Reliability." U.S. Nuclear Regulatory Commission, Washington, DC: 1992.

DOE Standard 1029-92, "Writer's Guide for Technical Procedures," December 1992.

ANSI/HFS (American National Standard Institute/Human Factors Society), 1981, "Practices for Respiratory Protection," Standard Z88.2-1980, March.

ANSI/HFS (American National Standard Institute/Human Factors Society), 1988, "Human Factors Engineering of Visual Display Terminal Work Stations," Standard 100-88, February 4.

CFR (Code of Federal Regulations), 1992, "Personal Protective Equipment," 29 CFR 1910.132 - 134, Office of Federal Registry, February.

U.S. Department of Defense (DOD), 1985, "Human Engineering Guidelines for Management Information Systems," DOD-HDBK-761A, June 28.

DOD, 1987, "Human Engineering Procedures Guide," DOD-HDBK-763, February 27.

DOD, 1989, "Human Engineering Design Criteria for Military Systems, Equipment, and Facilities," MIL-STD-1472D, March.

IEEE (Institute of Electrical and Electronic Engineers), 1988, "Guide for the Application of Human Factors Engineering to Systems, Equipment, and Facilities of Nuclear Generating Stations," Standard 1023, Oct.

Overlin, T., Romero, H., \& Ryan, T., 1995, Human Factors Engineering Checklists for Application in the SAR Process. INEL-95/0117, March.

USNRC (U.S. Nuclear Regulatory Commission), 1981, "Guidelines for Control Room Design Reviews," NUREG-0700, September. 
USNRC, 1985, "Human Engineering Guidelines for the Evaluation and Assessment of Video Display Units," NUREG/CR-4227, July.

UCRL (University of California Research Laboratory), 1985, "Human Factors Design Guidelines for Maintainability of Energy Nuclear Facilities," UCRL 15673, June.

\subsubsection{Hazard Category 2}

\section{Guidelines}

For Hazard Category 2, as indicated in the third column of Figure 6-7 at the end of this section, use standard evaluation instrument and direct observation (verification of availability) approaches appropriate for facility-wide, and local work area functions or tasks. Normally, the HCF analysis should be limited to: training, procedures, oversight, staffing, qualifications, and HFE. Other person-centered, taskcentered, and environment-centered factors should be analyzed in unique situations where they are deemed critical for achieving a credible result. Direct observation (verification of availability) should be employed with most HCFs other than HFE. For HFE standard evaluation checklists should be used. Weighting of HCFs for the purpose of human error likelihood computation is not normally done. All HCFs are assumed to be of equal weight.

\section{Hazard Category 2 Suggested References}

Function/task analysis results derived from the human system analysis.

ANSI/HFS (American National Standard Institute/Human Factors Society), 1981, "Practices for Respiratory Protection," Standard Z88.2-1980, March. 
ANSI/HFS (American National Standard Institute/Human Factors Society), 1988, "Human Factors Engineering of Visual Display Terminal Work Stations," Standard 100-88, February 4.

CFR (Code of Federal Regulations), 1992, "Personal Protective Equipment," 29 CFR 1910.132 - 134, Office of Federal Registry, February.

DOD, 1985, "Human Engineering Guidelines for Management Information Systems," DOD-HDBK-761A, June 28.

DOD, 1987, "Human Engineering Procedures Guide," DOD-HDBK-763, February 27.

DOD, 1989, "Human Engineering Design Criteria for Military Systems, Equipment, and Facilities," MIL-STD-1472D, March.

IEEE (Institute of Electrical and Electronic Engineers), 1988, "Guide for the Application of Human Factors Engineering to Systems, Equipment, and Facilities of Nuclear Generating Stations," Standard 1023, Oct.

USNRC (U.S. Nuclear Regulatory Commission), 1981, "Guidelines for Control Room Design Reviews," NUREG-0700, September.

USNRC, 1985, "Human Engineering Guidelines for the Evaluation and Assessment of Video Display Units," NUREG/CR-4227, July.

UCRL (University of California Research Laboratory), 1985, "Human Factors Design Guidelines for Maintainability of Energy Nuclear Facilities," UCRL 15673, June.

\subsubsection{Hazard Category 3}

\section{Guidelines}


For Hazard Category 3, as indicated in the right column of Figure 6-7 at the end of this section, use a subject matter expert judgment approach appropriate for the internal facility (local work area) functions or tasks being analyzed. This allows for less formal acquisition of data. The HCF analysis should be limited to training, procedures, oversight, staffing, qualifications, and HFE. These data will not normally be used to compute a quantitative result. A judgmental approach is appropriate for a Hazard Category 3 facility since the SAR allows for a qualitative analysis of human error likelihood to support the SAR Topic 11 accident analysis, or if an accident analysis is not done, to support the Topic $\underline{5}$ hazards analysis. Weighting of HCFs, for the purpose of human error likelihood computation, is not normally done unless the consensus judgment method being used requires it. For example, the Sequence Likelihood Index Method (SLIM) referred to below requires that weightings be given to each HCF.

\section{Hazard Category 3 Suggested References}

Function/task analysis results derived from the human system analysis.

Gertman, D. I., and Blackman, H. S. (1994) Human Performance Assessment and Safety Analysis Data Handbook, John Wiley \& Sons, Inc., New York.

NUREG/CR-4016, "Application of SLIM-MAUD: A Test of an Interactive Computer Based Method for Organizing Expert Assessment of Human Performance and Reliability." U.S. Nuclear Regulatory Commission, Washington, DC: 1986.

NUREG/CR-3518, "SLIM-MAUD: An Approach for Assessing Human Error Probabilities Using Structured Expert Judgment." U.S. Nuclear Regulatory Commission, Washington, DC: 1984.

NUREG/CR-3688, "Generating Human Performance Assessment Estimates Using Expert Judgment," U.S. Nuclear Regulatory Commission, Washington, DC: 1984. 
NUREG/CR-2743, "Procedures for Using Expert Judgment to Estimate Human Error Probabilities in Nuclear Power Plant Operations," U.S. Nuclear Regulatory Commission, Washington, DC: 1984.

\subsubsection{Application of HCF Analysis Results in the SAR}

Figure 6-8 at the end of this section provides a summary of the analysis and the application of its result in the SAR. The second step of the HF safety analysis process, HCF Analysis, represented by the middle box of Figure 6-8, is directed toward identifying and scoring the effects of person-centered, task-centered, and environment-centered factors on human safety performance. The results of this step provide:

- HCF evaluation scores for use in the remaining Human Performance Assessment step.

- Causal factors information that will systematically impact Human Performance Assessment results.

\subsubsection{HCF Analysis Product}

The product of the HCF analysis is an inventory of HCF scoring protocols. Figure 6-9 at the end of this section presents the results of the HCF availability analysis for the Category 2 facility function/task presented in earlier illustrations. Figure 6-9 is described as follows:

- $\quad$ Training is scored on whether formal training is provided by the facility on a human action sequence (e.g., driving a forklift). Formal training is demonstrated by existence of a written training plan or syllabus. A YES in the Training column of 
Figure 6-9 indicates that credit is given, NO indicates that credit is not given.

- Procedures is scored on whether a written procedure is used onthe-job to perform the human action sequence. YES in the Procedures column of Figure 6-9 indicates that credit is given, NO indicates that credit is not given.

- Direct Oversight is scored on the basis of whether a second person (e.g., supervisor) guides, checks, or directly observes the primary person performing the human action sequence. YES in the Oversight column of Figure 6-9 indicates that credit is given (work is directly observed/checked). NO indicates that credit is not given (work is not directly observed, however, a detailed operating procedure (DOP) sign-off may be verified).

- $\quad$ HFE was scored using the results of the HFE analysis. YES in the HFE column of Figure 6-9 indicates that credit is given (human-machine interfaces analyzed for the SAR Topic 14 are in full compliance with all critical requirements). NO in the HFE column indicates that credit is not given since major humanmachine interfaces are not in full compliance with all critical requirements).

Figure 6-10 through Figure 6-12 at the end of this section provide excerpts from HFE checklists usable for Category 1, 2, and 3 facilities. Figure 6-10, Communications, responds to DOE Order 5480.23, Attachment 1, Section 14a requirements concerning internal and external communications and operational aids. This particular HFE checklist excerpt relies primarily on NUREG-0700 for its criteria. Figure 6-11, Controls for User-Computer, responds to DOE Order 5480.23, 
Attachment 1, Section 14b requirements concerning instrumentation and controls. This particular HFE checklist excerpt relies primarily on the DOE Draft Standard 1026-93 for its criteria. Figure 6-1.2, Environment, responds to DOE Order 5480.23, Attachment 1, Section $\underline{14 c}$ requirements concerning workplace environmental factors.

- EXP indicates whether credit is given for experience on the job. YES in the EXP column of Figure 6-9 indicates that actual experience level is equal to the required experience level. NO in the EXP column indicates that actual experience is less than the required experience.

- The numbers circled at the bottom of Figure 6-9 represent the importance weighting given to each HCF on a scale of 1 (minimal importance) through 5 (maximum importance).

NOTE: (1) For a Category 2 facility weightings are not usually done. However, this facility requested that weightings be done.

(2) It was determined from the human system analysis that all HCFs specified by DOE were appropriate for this task (See discussion in Chapter 5, Section 5.4.2.4).

Figure 6-6 Matrix of Facility Classifications and HCF Selection Graded Approach

\begin{tabular}{|c|c|c|c|}
\hline & \multicolumn{3}{|c|}{ Facility Hazard Category Classifications } \\
\hline Human Safety Analysis Steps & Category 1 & Category 2 & Category 3 \\
\hline Weighted & $\mathbf{X}$ & & \\
\hline Others as appropriate & $\mathrm{X}$ & Analyzed only if crucial to human performance & \\
\hline DOE specified & $\mathrm{X}$ & $\mathrm{X}$ & $\mathrm{X}$ \\
\hline
\end{tabular}


Figure 6-7 Matrix of Facility Classifications and PSF Evaluation Graded Approach

\begin{tabular}{|c|c|c|c|}
\hline \multirow[b]{2}{*}{ Human Safety Analysis Steps } & \multicolumn{3}{|c|}{ Facility Hazard Category Classifications } \\
\hline & Category 1 & Category 2 & Category 3 \\
\hline Content Analysis & $\mathrm{X}$ & & \\
\hline Direct Comparison & $\mathrm{X}$ & $\mathrm{X}$ & \\
\hline Verification of Availability & $\bar{X}$ & $\mathrm{X}$ & \\
\hline Consensus Judgment & $\bar{X}$ & $\mathrm{X}$ & $\mathbf{X}$ \\
\hline
\end{tabular}


Figure 6-8 Matrix of DOE Facility Classifications and HCF Evaluation Graded Approach

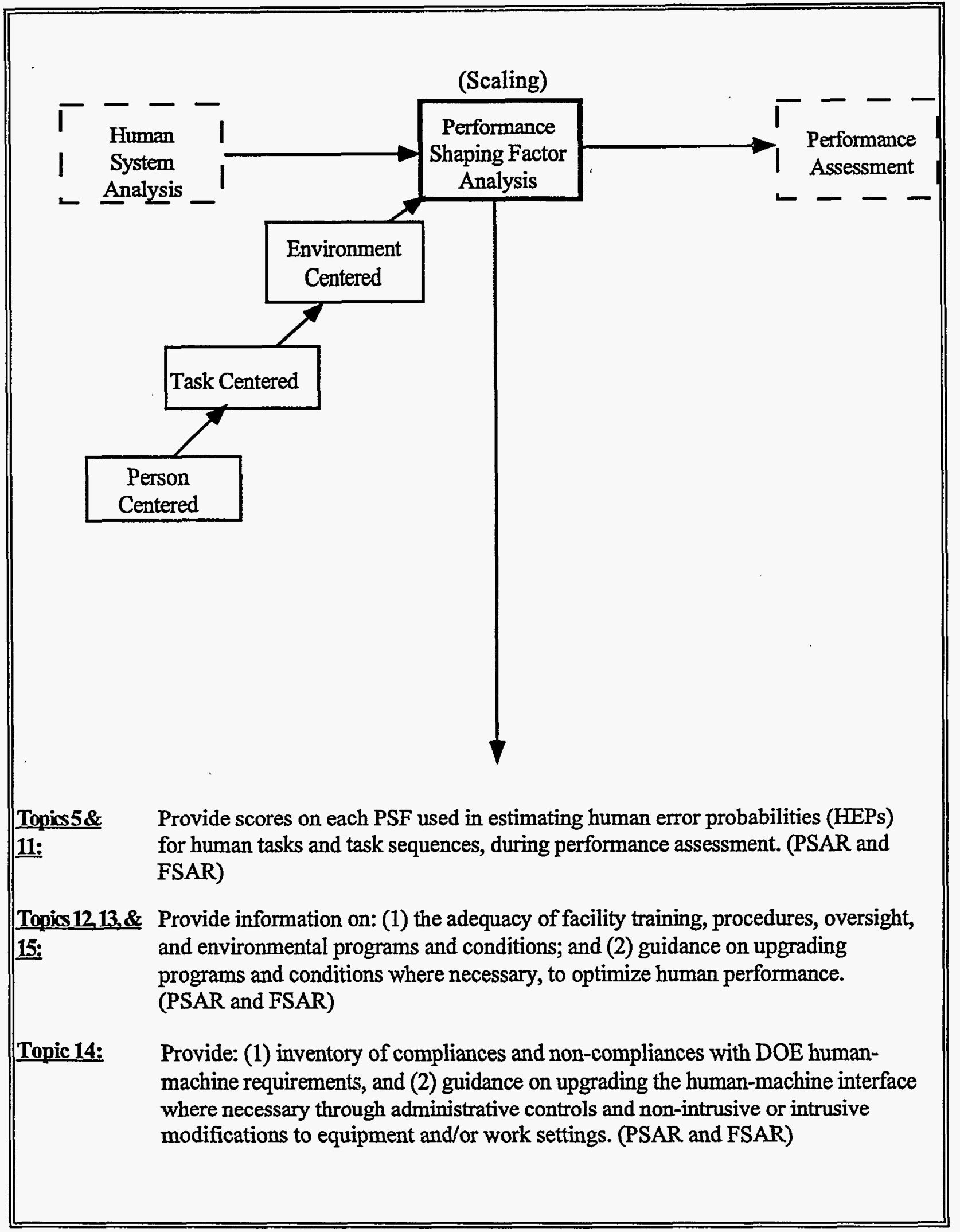


Figure 6-9 Human Causal Factor Analysis Graded Approach

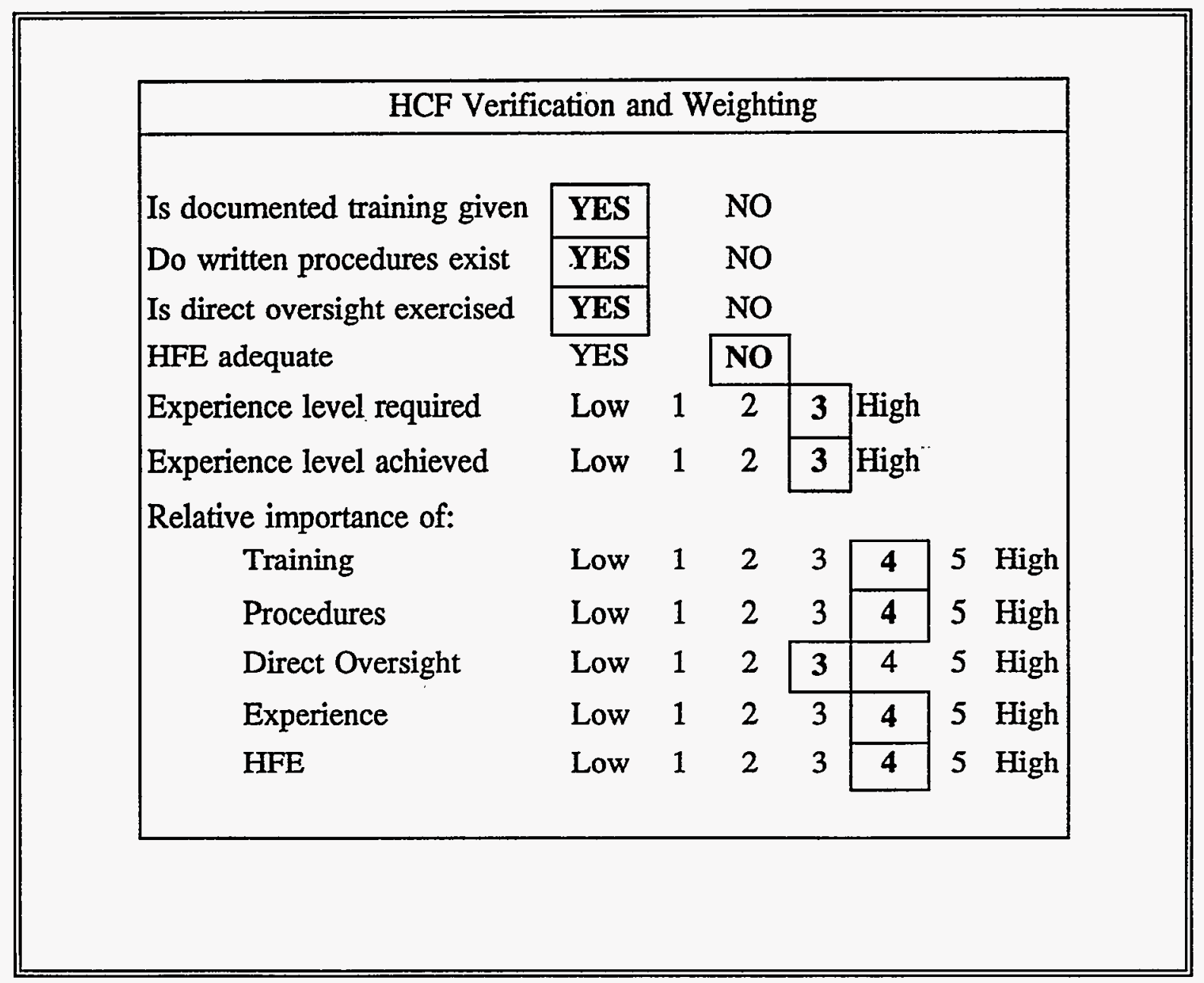


Figure 6-10 HFE Communications Checklist

System, Version, Description:

Revièwer:

Date:

\begin{tabular}{|c|c|c|c|c|}
\hline No. & CRITERIA/TTEM & $\mathbf{M} / \mathbf{R}$ & Y/N/NA & Comments \\
\hline 1. & $\begin{array}{l}\text { Does the powered telephone system provide good } \\
\text { frequency response in that it is intelligible to that } \\
\text { portion of the auditory spectrum which allows } \\
\text { individuals to hear clearly? (NUREG } 07006.2 .1 .2 \mathrm{a} \text { ) }\end{array}$ & $\mathbf{M}$ & & \\
\hline 2. & $\begin{array}{l}\text { Is the size and shape of the handset compatible with } \\
\text { the operator's hand size and mouth-ear distance? } \\
\text { (NUREG } 07006.2 .1 .2 \mathrm{bl} \text { ) }\end{array}$ & $\mathbf{M}$ & & \\
\hline 3. & $\begin{array}{l}\text { Is the operator able to maintain firm ear contact by the } \\
\text { receiver while the transmitter is positioned to receive } \\
\text { voice waves directly from the operator's mouth? } \\
\text { (NUREG } 07006.2 .1 .2 \mathrm{~b} 2 \text { ) }\end{array}$ & $\mathbf{M}$ & & \\
\hline 4. & $\begin{array}{l}\text { Are cords made of the non-kink or self-retracting type? } \\
\text { (NUREG } 07006.2 .1 .2 \mathrm{~b} 3 \text { ) }\end{array}$ & $\mathbf{M}$ & & \\
\hline 5. & $\begin{array}{l}\text { Are the cords of sufficient length to permit reasonable } \\
\text { operator mobility? (NUREG } 07006.2 .1 .2 \mathrm{~b} 4 \text { ) }\end{array}$ & $\mathbf{M}$ & & \\
\hline 6. & $\begin{array}{l}\text { Are cords positioned so as to avoid entangling critical } \\
\text { controls or endangering passing traffic? (NUREG } 0700 \\
6.2 .1 .2 \mathrm{~b} \text { ) }\end{array}$ & $\mathbf{M}$ & & \\
\hline 7. & $\begin{array}{l}\text { Are vertically mounted handset cradles designed and } \\
\text { located to prevent the handset from being knocked out } \\
\text { of the cradle by passing traffic? (NUREG } 0700 \\
6.2 .1 .2 \mathrm{~b} \text { ) }\end{array}$ & $\mathbf{M}$ & & \\
\hline 8. & $\begin{array}{l}\text { Where multiple telephone instruments are located close } \\
\text { together (e.g., on a single desk) are they coded to } \\
\text { indicate circuit or function? (NUREG } 07006.2 .1 .2 \mathrm{~b} \text { ) }\end{array}$ & $\mathbf{M}$ & & \\
\hline 9. & $\begin{array}{l}\text { Is the switching mechanism designed and/or } \\
\text { programmed to minimize delay in making desired } \\
\text { connections under both normal and emergency } \\
\text { conditions? (NUREG } 07006.2 .1 .2 \mathrm{cl} \text { ) }\end{array}$ & $\mathbf{M}$ & & \\
\hline 10. & $\begin{array}{l}\text { Is switching programmed to give the control room } \\
\text { automatic priority of access to the switching system? } \\
\text { (NUREG } 07006.2 .1 .2 \mathrm{c} 2 \text { ) }\end{array}$ & $\mathbf{M}$ & & \\
\hline 11. & $\begin{array}{l}\text { Is the loudness of telephone ringing adjustable at the } \\
\text { individual telephone station? (NUREG } 07006.2 .1 .2 \mathrm{~d} \text { ) }\end{array}$ & $\mathbf{M}$ & & \\
\hline
\end{tabular}

$M / R=$ Mandatory $/$ ecommended $\quad Y=Y e s \quad N=$ No $\quad N A=$ No Applicable 
Figure 6-11 HFE Instrumentation/Control Checklist

\begin{tabular}{|c|c|c|c|c|}
\hline \multicolumn{5}{|c|}{ System, Version, Description: } \\
\hline \multicolumn{5}{|c|}{ Reviewer: } \\
\hline No. & CRITERIA/TEM & MR & Y/N/NA & Comments \\
\hline 1. & $\begin{array}{l}\text { Does control selection conform to Table } 7 \\
\text { DOE STD-1062-93? (Selection of Common } \\
\text { Controls: } 5.1 .1 .1 \text { ) }\end{array}$ & $\mathbf{R}$ & - & \\
\hline 2. & $\begin{array}{l}\text { Are controls selected and distributed so that } \\
\text { none of the operator's limbs will be } \\
\text { overburdened? (Distribution of Work Load: } \\
\text { 5.1.1.2) }\end{array}$ & M & & \\
\hline 3. & $\begin{array}{l}\text { Are stops provided at the beginning and end } \\
\text { of the range of control positions if the control } \\
\text { is not required to be operated beyond the } \\
\text { indicated end positions or specified limits? } \\
\text { (Stops: } 5.1 .1 .3 \text { ) }\end{array}$ & M & & \\
\hline 4. & $\begin{array}{l}\text { Is the direction of control movement } \\
\text { consistent with the related movement of an } \\
\text { associated display, equipment component, or } \\
\text { vehicle? (Consistency of Movement: } \\
\text { 5.1.2.1) }\end{array}$ & M & & \\
\hline 5. & $\begin{array}{l}\text { Do rotary and hand wheel valve controls } \\
\text { open the valve with a counterclockwise } \\
\text { motion and is labeling provided with double- } \\
\text { ended arrows showing direction and } \\
\text { function? (Rotary and Hand Wheel Valve } \\
\text { Controls: 5.1.2.2) }\end{array}$ & $M$ & & \\
\hline 6. & $\begin{array}{l}\text { Are all controls that function in sequential } \\
\text { operation necessary to a particular task or } \\
\text { that operate together grouped together along } \\
\text { with their associated displays? (Grouping: } \\
\text { 5.1.3.1) }\end{array}$ & $M$ & & \\
\hline 7. & $\begin{array}{l}\text { When several steps of a sequence are } \\
\text { selected by one control are the steps } \\
\text { arranged by order of occurrence and is } \\
\text { cycling through the control's ON/OFF position } \\
\text { avoided? (Grouping: } 5.1 .3 .1 \text { ) }\end{array}$ & M & & \\
\hline 8. & $\begin{array}{l}\text { Where sequential operations follow a fixed } \\
\text { pattern are controls arranged to facilitate } \\
\text { operation? (Sequential Operation: } 5.1 .3 .2 \text { ) }\end{array}$ & M & & \\
\hline
\end{tabular}


Figure 6-12 HFE Environment Checklist

System, Version, Description:

Reviewer:

Date:

\begin{tabular}{|c|c|c|c|c|}
\hline No. & CRITERIA/TTEM & $\mathbf{M} / \mathbf{R}$ & $\mathbf{Y} / \mathbf{N} / \mathbf{N A}$ & Comments \\
\hline 1. & $\begin{array}{l}\text { When mobile personnel enclosures are used for } \\
\text { detail work or occupied for extended periods } \\
\text { of time is heating and air conditioning } \\
\text { provided to maintain interior dry bulb } \\
\text { temperature above } 100 \mathrm{C} \text { and below } 280 \mathrm{C} \text { ? } \\
\text { (Heating/Air Conditioning: } 8.1 .1 \text { ) }\end{array}$ & $\mathbf{M}$ & & \\
\hline 2. & $\begin{array}{l}\text { Within permanent and semi-permanent } \\
\text { facilities is provision made to maintain } \\
\text { temperature within the acceptable range of } \\
\text { operative temperatures and humidity as defined } \\
\text { in figure } 45 \text { DOE STD-1062-93? (Heating/Air } \\
\text { Conditioning: } 8.1 .1 \text { ) }\end{array}$ & $\mathbf{M}$ & & \\
\hline 3. & $\begin{array}{l}\text { Are heating and air conditioning systems } \\
\text { designed such that air is not directly } \\
\text { discharged on personnel? (Heating/Air } \\
\text { Conditioning: 8.1.1) }\end{array}$ & $\mathbf{R}$ & & \\
\hline 4. & $\begin{array}{l}\text { Is the temperature difference between floor and } \\
\text { head level less than } 5.50 \mathrm{C} \text { ? (Temperature } \\
\text { Uniformity: 8.1.1.1 \& 8.1.5) }\end{array}$ & $\mathbf{R}$ & & \\
\hline 5. & $\begin{array}{l}\text { Is adequate ventilation assured by introducing } \\
\text { fresh air into any personnel enclosure? } \\
\text { (ventilation: 8.1.2) }\end{array}$ & $\mathbf{M}$ & & \\
\hline 6. & $\begin{array}{l}\text { If the enclosure volume is } \leq \text { to } 4.25 \mathrm{~m}^{3} \text { per } \\
\text { person is a minimum of } 0.85 \mathrm{~m}^{3} \text { per minute of } \\
\text { air ventilation introduced into the enclosure? } \\
\text { (ventilation: } 8.1 .2 \text { ) }\end{array}$ & $M$ & & \\
\hline 7. & $\begin{array}{l}\text { Is the velocity of ventilation air moving past } \\
\text { personnel less than } 60 \mathrm{~m} \text { per minute and where } \\
\text { manuals or loose papers are used is airspeed } \\
\text { less than } 30 \mathrm{~m} \text { per minute? (ventilation: } 8.1 .2 \text { ) }\end{array}$ & $\mathbf{M}$ & & \\
\hline 8. & $\begin{array}{l}\text { Is ventilation or other protective measures } \\
\text { provided to keep gases, vapors, dust, and } \\
\text { fumes within the permissible exposure limits } \\
\text { specified by } 29 \text { CFR1910? (ventilation: } 8.1 .2 \text { ) }\end{array}$ & $\mathbf{M}$ & & \\
\hline
\end{tabular}




\subsection{Graded Approach for the Human Performance Assessment}

\subsubsection{Introduction}

The Human Performance Assessment graded approach assumes that some form of probabilistic result, derived either quantitatively or qualitatively, is required to support the SAR Topic $\underline{11}$ accident analysis and/or Topic $\underline{5}$ hazards analysis and, in turn, SAR Topics $\underline{12}$ through $\underline{15}$ whose format and content can be impacted by the degree to which their subject matter impacts nuclear safety.

This section of the chapter is organized in the following manner: Section 6.8.2 provides guidelines and references for acquiring nominal or base human error probabilities (HEPs) for probabilistic analyses; Section 6.8.3 provides guidelines and references for these probabilistic analyses; Section 6.8.4 describes the uses of Human Performance Assessment results in the SAR; and Section 6.8.5 provides guidelines and references for an operational experience analysis using information maintained by the facility and in the DOE Occurrence Reporting and Processing System (ORPS).

Figure 6-13 through Figure 6-22 relating to Sections 6.8.2 through 6.8.4 are presented at the end of Section 6.8.4. Figure 6-23 and Figure 6-24 relating to Section 6.8.5 are presented at the end of Section 6.8.5.

NOTE: $\quad$ Throughout this Course Text the phrase "Human Performance Assessment" is used to refer to indexing of data collected during the human system and HCF analyses steps of the human safety analysis. This includes a wide variety of indexing ranging from probabilistic to descriptive. The term "Human Performance Assessment" (HPA) is used in a more narrow sense, that is, to refer only to probabilistic analysis. 
NOTE: $\quad$ Section 6.9, which sums up Chapter 6 of this Course Text, is located after Figure 6-24.

\subsubsection{Bounding and Anchor Data Acquisition Step}

This section is for probabilistic assessments only. The human error probability estimating techniques, whether resulting in a numeric estimate (e.g., 3E-04) or a qualitative estimate (e.g., unlikely), require input anchor or bounding information on error likelihood.

6.8.2.1 Introduction Develop a data store employing, to the extent possible, facility information. Select from the data store human error likelihood estimates (bounding or anchor values) for each human action and action sequence.

- $\quad$ Bounding values represent what are believed to be the lowest and highest human error probabilities possible on the task for which a point probability is being computed. Some probabilistic assessment techniques interpolate between bounding values to achieve a point estimate.

- An anchor value is a single human error probability believed to represent a generic mean or median error probability for the task being analyzed. Some probabilistic assessment techniques compute a deviation score from the anchor value as the point human error probability. In summary, the probabilistic assessment technique being employed to compute point human error probabilities will determine whether bounding values or anchor points should be used. 
Data for this purpose can be obtained from any of three sources in descending order of rigor.

- First, by constructing (to the extent possible) a facility data base. This data base may be compiled from operational experience, training simulator runs, or direct observation. Such a data base minimizes uncertainty.

- Second, data from non-facility sources including other similar facilities, other type facilities which perform similar functions and tasks, general data bases such as DOE's ORPS or the Nuclear Computerized Library for Assessing Reactor Reliability (NUCLARR) listed in Section 6.8.2.2.

- Third, data from subject matter experts providing upper and lower bounds, and gradations in between these bounds on the functions and tasks of interest.

We suggest the following approach in light of the three-tiered grading scheme above.

\subsubsection{2}

\section{Hazard Category 1}

\section{Guidelines}

For Hazard Category 1, as indicated in the top half of Figure 6-13, use a facility data base (to the extent possible) appropriate for site-wide, facility-wide, and local work area functions and tasks being analyzed. It is recognized that there are limits on the kinds and amounts of data that might be available from individual DOE 
nuclear facilities. However, all quantitative results of the Human Performance Assessment should reflect, to the extent possible, the subject facility. Where necessary facility data will be supplemented by data gathered for a Hazard Category 2 analysis.

\section{Hazard Category 1 Suggested References}

NUREG/CR-1278, "Handbook of Human Performance Assessment with Emphasis on Nuclear Power Plant Operations." U.S. Nuclear Regulatory Commission, Washington, DC: 1983.

NUREG/CR-4772, "Accident Sequence Evaluation Program Human Performance Assessment Procedure," U.S. Nuclear Regulatory Commission, Washington, DC: 1987.

NUREG/CR-4639, "Nuclear Computerized Library for Assessing Reactor Reliability (NUCLARR)," (5 vols.), U.S. Nuclear Regulatory Commission, Washington, DC: 1988 through 1992.

Savannah River Site WSRC-TR-93-581, "Savannah River Site Human Error Data Base Development for Nonreactor Nuclear Facilities," 1994.

Fleishman, E.A., Buffardi, L.C., Morath, R.A., McCarthy, P.M., and Friedman, L., 1994, "Development of a Model to Predict Human Error Rates from the Ability Requirements of Job Tasks," George Mason University, CBCS-93-2, February.

\subsubsection{Hazard Category 2}

\section{Guidelines}

For Hazard Category 2, as indicated in the top half of Figure 6-13, use facility data if available, but use as a minimum non-facility data sources appropriate for the 
facility-wide and local work area functions or tasks being analyzed. This will necessitate establishing reasonable criteria for including/excluding data from other similar facilities.

\section{Hazard Category 2 Suggested References}

Same as for Hazard Category 1 except that: As a minimum, the data store should be supplemented to the extent possible with data developed for similar facilities. This does not preclude the use of facility-specific data, if such data is readily available.

\subsubsection{Hazard Category 3}

\section{Guidelines}

For Hazard Category 3, as indicated in the top half of Figure 6-13, use subject matter expert judgments appropriate for internal facility (local work area) functions or tasks being analyzed.

\section{Hazard Category 3 Suggested References}

Same as for Hazard Category 1 except that data stores such as the ones listed in the suggested references can be used directly in the analysis without supplementing with facility specific and/or similar facility data. This does not preclude the use of facility specific and/or similar facility data if it is readily available.

\subsubsection{Results Indexing (Scoring) Step}

Compute quantitative (probabilistic, non-probabilistic) results and/or judgmentally derived qualitative results for each human action, action sequence, or 
combinations of human actions and action sequences, analyzed during earlier steps of the human safety analysis. Where appropriate, analyze uncertainty and sensitivity factors to further assess the impact of these human actions and action sequences on facility safety.

As in the case of the other practices considered for Human Performance Assessment, there are a variety of ways in which the qualitative and quantitative data derived from the Human Performance Assessment might be indexed to meet SAR requirements. Refer to the bottom half of Figure 6-13 at the end of this section.

A three-tier approach is considered appropriate commensurate with a hazard category facility grading approach.

- First, probabilistic indexing capable of supporting reliability and risk assessments using either or both computational and judgmental techniques.

- Second, non-probabilistic indexing (percentages, deviation scores, measures of central tendency, inferential statistics, tallies) capable of supporting alternative assessments using either or both computational and judgmental techniques.

- Third, qualitative or diagnostic indexing capable of gaining insights into the strengths and weaknesses of the facility, and of suggesting remedial actions using judgmental techniques.

For purposes of completing these analyses commensurate with the three-tier hazard category facility grading scheme presented above, the following approaches are suggested. 


\section{Guidelines}

For Hazard Category 1, as indicated in the bottom half of Figure 6-13, do full scope quantitative probabilistic indexing. Include coarse and fine screening, uncertainty bounding, and recovery and sensitivity analyses (Base and Best case). Also include quantitative non-probabilistic indexing using quantitative techniques appropriate for site-wide, or beyond, and facility-wide, and local work area functions, tasks, and subtasks being analyzed.

Probabilistic results include human error likelihood estimates as initiators and mitigators of accident scenarios. For probabilistic assessments to support the hazards and accident analysis, two techniques are suggested. For screening analysis and providing anchor and bounding values for detailed probabilistic assessments, use the Accident Sequence Evaluation Program (ASEP) Human Performance Assessment Procedure, published by the U. S. Nuclear Regulatory Commission as NUREG/CR4772, in February 1987 (NRC 1987). Excerpts from NUREG/CR-4772 pertaining to input HEP selection are presented in Appendix A of this Course Text. Worksheets for applying the ASEP procedure are presented in Figure 6-14 and Figure 6-15.

Figure 6-14 is used to answer several questions about the task action or action sequence for which a HEP value is sought. Figure 6-15 allows the user to go into the data store by tracing YES/NO answers to questions posed in Figure 6-14. All four quadrants of the data store are used if the HEP value is used for screening or as a final input to the SAR Topics $\underline{5}$ and $\underline{11}$ hazards and accident analysis. If the data store is being used to provide anchor or bounding values for a more detailed THERP tree analysis as described below, only the top left quadrant of the ASEP data store is used. This is because the top left quadrant is the only segment of the store whose HEP estimates do not reflect the adverse effects of the HCFs. 
For detailed probabilistic tree analyses to support the SAR Topics $\underline{5}$ and $\underline{11}$ hazards and accident analysis, use the Technique for Human Error Rate Prediction (THERP) probabilistic tree analysis procedure described in the Handbook of Human Performance Assessment with Emphasis on Nuclear Power Plant Applications, published by the U. S. Nuclear Regulatory Commission as NUREG/CR-1278, in August 1983. Excerpts from NUREG/CR-1278 pertaining to probabilistic tree analysis are presented in Appendix B of this Course Text. Figure 6-16 is an explanation of the contents of the TMI Assembly Sizing sequence. Figure 6-7 through Figure 6-20 present the THERP probabilistic tree and calculation sheets for the TMI Assembly Sizing sequence. Figure 6-17 and Figure 6-18 present the base case and best case probabilistic trees; Figure 6-19 and Figure 6-20 present the base case and best case calculation sheets. Appendix $\mathrm{C}$ to this Course Text provides explanations for each of the column entries in Figure 6-17 and Figure 6-18.

\section{Hazard Category 1 Suggested References}

Function/task analysis results derived from the human system analysis.

HCF analysis results derived through content assessment, verification of availability, or expert judgment.

NUREG/CR-1278, "Handbook of Human Performance Assessment with Emphasis on Nuclear Power Plant Operations." U.S. Nuclear Regulatory Commission, Washington, DC: 1983.

NUREG/CR-2254, "A Procedure for Conducting a Human Performance Assessment of Nuclear Power Plants." U.S. Nuclear Regulatory Commission, Washington, DC: 1983.

NUREG/CR-4772, "Accident Sequence Evaluation Program Human Performance Assessment Procedure." U.S. Nuclear Regulatory Commission, Washington, DC: 1987. 
NUREG/CR-4016, "Application of SLIM-MAUD: A Test of an Interactive Computer Based Method for Organizing Expert Assessment of Human Performance and Reliability." U.S. Nuclear Regulatory Commission, Washington, DC: 1986.

NUS-3541, "Human Cognitive Reliability (HCR) Model for PRA Analysis." NUS Corporation, San Diego, CA: 1984.

NUREG/CR-5438, "Basic Considerations in Predicting Error Probabilities in Human Task Performance." U.S. Nuclear Regulatory Commission, Washington, DC: 1990.

ORNL, ES/CẺT-16, "Safety Analysis Report Update Program: Human Reliability Analysis Application Guide", Martin Marietta Energy Systems, Inc., May 1993.

\subsubsection{Hazard Category 2}

\section{Guidelines}

For Hazard Category 2, as indicated in the bottom half of Figure 6-13, do quantitative probabilistic indexing. Include coarse and fine screening, uncertainty bounding, and recovery and sensitivity analyses (Base and Best case). Also include non-probabilistic indexing, using quantitative techniques appropriate for facility-wide, or beyond, and local work area functions, tasks, and subtasks being analyzed. Probabilistic results include human error likelihood estimates as initiators and mitigators of hazard and accident scenarios.

\section{Hazard Category 2 Suggested References}

Function/task analysis results derived from the human system analysis. HCF analysis results derived through content assessment for HFE and verification of availability for other HCFs included in the analysis. The other suggested references are the same as for Hazard Category 1. 


\subsubsection{Hazard Category 3}

\section{Guidelines}

For Hazard Category 3, as indicated in the bottom half of Figure 6-13, do probabilistic indexing, and qualitative indexing using qualitative techniques appropriate for internal facility (local work area or beyond) functions, tasks, and subtasks being analyzed. Results of this analysis are used to support Topic 11 , accident analysis, or Topic $\underline{5}$, hazard analysis, if Topic $\underline{11}$ is not pursued for the SAR. Probabilistic results include human error likelihood estimates as initiators and mitigators of accident sequences, however, they are usually categorized as anticipated, likely, unlikely, highly unlikely, or incredible, rather than as numerics (e.g., 3E-03).

\section{Hazard Category 3 Suggested References}

Function/task analysis results derived from the human system analysis.

HCF analysis results derived through content assessment for HFE and expert judgment for the other HCFs included in the analysis.

NUREG/CR-4016, "Application of SLIM-MAUD: A Test of an Interactive Computer Based Method for Organizing Expert Assessment of Human Performance and Reliability." U.S. Nuclear Regulatory Commission, Washington, DC: 1986.

NUREG/CR-3518, "SLIM-MAUD: An Approach for Assessing Human Error Probabilities Using Structured Expert Judgment." U.S. Nuclear Regulatory Commission, Washington, DC: 1984.

NUREG/CR-3688, "Generating Human Performance Assessment Errors Using Expert Judgment." (2 vols.), U.S. Nuclear Regulatory Commission, Washington, DC: 1984. 
NUREG/CR-2743, "Procedures for Using Expert Judgment to Estimate Human Error Probabilities in Nuclear Power Plant Operations." U.S. Nuclear Regulatory Commission, Washington, DC: 1983.

ORNL, ES/CET-16, "Safety Analysis Report Update Program: Human Reliability Analysis Application Guide", Martin Marietta Energy Systems, Inc., May 1993.

\subsubsection{Application of Human Performance Assessment in the SAR}

Figure 6-21 provides a summary of the analysis and the application of its result in the SAR. The final step of the HF safety analysis process, Human Performance Assessment, involves quantitative and/or qualitative indexing (scoring) of human performance and the contribution made by HCFs, such that the results can be used as a technical basis for preparing HF related sections of the SAR. The results of this step provide:

- probabilistic and/or non-probabilistic estimates for the overall impact of human performance on public, onsite, and/or work area safety, and

- information on the scope and contents of SAR Topics $\underline{12}$ through $\underline{15}$ required.

\subsubsection{Human Performance Assessment Results}

Figure 6-22 presents a table of Human Performance Assessment results that would be provided to the hazards and accident analysis team. Figure 6-22 lists depicts the sample Category 2 facility and provides from left to right:

- function/task designator and description,

- YES/NO rating on each HCF included in the analysis, 
- weighting given to each HCF on a five-point scale. The sample facility requested that weightings be done even though it is a Category 2

facility, and

- $\quad$ base and best case HEP estimates.

Figure 6-13 Matrix of DOE Facility Classifications and Human Performance Assessment Graded Approach

\begin{tabular}{|c|c|c|c|}
\hline \multirow[b]{2}{*}{ Human Safety Analysis Steps } & \multicolumn{3}{|c|}{ Facility Hazard Category Classifications } \\
\hline & Category 1 & Category 2 & Category 3 \\
\hline $\begin{array}{l}\text { Bounding Data } \\
\text { Facility Specific } \\
\text { Similar Facilities } \\
\text { Consensus Judgment }\end{array}$ & $\begin{array}{l}X \\
X \\
X\end{array}$ & $\begin{array}{l}X \\
X\end{array}$ & $\mathrm{X}$ \\
\hline $\begin{array}{l}\text { Indexing } \\
\text { Probabilistic Quantitative } \\
\text { Probabilistic Qualitative } \\
\text { Non-Probabilistic Quantitative } \\
\text { Non-Probabilistic Qualitative }\end{array}$ & $\begin{array}{l}\mathrm{x} \\
\mathrm{x}\end{array}$ & $\begin{array}{l}\mathrm{X}^{*} \\
\mathrm{X}^{*}\end{array}$ & $\begin{array}{l}\mathrm{x} \\
\mathrm{x}\end{array}$ \\
\hline $\begin{array}{l}\text { Hazard Category } 1 \text { and } 2 \text { facility re } \\
\text { preceding Human System Analysis } \\
\text { Category } 2 .\end{array}$ & $\begin{array}{l}\text { differ as a fu } \\
\text { ICF Analysis }\end{array}$ & e lesser scop & $\begin{array}{l}\text { lent of the } \\
\text { sis for Hazard }\end{array}$ \\
\hline
\end{tabular}




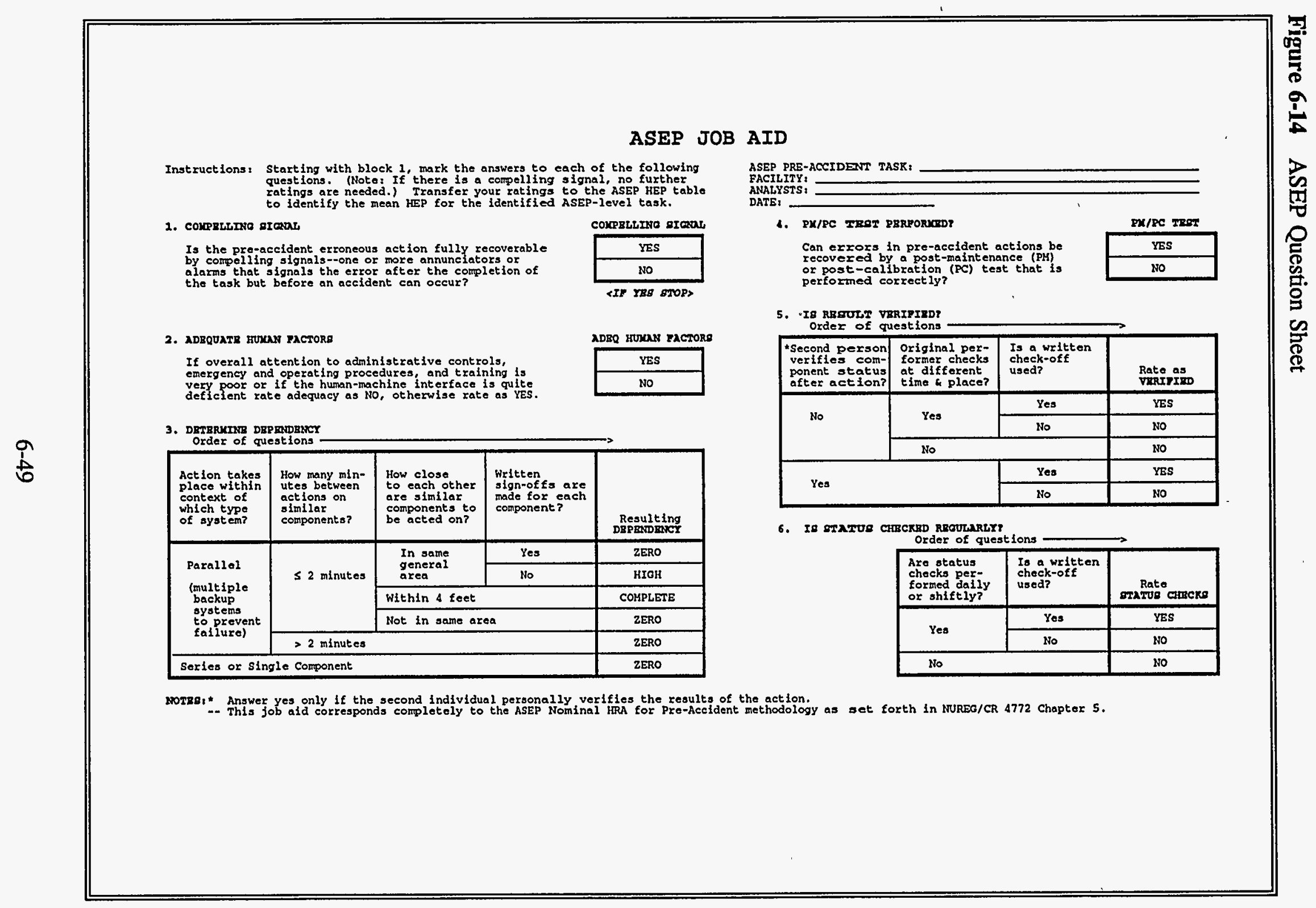




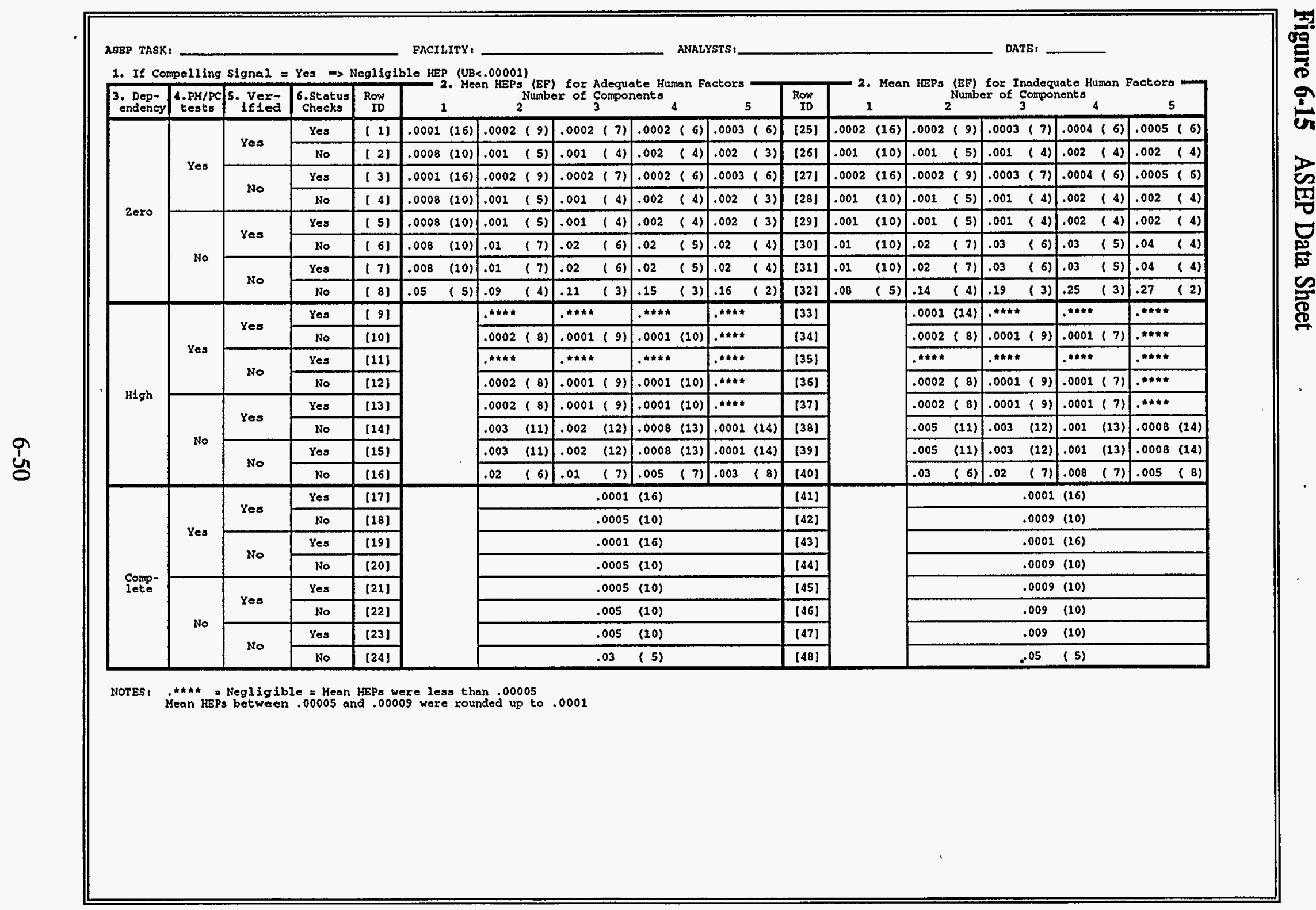


Figure 6-16 Human Performance Assessment Using THERP

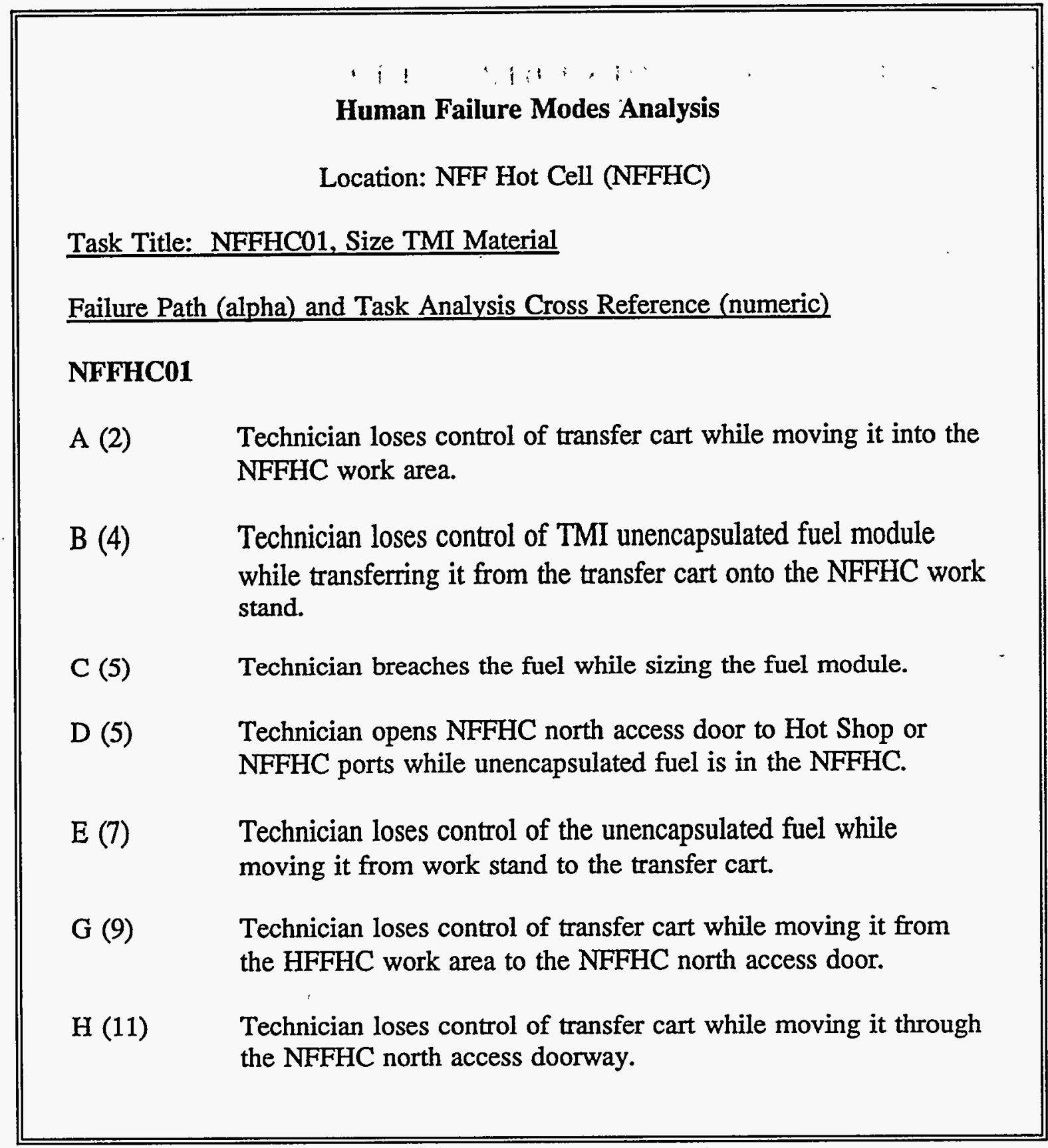




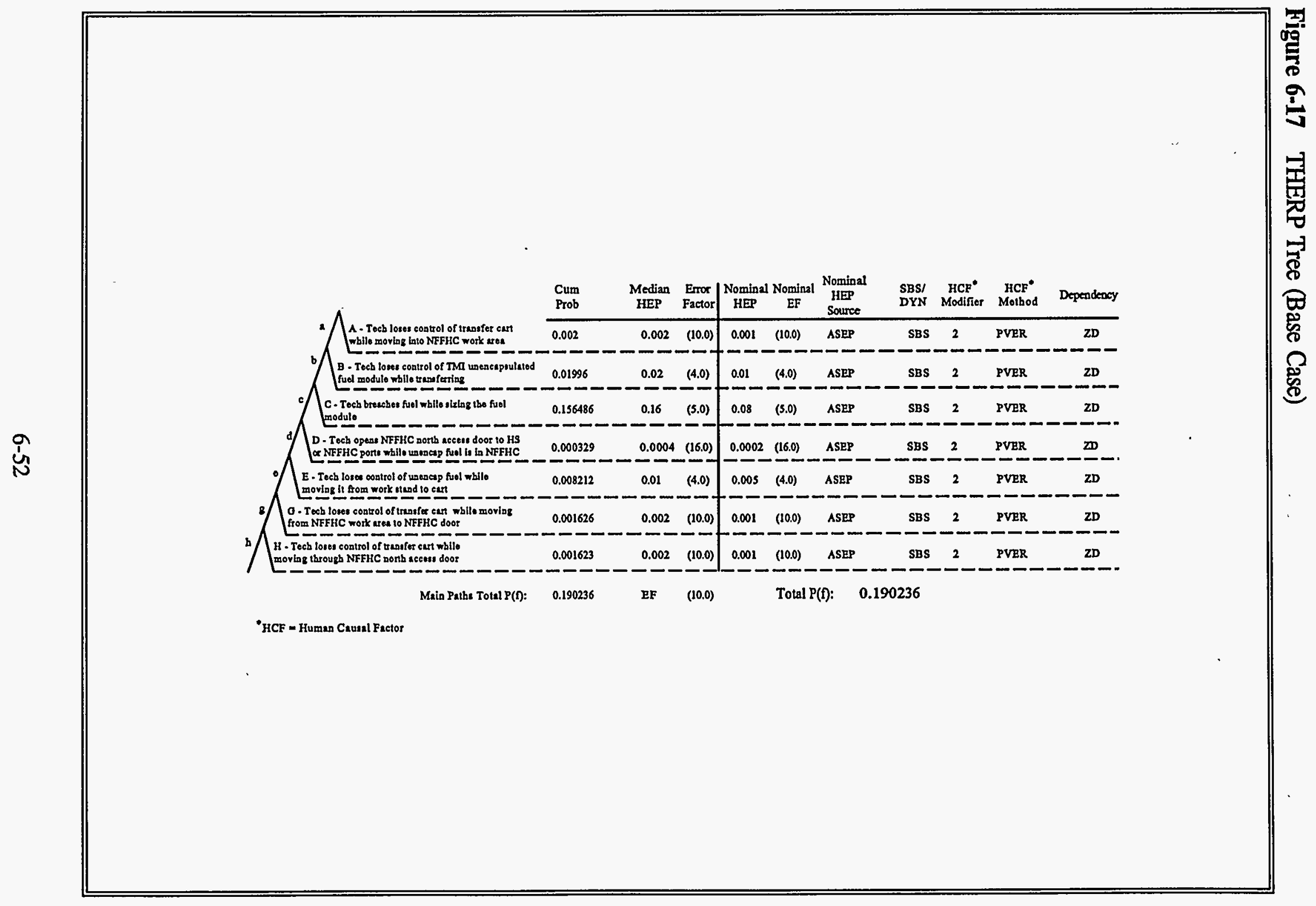




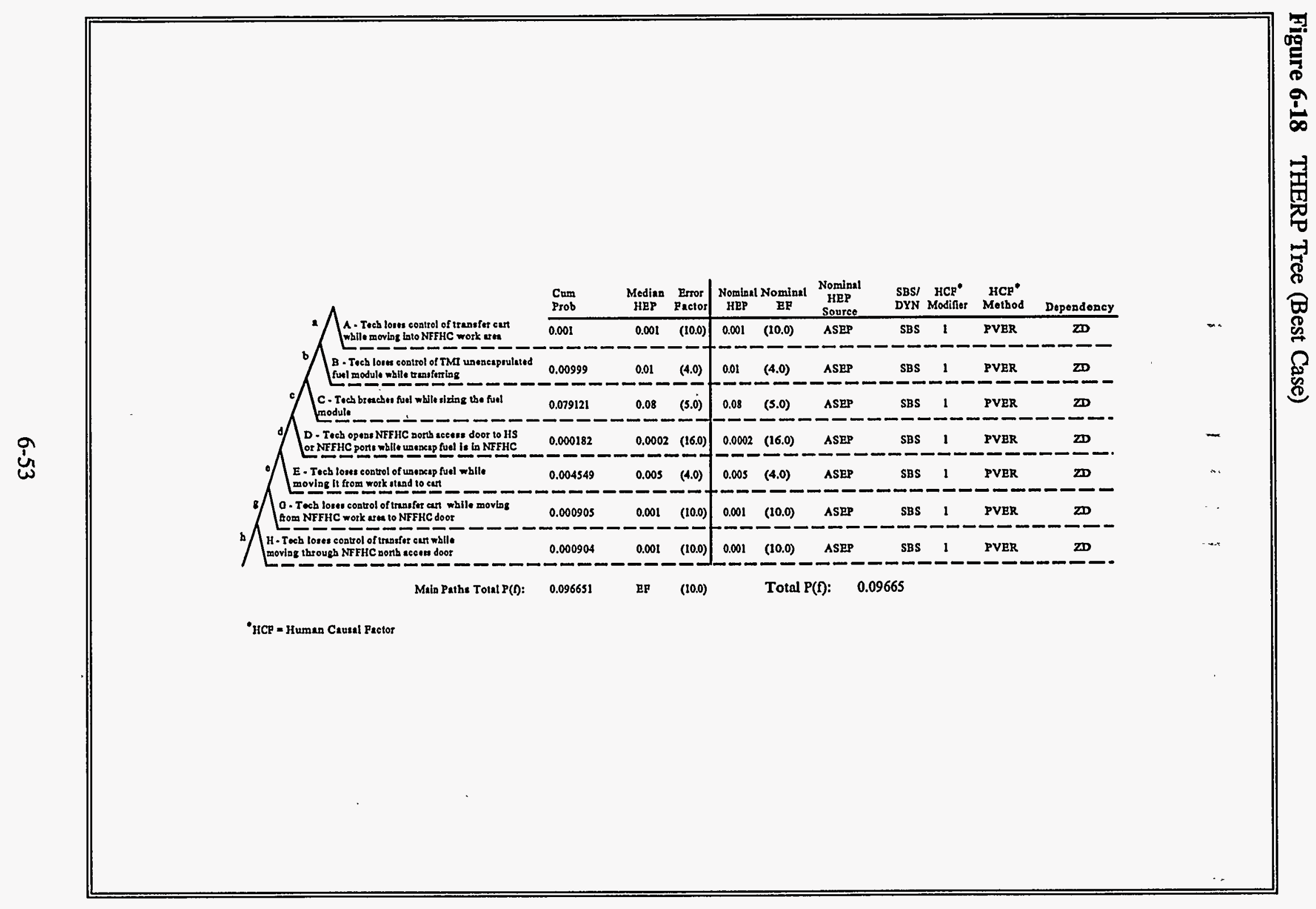




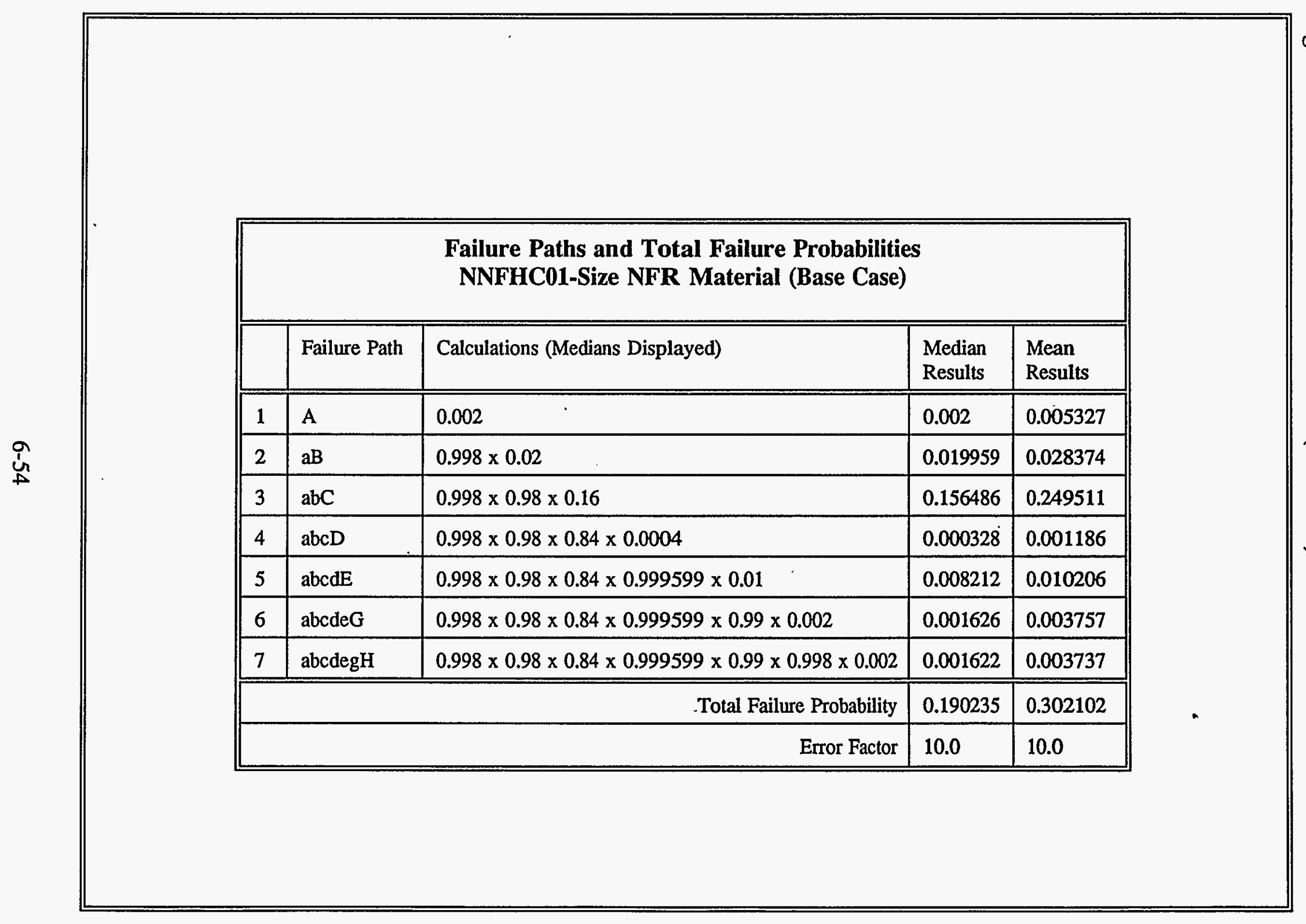




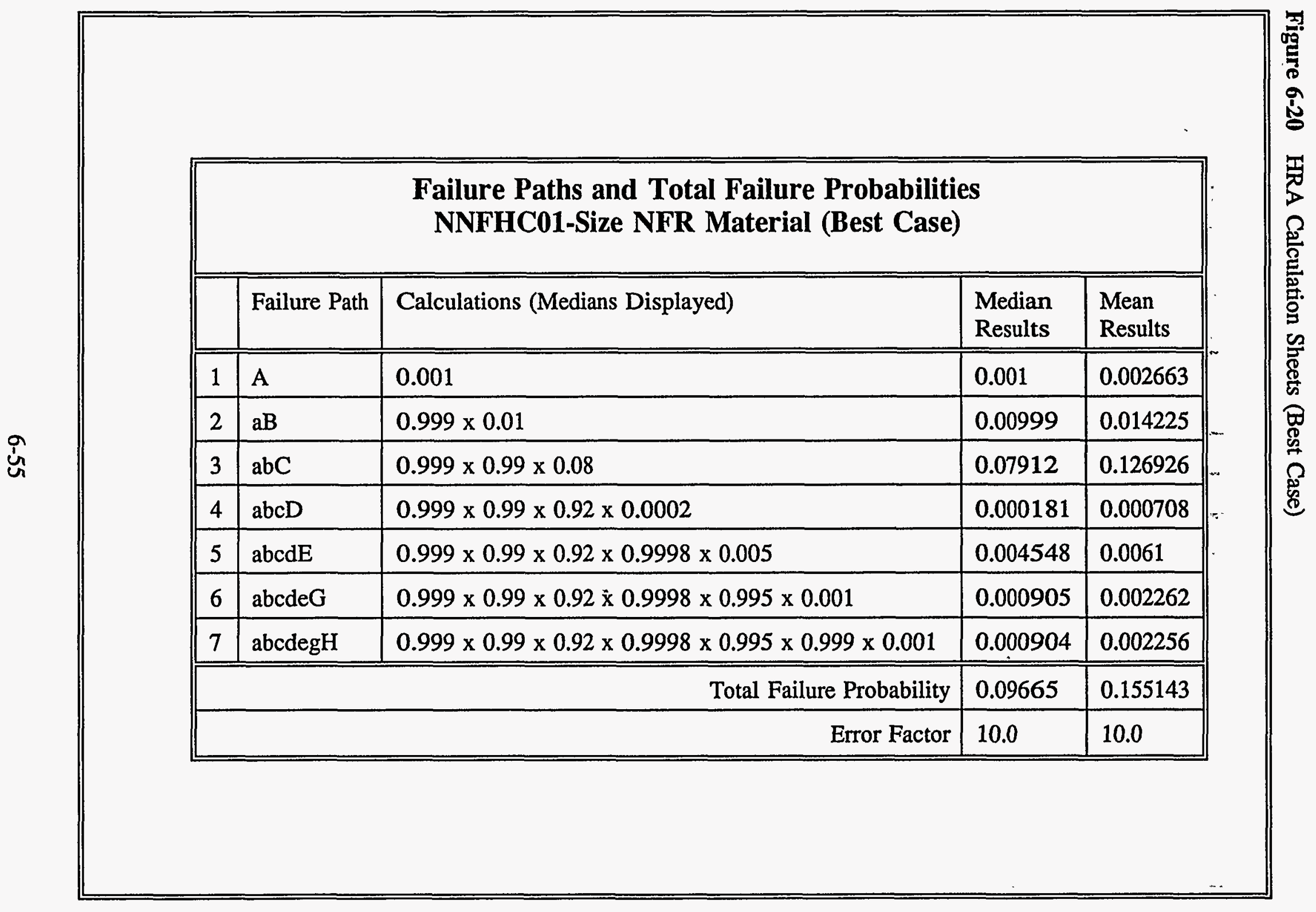


Figure 6-21 Matrix of DOE Facility Classifications and Human Performance Assessment Graded Approach

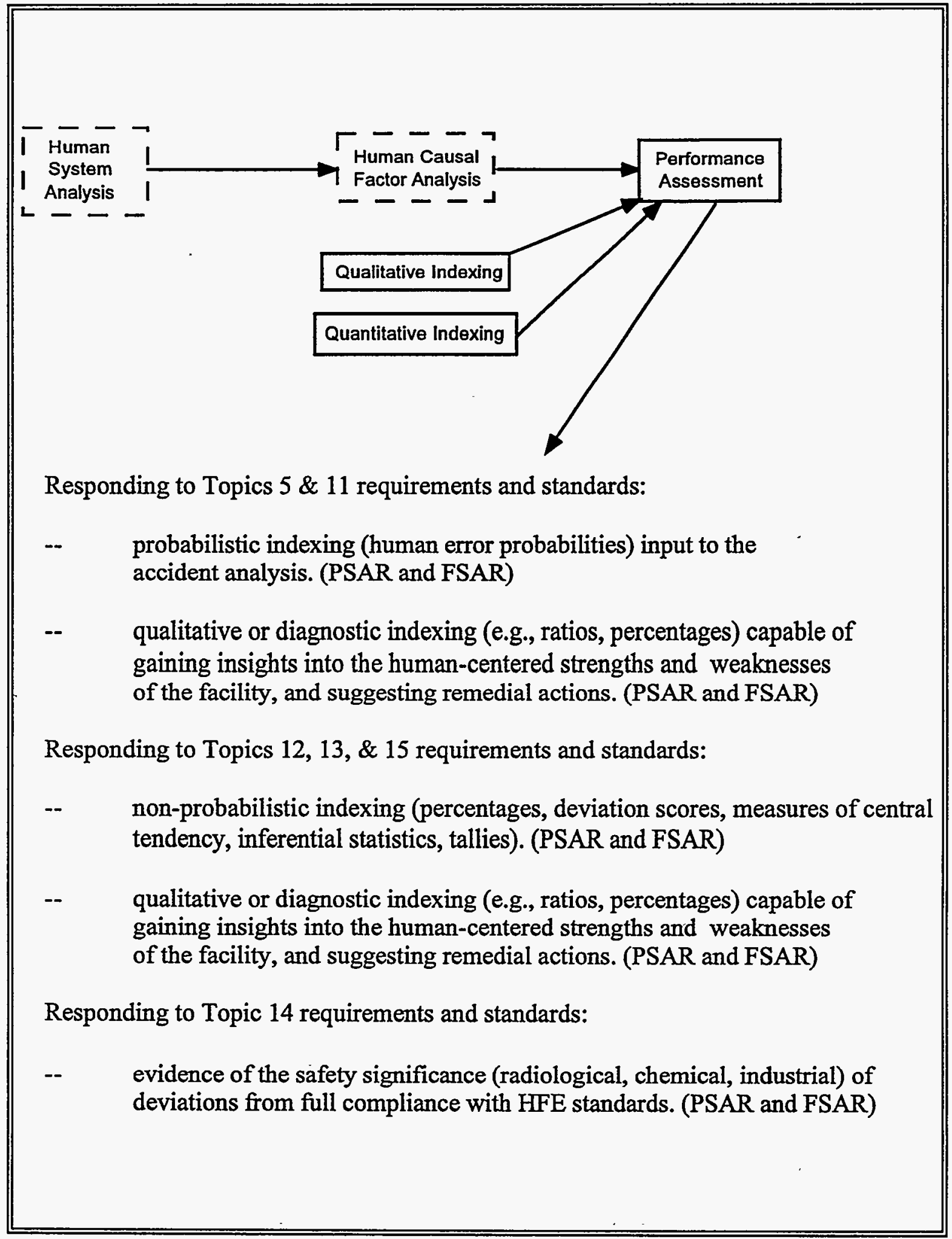




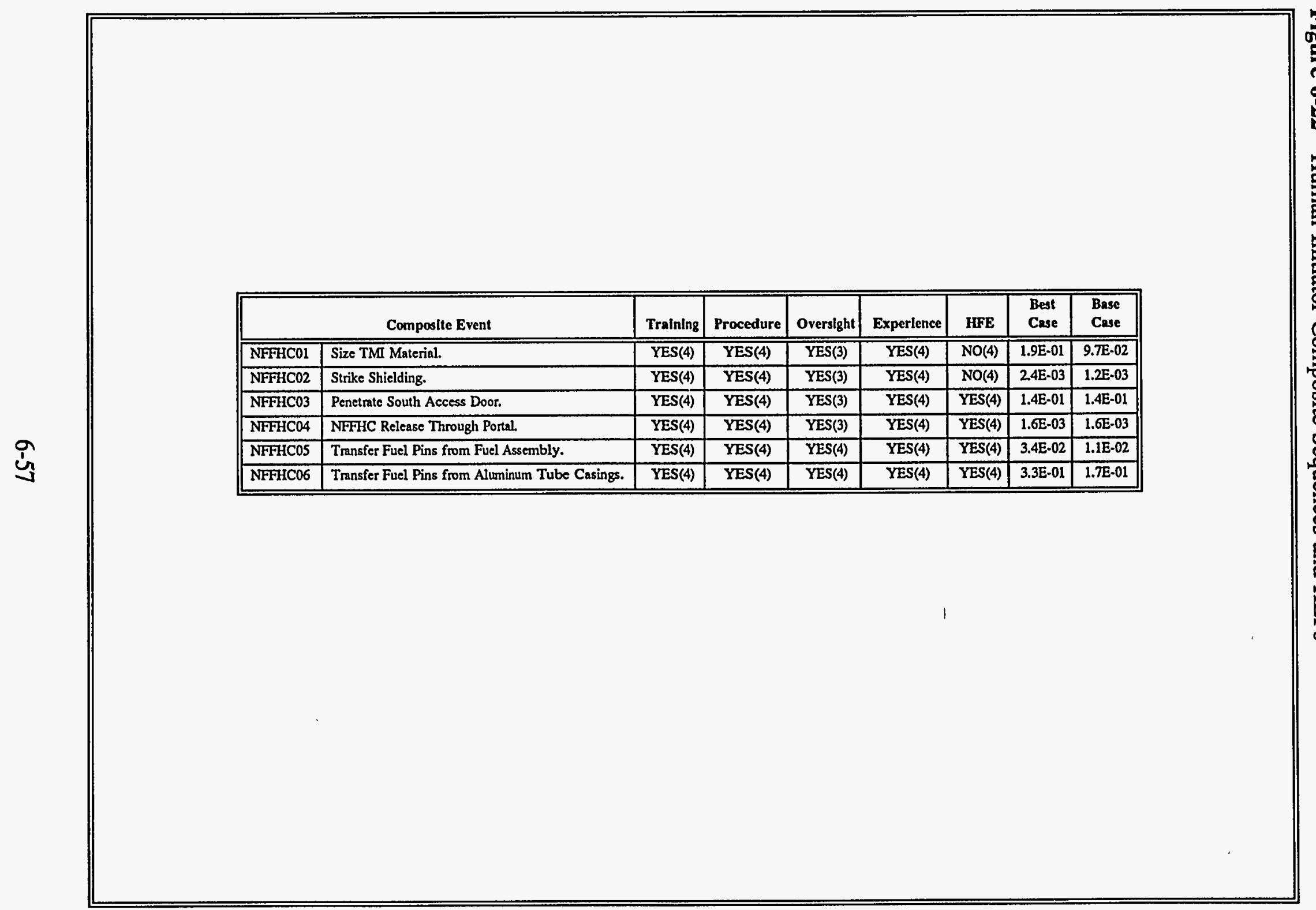




\subsection{Operational Experience Assessment}

Chapter 5 of this Course Text describes how operational experience information can and should be used as an input to the human safety analysis. The graded approach described in this section suggests that operational experience data be used to verify the results of the Human Performance Assessments using the graded approach discussed above, and to investigate how human error is being managed by the facility. Figure 6-23 and Figure 6-24 (at the end of this section) suggest a graded approach for using operational experience data to verify other analysis results and trend human error and its causal factors.

\subsubsection{Hazard Category 1}

\section{Guidelines}

For Hazard Category 1, as indicated in Figure 6-23, analyze recurring event data to verify, where possible, quantitative and qualitative human error probability estimation results. Use facility recurring event and self-awareness program data to trend facility human error, by years for which data are available. Finally, use the facility's self-maintained data stores and the Occurrence Reporting and Processing System (ORPS) data store to trend facility human error rates, by year since March 1990, and compare those rates with a representative sample of similar facilities. DOE facilities are required to participate in the ORPS program under provisions established by DOE Order 5000.3B (DOE 1993). The facility may or may not retain other operational experience data that can be used for supporting the operational data analysis. As a minimum, the ORPS data should be used for this purpose. 
Figure 6-23 Operational Data for the Graded Approach

\begin{tabular}{|c|c|c|c|}
\hline & \multicolumn{3}{|c|}{ Facility Hazard Category Classifications } \\
\hline Assessment & Category 1 & Category 2 & Category 3 \\
\hline Recurring Event Analysis & $\bar{x}$ & & \\
\hline Self-Awareness Analysis & $\mathrm{X}$ & $\mathrm{X}$ & \\
\hline ORPS Analysis & $\bar{X}$ & $\mathrm{X}$ & $\bar{x}$ \\
\hline
\end{tabular}

\section{Hazard Category 1 Suggested References}

Facility recurring event data store. These data are usually found in hardcopy or computerized data stores maintained in the Operations Section of the facility, or can be extracted from the facility operating logs.

Facility self-awareness data store. This data can be used if it includes incident or event cause codes. In many instances facilities keep this information for after action, but do not record cause codes.

ORPS on-line data store. This information can be easily retrieved for the facility and other participating facilities within the DOE system. Retrieval is usually a twostep process.

- $\quad$ For the facility and comparison group, total ORPS reports, by year since March 1990, and numbers of these reports attributable to human error.

- For the facility and comparison group, cause codes (e.g., procedures, training, management, HFE), by year, for ORPS reports attributable to human error. 


\subsubsection{Hazard Category 2 .}

\section{Guidelines}

For Hazard Category 2, as indicated in Figure 6-23, use facility self-awareness program data to trend facility human error, by years for which data are available. Finally, use the ORPS data store to trend facility human error rates, by year since March 1990, and compare those rates with a representative sample of similar facilities.

\section{Hazard Category 2 Suggested References}

Facility self-awareness data store. (Same as for Hazard Category 1)

Use the ORPS on-line data store. (Same as for Hazard Category 1)

\subsubsection{Hazard Category 3}

\section{Guidelines}

For Hazard Category 3, as indicated in Figure 6-11, use the ORPS data store to trend facility human error rates, by year since March 1990, and compare those rates with a representative sample of similar facilities.

\section{Hazard Category 3 Suggested References}

Use the ORPS on-line data store. (Same as for Hazard Category 1)

\subsubsection{Application of Results in the SAR}

Figure 6-24 at the end of this section shows an ORPS human error assessment data table. The top portion of Figure 6-24 shows the comparison group trends for the period 1990-1994; the lower portion of Figure 6-24 shows trends for the sample 
Category 2 facility for the same period. Remember that further interrogations of the ORPS data store are required to analyze causal factors of the reports attributable to human error. Later in the SAR, the HF practitioner will want to account for the overall impact and trends for each of the HCFs included in the human safety analysis.

Figure 6-24 Facility-Comparison Group ORPS Data Table

\begin{tabular}{|lllll||}
\hline & & & & \\
& Facilities & Total & Human Error & \\
Geporting & Reports Reports & Percentage \\
\hline & & & & \\
1990 (Partial Year) & 17 & 77 & 31 & 40 \\
1991 & 52 & 495 & 221 & 45 \\
1992 & 48 & 603 & 276 & 46 \\
1993 & 41 & 669 & 205 & 31 \\
1994 (thru May) & 19 & 158 & 20 & 13 \\
& & & & \\
NFF & & & & 33 \\
1990 (Partial Year) & 1 & 6 & 2 & 100 \\
1991 & 1 & 2 & 2 & 100 \\
1992 & 1 & 4 & 4 & 80 \\
1993 & 1 & 5 & 4 & 0 \\
1994 (thru May) & 1 & 0 & 0 & \\
& & & & \\
\hline
\end{tabular}

\subsection{Summing Up}

This chapter has described one graded approach for carrying out the human safety analysis. The purpose of the approach is to respond to the requirements of DOE Order 5480.23 cost-effectively while maintaining credibility and auditability (DOE 1992a). The graded approach was applied to each of the three steps of the human safety analysis process. Operational experience data were used to verify the general credibility of the human safety analysis inputs to the hazards and accident analysis, and to assess the facility's management of human error. Chapter 7 will present an approach for documenting the human safety 
analysis for subsequent use in preparing the SAR, and for supporting future HF activities of the facility. 


\section{Chapter 7}

\section{Preparation of HF Documentation to Support the SAR Process}

The overall objective of Chapter 7 is to provide guidance on documenting the results of the human factors (HF) analysis for the purpose of making safety relevant determinations and for serving as a technical basis for the HF segments of the Safety Analysis Report (SAR).

\subsection{Introduction and Purpose}

The human safety analysis presented in Chapter 6 can be expected to generate considerable data, results and findings, some of which will:

(1) be presented in the SAR,

(2) be referenced by the SAR, and

(3) become elements of the facility's human factors program supporting current and future operations of the facility and, in turn, revisions in the SAR.

In order to ensure that HF data and results are organized and readily available to support SAR, TSR, and future facility operations, HF data and results should be recorded in one or more controlled documents (DOE 1992a, 1994b). The following paragraphs suggest a two document approach that has been used successfully to support the SAR process, and the sustaining facility human factors program. 


\subsection{Chapter 7 References}

DOE, 1989, "General Design Criteria," Section 1300-12, "Human Factors Engineering," Order 6430.1A, April.

DOE, 1992a, "Nuclear Safety Analysis Reports," Order 5480.23, April.

DOE, 1992b, "Technical Safety Requirements," Order 5480.22, September.

DOE, 1992c, "Hazard Categorization and Accident Analysis Techniques for Compliance with DOE Order 5480.23, Nuclear Safety Analysis Reports," DOE Standard 1027-92, December.

DOE, 1993a, "Nuclear Reactor Safety Design Criteria," Section 8.c.(9) and Attachment 3 Section 3.a.(9), Order 5480.30, January.

DOE, 1993b, "Occurrence Reporting and Processing of Operations Information," Order 5000.3B, January.

U.S. Department of Energy (DOE), 1994a, 4330.4B, "Maintenance Management Program," February.

DOE, 1994b, "Preparation Guide for U.S. Department of Energy Nonreactor Nuclear Facility Safety Analysis Reports," DOE Standard 3009-94, July.

\subsection{Information Sources}

Function/Task Analysis worksheets (flow diagrams and narratives)

Human vulnerability analysis and human failure modes worksheets

Human causal factor (HCF) selection and evaluation worksheets

Human factors engineering (HFE) checklists and worksheets recording compliances and non-compliances, and 
Other human factors controls (e.g., procedures, training, oversight, staff, qualifications) included in the analysis, and worksheets recording compliances and non-compliances.

Human Performance Assessment worksheets

Probabilistic analysis diagrams used to derive human error rates (THERP trees and computation tables), and

Non-probabilistic compilations of performance information presented as tallies, measures of central tendency, percentages, or deviations scores (operational experience data).

\subsection{Human Factors Analysis Results and Findings Report}

The suggested human factors analysis report presents the background, methodology, and findings of a human factors analysis of the facility to support its SAR (PSAR or FSAR), in responding to the requirements of Department of Energy (DOE) Order 5480.23 and DOE Standard 3009-94 (DOE 1992a, 1994b). Depending on the type of facility, the analysis should focus on general building areas, workstations, handling devices, and human factors elements (e.g., procedures, training, HFE, management oversight) involved in or directly supporting the administrative and/or technical operations of the facility. These technical operations include testing, surveillance, and preventive and recovery maintenance activities required to support technical operations. Figure 7-1 presents a suggested annotated outline for reporting human factors analysis results and findings.

The human factors analysis report, since it precedes knowledge of the hazards and accident analysis results, makes no attempt to interpret or evaluate the nuclear safety significance of the human factors analysis findings. The human factors analysis findings presented in this report, when integrated into the facility SAR Topic $\underline{5}$ Hazards Analysis and 
Classification and Topic $\underline{11}$ (Accident Analysis), provide a safety basis for responding to facility SAR Topic 12 (Management, Organization and Institutional Safety Provisions), Topic 13 (Procedures and Training), Topic 14 (Human Factors Engineering), and Topic 15 (Initial Testing, In-service Surveillance, and Maintenance). These results and findings also provide a secondary source for responding to other SAR topic requirements as described in Chapter 4 of this text (e.g; operational safety, emergency preparedness). The findings presented in the human factors analysis report allow the SAR to respond fully to primary human factors requirements established in Department of Energy (DOE) Order 5480.23 for Hazard Category 1 facilities, and as interpreted by DOE Standard 3009-94 for Category 2 and 3 nonreactor facilities (DOE 1992a, DOE 1994b). The human factors analysis results and findings report also performs a second function as an element of the facility's human factors program required by DOE Order 6430.1A for nonreactor facilities, or DOE Order 5480.30 for reactor facilities (DOE 1989, 1993a).

Figure 7-1 organizes the human factors analysis results and findings report into five sections and three appendices. Section 1 provides an introduction and summary of the human factors analysis results. Section 2 provides background information on the human factors discipline. Section 3 describes the methodology used to perform the HFE analysis. Included are:

- the technical approach and related SAR guidance (DOE Standard 3009-94, local DOE Field Office),

- the HCFs that are the subjects of the analysis (e.g., HFE, procedures, training, management controls, staffing),

- the facility's recent operating history, based on DOE's Occurrence Reporting and Processing System (ORPS) reports, as it pertains to human error susceptibility, 
- a listing of the functions, tasks, and sequences that provide the scope and context for the human factors analysis, and

- $\quad$ specific SAR requirements for human factors established by the DOE, and human factors standards used to assess compliance with DOE requirements.

Section 4 presents the human factors analysis results and findings. Section 5 presents references used to support the human factors analysis. Appendix A provides the results of the human factors analysis in tabulated form and is an extension of Section 4 in that it is a more detailed summary of findings broken down into individual workstations, building areas, handling devices, and functions and tasks for each human factors control included in the analysis (e.g. procedures, training, HFE, institutional controls). Appendix B provides a narrative description of deviations from full compliance for each human causal factor (HCF) identified during the analysis in the general building areas, by operation, and by piece of equipment. Appendix B also provides information that will be needed to make disposition of non-compliances enabling each human factor control to be fully capable of supporting the facility's SAR commitments to DOE. Appendix C provides copies of checklists, worksheets, and other materials that were used to assess the adequacy of the human factors controls included in the human factors analysis.

\subsection{Human Performance Assessment (HPA) Results and Findings Report}

This report presents the background, methodology, results and findings of the HPA for accident scenarios capable of being initiated and/or mitigated by human means, near to and within the facility. Figure 7-2 presents a suggested annotated outline for preparing an HPA results and findings report.

The results of this HPA are integrated into the larger hazards and accident analyses, which in turn serve as the safety basis for the human factors segments of the SAR. More 
specifically, the HPA results and findings report responds to the requirements of DOE Order 5480.23 , Section $8 \mathrm{~b}(3)(\mathrm{k})$ and Attachment 1 , Topic 11 , requiring that analyses be done of normal, abnormal, and accident conditions, including design basis accidents, assessments of risk, assessment of contributory and causal events both hardware and human, mechanisms, phenomena, and if appropriate, beyond-design-basis accidents (DOE 1992a).

The HPA focuses on general building areas, workstations, and handling devices involving human-machine or human system design interfaces, involved in or directly supporting the administrative and/or technical operations of the facility. Figure 7-2 organizes the HPA results and findings report into five sections and two appendices.

- Section 1 provides an introduction and summary of the HPA results.

- Section 2 describes the overall approach to the HPA.

- Section 3 describes the methodology used to perform the human initiator and mitigator HPA.

- Section 4 describes the results of the initiator and mitigator HPA.

- Section 5 presents references used to guide and perform all aspects of HPA.

- Appendix A presents the function, task, and human failure modes analyses of the facility's administrative and/or technical activities that served as the basis for the HPA. These analyses should be represented by annotated step-by-step descriptions, by systems, structures, and components involved in each action step, and by human error modes associated with each action step. Additionally, check sheets for each action sequence, verifying that the availability/non-availability and adequacy of training, procedures, oversight, and experiences, and their relative weightings are also included. 
- Appendix B is organized into five sections.

The first section presents the results of the HPA of potential human initiators or human contributors to initiation of fires, radiological and chemical spills and releases. Additionally, worksheets should also be included for each initiator action sequence, that evaluate or verify the availability/non-availability of HCFs (e.g., training, procedures, HFE, management controls) and their relative weightings if appropriate.

The second section presents the results of the HPA of potential human mitigators of offsite and onsite fires, radiological and chemical spills and releases. Additionally, worksheets should also be included for each mitigator action sequence, that evaluate or verify the availability/non-availability of $\mathrm{HCF}$ (e.g., training, procedures, HFE, management controls) and their relative weightings if appropriate.

The third section provides information on any screening method used in the HPA. This might be Accident Sequence Evaluation Program (ASEP) Human Performance Assessment Procedure, published by the U. S. Nuclear Regulatory Commission as NUREG/CR-4772, in February 1987. Excerpts from NUREG/CR-4772 are provided in Appendix A of this course text.

The fourth section provides information on the method used for doing the detailed HPA. This might be the Handbook of Human Performance Assessment with Emphasis on Nuclear Power Plant Applications, published by the U. S. Nuclear Regulatory Commission as NUREG/CR-1278, in August 1983. Excerpts from NUREG/CR-1278 are provided in Appendix B to this course text. 
The fifth section provides a description of any other technique that is used to support the HPA. For example, the Idaho National Engineering Laboratory has developed a computer code (HEPGen) for executing the Technique for Human Error Rate Prediction (THERP) described in NUREG/CR-1278. If such a technique has been used, it should be described in this section of the appendix. Information on displaying and calculating composite and component human error likelihood rates using the HEPGen Computer Code are provided in Appendix C.

\subsection{Summing Up}

This chapter has stated a need for documenting the results of the human safety analysis such that they can be used to support SAR and TSR preparation. This documentation also contributes to configuration management and TQM, goals of DOE to promote SAR usefulness to facility operators and DOE regulators. The chapter pointed out that the documentation serves several purposes: (1) technical bases for the SAR and TSRs, (2) repository for raw HF data and worksheets, and (3) guidance for future facility HF activities as part of the sustaining facility HF program. The chapter suggests two documents. The first is a human factors analysis results and findings report to document methods, techniques, and data on the HCFs included in the analysis. The second is of an HPA results and findings report that documents methods, techniques and data developed to support the hazard and accident analysis. Finally, the chapter provided as illustrations two annotated outlines for preparing the human factors analysis and Human Performance Assessment reports. In the next chapter, we turn to the resolution of deviations from HF compliance standards which were identified by the human safety analysis, and documented in the reports of human factors analysis and HPA results and findings. 
Figure 7-1 Human Factors Analysis Report Annotated Outline

Table of Contents

List of Tables

List of Figures

List of Acronyms

\section{Introduction and Summary}

This section should provide a summary of the human factors analysis of the facility human factors controls (e.g., HFE, procedures, training, oversight, staff, qualifications), involved in the administrative and/or technical mission of the facility. It should also include a summary of the methods used to conduct the human factors analysis, and the results of the human factors analysis. Finally, this section should state the DOE SAR and TSR requirements being responded to, and the guidelines and standards being used to respond to those requirements.

\subsection{Purpose}

\subsection{Mission}

\subsection{Summary of Human Factors Analysis Results}

1.3.1. Function, task, human failure modes analyses

1.3.2. Human factors checklists and other evaluation criteria used to assess human factors elements compliance

1.3.3. Methodology used to conduct the human factors analysis

1.3.4. Compliances with human factors standards and criteria

1.3.5. Deviations from full compliance with human factors standards and criteria

1.3.6. Operational experience assessment using ORPS data

1.3.7. Conclusion(s) 
Figure 7-1 (cont.) Human Factors Analysis Report Annotated Outline

\subsection{Organization of Human Factors Analysis Report}

This section should briefly describe the contents of the remainder of the human factors analysis report.

\section{Technical Background}

This section should provide background information on human factors including Human Performance Assessment and how they relate to the facility SAR and TSR project. For example:

Human factors as a scientific discipline dates back to World War II, during which complex socio-technologies in aviation, radar, and weapons control were introduced and advanced. The behavioral and social sciences body of knowledge from which human factors emerged, however, dates back well into the last century. Therefore, as a scientific and engineering support discipline, human factors applies behavioral and social sciences principles developed over the past century to system settings, with the goal of optimizing human--and ultimately-system performance. There are three somewhat overlapping areas within human factors:

- The first area is HFE or, simply, human engineering (sometimes referred to as ergonomics). HFE primarily addresses person-machine issues such as equipment design (e.g., displays, controls, and their juxtaposition); workspace layout and accessibility; and habitability (e.g., temperature, light, noise, radiation). HFE is the subject of Topic 14 of the facility SAR and, in turn, the Action Statements, Surveillance Requirements, Administrative Controls, and Technical Basis sections of the TSR document. 
Figure 7-1 (cont.) Human Factors Analysis Report Annotated Outline

- The second area is human system design (HSD). It primarily addresses person-person issues such as allocation of duties and responsibilities, staffing, qualifications, selection, training, operating procedures, technical and administrative management and organizational controls. HSD is a subject in Topics 12,13 , and 15 of the facility SAR and, in turn, the Action Statements, Surveillance Requirements, Administrative Controls, and Technical Basis sections of the TSR document.

- The third area is Human Performance Assessment (HPA). It addresses both person-machine and person-person issues pertaining to human performance measurement whether qualitative or quantitative, including probabilistic analysis. HPA is a subject in Topics $\underline{\mathbf{5}}$ and $\underline{11}$ of the facility SAR.

\section{Methodology of SAR Human Factors Analysis}

This section should describe the methodology followed in the human factors analysis including the technical approach and individual steps of the analysis process.

\subsection{Technical Approach}

The technical approach pursued should be based on the following considerations:

- current facility mission,

- facility hazard category classification,

- complexity of the facility operating configuration,

- life cycle status, and

- $\quad$ operating history.

\subsection{Description of Tasks}

This section should describe the tasks performed to accomplish the human factors analysis. This usually includes function/task analyses, development of 
Figure 7-1 (cont.) Human Factors Analysis Report Annotated Outline

checklists and worksheets for evaluating the human factors controls included in the analysis, conducting the analysis, and methods for recording and organizing the results of the analysis.

\subsubsection{Task 1: Conduct Walkdown Task Analyses}

The results of the walk-down task analyses are used as: (1) the basis for developing the Task 2 HFE checklists, (2) criteria against which the evaluate human causal factors such as training, procedures, oversight, staffing, and qualifications, and (3) the technical basis for identifying human failure modes to support the Human Performance Assessment (HPA) segments) of the hazards and accident analysis.

NOTE: The function, task, and human failure modes analyses flow diagrams and narrative are recorded as Appendix A of the HPA report outlined in Figure 7-2.

\subsubsection{Task 2: Prepare Checklists and Other Assessment Instruments}

The resulting series of human factors assessment checklists and worksheets should be based on DOE requirements and standards referenced by DOE. For example, in the case of HFE, checklists should address the following person-machine interface requirements established by DOE 5480.23 , Attachment 1, Section 14a through 14c:

$\begin{array}{ll}\text { - } & \text { Panel Layout } \\ \text { - } & \text { Instrumentation (displays) } \\ \text { - } & \text { Labeling } \\ \text { - } & \text { Physical access } \\ \text { - } & \text { Opternal and external communications } \\ \text { - } \quad \text { Protective clothing } \\ \text { - } \quad \text { Heat } \\ \quad & \text { Lighting }\end{array}$


Figure 7-1 (cont.) Human Factors Analysis Report Annotated Outline

- Noise

- Vibration

- Humidity

- Remote handling

- Vehicle/crane operation

Chapter 4 of this text lists suggested sources from which HFE checklists can be developed, as well as sources for other human factors controls specified by DOE.

Section $14 \mathrm{~d}$ of Attachment 1 to DOE Order 5480.23 requires a demonstration of human performance during abnormal operations. For this purpose, operating history information should be used. This information should include internal occurrence reports involving human error if such information is available, and occurrence reports submitted to DOE under its Occurrence Reporting and Processing System (ORPS).

The function and task analyses serve as the criteria for evaluating the adequacy of the other human causal factors (SAR Topic 12: staffing, qualifications, oversight; and SAR Topic 13: procedures and training).

\subsubsection{Task 3: Conduct Human Factors Analysis}

The section should describe how the analysis was carried out. This may involve documentation reviews, walkdowns, inspections, interviews, group discussions, surveys, or a combination of these data collection techniques.

\subsubsection{Task 4: Organize Human Factors Analysis Data}

This section should describe how the human factors analysis data is recorded and organized for use by SAR and TSR analysts, writer, reviewers, and DOE regulators.

\subsection{Facility Work Areas, Equipment, and Process Tasks}

This section should describe and list facility structures, work areas and equipment, functions, tasks, and sequences identified from the human systems analysis as the context for the human factors analysis.

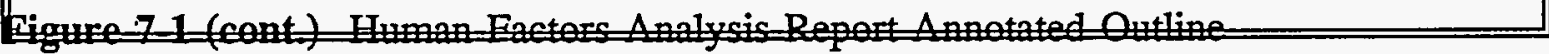




\subsection{DOE Requirements and HFE Standards}

This section should itemize DOE SAR requirements and related DOE requirements bearing on the human factors controls on which the analysis focuses. This section should also list the DOE and DOE referenced compliance standards for human factors assessments, from which the checklists and other worksheets were developed.

\subsubsection{DOE Requirements (examples)}

- Code of Federal Regulations, 29 CFR 1910, on Occupational Safety (CFR 1992).

- DOE 1324A, on Records Disposition (DOE 1988)

- DOE 5600.6C, on Quality Assurance (DOE 1990)

- DOE 5480.23, Attachment 1, Section 14, on Human Factors Engineering (DOE 1992)

- DOE 6430.1A, Section 1300-12, on Human Factors Engineering (DOE 1989)

- IEEE 1023-88, on Human Factors Engineering of Systems (IEEE 1988).

- DOE 5000.3B, on Occurrence Reporting and Processing (DOE 1993b).

\subsubsection{Human Factors Standards (examples)}

- $\quad$ ANSI Z88.2-1980, on Practices for Respiratory Protection (ANSI 1981)

- DOE 1027-92, on Hazard Classification and Accident Analysis (DOE 1992a)

- NUREG-0700, on Guidelines for HFE Design Reviews (USNRC 1981). 
Figure 7-1 (cont.) Human Factors Analysis Report Annotated Outline

- $\quad$ MIL-STD-1472D, on Human Factors Engineering System Design Criteria (DOD 1989).

- UCRL 15673, on Guidelines for HFE in Maintenance and Maintainability (UCRL 1985).

- DOE Draft Standard 1062-93, on HFE Design Criteria (DOE 1993).

- DOE Standard 1029-92, on Preparing Technical Procedures (DOE 1992)

- DOE Draft Standard 3009-94, on SAR Preparation (DOE 1994)

\subsection{Selection of Criteria for Inclusion in the Human Factors Assessment Instruments}

This section should describe factors taken into consideration when developing the instruments for the human causal factors assessment. The following are some examples of these considerations:

- Facility hazard classification,

- Computer-assisted versus manual operations,

- Degree to which other advanced technologies are used to perform the facility mission (e.g., communications, robotics),

- Situational contexts for relying on the human factors controls included in the analysis, and

- $\quad$ Possible decontamination and decommissioning (D\&D) status of certain workstation equipment, general building areas, and handling devices that are included in the analysis. 
Figure 7-1 (cont.) Human Factors Analysis Report Annotated Outline

\section{Results}

This section should present the results of the human factors analysis for each human causal factor. The status of the facility's overall compliance with human factors standards should be summarized first. Then judged deviations from full compliance with human factors standards should be summarized. Appendix A and Appendix B should be used to provide more detailed summaries of the results and provide narrative descriptions of the deviations from full compliance.

\subsection{Introduction}

\subsection{Compliance Summary by Human Factors Control}

\subsubsection{Human Factors Engineering}

4.2.2. Procedures

4.2.3. Training

4.2.4. Management Controls

4.2.5. Staffing

4.2.6. Personnel Qualifications

4.2.7. Other Human Factors Controls Included in the Analysis

\subsection{Judged Deviations from Full Compliance by Human Factors Control}

4.3.1. Human Factors Engineering

4.3.2. Procedures 
Figure 7-1 (cont.) Human Factors Analysis Report Annotated Outline

\subsubsection{Training}

\subsubsection{Management Controls}

\subsubsection{Staffing}

\subsubsection{Personnel Qualifications}

\subsubsection{Other Human Factors Controls Included in the Analysis}

\subsection{Operational Experience Human Error Trending of Potential Abnormal Events}

This section should report the results of the operational experience analysis. It should report both a trending analysis for the facility, and should compare the facility trends with those of other similar DOE facilities. DOE Order 5480.23, Attachment 1, Section $14 \mathrm{~d}$ requires a demonstration of human performance during abnormal conditions (DOE 1992). For this purpose, both the results of the hazards and accident analysis, and operating experience data should be reported here. If the facility is pursuing more than one occurrence reporting activity that has the potential of reducing human error, data from all of these activities should be used in the analysis.

\subsubsection{Human Error Trending for the Facility}

The trending analysis reported here should include a breakout of human factors controls as causal factors of the human errors.
4.4.1.1.
4.4.1.2.
Self-Awareness Programs
ORPS Reports

\subsection{Suggested Interpretations and Resolution of Judged Deviations from Full Human Factors Compliance}

The following sections should address two issues confronting the human factors analyst involved in the SAR process. The first involves safety, that is, judged non-compliances based on their relation to nuclear safety. This issue is 
Figure 7-1 (cont.) Human Factors Analysis Report Annotated Outline

discussed in Chapter 8 of the text and involves the results of the hazards and accident analysis. Section 4.5.1 should provide this information.

The second are mechanisms for correcting judged non-compliances, especially those of workstations, building areas, and handling devices involved in high likelihood/consequence accident scenarios. Suggested interventions for correcting human factors deviations from full compliance are also discussed in Chapter 8 of the text.

NOTE: This report makes no attempt to determine nuclear safety significance, or to resolve human factors deviations from compliance.

4.5.1. Interpretations of Judged Deviations from Full Compliance with HFE Standards, and Safety

4.5.1.1. Human Factors Engineering

4.5.1.2. Procedures

4.5.1.3. Training

4.5.1.4. Management Controls

4.5.1.5. Staffing

4.5.1.6. Personnel Qualifications

4.5.1.7. Other Human Factors Controls Included in the Analysis

\subsubsection{Alternatives for Resolving Deviations from Full Compliance with HFE Standards}

This section should report disposition of deviations for all human factors controls reported in Section 4.5.1 using one or more of the interventions listed below.

- $\quad$ Administrative Control Interventions

- Non-Intrusive Interventions

- Intrusive Interventions

- Grandfathering 
Figure 7-1 (cont.) Human Factors Analysis Report Annotated Outline

\subsubsection{Human Error Trending Comparing the Facility with Other Similar DOE Facilities}

This comparative analysis is expected to be limited to ORPS reports since the human factors analyst would not be expected to have self-awareness program data from other DOE facilities.

\section{References}

This section should provide full citations for all sources cited in the text of the human factors report.

Appendix A - Summary of Human Factors Deviations from Full Compliance

This appendix should provide additional details summarizing the results of the human factors analysis reported in Section 4 of this report.

Appendix B - Narrative Descriptions of Human Factors Deviations from Full Compliance

This appendix should provide narrative descriptions for each deviation from full compliance in sufficient detail that dispositions can be made.

\section{Appendix C - Human Factors Assessment Instruments}

This appendix should present the checklists and other worksheets used to assess each of the human factors controls included in the analysis. 
Figure 7-2 Human Performance Assessment Report Annotated Outline

Table of Contents

List of Tables

List of Figures

List of Acronyms

\section{Introduction And Summary}

This section should provide an introduction and summary of the Human Performance Assessment (HPA) of the facility human initiators and mitigators of accident sequences, analyzed to support the facility hazards and accident analysis. It should also include a summary of the methods used to conduct the HPA, and the results of the HPA. Finally, it should include a statement concerning the DOE requirements being responded to and DOE guidance used to respond to these requirements.

\subsection{Purpose}

\subsection{Mission of the Facility}

\subsection{Summary of the HPA}

\subsubsection{HPA Methods and Data}

1.3.2. HPA Sequences

1.3.3. HPA Results

\subsubsection{Conclusion(s)}

\subsection{Organization of HPA Report}

This section should briefly describe the remainder of this HPA report.

\section{Methodology for Performing the HPA}

This section should describe the methodology followed to do the HPA including the technical approach and individual steps of the HPA process. 
Figure 7-2 (cont.) Human Performance Assessment Report Annotated Outline

\subsection{Technical Approach for the HPA}

The technical approach pursued should be based on the following considerations:

- current facility mission,

- facility hazard category classification,

- complexity of the facility operating configuration,

- life cycle status, and

- operating history.

\subsection{Description of HPA Tasks}

This section should described the tasks that were performed to carry out the HPA. For example:

\subsubsection{Task 1: Conduct Function, Task, and Human Failure Modes Analyses}

This section should describe how the sequences were derived, along with results of the function, task, and human failure modes analyses, to support the HPA segments of the hazards and accident analysis. The flow diagrams and narratives resulting from these analyses are provided in Appendix A to this report.

\subsubsection{Task 2: Select Human Causal Factors (HCFs)}

This section should describe the human factors controls that are integrated into the HPA as human causal factors (HCFs). It should also describe how each of these controls is evaluated and the scheme used to score it for use in the HPA.

\subsubsection{Task 3: Select Initiator and Mitigator Quantification Methods}

This section should describe the methods that are used to do the HPA calculations (quantitative, qualitative) and why these methods were selected. DOE references two methods commonly used for this 
Figure 7-2 (cont.) Human Performance Assessment Report Annotated Outline

purpose. These include a Human Error Probability (HEP) screening method: Accident Sequence Evaluation Program (ASEP) Human Performance Assessment Procedure, published by the U. S. Nuclear Regulatory Commission as NUREG/CR-4772, in February 1987, and the Handbook of Human Performance Assessment with Emphasis on Nuclear Power Plant Applications, presenting the Technique for Human Error Rate Prediction (THERP), published by the U. S. Nuclear Regulatory Commission as NUREG/CR-1278, in August 1983.

\subsubsection{Task 4: Calculate Initiator and Mitigator Quantifications}

\section{Results}

This section should present the results of the HPA. Results will be provided in two sections as indicated below. Both sections should include summary tables and figures as appropriate.

- $\quad$ Summarize Base and Best Case human event sequence HEPs and error factor values. The Base Case represents the current operating configuration of the facility with regard to the human factors controls. The Best Case represents an optimal operating configuration, that is, all human factors controls are optimized.

NOTE: $\quad$ Section 3 of this report should be used to summarize the results. Appendix $B$, Sections 1 and 2, should be used to present the THERP trees and calculations for the initiator and mitigators respectively.

- Provide information on human factor controls or HCF scoring and weighting,

- Provide notations on other factors taken into consideration when doing the HEP calculations (e.g., dependency, recovery) 
Figure 7-2 (cont.) Human Performance Assessment Report Annotated Outline

\subsection{Human Initiator Base and Best Case Results}

\subsection{Human Mitigator Base Case and Best Case Results}

\section{References}

HPA.

This section should present full citations of sources used to conduct the

Appendix A - Function, Task, and Human Failure Modes Analyses

Appendix A should present the function, task, and human failure modes analyses of the facility's administrative and/or technical activities that served as the basis for the HPA. These analyses should be represented by annotated step-by-step descriptions systems, structures, and components involved in each action step, and human error modes associated with each action step. Additionally, check sheets for each action sequence, verifying the availability/non-availability of training, procedures, oversight, and experiences, and their relative weightings.

\section{Appendix B - $\quad$ HPA Initiator and Mitigator Results}

It is suggested that Appendix B be presented in five sections. The first section should present the human initiator results including human failure modes analyses, THERP trees and calculations sheets. The second section should present the human mitigator results including human failure modes analyses, THERP trees and calculations sheets. The third section should provide information on any screening method used in the HPA. The fourth section should provide information on the method used for the detailed HPA. The fifth section provides a description of any other technique that is used to support the HPA. 


\section{Chapter 8}

\section{Determination of Nuclear Safety Significance and Resolution of Deviations from HF Compliance Standards}

The overall objective of this chapter is to provide the means for:

(1) determining from the hazards and accident analyses which human factors (HF) judged compliances and non-compliances) are relevant to nuclear safety, and

(2) resolving deviations that are judged relevant to nuclear safety but not in compliance with $\mathrm{HF}$ standards.

\subsection{Introduction}

The following sections of this chapter address two issues confronting the HF practitioner involved in the Safety Analysis Report (SAR) process. The first issue involves judged non-compliances based on their relatedness to nuclear safety. The second issue is mechanisms for correcting judged non-compliances, especially those of person-centered, taskcentered, and environment-centered factors involved in nuclear safety commitments being made in the SAR.

NOTE: The material presented in this chapter is directed not only to the $H F$ practitioner, but also to others involved in the SAR process, that is, facility managers, and the Department of Energy (DOE) counterpart with responsibility for the facility. Final decisions 
concerning the safety relevance of human safety analysis results, and the means by which deviations from human factors compliance standards will be handled in the SAR and TSRs, are the prerogatives and responsibilities of the facility management and DOE representative.

\subsection{Chapter 8 References}

U.S. Department of Energy (DOE), 1989, "General Design Criteria for Nonreactor DOE Facilities," Order 6430.1A, April.

DOE, 1992, "Nuclear Safety Analysis Reports," Order 5480.23, April.

DOE, 1993a, "Occurrence Reporting and Processing System (ORPS)," Order 5000.3B, January.

DOE, 1993b, "Nuclear Reactor Safety Design Criteria," Order 5840.30, January.

DOE, 1994, "Preparation Guide for U.S. Department of Energy Nonreactor Nuclear Facility Safety Analysis Reports," Standard 3009-94, July.

Human Factors Analysis Results and Findings Report (See Chapter 7 of this Course Text).

Human Performance Assessment (HPA) Results and Findings Report (See Chapter 7 of this Course Text).

Topics $\underline{5}$ and $\underline{11}$ Hazards and Accident Analysis, of the facility SAR. 


\subsection{Identification and Interpretation of Judged Deviations from Full Compliance with HF Standards, and Safety}

DOE Order 5480.23, establishing HF requirements, refers to safety without specifically distinguishing among radiological, chemical, and industrial safety (DOE 1992). Nevertheless, to respond to the graded approach, the results of the human safety analysis must at least be interpreted for their relevance to nuclear safety.

Each HF criterion derived from references provided in Chapter 4 of this Course Text is, without exception, related to safety in that failure to comply raises the likelihood of human error which in turn leads to an increased probability of an unsafe condition. HFE criteria are based on scientific literature developed in the behavioral and social sciences over the past century, and on the human system analysis described in Chapter 6 of this Course Text. Whether an unsafe condition induced by non-compliance with human factors criteria has the potential for nuclear safety consequences is determined by the type of hazard or accident sequence in which the person-centered, task-centered, or environment-centered factor is involved.

\subsubsection{Safety Determination of Results and Findings Using the Hazards and Accident Analysis}

For purposes of the SAR, deviations from full compliance should be categorized under nuclear safety, using the results of the SAR Topic $\underline{5}$ hazards analysis, Topic 11 accident analysis, and other safety analyses that support the SAR such as the operational experience analysis (also described in Chapters 5 and 6). For example, Topic 11 categorizes accident scenarios (according to their likelihood/consequence combinations) ranging from dominating and significant to incredible and insignificant. Deviations from full compliance can be categorized using the same scheme. Topics $\underline{5}$ and $\underline{11}$ hazard and accident analysis results focus primarily on radiological and chemical safety. 
Remaining deviations from full human factors compliance can be categorized as industrial safety issues. Human factors deviations involved in chemical scenarios screened from the accident analysis as well as deviations involved in incredible radiological accident sequences can also be categorized as potential industrial safety issues.

Finally, Best Case human error likelihood estimates from the HPA results and findings report should be reviewed to assess the degree to which optimizing the HCFs included in the human safety analysis will reduce overall human error likelihood and, in turn, the overall impact of human performance on risk. This information will be very important for considering the alternative interventions suggested in Sections 8.3.5 through 8.3 .8 of this chapter.

\subsubsection{Safety Determination of Results and Findings Using the Defense in Depth and Worker Safety Concepts}

A second source of information is decisions made by the facility management and its DOE counterparts regarding structures, systems, components, and administrative controls, that will be included in the TSRs due to defense in depth and/or worker safety considerations. DOE Standard 3009-94, Section 5.3.1, TSR Coverage, makes provisions for TSRs not emerging directly from the hazards and accident analysis, but which are selected for inclusion based on their contribution to defense in depth and/or worker safety (DOE 1994). As part of determining the nuclear safety relevance of the human safety analysis results and findings, the HF practitioner should consult with the SAR managers, facility managers, and if appropriate the DOE counterpart, to ensure that HF deviations involving all structures, systems, components, and administrative controls that will be included in the SAR and TSRs as nuclear safety commitments, are identified and resolved in accordance with alternatives such as those suggested in Sections 8.3.5 through 8.3.8 of this chapter. 


\subsubsection{Safety Determination of Results and Findings Using the Operational Experience Analysis}

A third source of information is the facility's operating experience. DOE Order 5000.3B, Occurrence Reporting and Processing System (ORPS) requires that facilities report operational events including causes and remediation plans for correcting the cause codes (DOE 1993a). ORPS human error trending and comparison data that were developed during the Human Performance Assessment segment of the human safety analysis (See Chapter 6), are the subject of this section. This information is contained in the Human Factors Analysis Results and Findings Report. Operational experience data and the analysis should be reviewed and the following questions answered:

- Have the yearly percentages of total facility ORPS reports attributable to human error -- for the period March 1990 to the present -- declined, increased, remained steady, or do they form a curvilinear relationship?

- How do the facility yearly trends compare with the trends for the similar facility comparison group (above, similar to, below the average)?

- Assess the frequency with which each of the HCFs included in the human safety analysis (e.g., procedures, training, oversight, HFE) are cited as root, direct, and contributing causes of the human error. Have the yearly percentages of HCF causal citations relative to the total number of facility ORPS reports attributable to human error for the period March 1990 to the present declined, increased, remained steady, or do they form a curvilinear relationship? 
- Review ORPS reports citing individual HCFs as causal factors. What kinds of remedial action were taken in each case? How successful were these remedial actions in reducing the frequency with which HCFs are cited as causal factors in subsequent ORPS reports attributable to human error?

This latter analysis is extremely important for discussions with facility management and other cognizant individuals in considering alternative interventions such as those suggested in Sections 8.3.5 thought 8.3.8 of this chapter.

A similar review should be done of data compiled from other facility data sources (e.g., recurring events, event reports not meeting the ORPS reporting threshold). Once deviations from full HF compliance have been categorized, facility managers and DOE regulators can make safety-based decisions regarding their resolution.

\subsubsection{Alternatives for Resolving Judged Deviations from Full Compliance with HF Standards}

Person-centered, task-centered, or environment-centered factors deviating from full compliance with HF standards may involve a variety of equipment, training materials, procedures, oversight techniques, and staffing issues. In the case of hardware, some will have been obtained "off-the-shelf" whose designs are beyond the immediate control of facility managers. For the most part, DOE non-reactor facility hardware was designed and built prior to the 1989 publication of DOE Order 6430.1A, which first established explicit HF requirements for equipment design and operation, especially those involving HFE human-machine interfaces (DOE 1989). Explicit human factors design requirements were first established by DOE for its reactor facilities, in January 1993, with publication of DOE Order 5840.30 (DOE 1993b). The dilemma then for SAR preparers, facility managers, and DOE regulators is disposition 
of deviations from full compliance with HFE and other compliance standards, especially when these human-machine interfaces involve safety-class, safetysignificant, defense-in-depth, or worker-safety related structures, systems and components. Categorization of deviations from full HF compliance, as discussed in Section 8.2 of this chapter, will serve as the technical input to facility managers and DOE regulators in deciding on one of the corrective interventions, or grandfathering, discussed in the following paragraphs.

The four interventions presented below do two things for resolving human factors deviations. First, they minimize disruption of existing processes, structures and equipment. Second, they can achieve acceptable levels of nuclear safety while at the same time minimizing costs.

\subsubsection{Administrative Control Interventions}

Administrative controls involve changes in training, written procedures, staffing, and direct oversight, or any combination capable of compensating for most HF deviations, including some HFE deviations. These interventions are especially valuable for resolving HFE deviations since they do not impact the current equipment design and configuration. For example, improper positioning of displays and controls relative to one another that preclude individual workers from operating the equipment can often be overcome by adding a second participating worker. Marginal labelling can often be overcome through additional training of workers or expanded written procedures for operating equipment associated with the marginal labelling.

\subsubsection{Non-Intrusive Interventions}

These interventions primarily involve HFE deviations, that is, changes in equipment operating configurations without changing the equipment itself. For example, higher wattage light bulbs can sometimes be added without modifying the 
electrical system or electrical fixture. Individual pieces of equipment and furniture making up a workstation can be physically rearranged to achieve compliance.

\subsubsection{Intrusive Interventions}

These interventions involve HFE deviations, and require actual changes to the equipment. They are used when administrative controls and non-intrusive interventions cannot be demonstrated to achieve acceptable performance levels. They may be necessary in all cases of equipment involved as contributors to nuclear safety commitments to DOE.

\subsubsection{Grandfathering}

This is not so much an intervention as it is an exclusion from change and an acceptance of risk. It was stated in Section 8.3.4 that most DOE nonreactor facility structures, systems, and components, and their upgrades were accomplished before April 1989 (publication date of DOE Order 6430-1A), and for most reactor facilities before January 1993 (publication date of DOE Order 5480.30). Given a good operating history (operational experience assessment) consideration might be given to excusing HF deviations from full compliance especially where they involve low potential for hazard or accident or Best Case analysis suggests that something less than optimal performance can be achieved by introducing any or all of the previous interventions. Decisionmakers are cautioned to examine fully the potential for human error before choosing the grandfathering alternative, even if further human factors/Human Performance Assessment analyses are required to more precisely measure human error potential. This may be especially true for Hazard Category 2 and 3 facilities since the graded approach produces more general and less rigorous results for these facilities than for Hazard Category 1 facilities. In summary, a decision to grandfather should only be made when risk cost-benefit tradeoffs clearly favor such a decision. 
NOTE: In the event that optimizing any or all HCFs does not resolve the problem, consideration must be given to reallocating responsibilities between the human and the equipment to achieve optimal results.

\subsection{Summing Up}

This chapter has focused on the nuclear safety relevance of the human safety analysis results, and resolution of negative results, in order to prepare the human factors segments of the SAR. The chapter suggested that the results of the hazards and accident analysis (Topics $\underline{5}$ and 11 of the facility SAR) be used for making human factors determinations related to nuclear safety. The chapter suggested that human safety analysis results not pertinent to nuclear safety might be industrial safety issues. The chapter also suggested a review of operational experience analysis results to confirm results of the hazards and accident analysis. Finally, the chapter proposed four potential interventions that might be used to resolve deviations from full human factors compliance. The next chapter of this Course Text focuses on writing the human factors segments of the SAR. 


\section{Chapter 9}

\section{Preparation of Human Factors Including Human Performance Assessment Sections of the SAR}

The overall objective of this module is to provide guidance and examples for using the human safety analysis information generated by means of Chapters 1 through 8, for demonstrating in the Safety Analysis Report (SAR) that the human factors element(s) are fully capable of supporting the current nuclear safety SAR commitments to the Department of Energy (DOE).

\subsection{Introduction}

The purpose of this chapter is to provide one approach and guidelines for preparing human factors topics of the SAR. This chapter focuses on the six primary HF topics described in Chapter 4 of this Course Text. These 5480.23 (DOE 1992a) primary topics include:

Topic 5: $\quad$ Hazard Classification

Topic 11: Accident Analysis

Topic 12: $\quad$ Management, Organization, and Institutional Safety Provisions

Topic 13: $\quad$ Procedures and Training

Topic 14: Human Factors Engineering

Topic 15: Initial Testing, In-Service Surveillance, and Maintenance

Results obtained by means of the human safety analysis (performed in accordance with earlier Chapters 4 through 8 of this Course Text) also provide a technical basis for other SAR topics. Finally, the human safety analysis results are used as a technical basis for the TSR 
operating and surveillance requirements, and administrative controls (discussed in Chapter $10)$.

\subsection{Chapter 9 References}

U.S. Department of Energy (DOE), 1992a, "Nuclear Safety Analysis Reports," Order 5480.23, April.

DOE, 1992b, "Hazard Categorization and Accident Analysis Techniques for Compliance with DOE Order 5480.23, Nuclear Safety Analysis Reports," Standard 1027-92, December.

DOE, 1994, "Preparation Guide for U.S. Department of Energy Nonreactor Nuclear Facility Safety Analysis Reports," Standard 3009-94, July.

Human Factors Analysis Results and Findings Report.

Human Performance Assessment (HPA) Results and Findings Report.

Self-Awareness Program and Occurrence Reporting and Processing System (ORPS) Analysis (provided in the Human Factors Analysis Results and Findings Report).

SARs for reactor facilities will usually have topic and section numbers identical with 5480.23 topic numbers (DOE 1992a). For example, Topic $\underline{5}$ (Hazard Classification) and Topic 11 (Accident Analysis) usually carry those chapter numbers in the SAR. SARs for nonreactor Hazard Category 2 facilities, prepared in accordance with DOE Standard 3009-94 (DOE 1994) will usually carry the following chapter numbers:

Chapter 3: $\quad$ Hazards and Accident Analyses,

Chapter 10: Initial Testing, In-Service Surveillance, and Maintenance,

Chapter 12: $\quad$ Procedures and Training, 
Chapter 13: Human Factors Engineering, and

Chapter 17: $\quad$ Management, Organization, and Institutional Provisions and Controls (DOE 1994).

SARs for nonreactor Category 3 facilities, responding to DOE Standard 3009-94, are not required to perform an accident analysis, nor are separate chapters required to cover the other human factors including Human Performance Assessment (HF) primary topics (DOE 1994). Therefore, human safety analysis results are used to prepare section inputs to Topic $\underline{5}$, Hazards Classification, and to an administrative control chapter covering the other HF primary topics.

\subsection{Requirements}

DOE Order 5480.23 and DOE Standard 3009-94 require that chapters or sections of the SAR do three things (DOE 1992a, 1994).

1. DESCRIBE the technical basis for the scope and contents of the HF chapters or sections based on a graded approach that considers the facility hazard classification, complexity, mission, life cycle status, and any other factors that might influence safety.

2. DESCRIBE provisions and programs established at the facility in each topic area that responds to DOE orders and DOE endorsed government regulations, including those carried out to support the SAR process.

3. DEMONSTRATE that current provisions and programs are fully capable of supporting the facility safety mission, including its SAR commitments to DOE. 


\subsection{Organization of the Chapter}

The remaining sections of this chapter provide guidelines and examples for preparing inputs to the SAR covering each of the HF primary topic areas. Section 9.5 is divided into five subsections each followed by examples of the SAR input. Subsection 9.5.1 focuses on Topics $\underline{5}$ and 11: Hazards and Accident Analysis. Subsection 9.5.2 focuses on Topic 12: Management, Organization, and Institutional Safety Provisions. Subsection 9.5.3 focuses on Topic 13: Procedures and Training. Subsection 9.5.4 focuses on Topic 14: Human Factors Engineering (HFE). Subsection 9.5.5 focuses on Topic 15: Initial Testing, In-service Surveillance, and Maintenance. Section 9.6 sums up the chapter.

\subsection{Suggested Guidelines and Examples}

The following subsections and illustration examples are directed toward applying human safety analysis results for answering each of the three requirements stated above for the six primary HF SAR topics. In summary, the minimum inputs involve major sections to Topics $\underline{5}$ and $\underline{11}$, the entire SAR response to Topic $\underline{14}$, and safety demonstration inputs to SAR Topics $\underline{12}, \underline{13}$, and $\underline{15}$. This does not preclude the SAR preparer, from using the human safety analysis results for supporting other sections of the SAR (See Chapter 4 of this course text). The preparer of the HF inputs to the SAR is expected to contribute inputs to the SAR as follows:

- Topics $\underline{5}$ and 11 , Hazards and Accident Analysis: provide HPA Approach, Methodology and Results Sections to the chapter(s).

- Topic 12, Management, Organization, and Institutional Safety Provisions: provide Demonstration of Safety Significance and Resolution of Discrepancies Sections to the chapter. 
- $\quad$ Topic 13, Procedures and Training: provide Demonstration of Safety Significance and Resolution of Discrepancies Sections to the chapter.

- Topic 14, Human Factors Engineering: provide all sections of the chapter.

- Topic 15, Initial Testing, In-service Surveillance, and Maintenance: provide Demonstration of Safety Significance and Resolution of Discrepancies Sections to the chapter.

- Provide inputs to other SAR chapters as appropriate.

\subsubsection{Topics $\underline{\mathbf{5}}$ and 11: Hazards Analysis and Accident Analysis}

This subsection and Figure 9-1 through Figure 9-3 presented at the end of the section provide a general approach for contributing HF inputs to the hazards and accident analysis. Inputs to the hazards analysis can be expected to consist of primarily a screening HPA using, for example, the Accident Sequence Evaluation Program (ASEP) procedure described in Chapter 6, Section 6.8.3.1, and Appendix A of this text. The accident analysis can be expected to consist of primarily a detailed HPA using, for example, the Technique for Human Error Rate Prediction (THERP) methodology described in Chapter 6, Section 6.8.3.1, and Appendix B of this text.

\subsubsection{Graded Technical Approach The technical approach for} providing an HF input to the SAR hazards analysis topics is derived from the HPA Results and Findings Report. The HPA Results and Findings Report is prepared in accordance with the guidelines presented in Chapter 7 of this text, and describes any special grading considerations for the facility (e.g., mission, urban versus rural facility location). Figure 9-1 contains a sample write-up of a technical approach for the HF segment of the hazards analysis and the accident analysis. 
9.5.1.2 Description of HPA Methodology and Results This part of the HPA input to the SAR hazards and accident analysis topics presents descriptions of the screening (hazards) and detailed (accident sequences) HPA that were done. This input also provides the rationale for selecting hazards screening data sources and assessment methods and techniques, especially if the data sources and assessment methods and techniques were not developed or referenced by DOE. Topics included are the sources of: (1) facility hazards and accident sequence data, (2) human performance input data primarily regarding the Human causal Factors (HCFs) included in the human safety analysis, (3) nominal error likelihood estimates, (4) methods and techniques used to assess the degree to which human performance is a contributor to each hazard and accident sequence, and (5) the results of these assessments.

For other than Category 3 nonreactor facilities, these descriptions and rationales are subdivided as follows: (1) screening from detailed assessments, and (2) human performance as an initiator and human performance as a mitigator. This information (used to describe the hazards and accident analysis provisions used for the SAR) is extracted from the HPA Results and Findings Report. Figure 9-2 contains a sample write-up for the HF methods section of the hazards analysis and accident analysis pertaining to human performance as an accident initiator. Figure 9-3 contains a sample write-up for the HF methods section of the hazards analysis and accident analysis pertaining to human performance as an accident mitigator.

\subsubsection{Demonstration of Safety Adequacy This part of the HPA} process relies on the results of the hazards and accident analysis. Once the hazards and accident analysis results are known, including information on the degree to which human performance is a contributor to risk, the HPA input to the SAR must do three things. First, it must show what contribution human performance makes in initiating or mitigating an accident, and answer the 
question, "is this level of human performance acceptable?" If human performance is a major contributor and the level of performance is not acceptable, the HPA Results and Findings Report should be consulted to determine if the Best Case human performance level (all HCFs are optimized) is acceptable. Second, if the Best Case human performance is not acceptable, the analyst must investigate and make hardware configuration changes to bring the hazard likelihood and consequences to an acceptable level. If the Best Case human performance is acceptable, the analyst must investigate ways to improve the HCFs included in the HPA, such that they are optimized. The options suggested in Chapter 8 of this text should be consulted for optimizing the HCFs. Information concerning the current state of each HCF is contained in the HPA Results and Findings Report. Third, the operating configuration representing the hardware and/or HCF interventions should be documented in the SAR. Remember, the SAR cannot report an operating configuration that is incapable of fully supporting the safety mission of the facility, including its SAR commitments to DOE. 
Figure 9-1 Human Performance Assessment Technical Approach

\subsubsection{Purpose}

The purpose of this section is to present the methodology and results of the Nuclear Fuels Facility (NFF). Included are composite Base Case and Best Case human error probabilities (HEPs) for human event sequences included in the HPA. Component HEPs are presented in Appendix B, Section 1, of the HPA results and findings report.

\subsubsection{HPA Data Gathering}

The HPA was conducted using a two-phase process. The first phase involved walkdowns and information gathering on human causal factors (HCFs) that could impact the likelihood of human error under a given set of circumstances (Appendix A). The second phase involved quantifying the likelihood that individual and combinations of human errors might occur using the Technique for Human Error Rate Prediction (THERP) and Accident Sequence Evaluation Program (ASEP) procedure. Appendix B, Section 1, of the HPA results and findings report, contains a detailed description of human events, human error modes, and THERP trees and calculations resulting in component and composite HEPs.

\subsubsection{Walkdown Task Analyses}

Walkdown task analyses of human action sequences were conducted onsite involving all of the NFF systems, structures, and components listed in Table 1, with the assistance of NFF documentation (e.g., written procedures) and experienced NFF operator and supervisory personnel. The purpose of the walkdowns was, in part, to identify initiator human action sequences and error modes possibly leading to accident events, and to gain insights into HCFs, including factors such as task difficulty that could impact human error likelihood. A total of 50 human action sequences involving 573 human error modes were identified from the walkdowns. Table 1 summarizes these sequences and error modes. Appendix A of the HPA results and findings report contains a complete listing of descriptions, equipment interfaces, and human failure modes identified during the walkdowns. 
Figure 9-1 (cont.) Human Performance Assessment Technical Approach

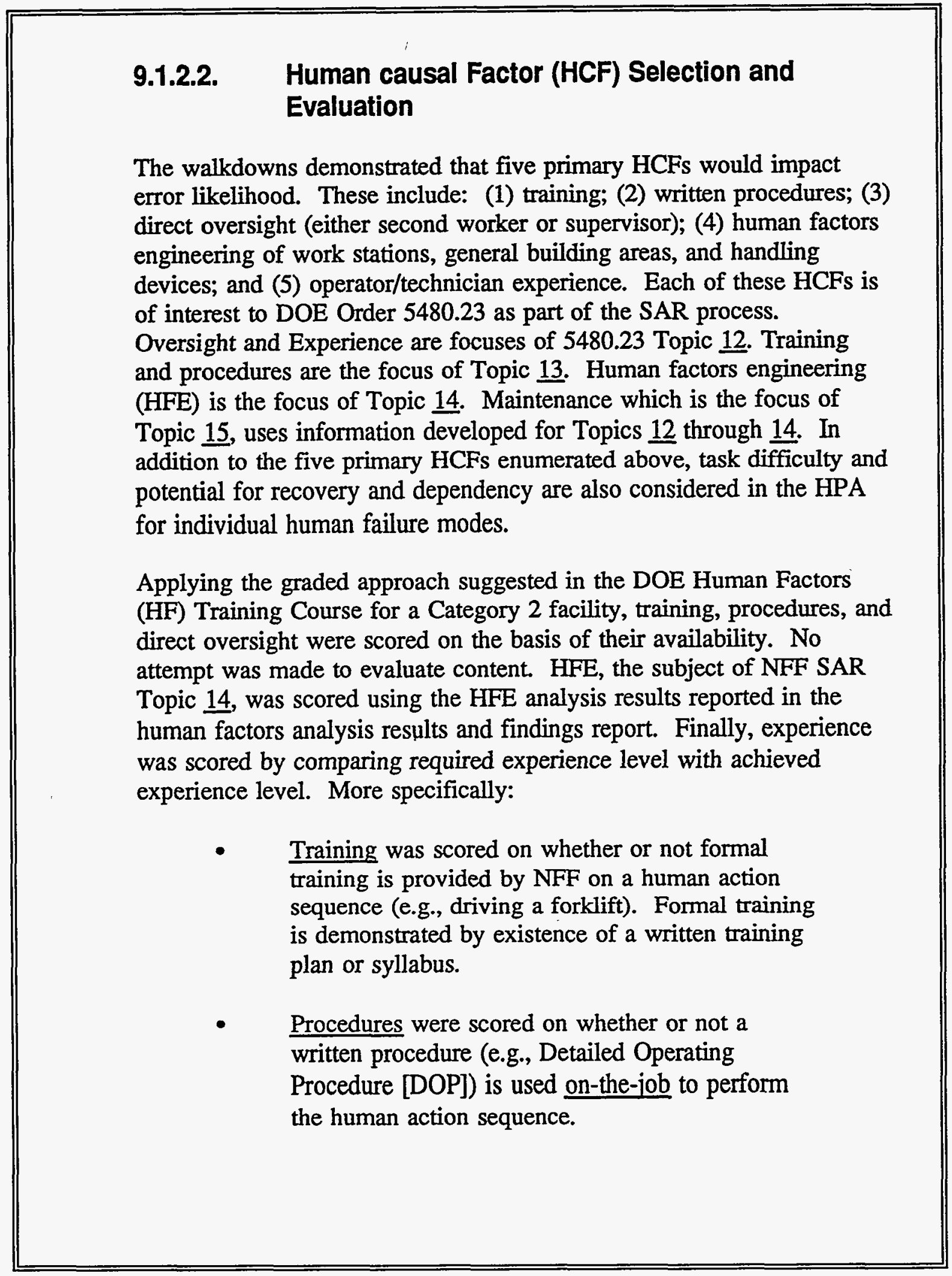


Figure 9-1 (cont.) Human Performance Assessment Technical Approach

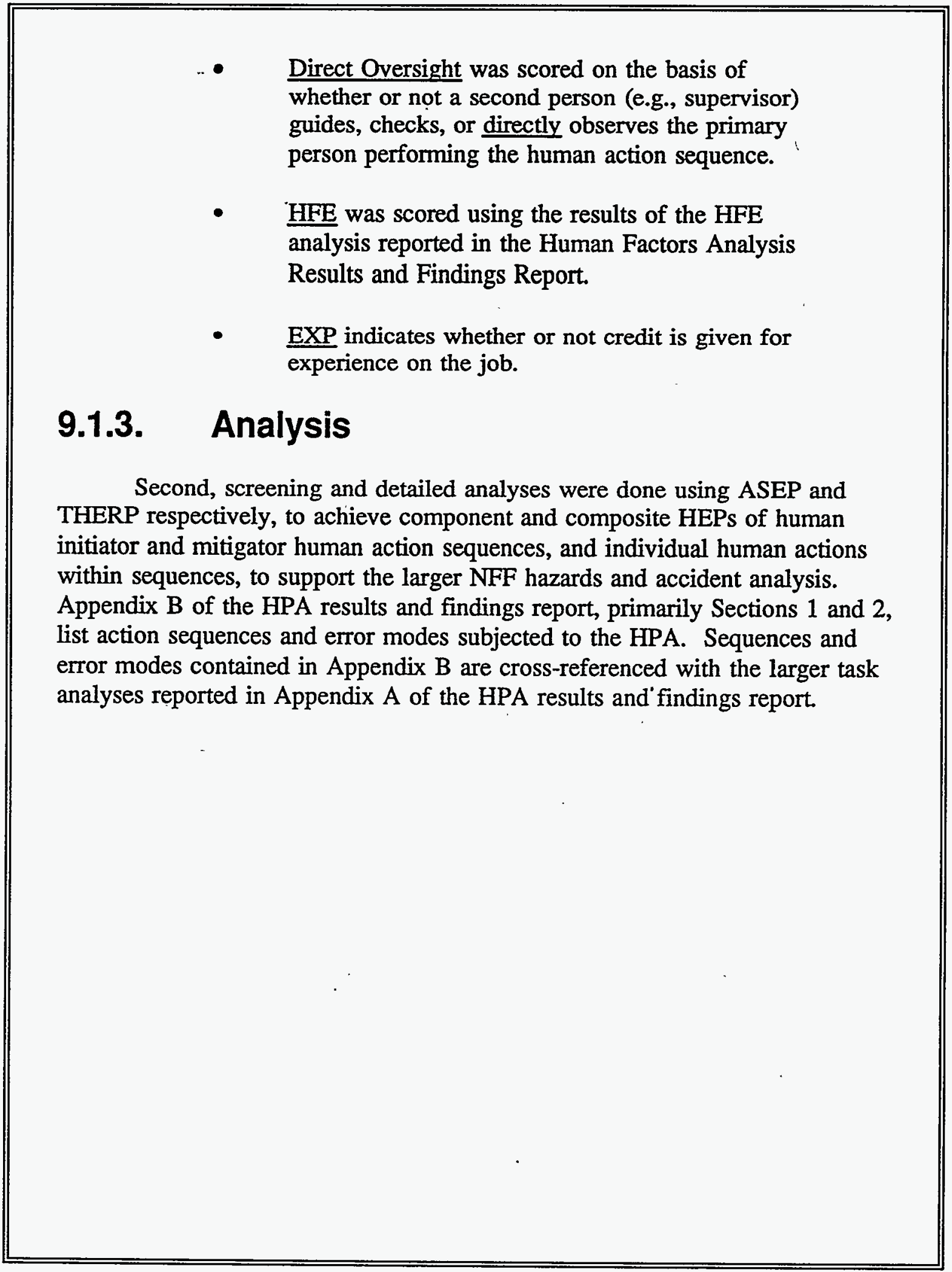


Figure 9-1 (cont.) Human Performance Assessment Technical Approach

Table 1 Human Action Sequences and Human Error Modes Analyzed

Building/Storage Operation Human Action Sequences Human Error Modes

Hot Shop

12 297

NFF Hot Cell

2

12

Filter Change Room

1

7

Liquid Waste Removal Building

3

13

Storage Building A

2

16

Storage Building B and Pad

4

32

Storage Pads A and B

4

22

General Task (Hot Work, Welding)

1

2

General Task (Inspection)

1

2

General Task (Structural Work)

1

2

General Task (Surveillance/

Maintenance)

2

5

Total

33

409 


\subsubsection{Human Action Sequences}

A total of 26 human action sequences, along with a total of 158 error modes not screened out of earlier Nuclear Fuel Facility (NFF) hazards and accident analyses, were the subject of this initiator Human Performance Assessment (HPA). Action sequences and their accompanying 158 human error modes are tallied in Table 1, for the NFF source material processing locations, that could potentially involve one or more human errors leading to or contributing to initiation of an accident sequence.

\subsubsection{Human Initiator Quantification Method}

Human error probability (HEP) calculated values and error factors were derived through a two-phase process. First, HPA event tree component median HEPs and error factors were derived using the Accident Sequence Evaluation Program (ASEP) Human Performance Assessment Procedure, published by the U. S. Nuclear Regulatory Commission as NUREG/CR-4772, in February 1987. Excerpts from NUREG/CR-4772 pertaining to input HEP selection are presented in Appendix B, Section 3 of the HPA results and findings report. Section 3 also contains a discussion of how component median HEPs were selected using ASEP. Second, THERP trees were formulated and composite median HEPs and error factors were computed using the Technique for Human Error Rate Prediction (THERP) procedure described in the Handbook of Human Performance Assessment with Emphasis on Nuclear Power Plant Applications, published by the U. S. Nuclear Regulatory Commission as NUREG/CR-1278, in August 1983. Excerpts from NUREG/CR-1278 pertaining to THERP tree analysis are presented in Appendix B, Section 4 of the HPA results and findings report. The ASEP and THERP procedures were selected for the NFF HPA because they are quantitative and are capable of considering the human causal factors (HCFs) included in the analysis. Both of these capabilities respond to DOE 5480.23 requirements for a Category 2 facility. Base Case and Best Case HEPs are computed for each composite action and component error mode.

- $\quad$ Base Case composite error likelihood estimates were derived from assessments of current NFF training, operating procedures, direct oversight, human factors engineering, and personnel experience. 
Figure 9-2 (cont.) Human Initiator HPA

Table 1 (Revised) HPA Action Sequences and Human Error Modes by NFF Location

Building/Storage Operation Action Sequences Human Error Modes

Hot Shot

12

112

NFF Hot Cell

2

2

Filter Change Room

1

3

Liquid Waste Removal Building

3

15

Storage Pads A and B

3

16

General Task (Hot Work, Welding) 1

2

General Task (Inspection)

1

2

General Task (Structural Work) 1

2

General Task (Surveillance/ Maintenance)

2

5

Total

26

158

- Best Case composite error likelihoods were derived assuming optimal NFF training, operating procedures, direct oversight, human factors engineering, and personnel experience. 
Figure 9-2 (cont.) Human Initiator HPA

- Task difficulty, potential for recovery, and dependency were also considered. These factors were not adjusted between Base and Best Case calculations since the content of the tasks and the context in which they are performed did not change between Base and Best Case conditions.

\subsubsection{Initiator HEP Quantifications}

The purpose of this section is to summarize the results of the human initiator HPA. Appendix B, Section 1 of the HPA results and findings report contains complete and annotated descriptions of all human events included in the initiator HPA; along with inputs, computations, and outputs for Base and Best Case representations on these human events.

Base and Best Case composite median HEPs and error factors, calculated for each human initiator event are summarized in the Base and Best Case columns of Table 2.

\subsubsection{Regarding Table 2}

Training was scored on whether or not formal training is provided by NFF on a human action sequence (e.g., driving a forklift). Formal training is demonstrated by existence of a written training plan or syllabus. A YES in the Training Column of Table 2 indicates that credit is given, NO indicates that credit is not given. The number in parentheses following the YES or NO in the training column is the importance rating given to training on a scale of 1 (minimal importance) through 5 (maximum importance).

Procedures were scored on whether or not a written procedure (e.g., Detailed Operating Procedure [DOP]) is used on-the-iob to perform the human action sequence. YES in the Procedures coiumn of Table 2 indicates that credit is given, NO indicates that credit is not given. The number in parentheses following the YES or NO in the procedures column is the importance rating given to procedures on a scale of 1 (minimal importance) through 5 (maximum importance). 
Direct Oversight was scored on the basis of whether or not a second person (e.g., supervisor) guides, checks, or directly observes the primary person performing the human action sequence. YES in the Oversight column of Table 2 indicates that credit is given (work is directly observed/checked). NO indicates that credit is not given (work is not directly observed, however, a DOP sign-off may be verified). The number in parentheses following the YES or NO in the oversight column is the importance rating given to oversight on a scale of 1 (minimal importance) through 5 (maximum importance).

HFE was scored using the results of the HFE analysis reported in the human factors analysis results and findings report. YES in the HFE column of Table 2 indicates that credit is given (human-machine interfaces analyzed for the NFF SAR Topic 14, are in full compliance with all critical requirements). NO indicates that credit is not given (human-machine interfaces analyzed for the NFF SAR Topic 14, are not in full compliance with all critical requirements). The number in parentheses following the YES or NO in the HFE column is the importance rating given to HFE on a scale of 1 (minimal importance) through 5 (maximum importance).

EXP indicates whether or not credit is given for experience on the job. YES in the EXP column of Table 2 indicates that actual experience level is equal to the required experience level. NO in the EXP column indicates that actual experience is less than the required experience.The number in parentheses following the YES or NO in the EXP column is the importance rating given to EXP on a scale of 1 (minimal importance) through 5 (maximum importance).

The Base and Best Case numeric values presented in Table 2 are composite HEPs. They are combinations of from one to 20-25 component (error mode) HEPs of lesser magnitude. The reader is directed to Appendix B, Section 1 of the HPA results and findings report, for additional information on the numeric values of these component HEPs. 
Figure 9-2 (cont.) Human Initiator HPA

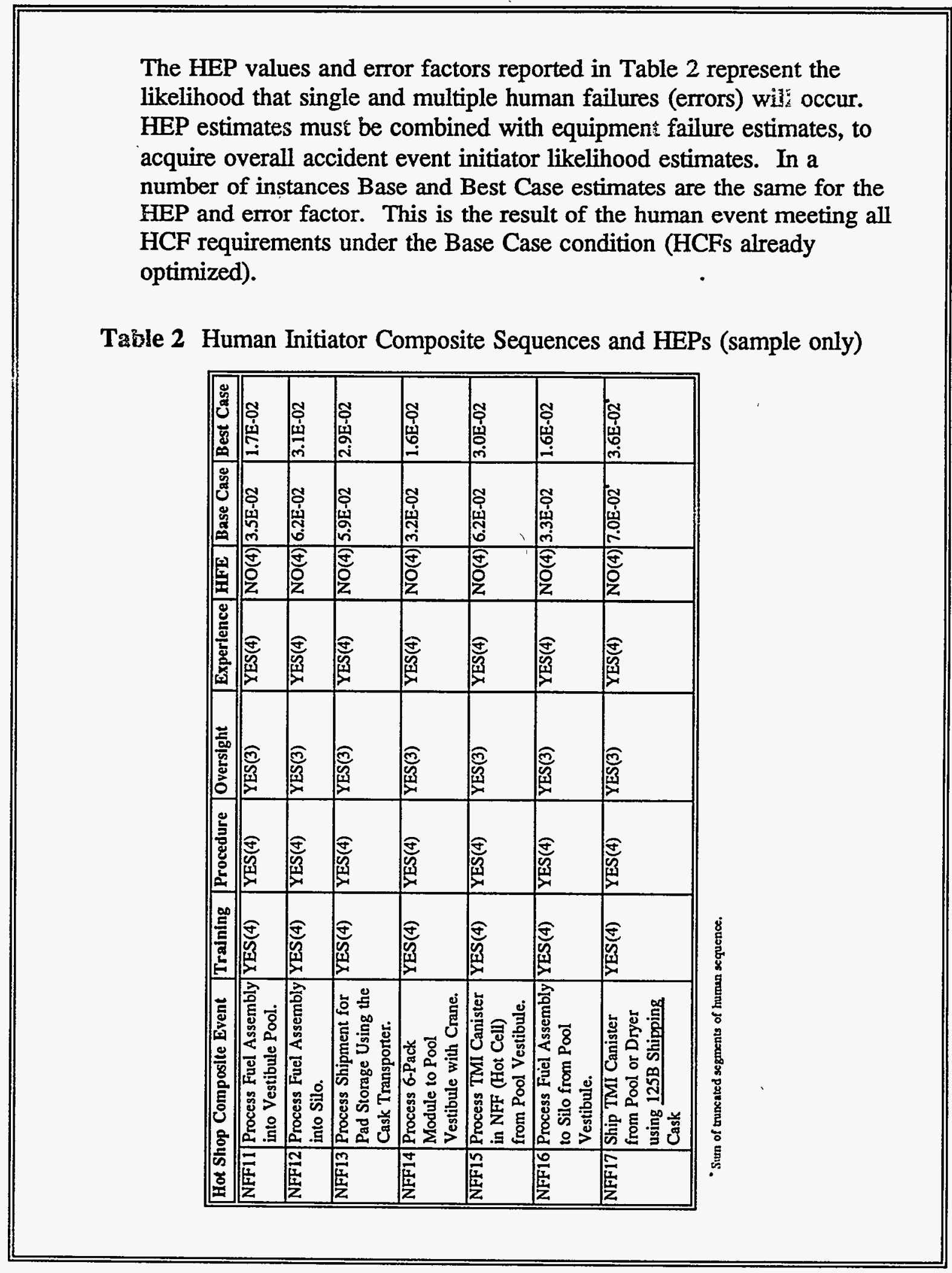




\subsubsection{Purpose}

The purpose of this section is to present the methodology and results of the Nuclear Fuels Facility (NFF) human mitigator Human Performance Assessment (HPA). Included are NFF areas analyzed and those selected for inclusion in the HPA. Also included are composite Base Case and Best Case human error probabilities (HEPs) for human event sequences included in the HPA. Component HEPS are presented in Appendix B, Section 2 of the HPA results and findings report as part of the THERP tree and failure path calculations. More specifically, this section describes the HPA performed of the NFF Incident Response Team (IRT), Emergency Coordinator, Onsite Fire Brigade, Civilian Fire Department, and NFF personnel, as mitigators of operational events (e.g., fires, spills, releases, natural phenomena). Numeric results of the HPA are summarized in Table 2 at the end of this section. They represent Base Case and Best Case composite median HEPs involving individual and combinations of the agencies listed above, in responding to and containing accidents originating offsite and onsite which could have consequences for NFF. Appendix B, Section 2 of the HPA results and findings report contains a detailed description of human action sequences, human error modes, and THERP trees and calculations resulting in component and composite human mitigator HEPs, used in the NFF hazards and accident analyses.

\subsubsection{Human Mitigator Sequences Analyzed}

Seventeen base action sequences were broken into 36 emergency response sequences applying to fires, spills and releases of radiological and chemical materials. Emergency response sequences, along with 171 associated human error modes, are tallied in Table 1.

\subsubsection{Mitigator HPA Methodology}

The mitigator HPA was conducted using the following sequential but iterative steps. These parallel the technical approach followed for the initiator HPA described in Figure 9-2. 
Figure 9-3 (cont.) Human Accident Mitigator HPA

- $\quad$ Conducted a review of operating policies and procedures concerning surveillance, reporting, and recovery from building fires, radiological and chemical spills, and radiological and chemical releases.

Table 3 Mitigator Human Event and Human Error Mode Tallies Used in the HPA (Sample only)

Offsite/Onsite Scenarios

MG01: $\quad$ Suppress Offsite Fire.

MG02: $\quad$ Suppress Onsite Fire

MG03: $\quad$ Suppress Building Fire

MG04:

MG05:

Industrial Accident.

MG06: Respond to Internal or

External Flood.

MG07: Respond to Earthquake.

MG08: Respond to Airplane Crash.

MG09:

MG12:

MG13:

MG15:

Respond to Hot Shop

Outside Release.

Inside Release.

Loss of Onsite Power During

- Normal Duty Hours.

MG16: Loss of Onsite Power During Off

Duty Hours.

MG17:

Potential Release Due to Onsite

Transportation Accident.
Truncations Human Error Modes

10

12

12

3

18

$\begin{array}{ll}4 & 7\end{array}$

$1 \quad 13$

$5 \quad 9$

$1 \quad 12$

$2 \quad 12$

29

$\begin{array}{ll}2 & 7\end{array}$

$3 \quad 10$

$1 \quad 18$

322

36

171

Total 
Figure 9-3 (cont.) Human Accident Mitigator HPA

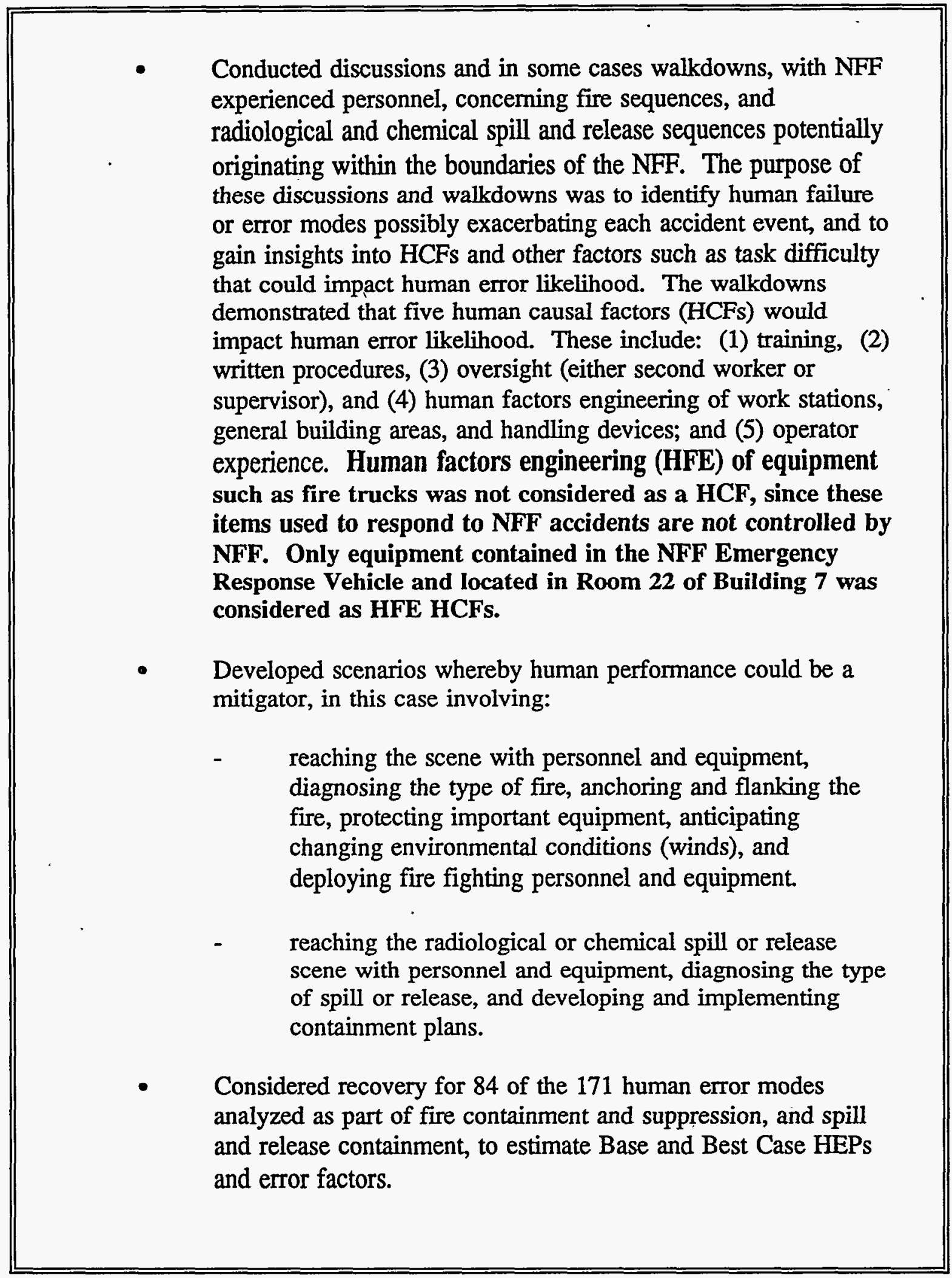


Figure 9-3 (cont.) Human Accident Mitigator HPA

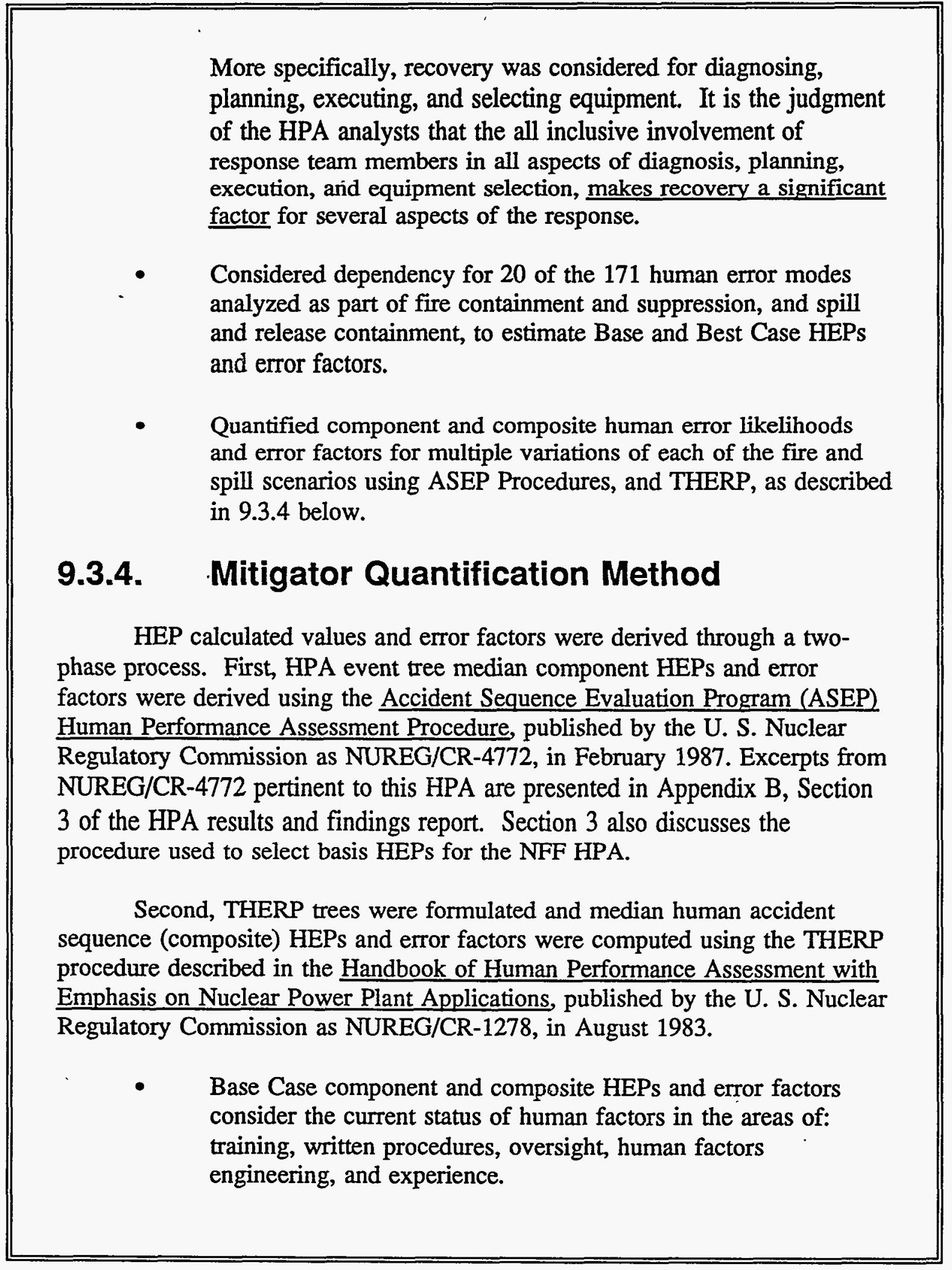


Figure 9-3 (cont.) Human Accident Mitigator HPA

- Best Case component and composite HEPs and error factors consider optimized human factors in the areas of: training, written procedures, oversight, human factors engineering, and experience.

The ASEP and THERP procedures were selected for the NFF HPA because they are quantitative and are capable of considering the HCFs included in the analysis. Both of these capabilities respond to DOE 5480.23 requirements for a Category 2 facility.

\subsubsection{Mitigator HEP Quantifications}

Base and Best Case composite median HEPs for the 36 mitigator sequences and truncations that were quantified are presented in Table 4. The median HEP values and error factors reported in this subsection represent the likelihood that single and multiple human errors will occur. Equipment mitigator failure rates must be combined with HEPs and error factors to acquire overall accident event mitigator likelihood estimates. The reader is directed to Appendix B, Section 2 of the HPA results and findings report for additional information on the numeric values of the component HEPs.

\subsubsection{Regarding Table 4}

Training was scored on whether formal training is provided by NFF on a human action sequence (e.g., driving a forklift). Formal training is demonstrated by existence of a written training plan or syllabus. A YES in the Training Column of Table 4 indicates that credit is given, NO indicates that credit is not given. The number in parentheses following the YES or NO in the Training Column is the importance rating given to training on a scale of 1 (minimal importance) through 5 (maximum importance).

Procedures were scored on whether or not a written procedure (e.g., Detailed Operating Procedure [DOP]) is used on-the-job to perform the human action sequence. YES in the Procedures column of Table 4 indicates that credit is given, NO indicates that credit is not given. The number in parentheses following the YES or NO in the Procedures Column is the importance rating given to procedures on a scale of 1 (minimal importance) through 5 (maximum importance). 
Figure 9-3 (cont.) Human Accident Mitigator HPA

Direct Oversight was scored on the basis of whether a second person (e.g., supervisor) guides, checks, or directly observes the primary person performing the human action sequence. YES in the Oversight Column of Table 4 indicates that credit is given (work is directly observed/checked). NO indicates that credit is not given (work is not directly observed, however, a DOP sign-off may be verified). The number in parentheses following the YES or NO in the Oversight Column is the importance rating given to oversight on a scale of 1 (minimal importance) through 5 (maximum importance).

HFE was scored using the results of the HFE analysis reported in the human factors analysis results and findings report. YES in the HFE column of Table 4 indicates that credit is given (human-machine interfaces analyzed for the NFF SAR Topic 14 , are in full compliance with all critical requirements). NO indicates that credit is not given (human-machine interfaces analyzed for the NFF SAR Topic 14, are not in full compliance with all critical requirements). The number in parenthesis following the YES or NO in the HFE column is the importance rating given to HFE on a scale of 1 (minimal importance) through 5 (maximum importance).

EXP indicates whether credit is given for experience on the job. YES in the EXP column of Table 4 indicates that actual experience level is equal to the required experience level. NO in the EXP column indicates that actual experience is less than the required experience. The number in parenthesis following the YES or NO in the EXP column is the importance rating given to EXP on a scale of 1 (minimal importance) through 5 (maximum importance). 


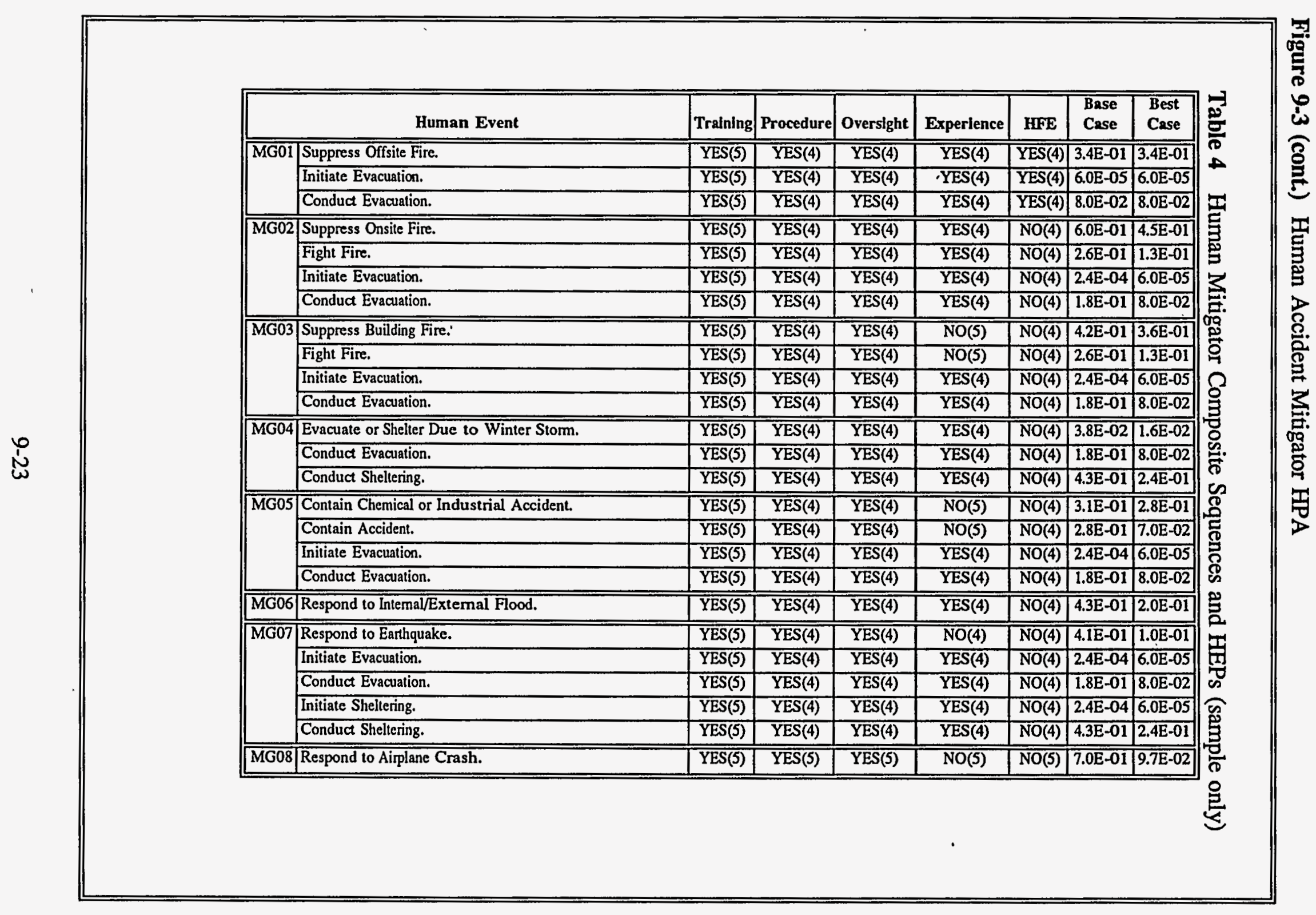


Figure 9-3 (cont.) Human Accident Mitigator HPA

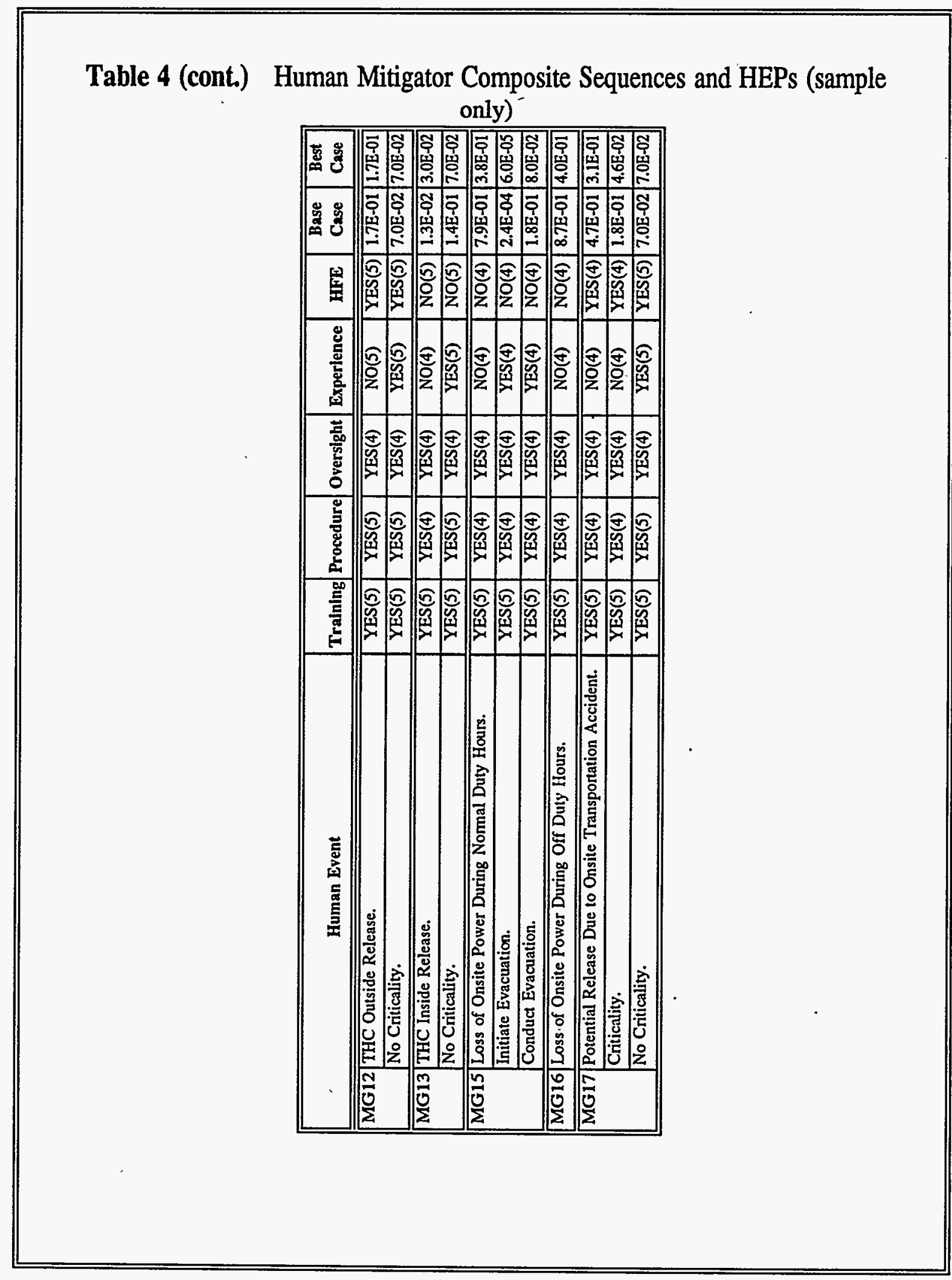




\subsubsection{Topic 12: Management, Organization, Institutional Provisions and Controls}

9.5.2.1 Technical Basis Using a Graded Approach This section of the topic response is usually prepared by an analyst other than the preparer of the HF inputs to the SAR.

\subsubsection{Description of Management and Organization Provisions or}

Program This section of the topic response is usually prepared by an analyst other than the preparer of the HF inputs to the SAR.

\subsubsection{Demonstration of Management and Organization Safety}

Adequacy The safety adequacy of the Management, Organization, and Institutional Safety Provisions Topic is demonstrated by the SAR preparer, through a three-step process:

(1) Discuss the hazards and accident analyses and demonstrate the degree to which management, organization, and institutional safety provisions are fully capable of supporting the current mission of the facility including its SAR commitments to DOE. Use the hazards and accident analyses reported as Topics $\underline{5}$ and 11 in the SAR, and the HPA Report as the information sources. Figure 9-4, Section 9.4.1, using a Category 2 facility, provides a sample write-up for this section of Topic 12 in the SAR.

(2) Discuss the ORPS analysis of facility events involving management, organization, and institutional safety provisions as causal factors. More specifically, discuss trends (percentage of facility total ORPS reports, by year, for the period March 1990 through current date) that cite one or more of these factors as 
root, direct or contributing causes. Use the HPA Results and Findings Report as the information source. Figure 9-4, Section 9.4.2, using a Category 2 facility, provides a sample write-up for this section of Topic 12 in the SAR.

(3) Resolve inadequacies identified as part of (1) using the interventions described in Chapter 8 of this text. Identify countermeasures instituted by the facility to reverse over representations of management. organization, and institutional safety provisions in the hazards and accident analysis. Discuss why these interventions and countermeasures enable facility programs involving management, organization, and institutional safety provisions to be fully capable of supporting the nuclear safety SAR commitments to DOE. Figure 9-4, Section 9.4.2, using a Category 2 facility, provides a sample write-up for this section of Topic 12 in the SAR. 
This section relates the Nuclear Fuels Facility (NFF) management and organizational provisions to safety. The hazards and accident analyses results presented in Safety Analysis Report (SAR) Topics $\underline{5}$ and $\underline{11}$, and NFF operating experience data since March 1990, are used to demonstrate the provisions' ability to fully support NFF commitments to the Department of Energy (DOE).

\subsubsection{NFF Hazards and Accident Analysis and Safety}

The NFF hazards and accident analyses identified and analyzed in excess of 60 potential accident sequences involving structures, systems and components (SSCs) for their safety relevance during NFF operations and maintenance activities (see SAR Topics $\underline{5}$ and 11 ). The Human Performance Assessment (HPA) segment of the accident analysis considered management and organizational oversight as a primary human causal factor (HCF) for determining absolute human error rates and subsequently assessing its overall impact on accident likelihood and consequences. One of the accident sequences achieved a significant offsite consequence, and since no credit was taken for associated SSCs, none of the SSCs meet the criteria established in DOE Draft Standard 3009-94 for safety class or safety significant. Therefore, management and organizational oversight is not a safety issue at NFF, as they pertain to radiological and chemical safety. The accident analysis results data presented in SAR Topics $\underline{5}$ and $\underline{11}$, suggest that NFF operations and maintenance activities pose no significant radiological or chemical safety hazard due to management and organizational oversight, and that the NFF oversight program is fully capable of supporting the current mission of the facility, including its SAR commitments to DOE.

\subsubsection{NFF Operational Experience and Safety}

NFF implements the DOE Occurrence Reporting and Processing System (ORPS), responding to the requirements of DOE Order 5000.3B, for identifying abnormal or undesirable conditions and events, including those involving management and organizational oversight. This process documents each occurrence in a structured manner, prioritizing, making causal reviews, determining proper corrective action, tracking resolution, applying lessons learned, officially closing out each abnormal or undesirable condition, and informing the originator. 
Figure 9-4 (cont) Management and Organizational Provisions and Safety

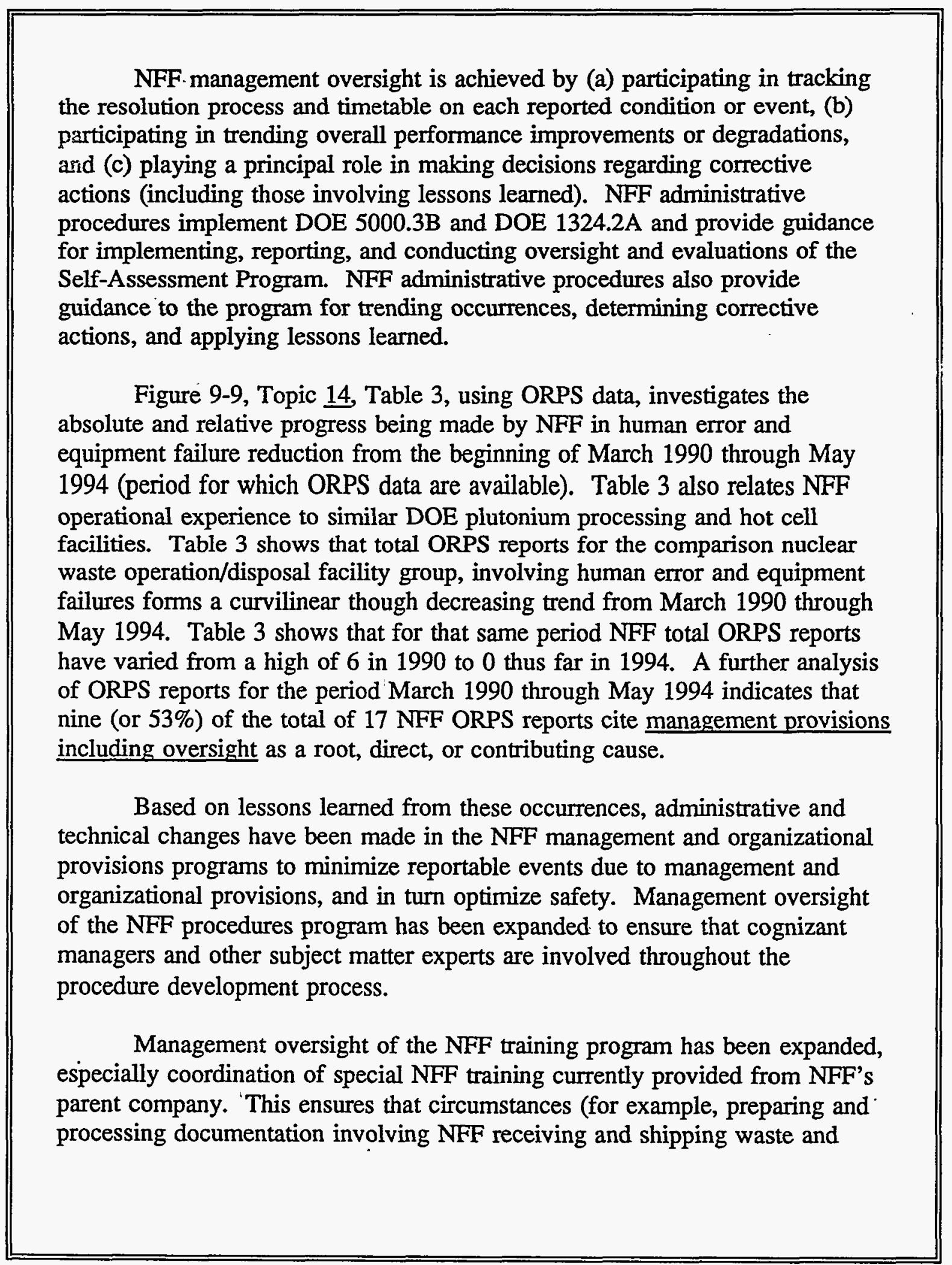


Figure 9-4 (cont.) Management and Organizational Provisions and Safety

other source material) are a primary focus of the training. Finally, NFF management oversight of day-to-day technical activities in and around the facility has been expanded to ensure verification of the completeness and correctness with which requirements and processes are communicated and carried out.

Since implementing these upgrades in the procedures program mid1993, NFF has no ORPS reports citing management and organizational provisions as root, direct, or contributing causes. As such, operational experience data suggest that NFF poses no significant threat to radiological and. chemical safety due to deficiencies in management and organizational provisions as causal factors. Also, the NFF management and organizational provisions programs are fully capable of supporting the nuclear safety SAR commitments to DOE. 


\subsubsection{Topic 13: Procedures and Training}

9.5.3.1 Technical Basis Using a Graded Approach This section of the topic response is usually prepared by an analyst other than the preparer of the HF inputs to the SAR.

\subsubsection{Description of Management and Organization Provisions or}

Program This section of the topic response is usually prepared by an analyst other than the preparer of the HF inputs to the SAR.

\subsubsection{Demonstration of Procedures and Training Safety Adequacy}

The safety adequacy of procedures and training is demonstrated by the preparer of the HF inputs to the SAR, through a three-step process:

(1) Discuss the hazards and accident analyses and demonstrate the degree to which procedures and training are fully capable of supporting the current mission of the facility including its SAR commitments to DOE. Use the hazards and accident analyses reported as Topics $\underline{5}$ and 11 in the SAR, and the HPA Results and Findings Report as the information sources. Figure 9-5, Section 9.5.1, using a Category 2 facility, provides a sample write-up for this section of Topic $\underline{13}$ in the SAR.

(2) Discuss the ORPS analysis of facility events involving procedures and training as causal factors using the human factors analysis report. More specifically, discuss trends (percentage of facility total ORPS reports, by year for the period March 1990 through current date) that cite one or more of these factors as root, direct or contributing 
causes. Figure 9-5, Section 9.5.2, using a Category 2 facility, provides a sample write-up for this section of Topic $\underline{13}$ in the SAR.

(3) Resolve inadequacies identified as part of the hazards and accident analyses using the interventions described in Chapter 8 of this text. Identify countermeasures instituted by the facility to reverse over-representation of procedures and training in their ORPS analysis. Discuss why these interventions and countermeasures enable facility programs involving procedures and training to be fully capable of supporting the nuclear safety SAR commitments to DOE. Figure 9-5, Sections 9.5.1 and 9.5.2, using a Category 2 facility, provides a sample write-up for this section of Topic $\underline{13}$ in the SAR. 
This section relates the Nuclear Fuels Facility (NFF) procedures and training programs to safety. The hazards and accident analyses results presented in Safety Analysis Report (SAR) Topics $\underline{5}$ and $\underline{11}$, and NFF operating experience data since March 1990, are used to demonstrate the programs' ability to fully support NFF commitments to the Department of Energy (DOE).

\subsubsection{NFF Hazards and Accident Analysis and Safety}

The NFF hazards and accident analyses identified and analyzed in excess of 60 potential accident sequences involving structures, systems and components (SSCs) for their safety relevance during NFF operations and maintenance activities (see SAR Topics $\underline{5}$ and 11 ). The Human Performance Assessment (HPA) segment of the accident analysis considered procedures and training as primary human causal factors (HCFs) for determining absolute human error rates and subsequently assessing their overall impact on accident likelihood and consequences. One of the accident sequences achieved a significant offsite consequence, and since no credit was taken for associated SSCs, none of the SSCs meet the criteria established in DOE Draft Standard 3009-94 for safety class or safety significant. Therefore, procedures and training are not safety issues at NFF, as they pertain to radiological and chemical safety. The accident analysis results data presented in SAR Topics $\underline{\mathbf{S}}$ and 11, suggest that NFF operations and maintenance activities pose no significant radiological or chemical safety hazard due to procedures and training, and that the NFF procedures and training programs are fully capable of supporting the current mission of the facility, including its SAR commitments to DOE.

\subsubsection{NFF Operational Experience and Safety}

NFF implements the DOE Occurrence Reporting and Processing System (ORPS), responding to the requirements of DOE Order 5000.3B for identifying abnormal or undesirable conditions and events, including those involving procedures and training. This process documents each occurrence in a structured manner, prioritizing, reviewing causes, determining proper corrective action, tracking resolution, applying lessons learned, officially closing out each abnormal or undesirable condition, and informing the originator. 
Figure 9-5 (cont.) Procedures, Training and Safety

NFF management oversight is achieved by (a) participating in tracking the resolution process and timetable on each reported condition or event, (b) participating in trending overall performance improvements or degradations, and (c) playing a principal role in making decisions regarding corrective actions (including those involving lessons learned). NFF administrative procedures implement DOE 5000.3B and DOE 1324.2A and provide guidance for implementing, reporting, and conducting oversight and evaluations of the Self-Assessment Program. NFF administrative procedures also provide guidance to the program for trending occurrences, determining corrective actions, and applying lessons learned.

Figure 9-9, Topic 14, Table 3, using ORPS data, investigates the absolute and relative progress being made by NFF in human error and equipment failure reduction from the beginning of March 1990 through May 1994 (period for which ORPS data are available). Table 3 also relates NFF operational experience to similar DOE plutonium processing and hot cell facilities. Table 3 shows that total ORPS reports for the comparison nuclear waste operation/disposal facility group, involving human error and equipment failures forms a curvilinear though decreasing trend from March 1990 through May 1994. Table 3 shows that for that same period NFF total ORPS reports have varied from a high of 6 in 1990 to 0 thus far in 1994. A further analysis of ORPS reports for the period March 1990 through May 1994 indicates that: (1) five (or 29\%) of the total of 17 NFF ORPS reports cite procedures as a root, direct, or contributing cause, and (2) two (or 12\%) of the total of 17 NFF ORPS reports cite training as a root, direct, or contributing cause.

Based on lessons learned from these occurrences, administrative and technical changes have been made in both the NFF procedures and training programs to minimize reportable events due to procedures and training, and in turn optimize safety. The validation element of the NFF procedures program has been expanded to ensure that all technical procedures are technically accurate, complete, and comprehensible, prior to their implementation. Management oversight of the program has been expanded to ensure that cognizant managers and other subject matter experts are involved throughout the procedure development process. Since implementing these upgrades in the procedures program in mid-1993, NFF has had no ORPS reports citing procedures as a root, direct, or contributing cause. 
Figure 9-5 (cont.) Procedures, Training and Safety

Coordination of the NFF training program, inside and outside the facility, has been expanded to ensure that non-NFF training elements of its parent company are cognizant of circumstances involving NFF receiving and shipping waste and other source material, especially its preparing accompanying documentation. NFF personnel directly involved in shipping waste and other source material have and are currently undergoing training focusing on receiving and shipping documentation. Additionally, the parent company is in the process of establishing a clearinghouse for coordinating, receiving, and shipping of waste and other source material to/from NFF within the parent company, and with entities external to the parent company. Since beginning implementation of these upgrades in its training program in mid1993, NFF has had no ORPS reports citing training as a root, direct, or contributing cause.

Operational experience data suggest that NFF poses no significant threat to radiological and chemical safety due to deficiencies in operating procedures or training. Also, the NFF procedures and training programs are fully capable of supporting the current nuclear safety SAR commitments to DOE. 


\subsubsection{Topic 14: Human Factors Engineering (HFE)}

9.5.4.1 Introduction Topic 14 of the SAR is directed solely at the human-machine interaction. More specifically it is directed at those interactions comprising structures, systems and components that are safety relevant as involving one or more of the following:

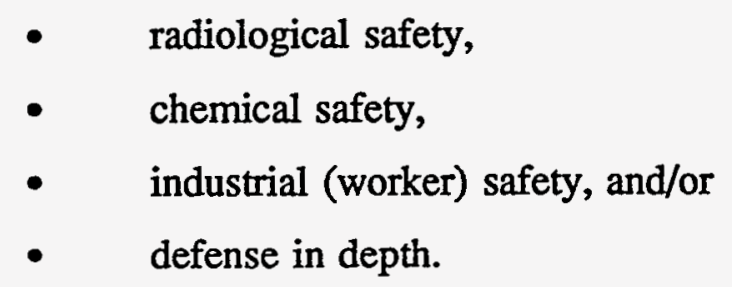

\subsubsection{Technical Basis Using a Graded Approach The technical} approach for providing an HF input to the HFE topic or section of the SAR is guided by the facility classification as Category 1,2 , or 3 . The facility classification is determined by the results of the hazards analysis discussed above. Figure 9-6 provides an example of a technical approach section of the HFE topic in the SAR.

\subsubsection{Description of DOE HFE Requirements and HFE Provisions} or Programs for Responding to Those Requirements This part of the HF input describes the manner in which HFE was evaluated as a HCF during the human safety analysis to support the HPA segments of the hazards analysis and accident analysis. Figure 9-7 and Figure 9-8 provide examples of HFE requirements and HFE program write-up for the SAR.

\subsubsection{Demonstration of Safety Adequacy Chapter 6 of this text} provides guidance for identifying and evaluating HFE related HCFs for Category 1,2, and 3 facilities. The safety adequacy of $\underline{\mathrm{HFE}}$ is demonstrated 
by the preparer of the HF inputs to the SAR, through a three-step process. Figure 9-9 presents an example of a write-up for the SAR.

(1) Discuss the hazards and accident analyses and demonstrate the degree to which HFE is fully capable of supporting the current mission of the facility including its SAR commitments to DOE. Use the Human Factors Analysis Results and Findings Report and the HPA Results and Findings Report. Figure 9-9, Section 9.9.1, provides a sample write-up of the HFE Analysis Section of SAR Topic 14. Use the hazards and accident analyses reported as Topics $\underline{5}$ and $\underline{11}$ in the SAR, and the HPA Results and Findings Report as the information sources. Figure 9-9, Section 9.9.2, provides a sample write-up of the HFE Deviations from Compliance and Safety Section of Topic 14 in the SAR. This section responds to requirements of DOE Order 5480.23, Attachment 1 , Sections $\underline{14 a}$ through $\underline{14 c}$.

(2) Discuss the ORPS analysis of facility events involving HFE as a causal factor. More specifically, discuss trends (percentage of facility total ORPS reports, by year for the period March 1990 through current date) that cite HFE as a root, direct or contributing cause. Use the Human Factors Analysis Results and Findings Report as the information source. Figure 9-9, Section 9.9.3, provides a sample write-up for the Human Performance under Abnomal Conditions Section of Topic 14 in the SAR. This section responds to requirements of DOE Order 5480.23, Attachment 1, Section 14d. 
(3) Resolve inadequacies identified as part of the hazards and accident analyses using the interventions described in Chapter 8 of this text. Identify countermeasures instituted by the facility to reverse over-representation of HFE in the ORPS analysis. Discuss why these interventions and countermeasures enable facility programs involving HFE to be fully capable of supporting the nuclear safety SAR commitments to DOE.

Figure 9-9, Sections 9.9.2.2 and 9.9.3.3, using a Category 2 facility, provide sample write-ups for the Safety Adequacy sections of Topic 14 in the SAR. 
Figure 9-6 Introduction and Technical Approach

This topic of the Nuclear Fuel Facility (NFF) Safety Analysis Report (SAR) is prepared in response to requirements established by DOE 5480.23, Safety Analysis Reporting, Attachment 1, Section 14, "Human Factors Engineering (HFE)," and as further defined by DOE Standard 3009-94, Chapter 13, "Human Factors."

\subsubsection{Introduction}

The purpose of this chapter is to describe human factors engineering requirements imposed by the Department of Energy (DOE), HFE and Human Performance Assessment analyses undertaken by NFF to respond to these requirements, and how human factors engineering impacts NFF safety for purposes of its Safety Analysis Report (SAR).

\subsubsection{NFF Mission}

The primary mission of NFF includes radiological, chemical, and industrial operations such as retrieving, transporting, unencapsulating, sizing, repackaging, and storing source materials from offsite, onsite above ground storage pads and buildings, and a storage pool. To fulfill this mission, NFF operates and maintains several types of structures, systems, and components (SSCs). Human-machine interfaces involving the following SSCs, included in the human factors analysis, are the subject of this chapter:

- $\quad$ NFF Operations (Hot Shop, Warm Shop, NFF Hot Cell, Storage Pool, Vestibule, Canister Dryer, Silo, Pool Filter Room);

- General Areas including storage areas, transit corridors, and emergency communications room;

- $\quad$ Liquid Waste Storage and Handling System;

- NFF General Outside Transport Areas;

- $\quad$ Pad A (Three Mile Island [TM] Abnormal Waste Storage) and Pad B (Dry Fuel Storage); 
Figure 9-6 (cont.) Introduction and Technical Approach

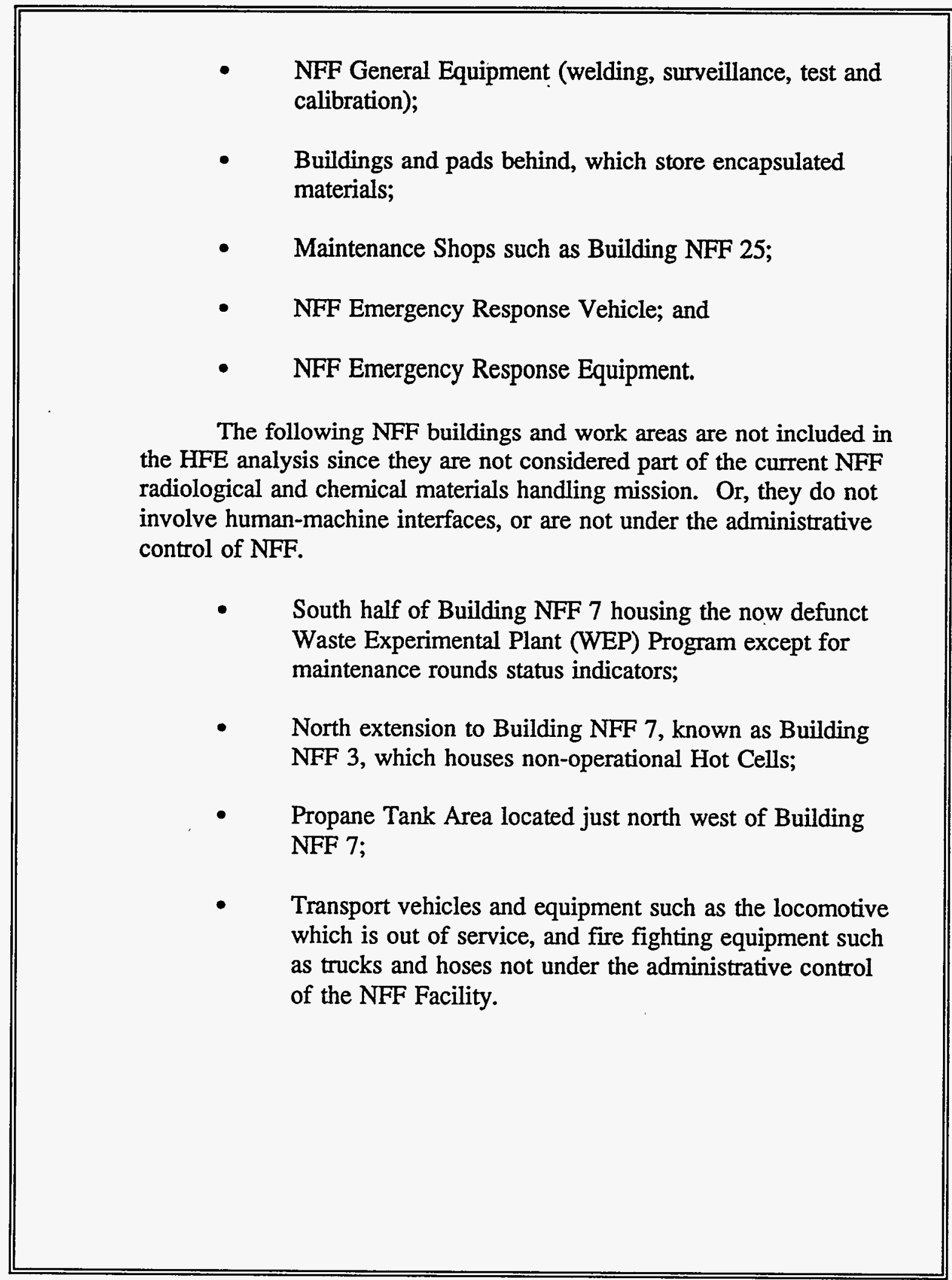


Figure 9-6 (cont.) Introduction and Technical Approach

\subsubsection{NFF Classification}

NFF has been classified a Hazard Category 2 facility based on criteria established in DOE 1027-92 regarding inventories of radiological and chemical materials. The technical approach to this chapter (e.g., scope and depth) is guided by the following additional considerations.

9.6.1.2.1. DOE Guidance DOE Standard 3009-94, Preparation Guide for U.S. Department of Energy Nonreactor Nuclear Safety Analysis Reports, May 1994, was reviewed for consistency with this HFE analysis. The review determined that the HFE safety analysis reported here fully responds to the intent of the guidance provided in DOE Standard 3009-94, commensurate with the NFF Hazard Category 2 considerations discussed below.

9.6.1.2.2. NFF Manual Operations NFF, a plutonium processing and hot cell operation, is characterized by:

- $\quad$ storing and managing source material on pads, in buildings, and in a storage pool;

- transporting encapsulated source material from/to offsite, onsite, and storage pool locations to/from a Hot Shop, and Hot Cell; and

- processing source materials (unencapsulating, drying, sizing, encapsulating, surveying) in a Hot Shop, and Hot Cell.

9.6.1.2.3. NFF Operating History The operating history of NFF over the past three years suggests that a reasonably good operating environment exists within the bounds of the current NFF operating configuration and mission (see Table 3

Figure 9-9). 
Figure 9-6 (cont.) Introduction and Technical Approach

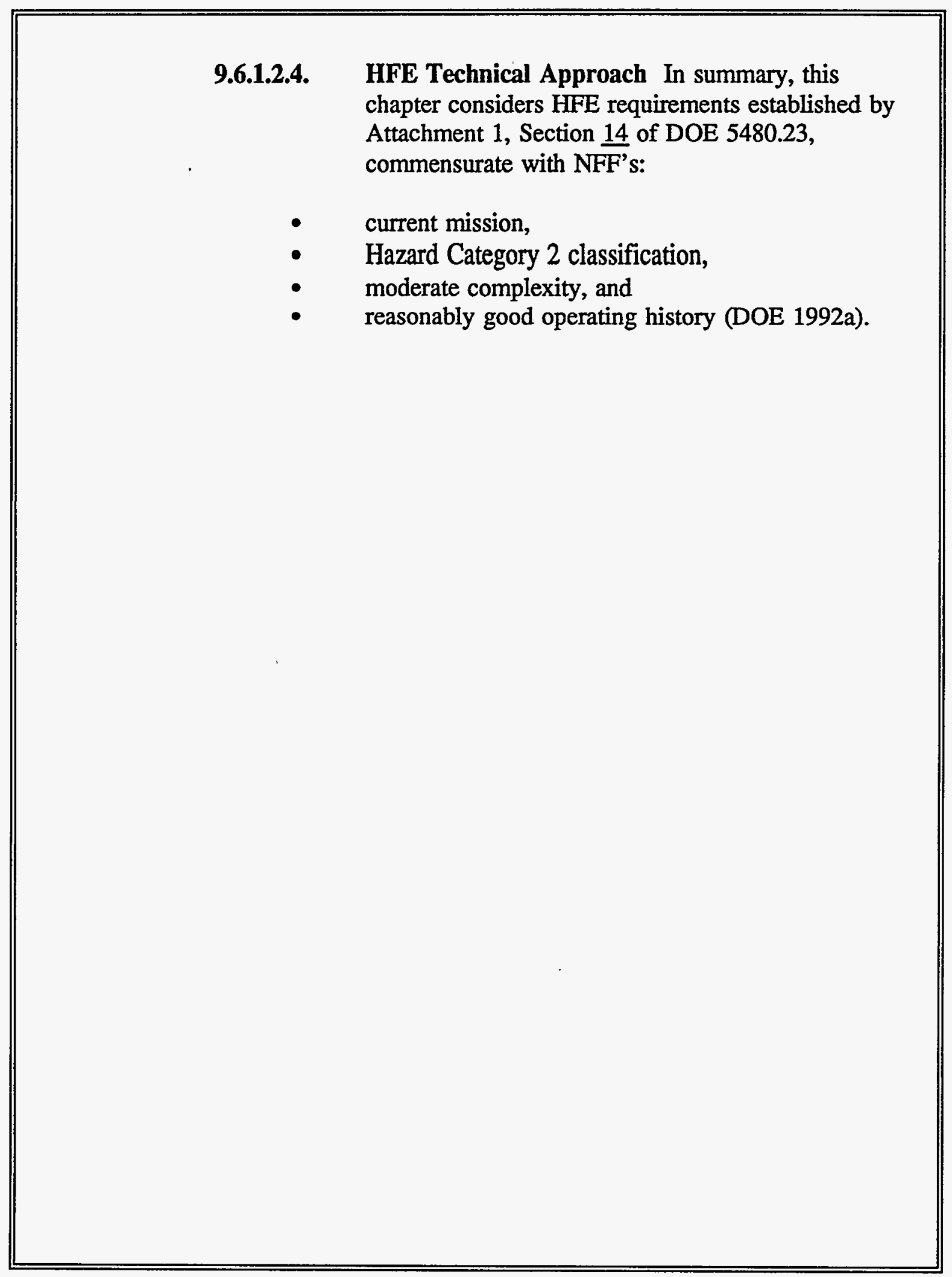




\subsubsection{DOE Requirements}

DOE Order 5480.23, Attachment 1, Section 3.b(1)(b) defines human factors safety to include: "allocation of control functions to humans and machines, staffing and qualifications of personnel, personnel training, written procedures to guide operations and maintenance, and design of human-machine interfaces." NFF has established human factors programmatic activities focusing on each of these areas responding to governing DOE Orders and standards, and non-DOE referenced standards, commensurate with NFF's classification as a Category 2 nonreactor nuclear facility. NFF human factors programmatic activities respond to the following requirements:

- allocation of control functions to humans and machines for operations and maintenance as required by DOE Orders 5480.19 , 5480.20, and 5480.23 Attachment 1 Topics $\underline{12}$ and 15 ;

- $\quad$ staffing and qualifications of personnel for operations and maintenance as required by DOE Orders $5480.19,5480.20$, and 5480.23 Attachment 1 Topics $\underline{12}$ and $\underline{15}$;

- $\quad$ personnel training for operations and maintenance as required by DOE Orders 5480.20, and 5480.23 Attachment 1 Topics $\underline{13}$ and $15 ;$

- written procedures to guide operations and maintenance as required by DOE Orders $5480.19,4330.4 \mathrm{~A}$, and 5480.23 Attachment 1 Topics $\underline{13}$ and $\underline{15}$; and DOE Standard 1029-92; and

- design of human-machine interfaces (human factors engineering), for operations and maintenance as required by DOE Orders 6430.1A Section 1300-12, and 5480.23 Attachment 1 Topic 14.

Allocation of control functions to humans and machines, staffing and qualifications of personnel, personnel training, and written procedures to guide operations and maintenance are covered primarily in SAR Topics 12,13 , and 15. The latter human factor engineering (HFE) area, the subject of this topic, is governed by the general design requirements provisions of DOE Order 6430.1A, Section 1300-12. Further, the DOE SAR Order 5480.23, Attachment 1 , Topic 14 requires that: 
"A systematic inquiry needs to be included into the importance to safety of reliable, correct, and effective human-machine interactions, including the effectiveness of surveillance, maintenance, and normal, abnormal and emergency operations. In those contexts in which reliable, effective human performance by the operating crew is important to safety, and in proportion to the importance-to-safety, safety analyses should document a systematic inquiry into the optimization of the design of the humanmachine interface to enhance reliable human performance."

Human-machine design considerations should include:

14a communication and operational aids

$14 \mathrm{~b}$ layout of controls and instrumentation and labeling

14c work environment factors such as heat, light, noise, physical access, protective clothing, and breathing apparatus

14 demonstrated ability of personnel to accomplish their responsibilities under normal, abnormal, and accident conditions. 


\subsubsection{Nuclear Fuels Facility (NFF) Human Factors Program}

In complying with the requirements of $6430.1 \mathrm{~A}$, and to support its SAR and TSR process responding to 5480.23 and DOE Order 5480.22 respectively, NFF has conducted and continues to update two analyses. The first is an HFE analysis to assess the degree to which NFF fully responds to the requirements of $14 \mathrm{a}$ through $14 \mathrm{c}$ above, given its classification as a Category 2 facility. The results of the current HFE analysis and SAR are summarized in Figure 9-9. The second is an analysis of NFF and similar facility Occurrence Reporting and Processing System (ORPS) reports, along with a Human Performance Assessment (HPA) calculating the impacts of human error on the results of the hazards and accident analysis reported in Topics $\underline{5}$ and $\underline{11}$, fully responding to the requirements of $14 \mathrm{~d}$. The results of the ORPS analysis and the HPA are also reported in Figure 9-9. Figure 14-1 portrays these programmatic steps to achieve a technical basis for this chapter of the NFF SAR.

\subsubsection{Human Factors Engineering (HFE) Analysis}

An HFE analysis of all NFF human-machine interfaces was conducted, as required by $6430.1 \mathrm{~A}$ and 5480.23 , involving SSCs involved in its current and anticipated technical activities. Compliance checklists employed in the HFE analysis were developed using non-DOE standards referenced in the DOE orders. These included MIL-STD 1472D, NUREG-0700, OSHA 29 CFR 1910.132, 1910.133, 1910.134; and, ANSI Z88.1980. NFF HFE checklists are contained in the HF analysis report Appendix C. The resulting series of HFE checklists (based on DOE requirements and standards referenced by DOE) addresses the following 17 human-machine interface requirements established by DOE 5480.23, Attachment 1, Section 14a through 14c:

- Operational Aids

- Control/Display Integration

- Controls - General

- Hand Operated Controls

- Foot Operated Controls

- Controls for User Computer Interface (UCI)

- $\quad$ Visual Displays

- Transilluminated Displays 
Figure 9-8 (cont) NFF Human Factors Program

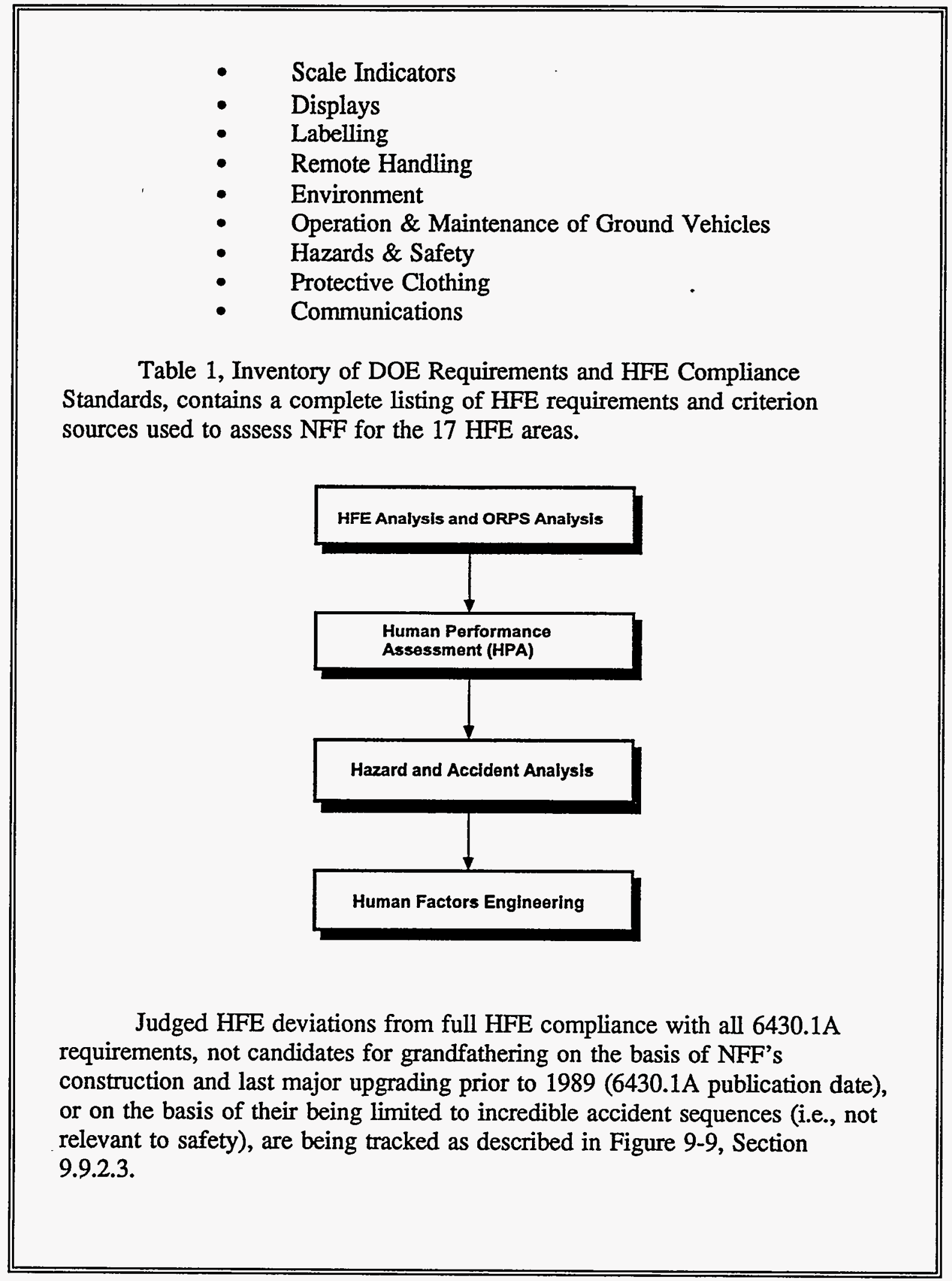


Human-machine interfaces included as human causal factors (HCFs), in the HPA segment of the hazards and accident analyses reported in SAR Topics $\underline{5}$ and 11 , are also reported in Figure 9-9, Section 9.9.1. Judged HFE deviations from full compliance with DOE referenced standards, as represented by the compliance checklists, and determined by the hazards and accident analyses to be involved in credible accident sequences (i.e., relevant to safety), if any, are tabulated in Figure 9-9, Section 9.9.1, along with their resolution for fully supporting NFF's SAR commitments to DOE.

\subsubsection{Human Performance under Abnormal Conditions}

Dependable performance by NFF management and staff under abnormal and emergency conditions is a high priority. All NFF programmatic activities, including its considerations of human factors, are directed toward this end. In order to assess the degree to which NFF is meeting this goal (for purposes of the FSAR and TSRs) information from the SAR Topics $\underline{5}$ and 11 hazards and accident analyses and Occurrence Reporting and Processing System (ORPS) is used.

In the first instance, human errors impacting credible accident sequences are examined to determine how much error likelihood can be reduced by optimizing one or more of the human factors assessed in the SAR Topics $\underline{5}$ and 11 hazards and accident analyses as HCFs (training, procedures, oversight, staffing and qualifications and a function of experience, and HFE). This is done by computing Best Case (all HCFs optimized) error likelihoods for all human actions and action sequences. Figure 9-9 reports the results of this process for HFE. 


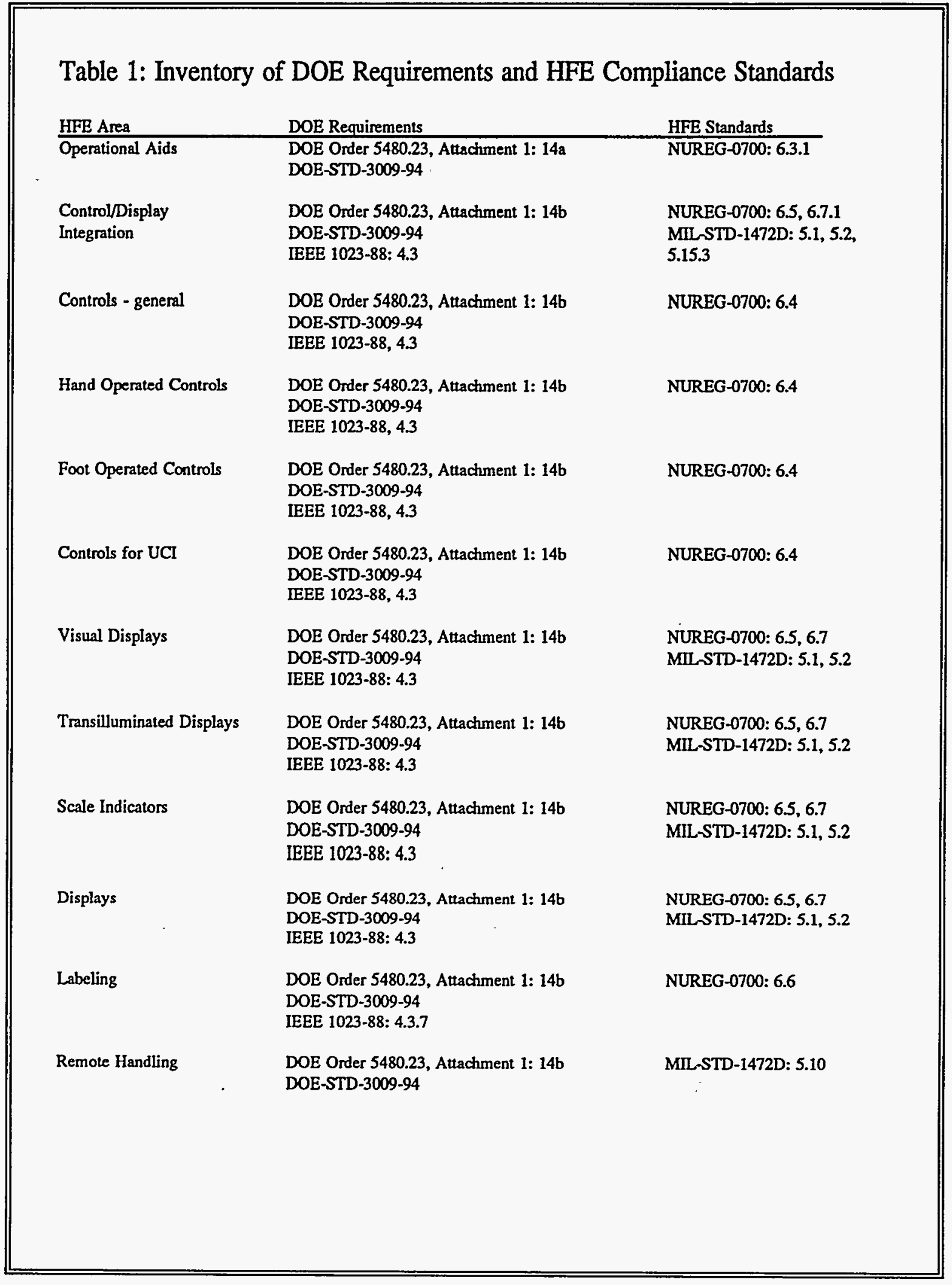


Figure 9-8 (cont.) NFF Human Factors Program

Table 1: Inventory of DOE Requirements and HFE Compliance Standards (cont)

\begin{tabular}{lll} 
HFE Area & DOE Requirements & HFE Standards \\
\hline Environment & DOE Order 5480.23, Attachment 1: 14c & MIL-STD-1472D: 5.8.1, 5.8.2, 5.8.3 \\
& DOE-STD-3009-94 & \\
& IEEE 1023-88: 4.2.1
\end{tabular}

Operation \&

Maintenance of

Ground Vehicles DOE Order 5480.23, Attachment 1: $14 \mathrm{c}$ DOE-STD-3009-94

Hazards \& Safety DOE Order 5480.23, Attachment 1: 14c DOE-STD-3009-94

MIL-STD-1472D: 5.8.1, 5.8.2, 5.8.3

IEEE 1023-88: 4.2.1

Protective Clothing

DOE Order 5480.23, Attachment 1: 14c

29 CFR 1910: 132, 133, 134

ANSI-STD-Z88.2-1988: $6.15,7.2$

Communications $\quad$ DOE Order 5480.23, Attachment 1: 14a

NUREG-0700: 6.2 .1

In the second instance, ORPS data are used to trend the percentages of total NFF ORPS reports, by year, involving personnel error as direct, indirect, or contributing causes. Additionally, these trends are compared with grouped yearly trends for other similar facilities. Facility and comparative trending results are reported in Figure 9-9, Section 9.9.3.

\subsubsection{Identification of Human-Machine Interfaces}

This section describes NFF structures, work areas and equipment identified from earlier walkdown task analyses as appropriate subjects of the HFE analysis. The HFE analysis focused on the NFF structure, several working areas in and around the structure, and 106 systems, components, and handling devices located or used in these work areas.

\subsubsection{Human-Machine Interfaces Included in the HFE Analysis}

Twenty NFF primary work areas are included in the HFE analysis. Within these work areas, various pieces of equipment were analyzed which play a direct or directly supporting role in the radiological, chemical, and industrial operations currently being carried out in NFF, 
and could therefore, have implications for the safety of local, onsite, and offsite personnel due to radiological or chemical consequences.

Detailed descriptions of SSCs involved in these work areas are provided in Topic $\underline{4}$ of this NFF SAR.

\subsubsection{Human-Machine Interfaces Not Included in the HFE Analysis}

A number of workstations, building areas, and handling devices, either within NFF, or external to NFF but part of the facility, were not included in the HFE analysis. They were not included for one or more of the following reasons (taking into consideration NFF's mission and classification as a Category 2 facility):

- They are not under the administrative control of NFF management and staff.

- They do not directly support, or no longer support, the technical mission of the facility, i.e., materials handling.

- They are redundant items and activities.

- They do not involve human-machine interfaces.

For one or more of the above reasons, the following workstations, building areas, and handling devices were not included in the HFE analysis:

- Administrative offices located on the main floor of NFF housing health physics and other operations not directly involved in NFF materials handling activities,

- $\quad$ Building areas not used to directly support the primary materials handling mission of the facility, 
Figure 9-8 (cont.) NFF Human Factors Program

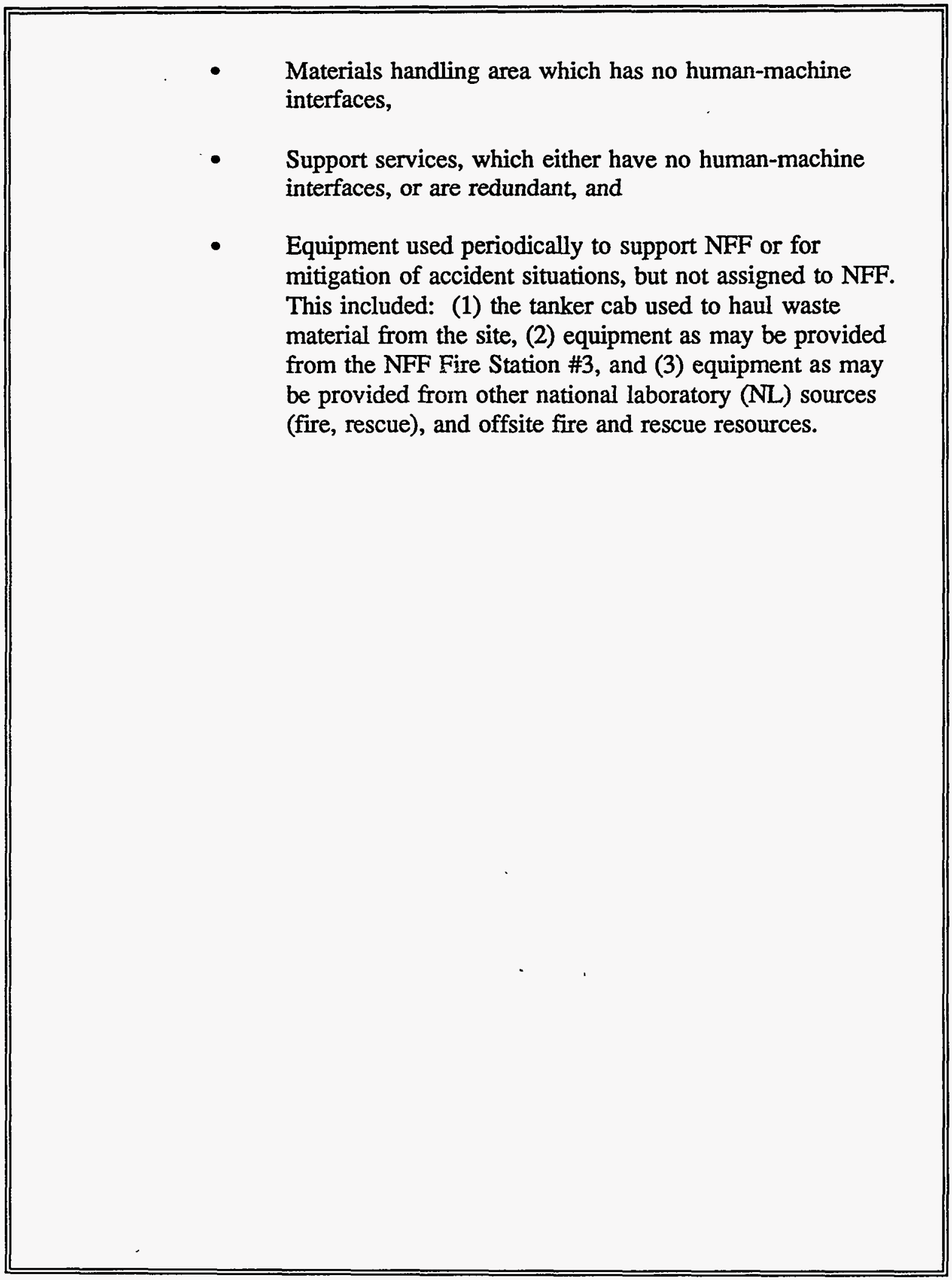


This section summarizes human factors engineering (HFE) analysis results of Nuclear Fuels Facility (NFF) compliances and deviations from full compliance with the DOE and DOE referenced compliance standards listed in Table 1. Section 9.9.1 presents the HFE analysis results, responding to the requirements of DOE Order 5480.23, Attachment 1 Topics $14 \mathrm{a}$ through $\underline{14 \mathrm{c}}$. Section 9.9.2 presents an analysis of judged deviations from full HFE compliance, and their relevance to safety based on the results of the SAR Topics $\underline{5}$ and 11 hazards and accident analyses. Responding to the requirements of DOE Order 5480.23, Attachment 1 Topic 14d, Section 9.9.3 presents a trending and comparative analysis of human error rates as a percentage of NFF ORPS reports, and compared with the mean percentages of a group of similar DOE facilities.

\subsubsection{HFE Analysis Results}

NFF was found to be in compliance with relevant HFE standards, and therefore with DOE HFE requirements, in 89 percent of applicable observations. Of the 4793 observations made, there were 525 human-machine interfaces judged to deviate from full compliance with the HFE standards. Table 2 presents a summary of the results of the HFE analysis. HFE findings are broken up into three human-machine interface categories.

- $\quad$ First are human-machine interfaces (HMIs) having to do with NFF general building area in which workstations are located.

- Second are HMIs associated with NFF workstations.

- Third are human-machine interfaces of interest having to do with materials handling devices located in NFF such as hand carts, remote manipulators, hoists, and cranes.

The General Building areas have the highest compliance rate at 98 percent, and the handling devices (e.g., remote manipulators, hoists, cranes) have the lowest compliance rate at 74 percent. Compliances are tallied in Table 2, and are presented in detail in the HF analysis report, Appendices A and $\mathrm{B}$. Table 2 combines all the information tabulated for the building into the $17 \mathrm{HFE}$ areas. The observations were counted and separated into three categories: Not Applicable, Compliance, and Deviation from full compliance. The total number of observations performed, both with and without the Not 
Table 2

\begin{tabular}{|c|c|c|c|c|c|c|c|c|}
\hline HFE Area & HFE Compliance Category & N/A & Non-Compliance & Compliance & $\begin{array}{l}\text { Total } \\
\text { Obs's }\end{array}$ & $\begin{array}{l}\text { Total Obs's } \\
\text { Minus N/A's }\end{array}$ & Pereent Compliance & $\begin{array}{c}\text { Percent } \\
\text { Non-Compliance }\end{array}$ \\
\hline \multirow[t]{11}{*}{ Workstation } & Control/Display Integration & 106 & 15 & 75 & 196 & 90 & $83.33 \%$ & $16.67 \%$ \\
\hline & Visual Displays & 4 & 4 & 25 & 33 & 29 & $86.21 \%$ & $13.79 \%$ \\
\hline & Transilluminated Displays & 35 & 10 & 54 & 99 & 64 & $84.38 \%$ & $15.63 \%$ \\
\hline & Scale Indicators & 247 & 49 & 508 & 804 & 557 & $91.20 \%$ & $8.80 \%$ \\
\hline & Displays & 216 & 2 & 79 & 297 & 81 & $97.53 \%$ & $2.47 \%$ \\
\hline & Controls-General & 495 & 36 & 267 & 798 & 303 & $88.12 \%$ & $11.88 \%$ \\
\hline & Hand Operated Controls & 3,708 & 61 & 521 & 4,290 & 582 & $89.52 \%$ & $10.48 \%$ \\
\hline & Foot Operated Controls & 12 & 8 & 208 & 228 & 216 & $96.30 \%$ & $3.70 \%$ \\
\hline & Controls for UCI & 75 & 1 & 31 & 107 & 32 & $96.88 \%$ & $3.13 \%$ \\
\hline & Labelling & 1,004 & 260 & 2,168 & 3,432 & 2,428 & $89.29 \%$ & $10.71 \%$ \\
\hline & Operational Aids & 21 & 2 & 13 & 36 & 15 & $86.67 \%$ & $13.33 \%$ \\
\hline \multirow[t]{4}{*}{ Building } & Environment & 14 & 0 & 20 & 34 & 20 & $100.00 \%$ & $0.00 \%$ \\
\hline & Hazards \& Safety & 35 & 1 & 17 & 53 & 18 & $94.44 \%$ & $5.56 \%$ \\
\hline & Protective Clothing & 7 & 0 & 57 & 64 & $5 ?$ & $100.00 \%$ & $0.00 \%$ \\
\hline & Communications & 37 & 1 & 34 & 72 & 35 & $97.14 \%$ & $2.86 \%$ \\
\hline \multirow[t]{2}{*}{ Handling } & Remote Handling & 42 & 15 & 19 & 76 & 34 & $55.88 \%$ & $44.12 \%$ \\
\hline & $\begin{array}{l}\text { Operation \& Maintenance of } \\
\text { Ground Vehicles }\end{array}$ & 84 & 60 & 172 & 316 & 232 & $74.14 \%$ & $25.86 \%$ \\
\hline & TANO Totals & 6,142 & 525 & 4,268 & 10,935 & 4,793 & $89.05 \%$ & $10.95 \%$ \\
\hline
\end{tabular}


Figure 9-9 (cont.) Design Optimization of Human-Machine Interfaces

Applicable observations included. The percent judged compliance and deviation from full HFE compliance are calculated by dividing the number of compliances or deviations from full compliance by the total number of observations not including the Not Applicables

The total NFF compliance and judged deviations from full HFE compliance percentage tallies presented in Table 2 are positive results given:

- NFF's use of off-the-shelf equipment from a variety of vendors, and

- $\quad$ age of most of the equipment, that is, predating 1989.

\subsubsection{NFF HFE Deviations and Safety}

This section relates judged deviations from full HFE compliance to safety, as required by DOE Order 5480.23, Attachment 1, Sections 14 a through 14d. This section uses information from the HF analysis report, HPA analysis report, and SAR Topics $\underline{5}$ and $\underline{11}$ hazards and accident analyses. .

Analysis of abnormal and accident conditions (including design basis accidents, man-made, and/or natural events) is prescribed by DOE Order 5480.23, which states: "Requirements, sub paragraph b.3.(k), human actions and decisions in response to abnormal events should be analyzed in order to assure the safety of the facility including the safety design and operational safety commitments, and human factors safety provisions." Further, Attachment 1., Section 11 of DOE Order 5480.23 requires that a safety analysis (conducted under the $\mathrm{SAR}$ ) should include deterministic safety analysis, Human Performance Assessment, and human factors safety analysis techniques as appropriate to the identification, investigation, and mitigation or control of vulnerabilities within the facility or accidents and accidental releases.

\subsubsection{Accident Analysis and Safety}

The NFF hazards and accident analyses reported as SAR Topics $\underline{5}$ and 11 , identified and analyzed in excess of 60 potential accident sequences involving structures, systems and components (SSCs). HFE was considered in the analysis as a primary human causal factor (HCF). 
Figure 9-9 (cont.) Design Optimization of Human-Machine Interfaces

None of the accident sequences achieved a significant offsite consequence, and since no credit was taken for associated SSCs, none of the SSCs meet the criteria established in DOE Draft Standard 300994 for safety class or safety significant. Therefore, none of the judged deviations from full HFE compliance surveyed in Table 2 are safety issues, as they pertain to radiological and chemical safety.

\subsubsection{Nuclear Safety Assessment}

The hazards and accident analysis results data presented in FSAR Topics $\underline{5}$ and 11 suggest that NFF operations pose no significant nuclear safety hazard due to human error, and that the NFF HFE operating configuration is fully capable of supporting the current mission of the facility, including its SAR commitments to DOE.

\subsubsection{Industrial Safety Assessment}

The 525 judged deviations from full HFE compliances tallied in Table 9-5 and described in detail in the HF analysis results and findings report (Appendices A and B), could have an impact on industrial safety as defined by 29 CFR 1910 . Each HFE criterion making up the HFE compliance standards contained in the HF analysis results and findings report Appendix $\mathrm{C}$ is, without exception, related to safety in that failure to comply raises the likelihood of human error which in turn leads to an increased probability of an unsafe condition. HFE criteria are based on scientific literature developed in the behavioral and social sciences over the past century. Whether an unsafe condition induced by noncompliance with one or more HFE criteria has the potential for radiological, chemical, and/or industrial consequences can only be determined by the type of accident analysis reported in Topics $\underline{5}$ and 11 of this SAR.

NFF is tracking these latter judged deviations, and will resolve them, if appropriate, on a case-by-case basis, through one or more of the options described in Sections 9.9.2.3.1 through 9.9.2.3.4 below. This approach will also be employed as part of facility upgrades such as the canister dryer planned for the Hot Shop, in keeping with DOE Order 6430.1A, Section 1300-12 (1300-12.1, Coverage), which states: " these [human factors engineering] criteria shall be considered for upgrading existing 
facilities where cost-benefit or risk-tradeoff analyses indicate justification for such expenditures." These options below do two things. First, they are directed toward minimizing disruption of existing structures and equipment. Second, they are directed toward achieving . acceptable levels of safety while minimizing costs.

9.9.2.3.1. Administrative Upgrades Administrative controls involve changes in training, written procedures, staffing, and direct oversight, or any combination capable of compensating for HFE deviations. These interventions do not impact the current equipment design and configuration. For example, improper positioning of displays and controls relative to one another that preclude individual workers from operating the equipment can often be overcome by adding a second participating worker. Marginal labeling can often be overcome through additional training of workers or expanded written procedures for operating equipment associated with the marginal labeling.

9.9.2.3.2. Non-Intrusive Upgrades These interventions involve changes to equipment operating configurations without changing the equipment itself. For example, higher wattage light bulbs can sometimes be added without modifying the electrical system or electrical fixture. Individual pieces of equipment and furniture making up a workstation can be physically rearranged to achieve compliance.

9.9.2.3.3. Intrusive Upgrades These interventions involve actual changes to the equipment. They are used where administrative controls and non-intrusive interventions cannot be demonstrated to achieve acceptable performance levels. They may be necessary in all cases of equipment involved in dominating accident sequences. In all cases where 
Figure 9-9 (cont.) Design Optimization of Human-Machine Interfaces

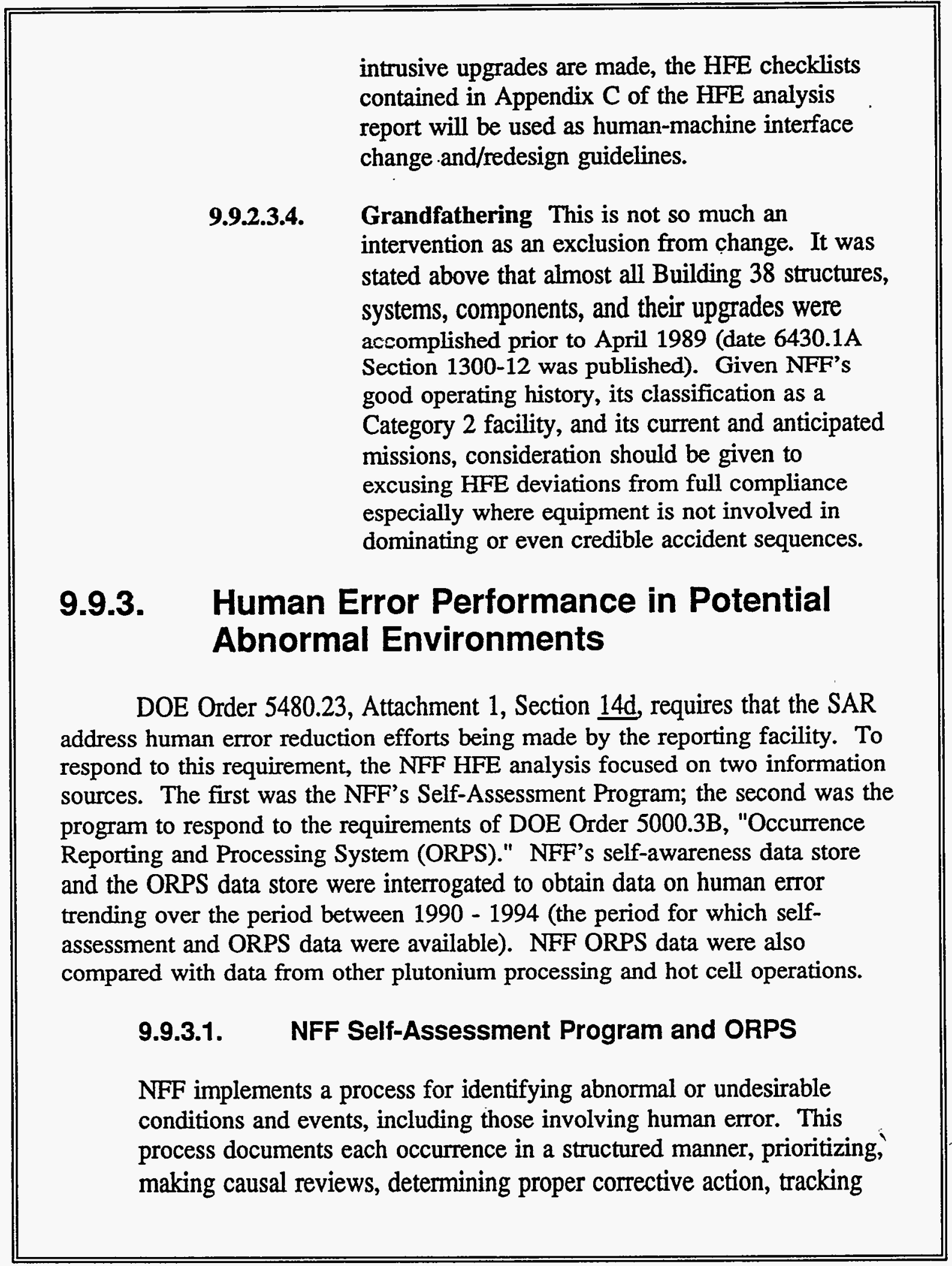


Figure 9-9 (cont.) Design Optimization of Human-Machine Interfaces

resolution, applying lessons learned, officially closing out each abnormal or undesirable condition, and informing the originator. NFF management oversight is achieved by (a) participating in tracking the resolution process and timetable on each reported condition or event, (b) participating in trending overall performance improvements or degradations, and (c) playing a principal role in making decisions regarding corrective actions (including those involving lessons learned). NFF administrative procedures implement DOE 5000.3B and DOE $1324.2 \mathrm{~A}$ and provide guidance for implementing, reporting, and conducting oversight and evaluations of the Self-Assessment Program. NFF administrative procedures implement DOE 5000.3B and provide guidance to the program for trending occurrences, determining corrective actions, and applying lessons learned.

\subsubsection{NFF Operational Experience}

This section describes the results of the analysis of NFF's SelfAssessment Program and their participation in the DOE ORPS. These results will provide a framework for comparing NFF's human error rates to other similar facilities. The findings presented in this section, along with the results of the NFF FSAR Chapter 3 hazards and accident analyses, respond to the requirements of DOE 5480.23, Attachment 1 , Section $14 \mathrm{~d}$, regarding human performance under abnormal conditions. Table 3 investigates the absolute and relative progress being made by NFF in human error reduction from the beginning of March 1990 through May 1994, using ORPS data. This investigation relates NFF to other plutonium processing and hot cell facilities, using ORPS data. The top segment of Table 3 shows reports initiated by the comparison group. The left column indicates the number of facilities reporting. The second column from the left reports the total number of ORPS reports submitted by the comparison group for each year. The third column reports the number of ORPS reports involving human error. Finally, the fourth column computes the percentage of the total reports involving human error. The bottom two segments of Table 3 report the same information for NFF. The top half of Table 3 shows the percentage of total reports for the comparison nuclear waste operation/disposal facility group, involving human error, forms a curvilinear although decreasing trend from March 1990 through May 
Figure 9-9 (cont.) Design Optimization of Human-Machine Interfaces

Table 3 ORPS Reports Trending and Comparisons

\begin{tabular}{llll} 
Facilities & Total & \multicolumn{2}{l}{ Human Error } \\
Reporting & Reports & Reports & Percentage
\end{tabular}

Comparison Group 1990

\begin{tabular}{|c|c|c|c|c|}
\hline Partial Year & 17 & 77 & 31 & 40 \\
\hline 1991 & 52 & 495 & 221 & 45 \\
\hline 1992 & 48 & 603 & 276 & 46 \\
\hline 1993 & 41 & 669 & 205 & 31 \\
\hline $\begin{array}{l}1994 \\
\text { thru May }\end{array}$ & 19 & 158 & 20 & 13 \\
\hline$\frac{N F F}{1990}$ & & & & \\
\hline Partial Year & 1 & 6 & 1 & 16 \\
\hline 1991 & 1 & 2 & 2 & 100 \\
\hline 1992 & 1 & 4 & 4 & 100 \\
\hline 1993 & 1 & 5 & 4 & 80 \\
\hline $\begin{array}{l}1994 \\
\text { thru May }\end{array}$ & 1 & 0 & 0 & 0 \\
\hline
\end{tabular}

1994, from $40 \%$ to $13 \%$. The bottom half of Table 3 shows that for that same period NFF ORPS reports involving human error show a similar curvilinear trend although at a higher human error involvement level except for 1990 and 1994. However, a content analysis of 1993 NFF ORPS reports indicates that none attributes HFE as a root, direct, or contributing cause. 
Figure 9-9 (cont.) Design Optimization of Human-Machine Interfaces

\subsubsection{Safety Assessment}

Table 2 operational experience data suggest that NFF poses no significant radiological or chemical safety hazards due to human error with HFE as a causal factor, and that the NFF HFE operating configuration is fully capable of supporting the current nuclear safety SAR commitments to DOE. 


\subsubsection{Topic 15: Initial Testing, In-Service Surveillance, and Maintenance}

9.5.5.1 Technical Basis Using a Graded Approach This section of the topic response is usually prepared by an analyst other than the preparer of the HF inputs to the SAR.

\subsubsection{Description of Management and Organization Provisions or}

Program This section of the topic response is usually prepared by an analyst other than the preparer of the HF inputs to the SAR.

\subsubsection{Demonstration of Testing, Surveillance and Maintenance}

Safety Adequacy The safety adequacy of testing, surveillance, and maintenance is demonstrated through a three-step process:

(1) Discuss the hazards and accident analyses and demonstrate the degree to which testing, surveillance and maintenance are fully capable of supporting the nuclear safety SAR commitments to DOE. Use the hazards and accident analyses reported as Topics $\underline{5}$ and $\underline{11}$ in the SAR and the HPA Results and Findings Report as the information sources. Figure 9-10, Section 9.10.1, using a Category 2 facility provides a sample write-up for this section of Topic $\underline{15}$ in the SAR.

(2) Discuss the ORPS analysis of facility events involving testing, surveillance and maintenance as causal factors. More specifically, discuss trends (percentage of facility total ORPS reports, by year for the period March 1990 through current date) that cite one or more of these factors as root, direct or contributing causes. Use the 
human factors analysis as the information source.

Figure 9-10, Section 9.10.2, using a Category 2 facility provides a sample write-up for this section of Topic 15 in the SAR.

(3) Resolve inadequacies identified as part of the hazards and accident analyses using the interventions described in Chapter 8 of this Course Text. Identify countermeasures instituted by the facility to reverse over-representation of testing, surveillance and maintenance in the ORPS analysis. Discuss why these interventions and countermeasures enable facility programs involving testing, surveillance and maintenance to be fully capable of supporting nuclear safety SAR commitments to DOE. Figure 9-10, Sections 9.10.1 and 9.10.2, using a Category 2 facility provide sample write-ups for the Safety Adequacy Sections of Topic 15 in the SAR. 
Figure 9-10 Initial Testing, In-service Surveillance, and Maintenance

This section relates the Nuclear Fuels Facility (NFF) initial testing, surveillance, and maintenance program to safety. The hazards and accident analyses results presented in Safety Analysis Report (SAR) Topics $\underline{5}$ and $\underline{11}$, and NFF operating experience data since March 1990 are used to demonstrate the programs' ability to fully support NFF commitments to the Department of Energy (DOE).

\subsubsection{NFF Hazards and Accident Analysis and Safety .}

The NFF hazards and accident analyses identified and analyzed in excess of 60 potential accident sequences involving structures, systems and components (SSCs) for their safety relevance during NFF operations and maintenance activities (see SAR Topics $\underline{5}$ and $\underline{11}$ ). The accident analysis considered several initial testing, surveillance and maintenance related activities for their potential as accident precursors, accident initiators, or contributors to accident initiation. Potential equipment failures and human error likelihood during initial testing, surveillance and maintenance were considered as primary human causal factors (HCFs) in the Human Performance Assessment (HPA) segment of the analysis. None of the accident sequences achieved a significant offsite consequence, and since no credit was taken for associated SSCs, none of the SSCs meet the criteria established in DOE Standard 3009-94 for safety class or safety significant. Therefore, initial testing, surveillance and maintenance are not safety issues at NFF, as they pertain to radiological and chemical safety.

Since the accident analysis results data presented in SAR Topics $\underline{\mathbf{5}}$ and 11 suggest that NFF operations pose no significant radiological or chemical safety hazard due to initial testing, surveillance, and maintenance, they are fully capable of supporting the current mission of the facility, including its SAR and TSR commitments to DOE.

\subsubsection{NFF Operational Experience and Safety}

NFF implements the DOE Occurrence Reporting and Processing System (ORPS), responding to the requirements of DOE Order 5000.3B, for identifying abnormal or undesirable conditions and events, including those involving initial testing, surveillance and maintenance. This process documents each occurrence in a structured manner, prioritizing, making causal reviews, determining proper 
Figure 9-10 (cont.) Initial Testing In-service Surveillance and Maintenance

corrective action, tracking resolution, applying lessons learned, officially closing out each abnormal or undesirable condition, and informing the originator.

NFF management oversight is achieved by (a) participating in tracking the resolution process and timetable on each reported condition or event, (b) participating in trending overall performance improvements or degradations, and (c) playing a principal role in making decisions regarding corrective actions (including those involving lessons learned). NFF administrative procedures implement DOE 5000.3B and DOE 1324.2A and provide guidance for implementing, reporting, and conducting oversight and evaluations of the Self-Assessment Program. NFF administrative procedures also provide guidance to the program for trending occurrences, determining corrective actions, and applying lessons learned.

Figure 9-9, Topic 14, Table 3, using ORPS data investigates the absolute and relative progress being made by NFF in human error and equipment failure reduction from the beginning of March 1990 through May 1994 (period for which ORPS data are available). Table 3 also relates NFF operational experience to similar DOE plutonium processing and hot cell facilities. Table 3 shows that total ORPS reports for the comparison nuclear waste operation/disposal facility group, involving human error and equipment failures forms a curvilinear though decreasing trend from March 1990 through May 1994. Table 3 shows that for that same period NFF total ORPS reports have varied from a high of 6 in 1990 to 0 thus far in 1994. A further analysis of NFF ORPS reports over the past three years, indicates that none attribute to the initial testing, surveillance, or maintenance as a root, direct, or contributing cause.

Operational experience data suggest that NFF poses no significant threat to radiological and chemical safety due to human error or equipment failure, with initial testing, surveillance, or maintenance as a causal factor, and that the NFF initial testing, surveillance, or maintenance program is capable of supporting the current nuclear safety SAR commitments to DOE. 


\subsection{Summing Up}

This chapter is directed toward using HF information developed in Chapters 6, 7, and 8 of this Course Text as a technical basis for preparing HF primary inputs to the SAR. The following topics were discussed.

- technical approach for assessing each HCF included in the human safety analysis;

- utilization of the hazards and accident analysis to assess the nuclear safety relevance of each HCF;

- utilization of operational experience data to verify the nuclear safety relevance of each HCF; and

- preparation of safety demonstration sections of the SAR for each of the primary HCFs included in the human safety analysis.

The concluding Chapter 10 of this text will discuss potential applications of human safety analysis and HF nuclear safety demonstration findings in the derivation and documentation of TSRs. 


\section{Chapter 10}

\section{Contribution of HF to the TSRs}

The overall objective of Chapter 10 is to describe the potential role of human factors $(H F)$ in selecting and developing Action Statements, Surveillance Requirements (SR), and Administrative Controls for the Technical Safety Requirements (TSRs).

\section{$10.1 \quad$ Introduction}

DOE Order 5480.22, Section 9.b states that the TSRs..."shall define the operating limits and surveillance, the basis thereof, safety boundaries, and management or administrative controls necessary to protect the health and safety of the public and to minimize the potential risk to the public and facility workers from the uncontrolled release of radioactive or other hazardous materials and from radiation exposure due to inadvertent criticality" (DOE 1992a). The purpose of this chapter is to acquaint the reader with HF requirements for Operating Limits (i.e., Limiting Control Settings [LCSs], Limiting Conditions for Operation [LCOs]), Action Statements and Time Limits, Surveillance Requirements and Intervals, Administrative Controls, and the Technical Basis sections of the TSR document, responding to DOE Order 5480.22 (DOE 1992a). The primary source of HF information and data to support the TSRs should be obtainable from HF supported chapters and sections of the Preliminary/Final Safety Analysis Report (PSAR/FSAR), prepared in accordance with requirements of DOE Order 5480.23 (DOE 1992b). The previous chapters of this text have presented a philosophy, technical approach, and candidate techniques for responding to PSAR/FSAR and TSR requirements. Sections 10.3 through 10.6 of this course text describe TSR information pertaining to HF and cross-references chapters and sections of 
the PSAR/FSAR and supporting documentation from which that information should be available.

Section 10.2 presents a list of information sources for supporting HF inputs to the TSRs. Section 10.3 focuses on LCS/LCO Action Statement requirements supported by HF. Section 10.4 focuses on LCS/LCO Surveillance Requirements supported by HF. Section 10.5 focuses on TSR Administrative Control requirements supported by HF. Section 10.6 focuses on TSR Technical Bases requirements supported by HF. Section 10.7 provides a brief summary of the previous sections of the chapter.

\subsection{Chapter 10 References}

U.S. Department of Energy (DOE), 1992a, "Technical Safety Requirements", Order 5480.22, September.

DOE, 1992b, "Nuclear Safety Analysis Reports," Order 5480.23, April.

DOE, 1994, "Preparation Guide' for U.S. Department of Energy Nonreactor Nuclear Facility Safety Analysis Reports," Draft DOE-STD-3009-94, July.

PSAR/FSAR chapter/sections containing HF hazard and accident analysis information.

PSAR/FSAR chapter/sections containing HF management, organization, and institutional safety provisions information.

PSAR/FSAR chapter/sections containing HF procedures and training information.

PSAR/FSAR chapter/sections containing HF human factors engineering analysis information.

PSAR/FSAR chapter/sections containing HF initial testing, in-service surveillance, and maintenance information. 
Other PSAR/FSAR chapters/sections using HF as a technical basis.

HF Analysis report prepared from guidance provided in Chapter 7 of this text.

HPA Analysis report prepared from guidance provided in Chapter 7 of this text.

Other facility authorization basis documents that contain information pursuant to $\mathrm{HF}$ capabilities and commitments to DOE.

\subsection{Action Statements}

Action Statements contain instructions to the operator for taking remedial or compensatory actions, and a time limit for completing the actions, to restore the facility to its original undergraded configuration should the facility enter a TSR condition. TSR entry conditions are normally defined in the Action Statements of the following:

- Limiting Control Settings (LCSs) - are settings on safety systems that control process variables to prevent exceeding Safety Limits (SLs).

- $\quad$ Limiting Conditions for Operation (LCOs) - are the lowest functional capability level of safety-related structures, systems, components and their support systems required for normal safe operation of the facility.

NOTE: $\quad$ Fissile Material, Radioactive Material, or Chemical Material Inventory Limits, based on the results of the safety analysis, and other safety considerations, can be maintained and recovered by means of administrative controls rather than specific Action Statements. As such, they become SAR commitments rather than TSR commitments.

Action Statements established for each LCS/LCO should be justified on the basis of programmatic and/or analysis-based information that can be derived from the following 
chapters/sections of the PSAR/FSAR, its supporting documentation, or other facility authorization basis documentation. The following $\mathrm{HF}$ information that might be required for each LCS/LCO Action Statement including its Time Limit, should be available directly from the accompanying PSAR/FSAR chapter or section, or facility documentation referenced by the chapter or section of the PSAR/FSAR.

- Management Oversight, Staffing, and Qualifications - PSAR/FSAR Topic 12, Topics $\underline{5} / 11$ hazards and accident analysis results, HPA Report, HF Analysis Report, other referenced facility programmatic documentation, and other facility authorization basis documents.

- $\quad$ Procedures and Training - PSAR/FSAR Topic $\underline{13}$, Topics $\underline{5} / \underline{11}$ hazards and accident analysis results, HPA Report, HF Analysis Report, other referenced facility programmatic documentation, and other facility authorization basis documents.

- Human Factors Engineering - PSAR/FSAR Topic 14 , Topics $\underline{5} / 11$ hazards and accident analysis results, HPA Report, HF Analysis Report, other referenced facility programmatic documentation, and other facility authorization basis documents.

- All of the above for Initial Testing, In-service Surveillance, and Maintenance - PSAR/FSAR Topic $\underline{15}$, Topics $\underline{5} \underline{11}$ hazards and accident analysis results, HPA Report, HF Analysis Report, other referenced facility programmatic documentation, and other facility authorization basis documents.

- $\quad$ Other PSAR/FSAR topics using HF results as inputs (e.g., Emergency Preparedness, Decontamination and Decommissioning) may also have to be consulted for HF inputs to the LCS/LCO Action Statement and time limits. 
The top portion of Figure 10-1 presents an example of an Action Statement and Time Limit written to DOE Order 5480.22 requirements (DOE 1992a).

\subsection{Surveillance Requirements}

Surveillance Requirements (SRs) relate to test, calibration, or inspection to ensure that the necessary operability and quality of structures, systems, components, and their support systems required for safe operation of the facility are maintained. SRs and Intervals document commitments to DOE, for optimizing the reliability of structures, systems, and components that are subjects of the TSR LCSs and LCOs. For each LCS and LCO, a requirement for surveillance and maximum intervals are stated between which the surveillance will be conducted. These requirements and intervals, as they pertain to HF, are derived from the various sources listed in Section 10.3, especially from DOE 5480.23 Topic 15, Initial Testing, In-service Surveillance, and Maintenance, and its supporting documents (DOE 1992b).

The bottom portion of Figure 10-1 presents an example of a Surveillance Requirement written to DOE Order 5480.22 requirements.

\subsection{Administrative Controls}

Administrative Controls are the provisions relating to organization and management, procedures, training, staffing, other operational aids, record keeping, reviews and audits necessary to ensure the safe operation of the facility. In summary, the TSR document must demonstrate, (and be supported by the PSAR/FSAR and supporting documentation) that there is sufficient programmatic backup to the Action Statements and Surveillance Requirements to ensure a high probability that they can be implemented and maintained. For each SL, LCS, LCO, and SR, there must be a discussion in the Technical Bases of applicable Administrative Controls such that a reasonable reviewer can conclude that the programmatic activities of the facility are capable of fully supporting the facility's TSR commitments to DOE. 


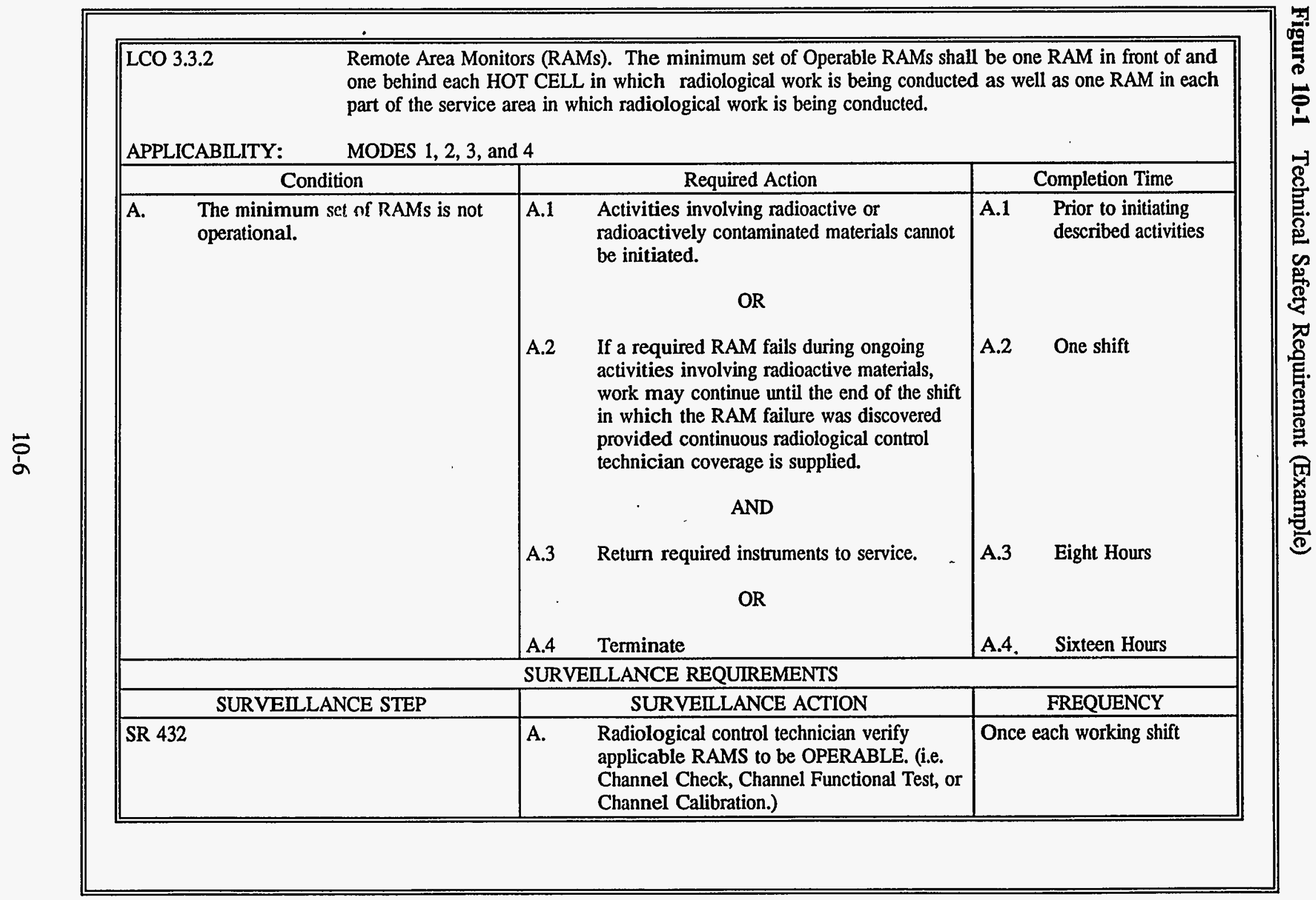


Administrative Controls, as they pertain to $\mathrm{HF}$, are derived from the various sources listed in Section 10.3 above.

Figure 10-2 presents an example of an administrative control presentation in the TSR document meeting DOE Order 5480.22 requirements. Technical bases, as they pertain to HF, should also be derived from the various sources listed in Section 10.3 above.

\subsection{Technical Bases}

The Technical Bases appendix documents the rationale for the Action Statement and Time Limits, and Surveillance Requirements and Intervals contained in the TSR document. The information in the Technical Bases appendix should be traceable back to the PSAR/FSAR and its supporting documentation. More specifically, the Technical Bases, as it pertains to HF, should be derived from the various sources listed in Section 10.3 above.

\subsection{Summing Up}

This chapter discussed TSR requirements, and the role that the HF chapters/sections of the PSAR/FSAR, and its supporting documentation, play in TSR development. In order for the HF practitioner to ensure that sufficient HF information and data are available to support TSR development, he or she must take into consideration potential TSR subject matter areas right from the beginning of the human safety analysis. The human system analysis (function/task/vulnerability) segment of the human safety analysis discussed in Chapters 5 and 6 of this Course Text, should include all operational, surveillance and maintenance actions and time limits, and human factors programmatic controls involving suspected safety class and safety significant structures, systems, and components.

NOTE: $\quad$ Based on DOE Standard 3009-94, there may be defense in depth andlor worker safety LCSs and LCOs that involve structures, systems, and components that are neither safety class not safety significant (DOE 1994). 
Figure 10-2 Facility Training and Procedures (Example)

\subsubsection{NFF FACILITY TRAINING}

(a) The FACILITY Training Group Manager shall provide classroom and on-thejob training for the NFF FACILITY technological and administrative staff because the NFF FACILITY has no internal training capability beyond supervisory oversight. Certification and skill sustainment training shall be provided to technicians, administrative personnel, and managers in accordance with training requirements established by DOE Order 5480.20 .

(b) Training shall respond to DOE Order 5480.20, as described in detail in Topic 14 of the NFF FACILITY SAR, and as implemented by the NFF practices and procedures. Training plans shall be prepared for all NFF FACILITY personnel and shall be updated periodically to reflect current requirements. The formal training requirements and program are designed to stress safety consciousness and are described in Topic 14 of the NFF FACILITY SAR. In addition to formal training, informal training shall be conducted through a required reading program, pre-job briefings, and safety meetings held at the NFF FACILITY. Formal and informal training are documented and controlled to ensure all affected personnel are included.

(c) The following are the specific training/staffing requirements for NFF FACILITY operations:

- All in-cell operations and fissile material handling operations shall be performed by a certified HOT CELL technician,

- A certified radiological controls technician shall monitor all material transfers into or out of the FACILITY and into or out of HOT CELLs that could subject individuals to radiation or radiological contamination,

- The NFF FACILITY supervisor or the designated alternate shall be in the FACILITY for NFF during all NFF FACILITY operations,

- A minimum of two qualified technicians shall be required for all HOT CELL loading/unloading operations, and

- A nuclear materiais custodian shall oversee all fissile material transfers.

\subsection{Procedures and Controls}

This section includes required procedures and controls that do not fit under SAFETY LIMITS (SLS) LIMITING CONTROL SETTINGS, or LIMITING CONDITIONS FOR OPERATION for a Hazard Category 2 FACILITY. 


\section{SUBJECT INDEX}

Accident Analysis . . . . G GLS-9, GLS-10, GLS-12, GLS-14, GLS-16, GLS-20, INTRO-11, 2-10, 3-6, 4-4, 4-5, 4-6, 4-7, 5-4, 5-6, 5-7, 5-19, 5-21, 5-25, 6-27, 6-37, 6-43, $6-44,6-46,6-47,6-61,7-2,7-3,7-4,7-8,7-12,7-14,7-17,7-18,7-20,7-21$, $8-2,8-3,8-4,8-9,9-1,9-2,9-3,9-4,9-5,9-6,9-10,9-26,9-27,9-32,9-35$, $9-44,9-53,9-54,9-62,9-64,10-2,10-4$ Accident Sequence Evaluation Program . . ACRO-1, INTRO-13, INTRO-17, 4-6, 4-7, 6-40, $6-43,6-44,7-7,7-22,9-5,9-8,9-12,9-20, \mathrm{~A}-1, \mathrm{C}-5$

Action statement $\ldots \ldots \ldots \ldots \ldots \ldots \ldots \ldots \ldots$ GLS-15, GLS-21, 10-2, 10-4, 10-5, 10-7

Administrative Control . . . GLS-1, GLS-5, INTRO-14, 5-13, 7-18, 8-7, 9-3, 9-39, 9-49, 10-2, 10-7

ASEP . . . ACRO-1, INTRO-17, 6-43, 6-49, 6-50, 7-7, 7-22, 9-5, 9-8, 9-10, 9-12, 9-20, 9-21, A-1, C-5, C-6

Auditability $\ldots \ldots \ldots \ldots \ldots \ldots \ldots$ GLS-2, INTRO-14, INTRO-16, 6-1, 6-3, 6-4, 6-61

Configuration Management ... GLS-3, INTRO-12, 1-1, 1-2, 1-4, 1-7, 1-8, 1-9, 2-7, 2-8, 3-7, $4-7,4-13,6-13,7-8$

Content Analysis $\ldots \ldots \ldots \ldots \ldots \ldots \ldots \ldots$ GLS-4, GLS-18, 5-17, 6-23, 6-31, 9-58

Department of Energy .. ACRO-1, GLS-7, INTRO-1, INTRO-2, INTRO-3, INTRO-15, 1-1, $1-2,2-2,2-3,3-1,3-2,4-1,4-2,4-6,4-7,4-8,4-9,4-11,4-13,5-2,6-1,7-2$, $7-3,7-4,8-1,8-2,9-1,9-2,9-27,9-32,9-38,9-40,9-62,10-2$

Direct Comparison ....................... GLS-4, 5-17, 6-23, 6-31 
DOE

ACRO-1, GLS-4, GLS-5, GLS-6, GLS-7, GLS-10, GLS-13, GLS-14, GLS-16, GLS-18, GLS-21, INTRO-1, INTRO-2, INTRO-3, INTRO-4, INTRO-5, INTRO-6, INTRO-7, INTRO-8, INTRO-9, INTRO-11, INTRO-12, INTRO-13, INTRO-14, INTRO-15, INTRO-16, INTRO-17, 1-1, 1-2, 1-3, 1-4, 1-6, 1-7, $1-8,1-9,2-2,2-7,2-8,2-10,2-11,3-1,3-2,3-3,3-4,3-5,3-6,3-7,4-1,4-2$, $4-3,4-5,4-6,4-7,4-8,4-9,4-10,4-11,4-12,4-13,5-1,5-2,5-3,5-4,5-8$, $5-13,5-14,5-15,5-16,5-17,5-19,5-20,5-21,5-22,5-23,5-24,6-1,6-2,6-3$, $6-4,6-5,6-6,6-14,6-19,6-20,6-21,6-22,6-24,6-29,6-30,6-32,6-35,6-36$, 6-37, 6-39, 6-48, 6-56, 6-58, 6-59, 6-61, 7-1, 7-2, 7-3, 7-4, 7-5, 7-6, 7-8, 7-9, 7-12, 7-13, 7-14, 7-15, 7-17, 7-19, 7-20, 7-21, 8-1, 8-2, 8-3, 8-4, 8-5, 8-6, 8-7, 8-8, 9-1, 9-2, 9-3, 9-6, 9-7, 9-9, 9-12, 9-21, 9-25, 9-26, 9-27, 9-28, 9-29, 9-30, 9-31, 9-32, 9-33, 9-34, 9-35, 9-36, 9-37, 9-38, 9-40, 9-41, 9-42, 9-43, 9-44, 9-45, 9-46, 9-47, 9-48, 9-51, 9-53, 9-54, 9-56, 9-57, 9-59, 9-60, 9-61, 9-62, $9-63,10-1,10-2,10-3,10-5,10-7,10-8$

Environment-Centered . . GLS-5, GLS-13, 5-13, 5-17, 6-20, 6-21, 6-22, 6-25, 6-28, 8-1, 8-3,

Experience . GLS-13, GLS-14, GLS-15, GLS-16, INTRO-2, INTRO-3, INTRO-11, 2-1, 2-4, $5-7,5-13,5-15,5-16,5-17,5-19,5-21,5-22,5-23,5-24,6-5,6-7,6-20,6-30$, $6-33,6-37,6-39,6-57,6-58,6-61,7-3,7-9,7-17,8-3,8-5,8-8,8-9,9-9,9-10$,

$9-12,9-13,9-15,9-16,9-19,9-20,9-21,9-22,9-23,9-24,9-27,9-28,9-29$, $9-32,9-33,9-34,9-46,9-57,9-59,9-62,9-63,9-64$, C-5, C-6

Function Analysis $\ldots \ldots \ldots \ldots \ldots \ldots \ldots \ldots$ GLS-5, GLS-6, GLS-20, 5-3, 5-4

Graded Approach GLS-2, GLS-3, GLS-6, INTRO-1, INTRO-2, INTRO-14, INTRO-16, 4-11, $5-21,5-25,6-1,6-2,6-3,6-5,6-6,6-7,6-9,6-10,6-14,6-19,6-23,6-30,6-31$, $6-32,6-33,6-37,6-48,6-56,6-58,6-59,6-61,8-3,8-8,9-3,9-9,9-25,9-30$,

9-35, 9-60

Grandfathering GLS-6, 7-18, 8-7, 8-8, 9-45, 9-56 
Guidelines . INTRO-1, INTRO-2, INTRO-7, 3-3, 4-12, 4-13, 5-21, 6-7, 6-9, 6-10, 6-20, 6-21, $6-22,6-23,6-24,6-25,6-26,6-37,6-39,6-40,6-41,6-43,6-45,6-46,6-58$, $6-60,7-9,7-14,7-15,9-1,9-4,9-5,9-56$

Hazard Category 1 . GLS-4, GLS-6, GLS-8, GLS-13, GLS-18, GLS-19, INTRO-3, INTRO-7, INTRO-13, INTRO-14, 5-14, 5-17, 6-5, 6-6, 6-7, 6-8, 6-9, 6-19, 6-20, 6-21, $6-23,6-39,6-40,6-41,6-43,6-44,6-45,6-48,6-58,6-59,6-60,7-4,8-8$

Hazard Category 2 . . GLS-4, GLS-8, GLS-13, GLS-18, GLS-19, INTRO-7, INTRO-13, 5-18, $6-5,6-6,6-9,6-10,6-11,6-21,6-22,6-25,6-40,6-41,6-45,6-48,6-60,8-8$, $9-2,9-40,9-41,10-8, \mathrm{C}-6$

Hazard Category 3 . . . GLS-13, GLS-18, GLS-19, GLS-20, INTRO-14, 5-18, 6-5, 6-6, 6-10, $6-11,6-22,6-26,6-27,6-41,6-46,6-60$

Hazards Analysis . . . . . . GLS-9, GLS-16, 4-4, 4-5, 5-6, 6-27, 6-37, 7-3, 8-3, 9-5, 9-6, 9-35

HEP . ACRO-1, GLS-7, 5-21, 6-43, 6-48, 6-49, 6-50, 7-22, 9-12, 9-14, 9-16, 9-20, 9-21, C-2, C-3, C-4, C-5, C-6, C-7.

HFE . ACRO-1, GLS-1, GLS-7, GLS-8, GLS-13, GLS-14, GLS-21, INTRO-13, 2-9, 3-3, 3-4, $3-5,3-7,4-2,4-11,5-4,5-14,5-15,5-16,6-5,6-13,6-17,6-20,6-21,6-22$, $6-25,6-27,6-29,6-30,6-33,6-34,6-35,6-36,6-45,6-46,6-57,6-59,7-2,7-3$, $7-4,7-5,7-7,7-9,7-10,7-12,7-13,7-14,7-15,7-18,8-3,8-5,8-6,8-7,8-8$, 9-4, 9-9, 9-10, 9-15, 9-16, 9-19, 9-22, 9-23, 9-24, 9-35, 9-36, 9-37, 9-38, 9-39, $9-40,9-41,9-42,9-44,9-45,9-46,9-47,9-48,9-49,9-51,9-52,9-53,9-54$, $9-55,9-56,9-58,9-59, \mathrm{C}-6$

HSD $\ldots \ldots \ldots \ldots \ldots \ldots \ldots \ldots$ ACRO-1, GLS-11, GLS-12, 2-9, 2-10, 4-2, 7-11

Human Causal Factor . . A ACRO-1, GLS-2, GLS-11, GLS-14, GLS-15, INTRO-16, 5-1, 5-2, $5-5,5-7,5-17,6-2,6-4,6-19,6-33,7-2,7-5,7-16,9-9,9-27,9-53$ 
Human error . . . ACRO-1, GLS-3, GLS-7, GLS-8, GLS-10, GLS-12, INTRO-13, INTRO-17, 2-3, 2-4, 2-5, 2-6, 2-7, 2-8, 2-9, 2-10, 2-11, 3-6, 5-3, 5-6, 5-16, 5-17, 5-21, $5-24,6-3,6-6,6-25,6-27,6-28,6-37,6-38,6-40,6-43,6-44,6-45,6-46,6-47$, $6-58,6-59,6-60,6-61,7-3,7-4,7-6,7-8,7-13,7-17,7-19,7-22,7-23,8-3$, $8-4,8-5,8-6,8-8,9-5,9-8,9-11,9-12,9-13,9-17,9-18,9-19,9-20,9-27$, 9-28, 9-32, 9-33, 9-44, 9-51, 9-54, 9-56, 9-57, 9-58, 9-59, 9-62, 9-63, A-1, C-3, C-7

Human error probability . . . . . . ACRO-1, GLS-7, GLS-12, 5-6, 6-38, 6-58, 7-22, 9-12

Human factors . . . . ACRO-1, GLS-7, GLS-8, GLS-10, GLS-11, GLS-13, GLS-14, GLS-16, GLS-21, INTRO-1, INTRO-2, INTRO-7, INTRO-8, INTRO-9, INTRO-11, INTRO-12, INTRO-13, INTRO-17, 1-4, 1-9, 2-1, 2-2, 2-9, 2-10, 2-11, 3-1, 3-2, 3-3, 3-4, 3-5, 3-6, 3-7, 4-1, 4-2, 4-4, 4-6, 4-9, 4-10, 4-11, 4-12, 4-13, 5-1, $5-3,5-4,5-8,5-24,6-3,6-5,6-19,6-24,6-25,6-26,6-49,6-50,7-1,7-2,7-3$, $7-4,7-5,7-8,7-9,7-10,7-11,7-12,7-13,7-14,7-15,7-16,7-17,7-18,7-19$, $7-21,7-22,8-1,8-2,8-3,8-4,8-5,8-6,8-7,8-8,8-9,9-1,9-2,9-3,9-4,9-5$, $9-9,9-10,9-12,9-13,9-15,9-19,9-20,9-21,9-22,9-30,9-35,9-36,9-38$, $9-42,9-44,9-46,9-47,9-48,9-49,9-50,9-51,9-53,9-61,10-1,10-2,10-4$, $10-7, \mathrm{C}-5, \mathrm{C}-6$

Human factors analysis results and findings report .. GLS-7, 7-3, 7-4, 7-8, 8-2, 8-5, 9-2, 9-9, $9-10,9-15,9-22,9-36$

Human Factors Engineering . . . . . ACRO-1, GLS-8, GLS-11, GLS-13, GLS-14, GLS-16, INTRO-1, INTRO-13, 2-9, 2-11, 3-3, 3-6, 4-1, 4-2, 4-4, 4-9, 4-10, 4-11, 4-12, $5-3,5-8,6-5,6-19,6-24,6-26,7-2,7-4,7-14,7-15,7-16,7-18,9-1,9-3,9-4$, 9-5, 9-9, 9-12, 9-13, 9-19, 9-20, 9-21, 9-35, 9-38, 9-42, 9-44, 9-51, 10-2, 10-4, C-5, C-6

Human failure modes analysis . . . . . . . . GLS-9, GLS-20, 5-4, 5-6, 5-7, 6-13, 6-18, 6-51 Human initiator $\ldots \ldots \ldots \ldots$. GLS-9, 6-57, 7-6, 7-23, 9-10, 9-12, 9-13, 9-14, 9-15, 9-16 Human mitigator $\ldots \ldots \ldots \ldots \ldots \ldots \ldots \ldots \ldots \ldots$ GLS-9, 7-23, 9-17, 9-23, 9-24 
Human performance assessment . . . . . ACRO-1, GLS-2, GLS-3, GLS-10, GLS-11, GLS-14, GLS-15, GLS-16, GLS-17, GLS-23, INTRO-8, INTRO-16, INTRO-17, INTRO-18, 1-9, 2-2, 2-11, 3-5, 3-6, 3-7, 4-2, 4-6, 4-7, 4-10, 5-1, 5-2, 5-5, 5-7, 5-8, 5-18, 5-19, 5-20, 5-25, 6-2, 6-3, 6-4, 6-6, 6-9, 6-12, 6-19, 6-20, 6-21, $6-23,6-27,6-28,6-37,6-40,6-42,6-43,6-44,6-46,6-47,6-48,6-51,6-56$, $7-3,7-5,7-7,7-8,7-10,7-11,7-12,7-20,7-21,7-22,7-23,8-2,8-5,8-8,9-1$, $9-2,9-3,9-8,9-9,9-10,9-11,9-12,9-17,9-20,9-27,9-32,9-38,9-44,9-53$, 9-62, B-1

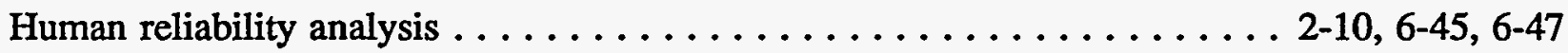

Human safety analysis . GLS-2, GLS-3, GLS-6, GLS-8, GLS-11, GLS-13, GLS-15, GLS-17, GLS-18, GLS-19, INTRO-1, INTRO-7, INTRO-10, INTRO-12, INTRO-14, INTRO-16, INTRO-17, 1-1, 3-4, 4-1, 4-13, 5-1, 5-2, 5-6, 5-7, 5-8, 5-19, 5-20, 5-23, 5-25, 6-1, 6-2, 6-3, 6-4, 6-5, 6-6, 6-11, 6-12, 6-13, 6-15, 6-19, 6-30, $6-31,6-37,6-42,6-48,6-58,6-61,7-1,7-8,8-2,8-3,8-4,8-5,8-9,9-1,9-3$, $9-4,9-6,9-35,9-64,10-7$

Human system analysis .. GLS-2, GLS-4, GLS-11, GLS-12, INTRO-16, 5-1, 5-2, 5-3, 5-18, $5-25,6-4,6-6,6-7,6-8,6-10,6-11,6-12,6-14,6-16,6-17,6-18,6-23,6-25$, $6-27,6-30,6-44,6-45,6-46,6-48,8-3,10-7$

Human vulnerability analysis $\ldots \ldots \ldots \ldots \ldots \ldots$ GLS-9, GLS-12, 5-5, 5-6, 5-12, 7-2

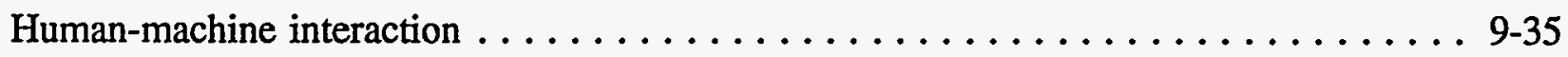

Knowledge-based $\ldots \ldots \ldots \ldots \ldots \ldots \ldots \ldots \ldots \ldots \ldots \ldots$ GLS-13, 5-17

LCO . . ................... ACRO-1, 10-2, 10-3, 10-4, 10-5, 10-6

LCS $\ldots \ldots \ldots \ldots \ldots \ldots \ldots \ldots \ldots \ldots \ldots \ldots$ ACRO-1, 10-2, 10-3, 10-4, 10-5

Limiting control setting $\ldots \ldots \ldots \ldots \ldots \ldots \ldots \ldots \ldots \ldots \ldots \ldots \ldots \ldots \ldots$ ACRO-1, GLS-15

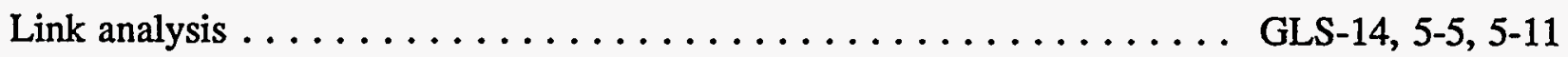


NRC ACRO-1, 2-4, 2-8, 3-3, 6-43

Nuclear Regulatory Commission ACRO-1, ACRO-2, INTRO-17, 2-3, 2-4, 3-2, 3-3, 4-6, 4-7, $4-8,4-12,6-9,6-23,6-24,6-26,6-27,6-28,6-40,6-43,6-44,6-45,6-46,6-47$,

$7-7,7-22,9-12,9-20$

Operating Limit

GLS-15

Oversight . . . . . GLS-1, GLS-4, GLS-11, GLS-12, GLS-13, GLS-15, GLS-18, INTRO-1, INTRO-3, INTRO-14, 2-2, 2-3, 2-7, 2-8, 2-10, 3-3, 3-7, 5-3, 5-7, 5-8, 5-14,

$5-15,5-16,5-17,5-18,6-5,6-19,6-20,6-21,6-22,6-25,6-27,6-29,6-33$, $6-57,7-3,7-6,7-9,7-12,7-13,7-23,8-5,8-6,8-7,9-9,9-10,9-12,9-13,9-15$, 9-16, 9-19, 9-20, 9-21, 9-22, 9-23, 9-24, 9-27, 9-28, 9-29, 9-33, 9-46, 9-55, $9-57,9-63,10-4,10-8, \mathrm{C}-5, \mathrm{C}-6$

Person-centered ... GLS-13, GLS-16, GLS-19, 5-13, 5-17, 6-20, 6-21, 6-22, 6-25, 6-28, 8-1, $8-3,8-6$

Procedures . . GLS-1, GLS-2, GLS-4, GLS-7, GLS-11, GLS-12, GLS-13, GLS-15, GLS-16, GLS-18, GLS-21, INTRO-1, INTRO-3, INTRO-8, INTRO-12, INTRO-14, 1-3, $1-6,2-3,2-8,2-9,2-10,3-2,3-3,3-5,3-6,3-7,4-2,4-4,4-7,4-8,4-9,4-12$, $4-13,5-3,5-4,5-7,5-8,5-13,5-14,5-15,5-16,5-17,5-18,6-4,6-5,6-6,6-8$, 6-10, 6-11, 6-19, 6-20, 6-21, 6-22, 6-23, 6-24, 6-25, 6-26, 6-27, 6-28, 6-29, $6-33,6-47,6-49,6-59,7-3,7-4,7-5,7-6,7-7,7-9,7-11,7-12,7-13,7-15$, $7-16,7-18,7-23,8-5,8-6,8-7,9-1,9-2,9-4,9-5,9-8,9-9,9-12,9-13,9-14$, $9-18,9-19,9-20,9-21,9-28,9-29,9-30,9-31,9-32,9-33,9-34,9-42,9-46$, $9-55,9-57,9-63,10-2,10-4,10-5,10-8$, C-5

Qualifications . GLS-7, GLS-11, GLS-13, GLS-16, INTRO-1, INTRO-8, 2-9, 2-10, 3-2, 3-5, 4-2, 4-8, 4-9, 5-8, 5-13, 5-14, 5-15, 6-5, 6-19, 6-20, 6-21, 6-22, 6-25, 6-27, $7-3,7-9,7-11,7-12,7-13,7-16,7-17,7-18,9-42,9-46,10-4$

Rule-based GLS-18, 5-17 
Safety analysis report .. ACRO-1, ACRO-2, GLS-5, GLS-16, GLS-18, INTRO-1, INTRO-4, INTRO-15, 1-1, 3-1, 5-1, 6-1, 6-45, 6-47, 7-1, 8-1, 9-1, 9-27, 9-32, 9-38, 9-62,

SAR . ACRO-2, GLS-5, GLS-6, GLS-7, GLS-8, GLS-9, GLS-10, GLS-12, GLS-14, GLS-16, GLS-18, GLS-19, GLS-21, GLS-22, INTRO-1, INTRO-2, INTRO-3, INTRO-4, INTRO-5, INTRO-7, INTRO-8, INTRO-9, INTRO-11, INTRO-12, INTRO-13, INTRO-14, INTRO-15, INTRO-16, INTRO-17, 1-1, 1-4, 1-5, 1-6, $1-7,1-8,1-9,2-9,2-10,2-11,3-1,3-3,3-4,3-5,3-6,3-7,4-1,4-2,4-3,4-4$, 4-5, 4-6, 4-10, 4-13, 5-1, 5-3, 5-4, 5-7, 5-8, 5-13, 5-14, 5-15, 5-16, 5-17, 5-19, 5-20, 5-22, 5-24, 5-25, 6-1, 6-3, 6-4, 6-8, 6-10, 6-11, 6-19, 6-20, 6-21, 6-22, 6-24, 6-27, 6-28, 6-29, 6-37, 6-42, 6-43, 6-44, 6-46, 6-47, 6-60, 6-61, 6-62, $7-1,7-3,7-4,7-5,7-8,7-9,7-10,7-11,7-13,7-14,7-15,7-17,8-1,8-2,8-3$, $8-4,8-6,8-9,9-1,9-2,9-3,9-4,9-5,9-6,9-7,9-9,9-15,9-22,9-25,9-26$, 9-27, 9-29, 9-30, 9-31, 9-32, 9-34, 9-35, 9-36, 9-37, 9-38, 9-42, 9-44, 9-46, 9-49, 9-51, 9-53, 9-54, 9-56, 9-59, 9-60, 9-61, 9-62, 9-63, 9-64, 10-3, 10-8

Skill-based $5-17$

Staffing . ..... GLS-1, GLS-7, GLS-11, GLS-13, GLS-21, INTRO-1, INTRO-3, INTRO-8, INTRO-14, 2-9, 2-10, 3-2, 3-3, 3-5, 3-6, 3-7, 4-2, 4-7, 4-8, 4-9, 4-12, 5-3, 5-8, $5-13,5-14,5-15,5-22,6-5,6-19,6-20,6-21,6-22,6-25,6-27,7-4,7-11,7-12$,

$7-13,7-16,7-17,7-18,8-6,8-7,9-42,9-46,9-55,10-4,10-5,10-8$

Subject matter expert $\ldots \ldots \ldots \ldots \ldots \ldots \ldots \ldots \ldots \ldots \ldots$ GLS-20, 6-27, 6-41

Surveillance requirements .. GLS-20, GLS-21, INTRO-17, 7-10, 7-11, 9-2, 10-1, 10-2, 10-5, $10-6,10-7$

Systems approach .. GLS-3, GLS-20, INTRO-12, INTRO-14, INTRO-15, 1-1, 1-4, 1-5, 1-6, $1-7,1-8,1-9,3-7$

Task analysis ... . . GLS-12, GLS-14, GLS-20, GLS-21, GLS-22, 3-5, 5-3, 5-4, 5-5, 5-6, 5-9, $6-23,6-25,6-27,6-44,6-45,6-46,6-51,7-2$ 
Technical bases GLS-21, INTRO-8, 7-8, 10-2, 10-5, 10-7

Technical safety requirement ACRO-2, GLS-22, 10-6

Technique for human error rate prediction GLS-8, INTRO-17, 6-6, 6-44, 7-8, 7-22, 9-5, 9-8, $9-12, \mathrm{C}-2$

THERP . . . GLS-8, INTRO-17, INTRO-18, 6-6, 6-43, 6-44, 6-51, 6-52, 6-53, 6-54, 7-3, 7-8, 7-22, 7-23, 9-5, 9-8, 9-10, 9-12, 9-17, 9-20, 9-21, B-1, C-1, C-2, C-3, C-4, $\mathrm{C}-5, \mathrm{C}-6, \mathrm{C}-7$

Timeline analysis $\ldots \ldots \ldots \ldots \ldots \ldots \ldots \ldots \ldots \ldots \ldots \ldots \ldots$ GLS-22, 5-5, 5-10

Total Quality Management .......... ACRO-2, GLS-23, INTRO-12, 1-1, 1-4, 1-6, 3-7 $\mathrm{TQM}$ ACRO-2, GLS-23, INTRO-12, 1-2, 1-4, 1-6, 1-7, 1-8, 1-9, 3-7, 7-8

Training . . . . GLS-1, GLS-2, GLS-4, GLS-7, GLS-11, GLS-12, GLS-13, GLS-15, GLS-16, GLS-18, GLS-21, INTRO-1, INTRO-3, INTRO-8, INTRO-14, 2-3, 2-4, 2-9, 2-10, 3-2, 3-3, 3-5, 3-6, 3-7, 4-2, 4-4, 4-7, 4-8, 4-9, 4-12, 5-3, 5-4, 5-7, 5-8, $5-13,5-14,5-15,5-16,5-17,5-18,6-5,6-6,6-8,6-19,6-20,6-21,6-22,6-25$, 6-27, 6-28, 6-33, 6-39, 6-49, 6-57, 6-59, 7-3, 7-4, 7-5, 7-6, 7-7, 7-9, 7-11, $7-12,7-13,7-16,7-17,7-18,7-23,8-5,8-6,8-7,9-1,9-2,9-4,9-5,9-9,9-12$, $9-13,9-14,9-16,9-19,9-20,9-21,9-23,9-24,9-28,9-29,9-30,9-31,9-32$, $9-33,9-34,9-42,9-46,9-55,10-2,10-4,10-5,10-8$, C-5, C-6

TSR . ACRO-2, GLS-1, GLS-6, GLS-14, GLS-15, GLS-21, GLS-22, INTRO-4, INTRO-11, $1-1,1-4,1-6,2-11,3-6,5-19,6-1,6-4,6-10,7-1,7-8,7-9,7-10,7-11,7-13$, $8-4,9-1,9-44,9-62,10-1,10-2,10-3,10-5,10-7$

Unreviewed safety question $\ldots \ldots \ldots \ldots \ldots \ldots \ldots \ldots \ldots \ldots \ldots \ldots \ldots \ldots$ INTRO-4, 1-4 USQ . . . ACRO-2, INTRO-4, INTRO-11, 1-4 


\section{APPENDIX A}

\section{Excerpts from NUREG/CR-4772, Accident Sequence Evaluation Program (ASEP) Procedure for Human Error Rate Screening}


NUREG/CR -4772

SAND 86- 1996

' AN

:ed February 1987

\title{
Accident Sequence Evaluation Program Human Reliability Analysis Procedure
}

\author{
Alan D. Swain \\ - ed by \\ Sandia National Laboratories \\ Albuquerque, New Mexico 87185 and Livermore. Calilomia 94550 \\ for the United States Department of Energy \\ under Contract DE-AC04-76DP00789
}

\section{Prepared for}

U. S. NUCLEAR REGULATORY COMMISSION 
This chapter provides general information for the screening human reliability analysis (HRA) and the nominal HRA for pre-accident tasks (also in some PRAs called test and maintenance (T\&M) tasks). To develop rules for the screening and nominal HRAs, modifications were made to the HRA screening procedure used in the Risk Methods Integration and Evaluation Program (RMIEP) (Swain, 1985a), which in turn was based primarily on modifications.of NUREG/CR-1278. See Appendix A for more detail on the relationship of the RMIEP screening HRA to the ASEP HRA for pre-accident tasks. The rules for estimating human error. probabilities (HEPs) and uncertainty bounds (UCBS) for screening HRAs and nominal HRAs for ASEP pre-accident tasks are found in, respectively, Chapters 4 and 5 .

To develop an HRA procedure for pre-accident tasks, a simplified model of human behavior for these tasks was devised. The model includes a generic human error probability (HEP) of .03 that can be used for all such tasks, plus rules to adjust this basic HEP for the effects of recovery factors (RFs) and dependence effects. For estimating dependence effects, a special dependence model was developed, based on a simplification of the dependence model in NUREG/CR-1278. This chapter provides a short background for these models. For a more detailed background, see Swain (1985a) or a section on "Screening Rules for the Human Reliability Analysis in the Risk Methods Integration and Evaluation Program" in Volume 5 of NUREG/CR-4832 (Payne et al, 1987).

\section{Definitions of Terms}

Before proceeding further, it is suggested that the reader consult the prefatory pages to review the list of abbreviations and definitions of the following terms, which pertain to pre-accident tasks. Some of these terms are also defined in the text which follows.

\section{action}

activity

administrative control

basic conditions

basic human error probability (BHEP)

between-person dependence

checker

checklist

common-cause failure

compelling signal

complete dependence (CD)

conditional human error probability (CHEP)

conservative screening analysis

critical action

critical parameters

dependence (between two tasks) 


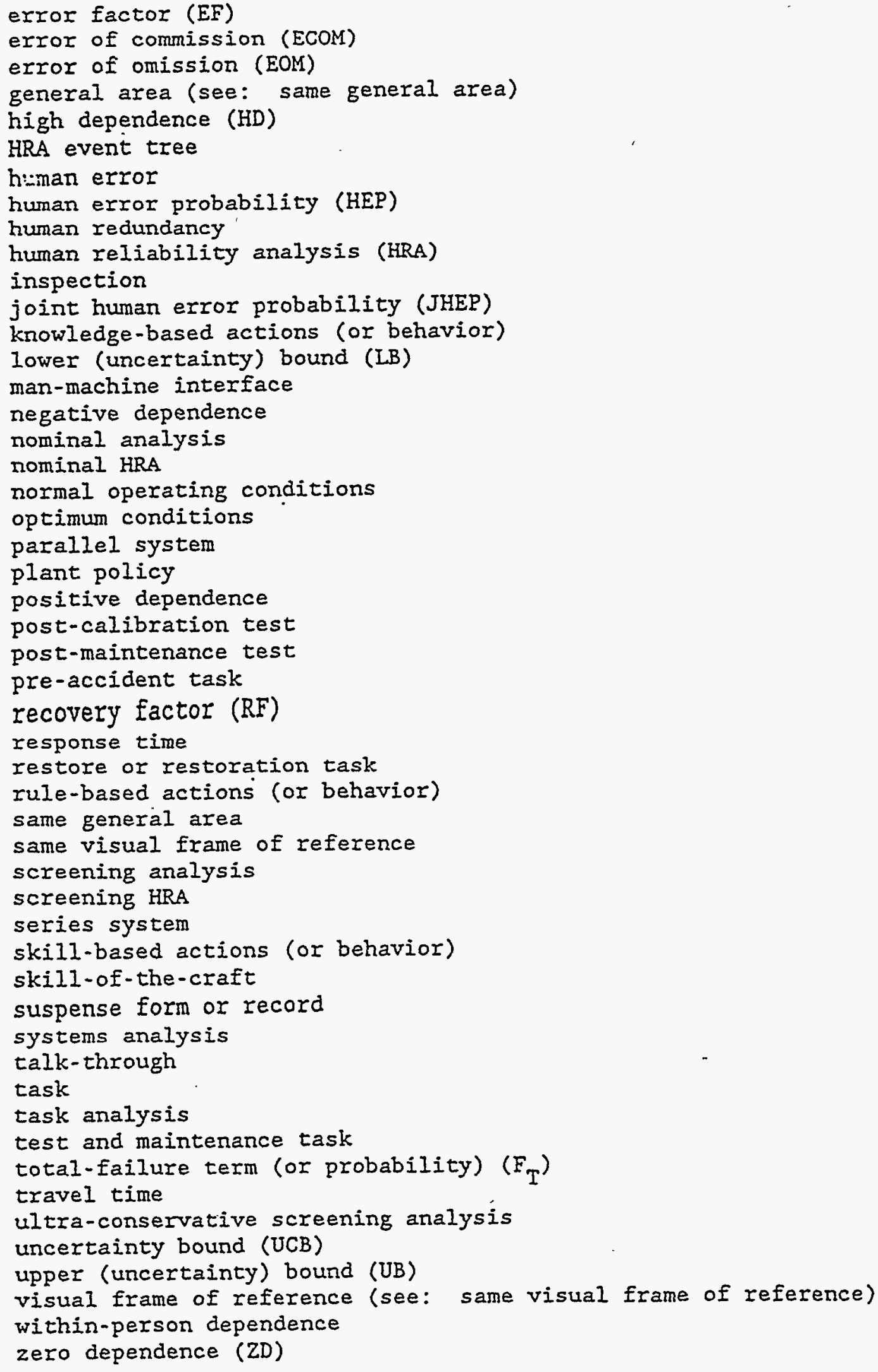


Pre-Accident Tasks of Interest

Pre-accident tasks typically of interest in a PRA consist of routine and corrective maintenance, calibration, surveillance tests, and restoration (i.e., the returning of components and systems to their normal conditions following maintenance, calibration, or testing). In some PRAs, the term "test and maintenance" ( $T \& M$ ) is used as a synonym for pre-accident tasks.

In a typical PRA, some potential errors in the maintenance of components are not included in the systems analysis because such errors have already been counted in the failure rate estimates for components, and it would be inappropriate to count human errors twice. These kinds of maintenance errors usually refer to repairs or adjustments, e.g., repacking a locally-operated valve. In addition, other maintenance errors may not be counted in a PRA because of post-maintenance (PM) tests which, if done correctly, would discover such errors. Similarly, errors in most calibration tasks also are not included in the PRA because of post-calibration (PC) tests. It is imperative that the analyst identify those cases in which PM or PC tests, even if performed correctly, will not identify maintenance or calibration errors. The ASEP HRA procedure allows for this contingency as well as for the possibility that a PM or PC test is incorrectly performed.

In general, the tasks of primary interest in an HRA of pre-accident operations will be those in which restoration errors are possible. A typical restoration task consists of opening or closing of locally-operated valves (also called manual valves) or motor-operated valves (MOVs) after completion of some repairs or a test, so that these valves are restored to their normal status. (Some analysts include restoration tasks as "maintenance tasks," but other analysts do not because the plant personnel designated as maintenance personnel normally do not change the status of valves; this is done by operations personnel, usually auxiliary reactor operators.)

Although pre-accident tasks may include elements of skill-based, rule-based, or knowledge-based behavior as defined in Table 2-1, typically only rule-based behavior is of interest for PRA purposes when assessing pre-accident tasks. That is, the HRA considers how well persons carry out rules (usually, written rules). For the pre-accident HRA emphasizing the estimated quantitative impact of human performance on system safety, the interest is with potential errors only, and not with potential response time, i.e., how long it would take persons to perform the pre-accident tasks. For other HRA purposes, of course, response time could be of concern, as, for example, if an HRA is being used to compare the efficiency of different maintenance procedures in terms of manpower utilization.

As with the post-accident HRA procedure, the pre-accident HRA procedure begins with the assumption that the critical man-machine interfaces have been identified by a team of systems analysts and human reliability analysts. This identification is not a one-time endeavor, of course, but must be continually evaluated and re-evaluated, especially to ensure that potential common-cause failures due to human error have not been overlooked. 


\section{A Basic HEP for Pre-Accident Tasks}

A basic HEP of .03 was selected as a conservative HEP for pre-accident tasks as part of the developmental effort in the Risk Methods Integration and Evaluation Program (RMIEP). This basic HEP was also adopted for the ASEP HRA Procedure. The .03 basic HEP (BHEP) was based on some HRAs and additional reviews of pre-accident procedures at the LaSalle nuclear power plant (NPP), a boiling water reactor (BWR). These HRAs and some of the other developmental background are presented in Swain (1985a) or the section on "Screening Rules for the Human Reliability Analysis in the Risk Methods Integration and Eval. uation Program" in Volume 5 of NUREG/CR-4832 (Payne et al, 1987).

The BHEP of .03 is for performance of pre-accident actions, exclusive of any recovery factors (RFs), and represents a combination of a generic HEP of .02 assessed for an error of omission (EOM) and a generic HEP of .01 assessed for an error of commission (ECOM), with the conservative assumption that an ECOM is always possible if an EOM does not occur. Thus for each critical action that must be accomplished, e.g., restore a valve to its normal operating position after maintenance, or perform a critical step in a calibration procedure, a total BHEP of .03 is used. The .03 represents the sum of the two possible failures, either (1) an EOM or (2) no EOM but an ECOM. Algebraically, the total-failure term (or probability) $F_{T}$ for a one-component system is,

$$
F_{T}=.02+(.98 \times .01)=.0298-.03
$$

Reference to the tables in Chapter 20 of NUREG/CR-1278 will show that the .03 , and its constituents of .02 and .01 , represent conservatism in that these ASEP HEPs are larger than many of the basic HEPs in that document that are related to pre-accident actions.

\section{Recovery Factors for Pre-Accident HRA}

To assess the effects of recovery factors (RFs) on the BHEP of .03, a conservative approach was taken. First, each RF is applied to the .03 rather than being applied separately for EOMs and ECOMs, a major conservatism. Second, the number of RFs that to be considered in the ASEP HRA Procedure is limited. For the screening HRA, the number of RFs to be considered is more severely limited than for the nominal HRA. Recovery factor HEPs are designated as . 1 , except for a $.01 \mathrm{HEP}$ of failing to perform or to perform correctly a required post-maintenance test or a post-calibration test. The .1 HEP is the nominal recovery BHEP for human redundancy stated as item NUREG/CR-1278.

The procedure makes a distinction between basic conditions in which no RFs are presumed to be available and optimum conditions in which allowable RFs are present. In the tables of RFs in Chapters 4 and 5 , each numbered basic condi. tion has its same numbered complementary optimum condition. For a case ir which all of the basic conditions apply, the BHEP of .03 is assessed as the human-caused failure of some critical safety component or system that i! 
unavailable. For a case in which all of the optimum conditions apply, $F_{T}$ is: considered to be negligible because of the multitude of RFs. For intermediate conditions, screening and nominal procedures are provided.

Some additional conservatisms are employed. For example, generally each available RF is counted only once, even in the case in which one check is made at the site of the operation and a different one inside the control room. Similarly, even though there may be a requirement for a shiftly or daily check of component status, no credit for the RF is allowed unless a written checkoff list is required for the checker. For the screening HRA, this RF is counted only once. For the nominal HRA, at least initially the RF is counted only once. However, if the resultant joint HEP (i.e., the product of the BHEP and the RF HEP) turns out to have a material effect in the systems analysis, periodic checks may be counted more than once, using the procedure described in Chapter 9 "Unavailability" in NUREG/CR-1278. (For example applications, see NUREG/CR-2254.)

In addition to applying each RF to the BHEP of .03 rather than separately to each EOM and ECOM, the following conservatism is used. If there is more than one component to be checked in a group of components being treated as a "system" for analysis purposes, the relevant RFs are applied to the components as a group, rather than to each component individually. This means that each $R F$ is treated independently of the number of components in a system; each $R F$ is counted only once to be conservative and, also, to account for the possibility that not all RFs will be employed on every occasion in which they should be employed. Thus, for any system, regardless of the number of components, the term at the end of each failure path in any HRA event tree can be multiplied by .1. This is equivalent to summing up the failure terms at the ends of all failure paths, without regard to RFs, and then multiplying the answer by the failure probability of an RF or the product of all failure probabilities of the RFs in question.

\section{Dependence Effects for Pre-Accident HRA}

The BHEP of .03 must be modified for the effects of dependence. The .I HEP for failure of a recovery factor already includes the effects of betweenperson dependence between the person originally performing the task and the second person or other recovery factor. Therefore, what remains is to define rules for assessing the effects of within-person dependence, that is, dependence between the tasks performed by one person (in this case, the original task performer or the recovery factor performer).

The positive dependence model and other dependence guidelines in Chapter 10 "Dependence" in NUREG/CR-1278 require considerable judgment of a qualified HRA specialist for each set of tasks in which dependence must be assessed. For ASEP, it was necessary to develop a new dependence model and associated rules of application that could be used by systems analysts who do not have a formal background in human factors technology or HRA. 
In the ASEP treatment of dependence, dependence effects are treated diffe:. ently for RFs and for original task performance. For RFs, dependence effects are not specifically considered because of the rüle that in any group of tasks, each RF will be applied only once, and because even in the exceptions for periodic checks, independence can be assumed.

For original task performance, dependence effects are treated differently for parallel systems and for series systems. A parallel system is one in which $F_{T}$ occurs only if all components in a system are unavailable; system succes ${ }^{T}$ occurs as long as at least one of the components is available. A series system is one in which system success occurs only if all components in a system are available; the failure of. only one component renders the entire system unavailable, and is designated as $F_{T}$. Because of the large amount of component redundancy in nuclear power plants (NPPs), most applications, of HRA are for parallel systems when more than one component defines the system.

For the screening HRA, dependence is treated very simply and conservatively. Zero dependence (ZD) is assessed among the same critical human actions on different components that are in series. For a parallel system, complete dependence (CD) is assessed among the same critical human actions on different components that are in parallel. However, if a testing schedule is such that different redundant trains or components within a train are tested or restored on different shifts, $Z D$ is assessed.

The treatment of dependence for the nominal HRA is more detailed. For parallel systems, zero dependence (ZD) is assumed for ECOMs while either $Z D$ or som. non-zero level of positive dependence can be assessed for EOMs. For conservatism, negative dependence is not used in parallel systems. For such systems, the use of positive dependence only results in conservatism.

For the treatment of series systems in the nominal HRA, the use of only positive dependence only results in a very small underestimation of HEPs, as long as the BHEP is not much larger than .01. The use of negative dependence would result in the most conservatism in a series system, but would add a considerable amount of complexity in the judgments required in the assessment of dependence. Furthermore, for the usual BHEPs assessed in an HRA, the use of negative dependence would add only a very small amount of conservatism as compared to an assessment of zero dependence. Consequently, for the analysis of series systems, $Z D$ is assessed for both ECOMs and EOMs. This seems to be a good balance between complexity avoidance and maximum conservatism. (Chapter 10 in NUREG/CR-1278 discusses positive and negative dependence in series and parallel systems and how to estimate their effects.)

Chapter 5 includes the detailed ASEP dependence model and procedure for the nominal HRA. 
An Example Illustrating Dependence Among Human Actions

Assume that there are some valves to be restored to their usual state after completion of some test or maintenance procedures. From a human factors viewpoint, the dependence among the restoration actions for these valves does not depend on whether the valves themselves are in series or in parallel with regard to how they work in the system. (We will assume that the operator's knowledge of whether they are in series or parallel has no major effect on his behavior.)

The operator may forget to initiate the entire restoration action because of distraction, or other influences. This error of omission (EOM) is not related at all to the design of the valves. In the dependence modeling for human actions, the probability of an operator making an EOM for the first valve to be restored is usually considered to include his probability of forgetting to initiate the entire restoration task. In this example we will drop this EOM from any treatment other than that associated with the first valve in the set.

Once the operator has initiated the task of restoration, he may forget any one or more of the valves in the set of valves (more EOMs), and for any valve he did not forget, he may make some error of commission (ECOM). For valve restoration, two kinds of ECOMs are possible that are usually considered in an HRA. One error would be the failure to fully open or fully close a valve. We can ignore this ECOM because the only credible way for this error to occur would be if the valve stuck in an intermediate position. Thus, the probability of this ECOM would be the joint probability of the valve's sticking and the operator's failure to note this equipment problem. This joint probability is usually assessed as being negligible. The other ECOM consists of a selection error. If any of the valves in a set are similar in position, appearance, or other factors, a selection error is likely. Usually, we consider that selection errors of this sort are completely independent, and we would assess a zero level of dependence (ZD) among such errors. For purpose of this example only, let us ignore the effects of dependence on ECOMs and restrict the example to EOMs. (Remember, as noted earlier in this chapter, in the ASEP HRA Procedure for pre-accident tasks, it is always assumed that an ECOM is possible if an EOM is not made.)

NUREG/CR-1278 provides rules for assessing the dependence among the separate valve restoration actions with regard to EOMs. The dependence among the restoration actions can range from zero dependence (ZD) to complete dependence (CD). (We will ignore the possibility of negative dependence, and assume positive dependence only for this example.) If the valves are located in completely different rooms and are in different steps in a checklist, clearly there is little if any dependence among the actions. In such a case, we assess $\mathrm{ZD}$. On the other hand, if the valves are all located in one central group, especially if they are all within the operator's visual field at once, we would usually assess CD for EOMs. For intermediate relationships, inter: mediate levels of dependence would be assessed.

Let us assume that we have only two different situations, the ones described above, and we have assigned $Z D$ and $C D$ to them as above. Let us simplify the problem and consider a set of valves to consist of only two valves, valves "A" 
and "B." Figure 3-1 shows an HRA event tree of this situation. The probability of an EOM for valve "A" is designated as the capital letter A. The probability of no EOM (i.e., 1 - A) is designated as the small letter a (the operator did remember to restore valve "A"). In HRA event trees, failure limbs are always indicated with capital letters, and are branched to the reader's right. Success limbs are indicated with small letters and are branched to the left. Because the HRA event tree is a binary decision tree, the probabilities assessed to the two limbs in each branching must sum to 1.0 , and the sum of the probabilities at the end of all the success and failure paths through the tree also must sum to 1.0. Equivalent notation is used for valve "B," except for illustrative purposes that the appropriate conditionality has been conventionally indicated with the $\mid$ sign, e.g., B/a means the probability of an EOM on Valve "B," given that no EOM has been made on valve "A." For simplicity, the full statement, $B / a$, is usually stated simply as $B$; the conditionality is understood. To avoid confusion in the $B$ statements, $B \mid A$ might be stated as $B^{\prime}$ (i.e., B prime). In the example below, the full statements are used. This standard notation is used throughout the report, and is described fully in Chapter 5 of NUREG/CR-1278.

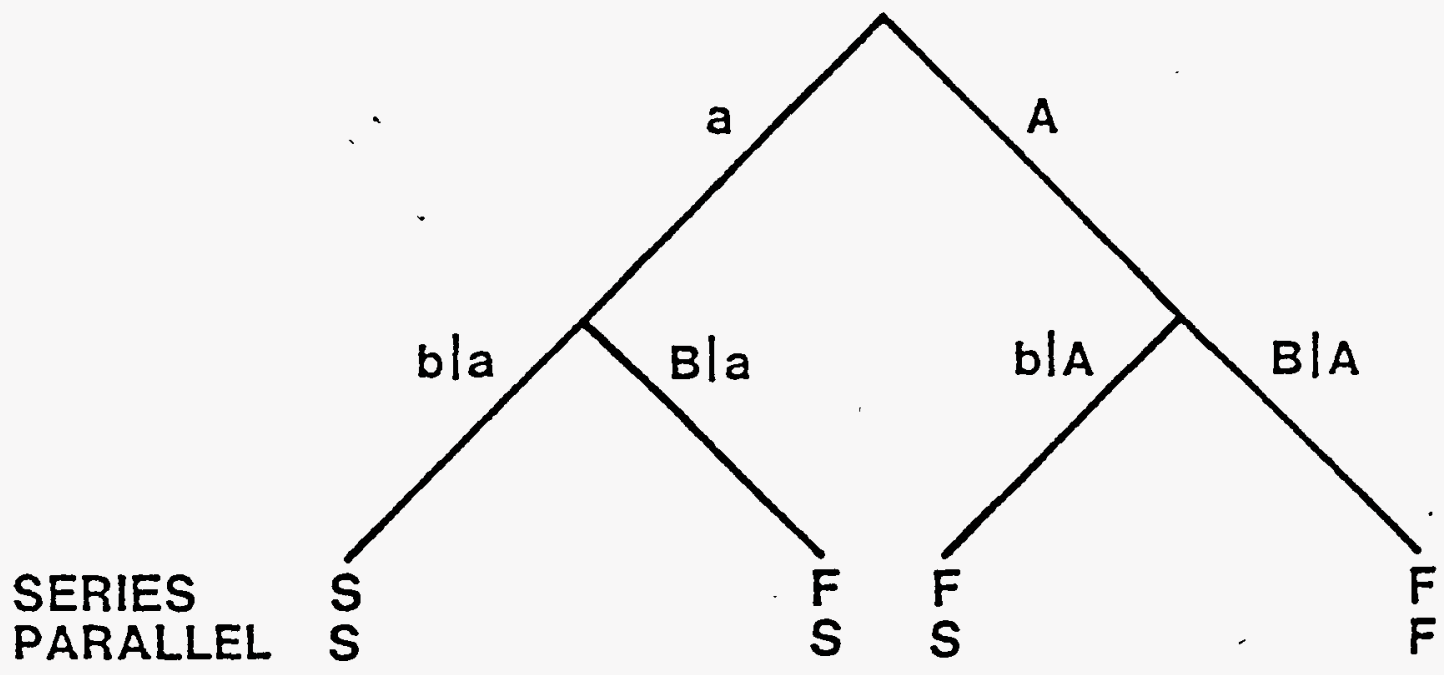

For series systems,

$F=1-a(b \mid a)$, or $a(B \mid a)+A(b|A+B| A)=a(B \mid a)+A$

For parallel systems, $F=A(B \mid A)$, or $1-\left[a(b \mid a)+a(B \mid a)+A(b \mid A)^{\prime}\right]$

Figure 3-1 HRA Event Tree for EOMs for Hypothetical Tasks "A" and "B" 
Consider the $Z D$ case first. The valves themselves might be connected in series (which we will call $\mathrm{ZD}, \mathrm{ser}$ ) or in parallel (ZD,par). If the valves are: connected in series, then from a systems point of view, $F \mid Z D$, ser $=a(B \mid a)+A$, or $1-a(b \mid a)$. That is, if an EOM is made for either valve, the system fails; both valves must be restored for system success to occur, i.e., $S=a(b \mid a)$. If the valves are connected in parallel, then from a systems point of view, $F \mid Z D$,par - $A(B \mid A)$. That is, the system will fail only if both valves are not restored. If either is restored, system success will occur.

Now consider the $C D$ case. Again, the valves themselves might be connected in series (which we will call $C D$, ser) or in parallel ( $C D$, par). If the valves are connected in series, then from a systems point of view, $F \mid C D$, ser $-a(B \mid a)+A$, or $I-a(b \mid a)$. If the valves are connected in parallel, then from a systems point of view, $F \mid C D$, par $=A(B \mid A)$. Note that the two sets of equations for $Z D$ and $C D$ are identical. The answers will be different when one puts in the appropriate conditional probabilities for the letter symbols denoting correct or incorrect human actions.

Let us assume in the case of the $Z D$ level of dependence that $A=B / A$. This equality is usually the case. It means that the basic human error probabilities (BHEPs) (i.e., the probabilities without considering the effects of dependence) of the two tasks (" $A$ " and "B") are equal. This is what one would expect if the restoration task is to restore similar-appearing valves. For the $C D$ case, by definition $B \mid A$ must equal 1.0 and $B \mid a$ must equal 0 .

Assume that $A=B \mid A=.03$, that is, the BHEPs are equal to .03 . Now we can work out the system failure probabilities for the above four cases:

$$
\begin{aligned}
& F \mid Z D, \text { ser }=1-a(b \mid a)=1-.97^{2}=.0591 \sim .06 \\
& F \mid Z D, \operatorname{par}=A(B \mid A)=.02^{2}=.0009-.001 \\
& F \mid C D, \text { ser }=1-a(b \mid a)=1-(.97 \times 1.0)=.03 \\
& F \mid C D, \operatorname{par}=A(B \mid A)=.03 \times 1.0=.03
\end{aligned}
$$

The above simplified HRA problem illustrates the point that what is designated as system success is defined by the way in which the system works, and that assessment of levels of dependence among human actions is based only on the interrelationships among the human actions themselves. The example also illustrates that for the typical HEPs used in an HRA of pre-accident tasks (i.e., HEPs not much larger than .01), dependence is an important consideration in the analysis of parallel systems, but not for series systems. 


\section{General Information}

In Chapter 2, the distinction between a nominal and a screening HRA was discussed, and also the distinction between a coarse and a fine screening HRA, as applied to pre-accident tasks. The ASEP HRA screening rules can be classified as a very fine level of screening. The primary characteristics of a very fine level of screening are (1) it is based on an initial plant-specific task analysis, (2) it includes some credit for human error recovery factors (RFs), and (3) it takes into account certain possibilities of task dependence that could result in common-cause failures resulting from within-person or betweenperson dependence. Note that in the ASEP screening HRA for pre-accident tasks each RF may be counted only once.

Either of two sets of estimated probabilities can be employed in the HRA screening procedure for pre-accident tasks. The first set involves the use of conservative total-failure terms $\left(F_{T} s\right)$ that have been calculated as described in Swain (1985a) and in the section on "Screening Rules for the Human Reliability Analysis in the Risk Methods Integration and Evaluation Program"_in Volume 5 of NUREG/CR-4832 (Payne et al, 1987). The second set involves the use of the upper bounds (UBs) of the estimated uncertainty bounds on the $F_{r} s$, calculated by the uncertainty bounds propagation computer program described in Appendix B. The use of the UBs of the $F_{T} s$ provides an ultra-conservative screening procedure. It is important to emphasize that this ultra-conservative screening method uses the UBs of the $F_{T} s$; it does not involve the use of the UBs for every estimated HEP that went into the calculations of each of the $\mathrm{F}_{\mathrm{T}} \mathrm{s}$ in the above tables. Such an approach would be an "extreme worst-case analysis," and would amount to no screening at all.

Because of time and fund limitations, neither screening procedure was used in the ASEP PRAs. Both are included here for completeness.

\section{The Procedure}

Table 4-1 presents the steps to follow in applying the ASEP HRA Screening Procedure for pre-accident tasks, and Tables 4-2 and 4-3 present the tables of estimated HEPs and other rules for the HRA screening procedure for pre-accident tasks. For background material used to develop these tables, including the rationale for the basic HEP of .03, see Swain (1985a) or the section on the HRA screening procedure in Volume 5 of NUREG/CR-4832 (Payne et aI, 1987). 
Table 4-1 Procedure for Screening HRA of Pre-Accident Tasks (pl/3)

1. Visit the plant initially to observe a sample of pre-accident tasks (especially calibration tasks, post-calibration and post-maintenance tests, and restoration tasks) and obtain relevant written procedures and other documentation that spells out operating sequences and rules.

a. The observations should include talk-throughs of several pre-accident procedures, emphasizing restoration tasks, and, if possible, some actual calibration tasks and post-calibration and post-maintenance tests. Failure to make these observations, including interviews with operating personnel who actually perform the tasks, will mean that the estimated HEPs will probably have to be higher than otherwise.

b. Carefully evaluate the quality of the administrative control, e.g., how well prescribed pre-accident tasks, especially human error recovery factors (RFs), will be performed. (See Chapter 16 in NUREG/CR-1278 for more detail.)

c. Other plant visits should not be necessary during the screening process, but may be necessary for the subsequent nominal HRA.

2. Based on the information obtained in step 1 , determine if the basic HEP of .03 should be adjusted upwards for unusually poor human factors, especially written procedures. No downward adjustment is permitted.

a. As the .03 already is a conservative HEP, the decision for an upward adjustment should be fully documented. The human factors in a plant would have to be unusually poor to require an upward adjustment.

b. If it is not possible to make this evaluation because of inability to observe pre-accident tasks (or to receive talk-throughs of these tasks) or because of inability to evaluate adequately the administrative control procedures, employ a .05 basic HEP in place of the .03 HEP. All the other numbers in the tables which are based on the .03 HEP will have to be changed, using the arithmetic implied by the tables.

3. Identify the pre-accident critical actions in terms of the systems analysis. (Note: Ideally, this step should be performed prior to the plant visit. In ASEP, this was not possible due to scheduling restrictions.) Obtain any additional written materials required.

4. Identify the recovery factors (RFs) listed below. Do not consider any other RFs. For each critical action, count each relevant RF only once.

a. Determine for which critical pre-accident actions, errors can be assessed as fully recoverable by "compelling signals, "usually one or more annunciators when a maintenance or calibration task is completed or before normal power operation can be resumed. 
Table 4-1 Procedure for Screening HRA of Pre-Accident Tasks(p2/3)

b. Determine for which critical pre-accident actions, errors will be recovered by a post-maintenance (PM) or post-calibration (PC) test if the test is performed correctly. (Just because a test is scheduled does not guarantee that it will be performed, and performed correctly.)

c. Determine for which critical pre-accident actions, (I) a second person is required to directly verify component status after completion of the actions by the original performer, or (2) the original performer is required to make a separate check of component status at a different time and place from his original performance. An example of the latter would be for an operator to restore a locally-operated valve to its normal operating condition following maintenance, and then to return to the control room and note that an appropriate indicator light shows the desired position of the valve. No recovery credit is given for either check unless a written checkoff list is used during the check.

d. Determine for which critical pre-accident actions there is a requirement for a shiftly or daily check of component status in or outside of the control room, using a written list. No recovery credit is given for either check unless a written checkoff list is used during the check.

5. Consider all of the following critical tasks, i.e., include them in the screening analysis: (Exclude all other tasks.)

a. All tasks which have no REs, as defined above.

b. All tasks for which there is a common-cause situation, i.e., incorrect performance of the task could fail redundant systems or components.

c. All tasks for which there is no common-cause situation and if any of the following RFs apply:

1) $4 . \mathrm{b}$ only

2) $4 . c$ only

3) 4.d only

4) $4 . c$ and $4 . d$ in combination

6. Assign a basic HEP (BHEP) of .02 for each error of omission (EOM) and .01 for each error of commission (ECOM). Assume that an ECOM is always possible if an EOM is not made. Therefore, for each critical action, assign a total BHEP of .03.

7. Assign a .1 HEP for failure of each relevant RF, except for a .01 failure to perform a required PM or PC test or to perform it correctly. The RF already includes between-person dependence, and is assumed to apply to the EOM and ECOM as a unit, i.e., to the BHEP of .03 for a complete critical action. Therefore, it is appropriate to multiply the .03 by the 
Table 4-1 Procedure for Screening HRA of Pre-Accident Tasks (p3/3)

product of the RF HEPs and to treat the final product as a unit. It is judged that the assessed probability of failure of each RF is high enough to also. include estimated failures of administrative control, i.e., the failure .. to . perform the prescribed RF. (See Chapter 16 in NUREG/CR-1278 for examples of administrative control.)

8. Consult Table 4-2. to ascertain which set of conditions apply to each critical action, and for the restrictions in the number of RFs to use. No other RFs are allowed than those in Table 4-2.

9. Consult Table 4-3 to determine which of nine cases applies to each critical action. For each case, the appropriate total-failure probability $\left(F_{T}\right)$ and its upper bound (UB) are listed, exclusive of the effects of within-person dependence. For a conservative screening analysis, use the $\mathrm{F}_{\mathrm{T}^{5}}$. For an ultra-conservative screening analysis, use the UBs of the $F_{T}^{T}$.

10. Decide whether the critical human actions are performed in the context of a parallel or a series system.

a. For a series system, assess zero dependence (ZD) among the same critical human actions on different components that are in series.

b. For a parallel system assess complete dependence (CD) among the same critical human actions on different components that are in parallel. However, if a testing schedule is scheduled such that different redundant trains or components within a train are'tested or restored on different shifts, assess $2 D$.

c. In the ASEP PRAs, other coupling of human actions were to be assessed as part of "Beta Factors," generic common-cause factors based on failure data and which were developed by systems analysts to account for unknown effects. Examples are improper maintenance of several components by the same person who used an incorrect maintenance method, or the miscalibration of several sensors resulting from faulty calibration equipment. The use of Beta Factors is not part of this screening HRA procedure. See Flemming et al (1985) for further information. (No screening analysis was used in the ASEP PRAs, including the ASEP HRAs.)

11. Enter the $F_{T} s$ (or UBs of the $F_{T} s$ ) in the appropriate system fault trees or system event trees, paying special attention that the dependence effects identified for human actions are preserved in the way in which the $\mathrm{F}_{\mathrm{T}^{5}}$ are used. See Chapters 5 and 10 of NUREG/CR-1278 for guidelines. 
Table 4-2 Basic and Optimum Conditions for Screening HRA of Pre-Accident Tasks, Exclusive of Within-Person Dependence Effects ( $\mathrm{pl} / 2$ )

Note 1: "Basic Conditions" refer to the absence of error recovery factors (RFs). "Optimum Conditions" refer to the presence of RFs. Each numbered Basic Condition has its same numbered complementary Optimum Condition.

\section{Basic Conditions}

Note 2: If all of the basic conditions apply (i.e., there are no RFs), the basic HEP of .03 is assessed; or, for an ultra-conservative screening analysis, its upper bound of .15 is assessed.

1. Unavailable component status is not indicated in the control room by some "compelling signal" such as an annunciator when the maintenance or calibration task or subsequent test is finished or before normal power operations can be resumed.

2. Component status is not verified by a post-maintenance (PM) or a postcalibration (PC) test; that is, it is not required or, if performed, does not verify. component status.

3. There is no requirement for an $R F$ involving (1) a second person directly to verify component status after completion of a maintenance or calibration task or (2) the original performer to make a separate check of component status at a different time and place from his original task performance, or (3) the verification does not require use of a written checkoff list.

4. Shiftly or daily checks of component status (in or outside of the control room) are done without using a written checkoff list, or are not done at all. 
Table 4-2 Basic and Optimum Conditions for Screening HRA of Pre-Accident Tasks, Exclusive of Within-Person Dependence Effects $(p 2 / 2)$

\section{Optimum Conditions}

Note 3: If all of the optimum conditions apply, or if optimum condition 1 only applies, a negligible HEP is assessed due to the excellence of the RFs. If an ultra-conservative screening analysis is being employed, use an HEP of .00001 .

1. Unavailable component status is indicated in the control room by some "compelling signal" such as an annunciator when the maintenance or calibration task or subsequent test is finished or before normal power operation can be resumed.

2. Component status is verifiable by a PM or PC test. If done correctly, full recovery of any related error is assumed. An HEP of .01 is assessed for failure to perform the test correctly (including failure to do the test).

3. There is a requirement for an $R F$ involving (1) a second person directly to verify component status after completion of a maintenance or calibration task, or (2) the original performer to make a separate check of component status at a different time and place from his original task performance. No credit is given for either check unless a written test is used during a check. An HEP of .1 is assessed for failure of this RF to catch an error by the original task performer. This RF is presumed to be inoperative if a required PM or PC test is not performed correctly, as such failure indicates inadequate quality assurance.

4. There is a requirement for a shiftly or daily check of component status (in or outside of the control room), using a written list. An HEP of . I is assessed for the failure of such a check to detect the unavailable status. For screening purposes, this RF may be used only once per error. 
Table 4-3 Applications of Table 4-2,

Exclusive of Within-Person Dependence Effects ( $1 / 2)$

Note 1: For each case below, the total failure probability, $F_{T}$, is listed with its error factor (EF) and upper bound (UB) in parentheses. The $F_{T}$ is the product of the basic HEP of .03 and the probabilities of failure of the relevant RFs. The EFs on the $F_{T} s$ were calculated using the UCBs propagation computer program described in Appendix $B$. For a conservative screening analysis, use the $F_{T} s$; for an ultraconservative analysis, use the UBs of the $F_{T} s$, i.e., the $F_{T} s$ divided by their EFs.

Note 2: In the first 4 cases, there is no "compelling signal" as feedback. In addition, the post-maintenance (PM) or post-calibration (PC) test is determined to be ineffective in the sense that, even if performed correctly, it will not catch the original error.

Case I - PM or PC Test not effective; no other RFs used:

a. All Basic Conditions apply.

b. BHEP $-.03=F_{T} \cdot(E F=5, U B=.15)$.

Case II - No compeliing signal feedback; PM or PC Test not effective; both other RFs used:

a. Basic Conditions 1, 2 apply.

b. Optimum Conditions 3, 4 apply.

c. $F_{T}=.03 \times .1 \times .1=.0003 .(E F-16, U B-.005)$.

Case III - No compelling signal feedback; PM or PC Test not effective; second person or other immediate RF used:

a. Basic Conditions 1, 2, 4 apply.

b. Optimum Condition 3 applies.

c. $F_{T}=.03 \times .1=.003 .(E F-10, U B \sim .03)$.

Case IV - No compelling signal feedback; PM or PC Test not effective; periodic check is made:

a. Basic Conditions 1, 2, 3 apply.

b. Optimum Condition 4 applies.

c. $\mathrm{F}_{\mathrm{T}}-.03 \times .1=.003 .(E F-10, \mathrm{UB}-.03)$. 
Table 4-3 Applications of Table 4-2, Exclusive of Within-Person Dependence Effects $(p 2 / 2)$

Note 3: In the last 5 cases, the PM or PC Test is determined to be effective, i.e., if performed correctly it will detect the original error.

Case V-Original error is annunciated; all other optimum conditions are immaterial:

a. At least Optimum Condition \#1 applies.

b. $F_{T}=$ negligible. (Assess UB of .00001).

Case VI - PM or PC Test is effective if performed correctly; no other RFs used:

a. Basic Conditions 1, 3, 4 apply.

b. Optimum Condition 2 applies.

c. Probability of not performing, or not performing correctly, the required $\mathrm{PM}$ or $\mathrm{PC}$ Test $=.01$

d. $F_{T}=.03 \times .01=.0003 .(E F-10, U B=.003)$.

Case VII - No compelling signal feedback; PM or PC Test is effective if performed correctly; both other RFs are used:

a. Basic Condition 1 applies.

b. Optimum Conditions 2, 3, 4 apply.

c. $F_{T}=.03 \times .01 \times 1.0 \times .1=.00003 .(E F-16, U B-.0005)$.

(Note: The 1.0 means no recovery credit is given for Optimum Condition 3 if the PM or PC Test is not done or done correctly per Opțimum Condition 2.)

Case VIII - No compelling signal feedback; PM or PC Test is effective if performed correctly; second person or other immediate RF is used:

a. Basic Conditions 1,4 apply.

b. Optimum Conditions 2,3 apply.

c. $F_{T}=.03 \times .01 \times 1.0=.0003 .(E F-10, U B=.003)$.

Case IX - No compelling signal feedback; PM or PC Test is effective if performed correctly; periodic check is made:

a. Basic Conditions 1,3 apply.

b. Optimum Conditions 2, 4 apply.

c. $F_{T}=.03 \times .01 \times .1=.00003 .(E F-16, U B-.0005)$. 
This chapter provides general information for the screening human reliability analysis (HRA) and the nominal HRA for post-accident tasks. To develop rules for the screening and nominal HRAs, modifications were made to the RMIEP screening HRA procedure [see Swain (1985a) or the section on "Screening Rules for the Human Reliability Analysis in the Risk Methods Integration and Evaluation Program" in Volume 5 of NUREG/CR-4832 (Payne et al, 1987)], which in turn was based primarily on modifications of NUREG/CR-1278. See Appendix A for more information on the relationship of the RMIEP screening HRA procedure to the ASEP HRA procedure for post-accident tasks. The rules for estimating human error probabilities (HEPs). and uncertainty bounds (UCBs) for ASEP screening HRAs and nominal HRAs for post-accident tasks are found in, respectively, Chapter 7 and Chapter 8.

To develop an HRA procedure for post-accident tasks, a simplified model of human behavior for these tasks was devised. The model makes some simplifying assumptions about diagnosis behavior, and clarifies some of the rules in INUREG/CR-1278 which were only implicit. In addition, rules for allowing credit for the new symptom-oriented emergency operating procedures (EOPs) are provided. This chapter provides a background for the general models found in Chapters 7 and 8 .

\section{Definitions of Terms}

Before proceeding further, it is suggested that the reader consult the prefatory pages to review the list of abbreviations and definitions of the following terms, which pertain to post-accident tasks. Some of these terms are also defined in the text which follows.

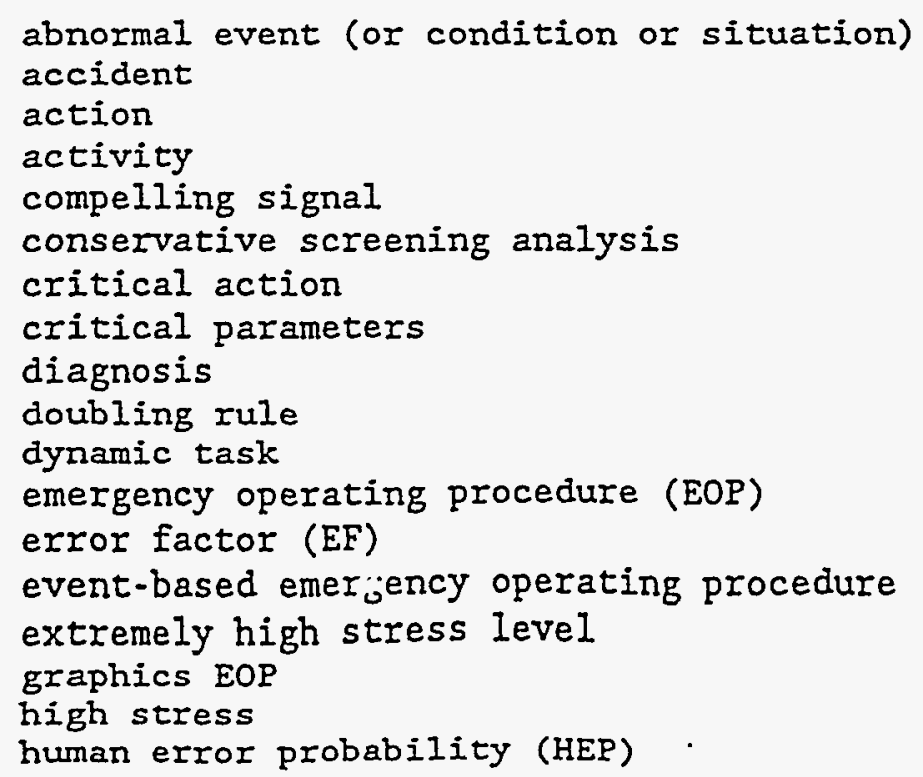




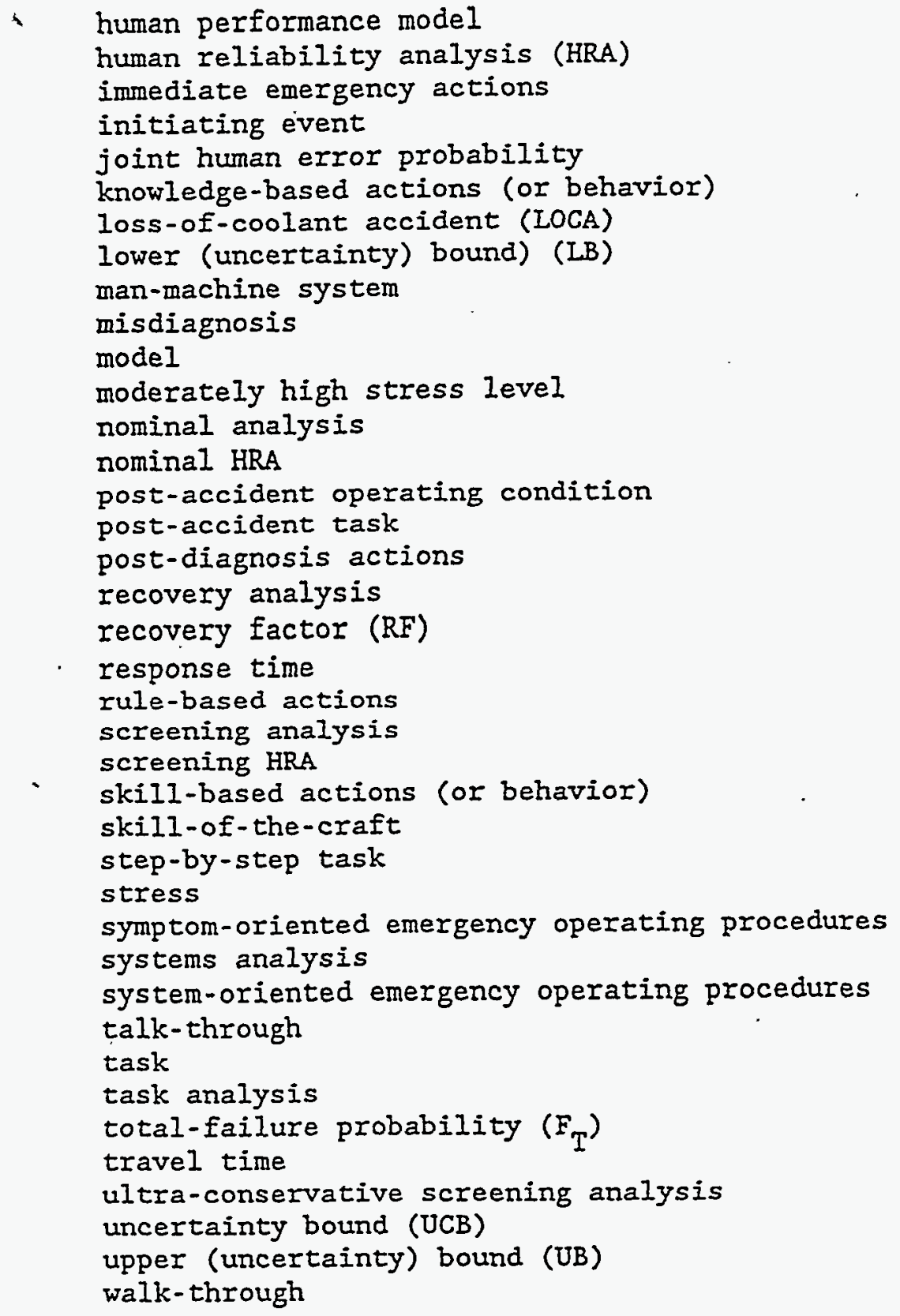

\section{Post-Accident Tasks of Interest}

Post-accident tasks are divided into diagnosis tasks and post-diagnosis tasks, both of which are intended to maintain or ensure reactor protection once some abnormal event has occurred. Diagnosis refers to the probability of a correct diagnosis within the time required to permit the carrying out of the required post-diagnosis actions. Diagnosis is defined as the attributing of the most likely cause(s) of an abnormal event to the level required to identify those systems or components whose status can be changed to reduce or eliminate the 
problem. In the context of the new symptom-oriented EOPs, diagnosis does not $\because$ necessarily require that some name be attached to the abnormal event, e.g., small loss-of-coolant accident (IOCA).

In short, diagnosis merely means figuring out what to do when an abnormal event has been recognized. Diagnosis involves knowledge-based behavior, as defined in Table 2-1. Post-diagnosis actions are those taken which logically follow a correct diagnosis of the abnormal event. Post-diagnosis actions involve rule-based or skill-based behavior (Table 2-1). Diagnosis and related words (cognition, interpret, decide, judgment, etc.) are often used differently by different people, and dictionary definitions are not always helpful, as indicated in the second column in Table 6-1. The ASEP HRA Procedure uses the definitions in the third column of this table. The human activity does not always follow the sequence shown in this column. Instead, there are many possible interactions and shortcuts in responding to an abnormal event, as shown in Figure 6-1.

The specific abnormal events to be analyzed in HRAs in the ASEP probabilistic risk assessments (PRAs) were designated by systems analysts. They included such events as station blackouts, anticipated transients without scram (ATWS), loss-of-coolant accidents (IOCAs), loss of AC or DC bus, and loss of component cooling water.

The identification of the related human behaviors and potential errors in each of the abnormal events analyzed in a PRA is accomplished by a team of systems analysts, human reliability analysts, appropriate plant personnel (especially licensed reactor operators and simulator instructors), and others as needed. The team uses the typical task analysis methods (interviews, observations, simulator exercises, etc.) described in Chapter 4 of NUREG/CR-1278 and in NUREG/CR-2254. As shown in Figure 6-2, an HRA of post-accident tasks typically starts with the annunciation (or other compelling signal) of an abnormal event: For purposes of PRA, there are only two success paths. One of these success paths (the top path in the figure) requires a correct diagnosis to be made within time constraints, as defined later, and the appropriate postdiagnosis actions (primarily rule-based behavior) to be correctly performed within their time constraints (again, as defined later). The other success path (which has rarely been considered in published PRAs, including the ASEP PRAs) allows a misdiagnosis, but assumes a successful recovery from the misdiagnosis, followed by the correct performance of the post-diagnosis actions, again all within the allowable time constraints. 
Table 6-1 Definitions of Cognition-Related Terms and Usage in the Handbook of Human Reliability Analysis ( $p 1 / 2$ )

(Copy of Table 12-1 from NUREG/CR-1278)

\begin{tabular}{|c|c|c|}
\hline Term & Dictionary Definition* & Handbook Usage \\
\hline Cognition & $\begin{array}{l}\text { the act or process of } \\
\text { knowing, including both } \\
\text { awareness and judgment }\end{array}$ & $\begin{array}{l}\text { restricted to those aspects of } \\
\text { behavior involved in diagnosis } \\
\text { of abnormal events }\end{array}$ \\
\hline Judgment & $\begin{array}{l}\text { the process of forming an } \\
\text { opinion or evaluation by } \\
\text { discerning and comparing }\end{array}$ & $\begin{array}{l}\text { not used in our models--too } \\
\text { imprecise; used only in the } \\
\text { context of expert estimation }\end{array}$ \\
\hline Perceive & $\begin{array}{l}\text { to attain awareness or } \\
\text { understanding; to become } \\
\text { aware through the senses }\end{array}$ & $\begin{array}{l}\text { used in the very narrow sense of } \\
\text { "awareness" without the further } \\
\text { meaning of "understanding," e.g., } \\
\text { "some annunciator tiles over } \\
\text { there are blinking" }\end{array}$ \\
\hline Discriminate & $\begin{array}{l}\text { to mark or perceive the } \\
\text { distinguishing or peculiar } \\
\text { features of; } \\
\text { to distinguish one like } \\
\text { object from another }\end{array}$ & $\begin{array}{l}\text { distinguishing one signal (or a } \\
\text { set of signals) from another, } \\
\text { e.g." "the coolant level in } \\
\text { Tank A is } 37 \text { feet," or if there } \\
\text { are limit marks on the meter, } \\
\text { "the coolant level is out of } \\
\text { limits" (in the latter case, some } \\
\text { interpretation is done for the } \\
\text { operator by the design of the } \\
\text { display) }\end{array}$ \\
\hline Interpret & $\begin{array}{l}\text { to conceive in the light } \\
\text { of individual belief, } \\
\text { judgment, or circumstance }\end{array}$ & $\begin{array}{l}\text { the assignment of a meaning to } \\
\text { the pattern of signals (or stimu- } \\
\text { li) that was discriminated, e.g., } \\
\text { "the coolant level in Tank A is } \\
\text { low, which means that the make-up } \\
\text { pump is not running, or there is } \\
\text { a leak somewhere, or the indica- } \\
\text { tor is out of order"; if there is } \\
\text { only one possible cause for the } \\
\text { observed signal, the interpre- } \\
\text { tation is equivalent to diagnosis }\end{array}$ \\
\hline
\end{tabular}

*Webster (1975) 
Table 6-I Definitions of Cognition-Related Terms and Usage

in the Handbook of Human Reliability Analysis ( $p 2 / 2)$

(Copy of Table 12-1 from NUREG/CR-1278)

\begin{tabular}{|c|c|c|}
\hline Term & Dictionary Definition* & Handbook Usage \\
\hline Diagnosis & $\begin{array}{l}\text { a statement or conclusion } \\
\text { concerning the nature or } \\
\text { cause of some phenomenon }\end{array}$ & $\begin{array}{l}\text { the attributing of the most like- } \\
\text { Iy cause(s) of the abnormal event } \\
\text { to the level required to identify } \\
\text { those systems or components whose } \\
\text { status can be changed to reduce } \\
\text { changed to reduce or eliminate } \\
\text { the problem; diagnosis includes } \\
\text { interpretation and (when } \\
\text { necessary) decision-making }\end{array}$ \\
\hline Decide & $\begin{array}{l}\text { to make a choice or } \\
\text { judgment }\end{array}$ & $\begin{array}{l}\text { "decision-making" used instead of } \\
\text { "deciding" }\end{array}$ \\
\hline $\begin{array}{l}\text { Decision- } \\
\text { making }\end{array}$ & & $\begin{array}{l}\text { (1) decision-making as part of } \\
\text { diagnosis: the act of } \\
\text { choosing between alternative } \\
\text { diagnoses, e.g. to settle on } \\
\text { the most probable cause of } \\
\text { the pattern of stimuli asso- } \\
\text { ciated with an abnormal event } \\
\text { (2) post-diagnosis decision- } \\
\text { making: the act of choosing } \\
\text { which acts to carry out after } \\
\text { a diagnosis has been made; } \\
\text { in most cases, these actions } \\
\text { are prescritad by rules or } \\
\text { procedures, and decision- } \\
\text { making is not required }\end{array}$ \\
\hline Action & $\begin{array}{l}\text { a thing accomplished } \\
\text { usually over a period of } \\
\text { time, in stages, or } \\
\text { with the possibility of } \\
\text { repetition }\end{array}$ & $\begin{array}{l}\text { carrying out one or more } \\
\text { activities (e.g., steps or } \\
\text { tasks) indicated by diagnosis, } \\
\text { operating rules, or } \\
\text { written procedures }\end{array}$ \\
\hline
\end{tabular}

Whebster (1975) 


\section{COGNITION-RELATED TERMS}

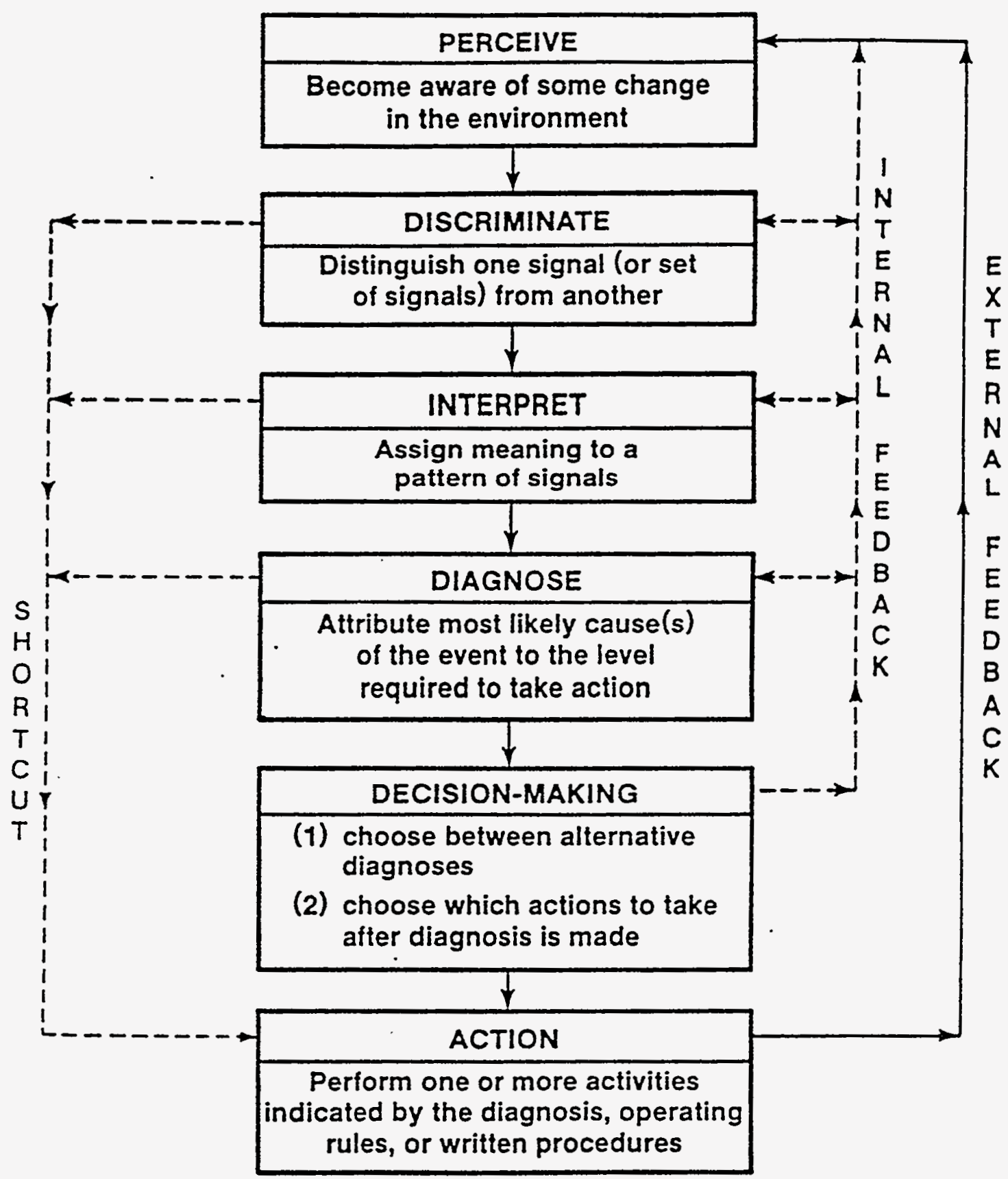

Figure 6-1 Interaction of Cognition-Related Terms .

(Copy of Figure 1 from Swain and Weston, 1987) 


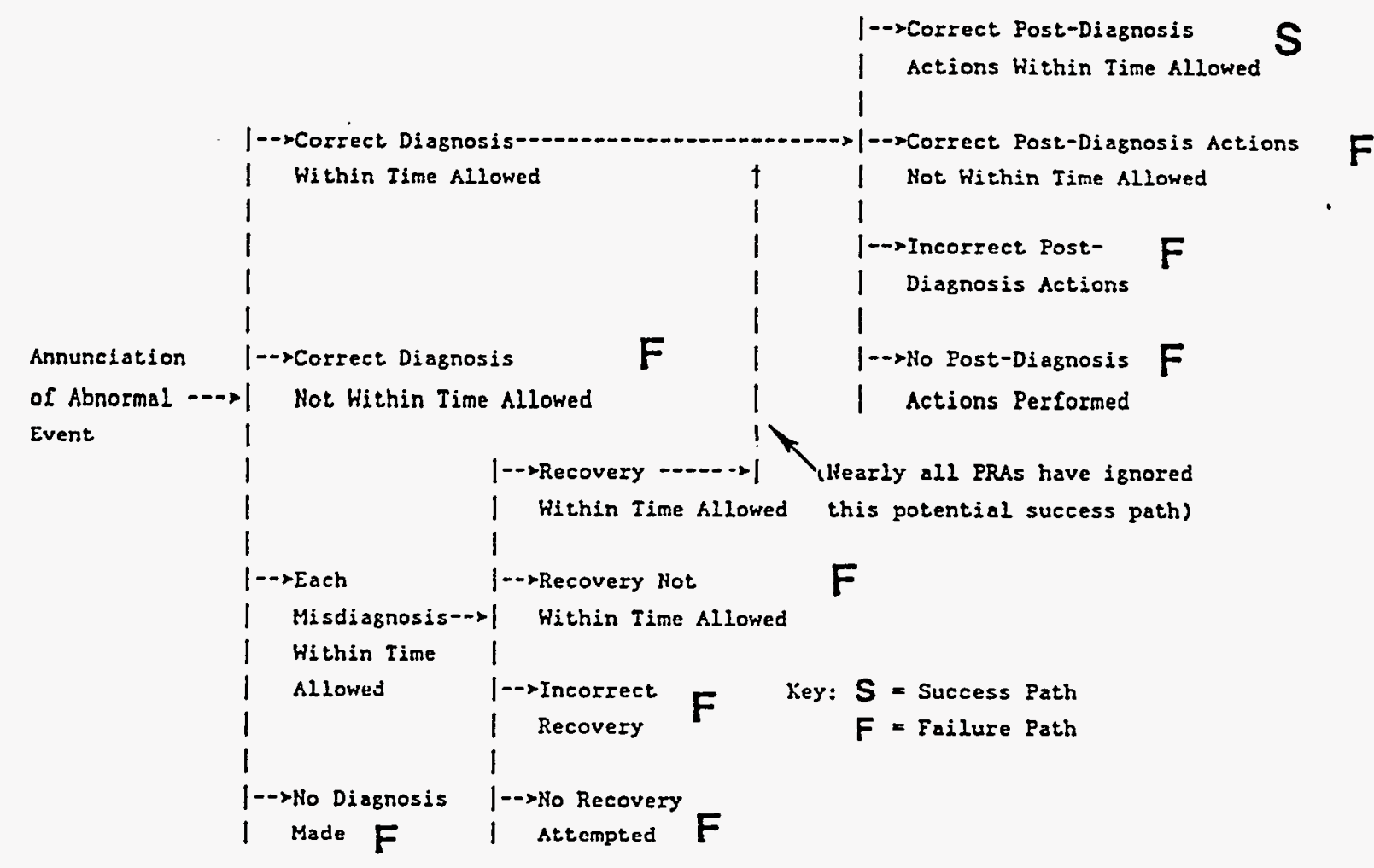

Figure 6-2 Success and Failure Paths Following an Abnormal Event

(Copy of Figure 2 from Swain and Weston, 1987)

There are eleven failure paths in Figure 6-2, as indicated by the left-most five $F$ terms at the.end of single paths, and the three right-most $F$ terms, each of which can be reached by two different paths through the event tree. Note that in these paths, diagnosis, recovery actions, and post-diagnosis actions are considered to be failures because they were not performed on a timely basis, or they were performed incorrectly, or no action at all was taken. Often it is desirable to estimate probabilities of specific incorrect actions, as they may result in worsening the abnormal situation. The ASEP HRA Procedure does not address this particular HRA problem; see p 21-14 to 21-24 of NUREG/CR-1278 for an example analysis of this difficult area.

\section{Some Simplifications in the HRA Procedure for Post-Accident Tasks}

In keeping with a primary goal of the ASEP, several important simplifications have been made. One of the major simplifications is to ignore the whole area of specific misdiagnoses. Instead, it is conservatively assumed that any failure to correctly diagnose an abnormal event within the allowable time will result in a core damage accident. No analysis is made of the possible kinds 
of erroneous diagnoses (i.e., misdiagnoses) that might be made for any abnormal event. For a suggested new approach to this problem, see Swain and Weston (1987).

Another simplification is to segment the estimated total time available for coping with an abnormal event into artificially independent parts. For example, consider the top success path in Figure 6-2. A total allowable time for coping with an abnormal event is specified by systems analysts and is divided into an allowable diagnosis time and an allowable post-diagnosis time. This HRA approach involves the estimation of two separate time-dependent probabilities: the probability of performing a correct diagnosis within its allowable time, and the probability of performing the correct post-diagnosis actions within its allowable time. Then, the product of these two probabilities is taken as the probability that a correct diagnosis will be made and that the correct post-diagnosis actions will be completed within the total allowable time. This is not literally true because different combinations of time-dependent probabilities for the two time periods are not considered. It appears that the simplification suggested can result in very conservative estimates of the total failure probabilities of coping successfully with abnormal events. In the absence of data which would permit full consideration of time dependencies, this simplification is considered to be acceptable.

Another simplification is to assume that there is only one correct sequence of activities in coping with any specified post-accident sequence. In the ASEP PRAs, the correct sequence was selected from the EOPs for an abnormal event. This restriction does not keep the analyst from analyzing several different sequences of activities for an abnormal event, as defined by different postaccident assumptions. For example, in an ATWS, one sequence might assume that boron injection is available, and a different sequence might assume that this engineered safety feature (ESF) is unavailable. In such a case, we really have two different abnormal events, and the human behaviors involved will have important differences. A different HRA is required for each different postaccident sequence.

Other simplifications specific to screening and nominal HRAs for post-accident tasks are stated in Chapters 7 and 8.

\section{Time Dependencies Between Diagnosis and Post-Diagnosis Tasks}

The approach used in the ASEP HRA Procedure to estimating HEPs for post-accident tasks is taken from Chapter 12 in NUREG/CR-1278. First, one ascertains by measurement or estimation the time that is required to perform the necessary rule-based actions once the control room personnel understand what needs to - be done. In short, these are the actions following a correct diagnosis. Once a . time measurement or estimation has been made for these post-diagnosis actions, this time is subtracted from the total man/machine system response time. that systems analysts have estimated is allowable for acceptable system response to the abnormal event. The time that is left after this subtraction is the time permitted for diagnosis. The problem, then, is to estimate the probability of a correct diagnosis within that allowable time. 
Figure 6-3 diagrams the above time relationships, and the following steps provide additional descriptive information. The procedure in chapters 7 and 8 is based on this approach, and examples in both chapters illustrate the use of Figure 6-3.

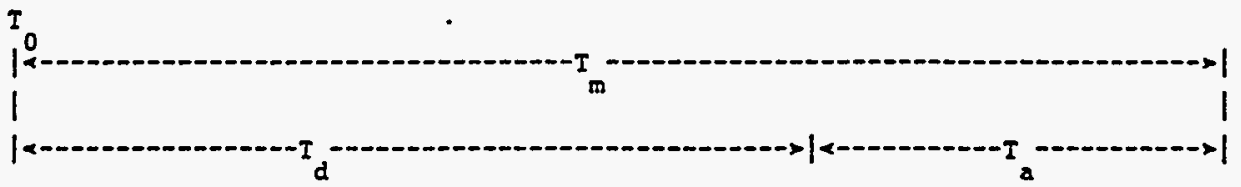

\footnotetext{
Key: $I_{0}$ - Annunciation (or other compelling sisnal) of an abnormal event

Im - Estimated maximum allowable time to have correctly diagnosed the abnormal. event and to have completed the required post-diagnosis actions so as to achieve system success criteria established by systems analysts

I - Estimated allowable time for a correct diagnosis which will still permit sufficient time to perform required post-diagnosis actions prior to $\mathrm{T}_{\mathrm{m}}$

$T_{\text {a }}$ - Estimated time needed to get to proper locations and to perform required post-diagnosis actions after a correct diagnosis
}

Figure 6-3 Time Relationships between Annunciation (or Other Compelling Signal) of an Abnormal Event, a Correct Diagnosis of the Event, and Performing the Required Post-Diagnosis Actions After a Correct Diagnosis

(Copy of Figure 3 from Swain and Weston, 1987)

\section{Procedure}

1. Estimate $T_{\mathrm{f}}$, the maximum allowable time to have diagnosed the abnormal event and have completed the necessary rule-based (or skill-based) actions. $T_{m}$ is determined by systems analysts, based on an analysis of plant operating characteristics. 
2. Identify the rule-based and skill-based actions that control room personnel would be likely to take following the correct diagnosis of each abnormal event in the accident sequence of interast. For the ASEP HRA Procedure, the PRA team selects one set of post-diagnosis actions as the most likely, and, for simplicity, assumes that this is the only plausible set.

3. Estimate $T$, the time needed to get to the proper locations inside or outside of the control room and to perform the required actions following correct diagnosis of an abnormal event (see Step 2). $T$ is designated as time for "post-diagnosis actions." The. HRA analyst pertorms this estimation using appropriate plant personnel as subjects. Actual measurements are used wherever possible, in the simulator for control room activities, and by using walk-throughs for activities performed outside the control room. Only as a last resort should opinions be substituted for time measurements, as data show that time estimates from judgments are quite variable, and usually underestimate the time required for tasks (see $p$ $6-11$ in NUREG/CR-1278).

To reduce the number of measurements needed, actions can first be grouped, based upon similarity of location and type of action. For example, all actions requiring movement of a simple switch and located on the same control-room panel can be grouped. Then, measurements need be taken on only one action per group, since similar times would be expected for all actions within a group.

In practice, estimates of $T$ tend to be conservative, that is, the estimates do not represent median response times. Instead, at least as practiced by the author, they represent times which should be quite sufficient to allow for error-free performance of the actions in question.

4. Calculate $T_{d}=T_{m}-T_{a}$, the estimated maximum allowable time permitted for correct diagnosis ${ }^{\mathrm{d}}$ so as to allow sufficient time to perform the required post-diagnosis actions prior to $\mathrm{T}_{\mathrm{m}}$.

5. Using the procedure in Chapter 7 or 8 , estimate the probability of failing to correctly perform within $T_{a}$ the required post-diagnosis actions identified in Step 3 .

6. Using the procedure in Chapter 7 or 8 , estimate the probability that a control room team will fail to diagnose correctly each abnormal event of interest within its time $T_{d}$, the maximum time allowable for the crew to figure out what must be done so that they still have time to perform the necessary post-diagnosis actions by the end of $\mathrm{T}_{\mathrm{m}}$. 


\section{General Information}

Unlike the HRA screening procedure for pre-accident tasks (see Chapter 4), the screening procedure for post-accident tasks does not provide upper uncertainty bounds as a basis for an ultra-conservative screening analysis. It is judged that the screening analysis presented herein is already sufficiently conservative. The screening procedure in this chapter is very similar to the RMIEP HRA Screening Procedure for post-accident tasks [see Swain (1985a) or the section on "Screening Rules for the Human Reliability Analysis in the Risk Methods Integration and Evaluation Program" in Volume 5 of NUREG/CR-4832 (Payne et al, 1987)], with some exceptions to increase the conservatism of the ASEP screening HRA. See Appendix A for more detail on the relationship of RMIEP HRA Screening Procedure to the ASEP HRA screening HRA for post-accident tasks.

The following tables and figures present the background material for the ASEP screening HRA for post-accident tasks. Table 2-1 defines skill-, rule-, and knowledge-based behavior. Table 6-1 and Figure 6-I define and diagram the interrelationships of diagnosis and other cognition-related terms. Figure 6-3 shows the required time relationships among $T_{0}, T_{m}, T_{a}$, and $T_{d}$.

With the exception of the HEPs in Table 7-3 for post-diagnosis actions, the error factors (EFs) for the estimated screening HEPs are included in the tables taken from NUREG/CR-1278. The EFs listed in Table 7-3 were selected to provide conservatism, especially to avoid unduly low uncertainty bounds.

\section{The Procedure}

The detailed procedure for the screening HRA for post-accident tasks is presented in Tables 7-1, 7-2, and 7-3 and Figure 7-1. Table 7-1 provides the basic procedure, with references to other tables (or figures), as appropriate. Table 7-2 and and Figure 7-1, the screening diagnosis model, are taken from NUREG/CR-1278. Table 7-3 presents the rules for estimating HEPs for the postdiagnosis tasks. A hypothetical example at the end of this chapter shows how the ASEP screening HRA procedure might be used for post-accident tasks. 
Table 7-1 Procedure for Screening HRA of Post-Accident Tasks (p1/4)

1. Review the definitions and concepts in Table 2-1 (defining skill-, rule-, and knowledge-based behavior) and Table $6-1$ and Figure $6-1$ (defining and diagramming diagnosis and other cognition-related terms), and Figure 6-3 - (showing the required time relationships of $T_{0}, T_{m}, T_{a}$, and $T_{d}$ ).

2. For the following cases, assess HEP - 1.0 for the entire HRA for the abnormal event in question; no further HRA is required:

a. Critical activities must be performed outside of the control room area.

b. Critical skill-based or rule-based post-diagnosis actions are not described in written procedures. (Details of skill-based actions are not required to be written if they can be classified as "skill-of-thecraft" - see the prefatory section "Definitions of Technical Terms.") This assessment is used even though it may be required for personnel to have memorized these actions. Instead, they would likely refer to the written procedures at a later time during the usual checking to see that all immediate emergency actions had been performed correctly. lack of written procedures is considered indicative of inadequate quality assurance, and is the justification for this assessment. However, it is not expected that the diagnosis aspect of every abnormal event would be treated in detail in the written procedures; the rules in this table for assessing diagnosis HEPs are treated separately.

c. The required instrumentation fails to support diagnosis or post-diagnosis behavior, or the instrumentation is inaccurate (i.e., misleading).

3. Using systems analysis methods, and referring to Figure 6-3, estimate $T_{m}$, the maximum allowable time to have correctly diagnosed an abnormal event and to have completed the necessary human actions following $T_{0}$, the annunciation (or other compelling signal) of an abnormal event. For definitions of diagnosis and related terms, see Table 6-1 and Figure 6-1.

4. Identify the actions required to successfully-cope with the abnormal event, once a correct diagnosis has been made.

5. For post-diagnosis actions to be performed in the control room area, estimate travel time and manipulation time, as follows:

a. If there is a requirement to use written procedures, i.e., the human actions to be performed cannot be assumed to be committed to memory, assess a 5-minute delay, after correct diagnosis, before the required post-diagnosis actions will be initiated. 
Table 7-1 Procedure for Screening HRA of Post-Accident Tasks (p2/4)

b. Assess 1 minute as the required travel and manipulation time combined for each control room (CR) control action taken on the primary operating panels which are normally in visual access of the $C R$ operator. An example is activation of the manual. trip button.

c. For required control actions in the control room area, but on other than the primary $C R$ operating panels, assess 2 minutes as the required travel and manipulation time for each such control action.

d. For screening purposes, do not consider possible assignments of personnel to monitor particular panels.

6. Sum the estimated times from step 5 to calculate $T$, the time needed to get to a particular location plus the time needed to perform required actions once a diagnosis of an abnormal event has been made.

7. Calculate $T_{d}-T_{m}-T_{a}$, which is the allowable time for a diagnosis which permits the performance of the required actions within the total allowable time, $T_{m}$. See Figure 6-3.

8. Using $T_{d}$, select the appropriate diagnosis HEP from Figure 7-I or Table 72. This screening diagnosis HEP is a joint HEP representing the performance of the entire control room crew. Adjust the HEP using the rules stated below.

a. This diagnosis HEP is considered the probability of misdiagnosis which will result in a core damage accident.

b. For the case of more than one abnormal event occurring closely in time (i.e., within 10 minutes), use Table 7-2 to estimate the diagnosis HEP for the second or subsequent simultaneously occurring abnormal event. Use the guidelines below in judging whether to assess more than one abnormal event in an accident sequence being evaluated. .

1) If it is not possible to obtain the information in items 2) - 5) below, make the most conservative assumption. 
Table 7-1 Procedure for Screening HRA of Post-Accident Tasks (p3/4)

2) If the emergency operating procedure (EOP) appropriate to the accident sequence does not specifically describe any additional events being evaluated, including any change in first-event status being evaluated, reapply the screening diagnosis model. In deciding whether to reapply this model, it is not necessary that the EOP specifically name the additional abnormal events or changes in status; it must, however, lead the operators to cope successfully with these conditions if they correctly use the EOP. That is, the EOP must enable the operators to figure out what to do (or be led to the correct actions) in coping with the accident sequence details being evaluated. If the EOP does provide this guidance, do not assess the need for a second or subsequent diagnosis.

3) If the second or subsequent abriormal event occurs "closely in time" with the first event, as defined in the first footnote to Table 7-2, employ the second column in the table. If the second or subsequent abnormal event occurs later, and it can be judged that the control room personnel are no longer actively engaged in diagnosing and/or planning the responses to cope with the first event, use the first column for such additional events.

4) Note that for any third or subsequent abnormal event assessed as occurring "closely in time," as defined in Table 7-2, a diagnosis HEP of 1.0 is assessed.

5) Note that. in Table 7-2 $\mathrm{T}$ refers to a compelling signal of the initiation of any abnormal event and that a probability of 1.0 is assumed for observing that there is some abnormal situation. If there are more than two competing compelling signals (e:g. annunciators), assess a diagnosis HEP of 1.0 .

c. For the diagnosis HEP for reactor vessel/containment critical parameters which operating personnel must commit to memory, use the lower bound values in Figure 7-1 or Table 7-2 only if the recognition of these parameters * can be classified as skill-based behavior per Table $2-1$; otherwise, use the nominal values.

As an example of reactor vessel/containment critical parameters which all the CR reactor operators commit to memory, the four critical parameters at LaSalle Boiling Water Reactor (BWR) nuclear power plant (NPP) are:

- Check reactor power level. It must not exceed 1188.

- Check the water level in the core. It must not be below 12.5 inches above instrument zero.

- Check reactor pressure. It must not be over 1046 psi.

- Check containment temperature and pressure. Temperature must not be over 110 degrees and pressure must not be over 1.69 psi. 
Table 7-1 Procedure for Screening HRA of Post-Accident Tasks ( $\mathrm{p} / 4$ )

d. If it can be determined that all control room operators are trained to quickly initiate a manual scram signal with the SCRAM switches when the annunciation of an automatic scram has occurred, or when an immediate indication of a failure to scram has occurred, assess a negligible probability of a diagnosis error, and instead assess only the failure to perform the correct switching action given that a correct diagnosis has occurred. Assume that any correct activation of the SCRAM switches will occur within one minute of the annunciation of a call for an automatic scram. In the case of BWRs, the same argument applies to manual activation of the switch which precludes early closure of the Main Steam Isolation Valves (MSIVs) due to low steam pressure if the same signals and training for manual activation of the MSIV preclude switch (often called MODE switch) can be assumed. However, in the latter case, assume complete dependence (CD) between the activation of the manual SCRAM switch and the MSIV preclude switch. The above assessment is equivalent to assigning an HEP of .01 (from Table 7-3, item 5) for failure to correctly perform the manual switching action (or, for BWRs, actions).

9. Select the appropriate HEP(s) for post-diagnosis action(s) from Table 7-3.

10. Calculate the estimated total-failure probability, $F_{T}$, by adding the diagnosis HEP (Step 8) to the HEP(s) for carrying out the required postdiagnosis action(s) (Step 9). If this calculation results in a totalfailure probability greater than 1.0 , use 1.0 .

11. Enter the $F_{T} s$ in the appropriate system fault trees or system event trees, paying special attention that the dependence effects identified for human actions are preserved in the way the $F_{T}$ s are used. See Chapter 5 of NUREG/CR-1278 for guidelines. 


\section{NOMINAL DIAGNOSIS MODEL}

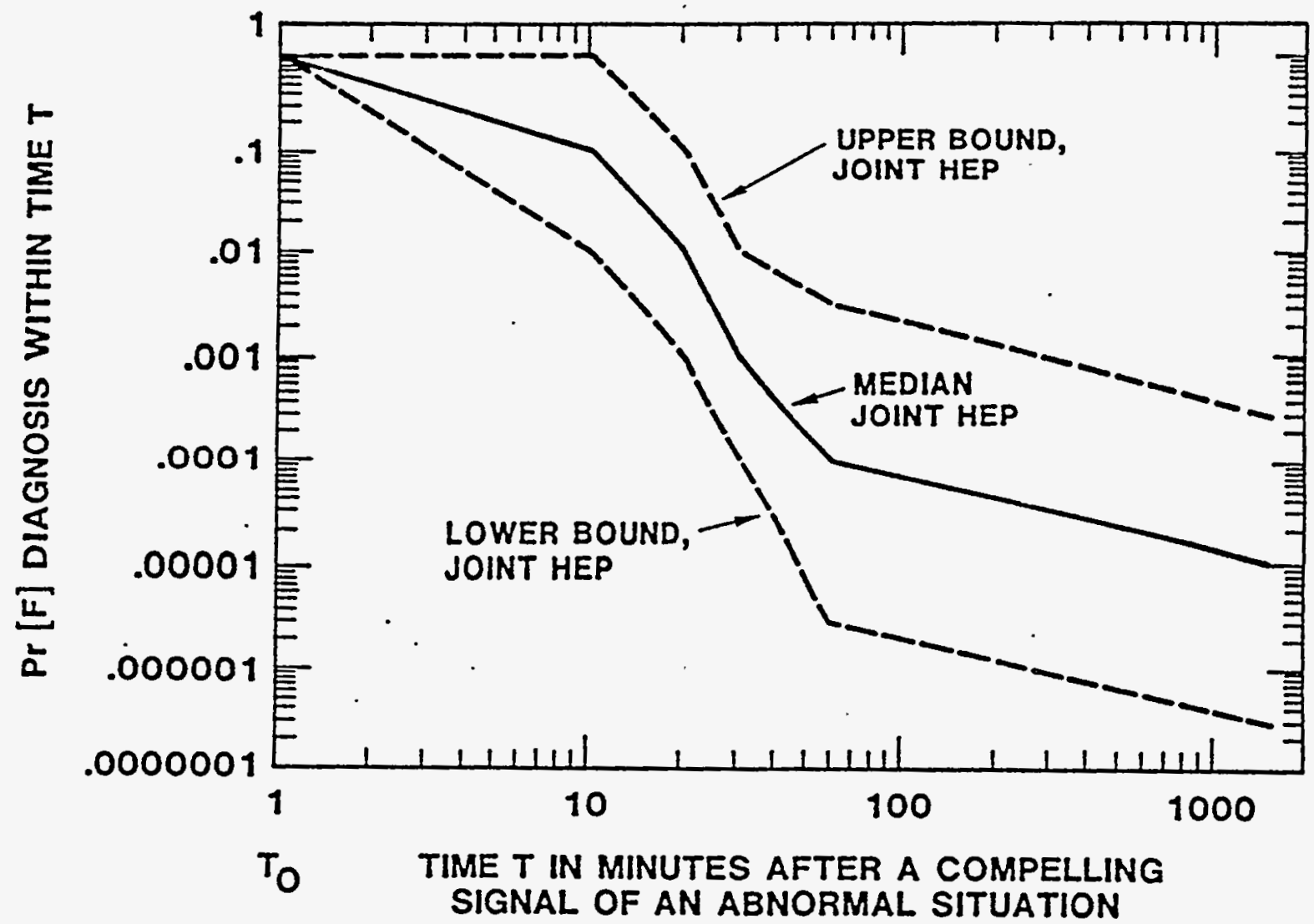

Figure 7-1 Initial-Screening Model of Estimated HEPs and UCBs for Diagnosis Within Time $I$ of One Abnormal Event by Control Room Personnel

(Revised copy of Figure 12-3 from NUREG/CR-1278. The revision corrects the labeling of the ordinate in the figure so that the " 1 " occurs where the three lines in the figure meet at the ordinate, as shown in the above figure.) 
Table 7-2 Initial-Screening Model of Within Time $T$ by Control Annunciated Closely in Time*

Estimated HEPs and EFs for Diagnosis : (Copy of Table 20-I from NUREG/CR-1278 with appropriate changes to figure number)

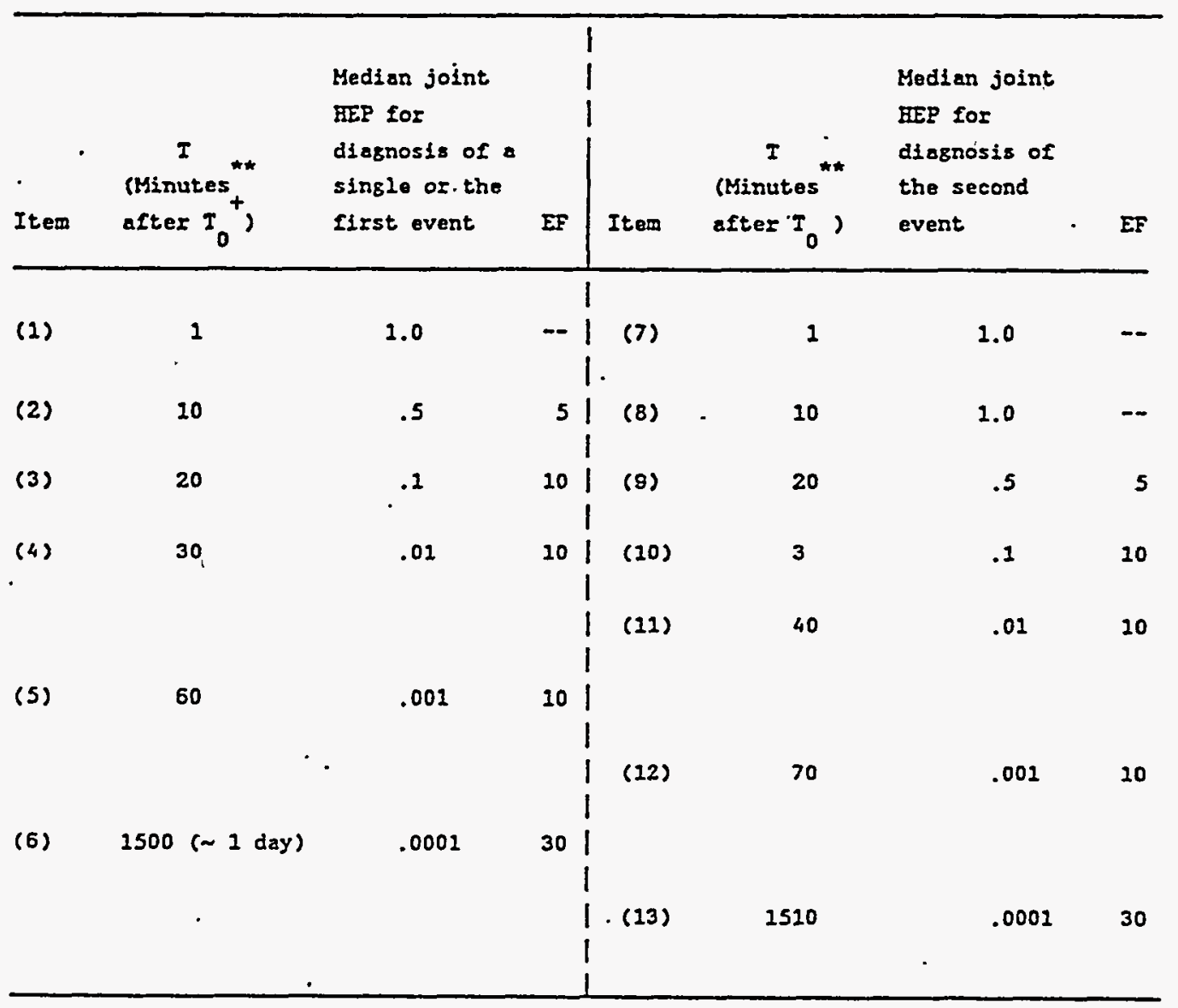

"Closely in time" refers to cases in which the annunciation of the second abnomal event occurs while $C R$ personnel are still actively engaged in diagnosing and/ar planning responses to cope with the first event. This is situation-specific, but for the initial analysis, use "within 10 minutes" as a working definition of "closely in time."

- Note that this model pertains to the $C R$ crew rather than to one individual.

- . ....

"For points between the times shown, use the medians and EFs from Figure 7-1 for the first event, and interpolate between the tabled values for the second event.

${ }^{+} I_{\text {f }}$ is a compelling signal of an abnormel sltuation and is usually taken as attern of annunciators. A probability of 1.0 is assumed for observing that there is some abnormal situation.

Assign HEP - 1.0 for tho diagnosis of the third and subsequent abnormal events annunclated closely in time. 
Table 7-3 Assessment of Screening HEPs for Post-Accident Post-Diagnosis Actions

Item HEP EF Action*

(1) 1.0 -- Perform a required action outside of control room.

(2) 1.0 -- Perform a critical skill-based or rule-based action correctly when no written procedures are available. (Details of skillbased actions are not required to be written if they can be classified as "skill-of-the-craft"**.) This assessment is used even though it may be required for personnel to have memorized these actions. Instead, they would likely refer to the written procedures at a later time during the usual checking to see that all immediate emergency actions had been performed correctly. (See Table 2-1 for definitions.)

HEPs (3) and (4) are for performing a critical procedural action correctly under "moderately high stress"** or "extremely high stress"**. For screening, at least moderately high stress is assessed for all post-accident conditions. Also for screening, do not give any credit for recovery factors, e.g., a second person. Assume that only one person is available to perform the postdiagnosis tasks, and no one is available to check his accuracy.

(3) .055 Perform a critical procedural action correctly under moderately high stress.

(4) .25 5 Perform a critical procedural action correctly under extremely high stress.

(5) .01

5 Perform a post-diagnosis immediate emergency action for the reactor vessel/containment critical parameters, when (a) it can be judged to have been committed to memory, (b) it can be classified as skill-based actions per Table 2-I, and (c) there is a backup written procedure.

*The HEPS are for independent actions or independent sets of actions in which the actions making up the set can be judged to be completely dependent. Other levels of dependence among actions can be assessed by the analyst, using one or more methods for assessing dependence described in Chapter 10 of NUREG/CR-1278.

$* *$ See the prefatory section "Definitions of Technical- Terms" for definitions of these frequently misunderstood terms. 


\section{A Hypothetical Example of a Post-Accident HRA}

The following hypothetical simple example illustrates the use of part of the screening procedure (Table 7-I), including the use of the method for estimating the appropriate time relationships between diagnosis and post-diagnosis actions (Figure 6-3), the screening diagnosis model (Figure 7-I and Table 72 ), and the screening rules for post-accident, post-diagnosis actions (Table $7-3)$.

Assume that the human responses to a particular abnormal event are to be analyzed, using a screening HRA. It has been determined that there is only one critical post-diagnosis action of interest, which requires the use of a written procedure, and this procedure is available. This critical action requires the manipulation of a switch in the control room, but the switch is not on the primary panel. In the accident sequence being evaluated, it is assumed that the required instrumentation and related displays work properly.

Per step 3 in Table $7-1$, the systems analysts have estimated $T$ as 30 minutes. Reference to Figure $6-3$ (as cited in step 3 of Table 7-19) shows that the control room crew must have completed all appropriate actions in the time interval between the annunciation of the event $\left(T_{0}\right)$ and $T \mathrm{~m}$, in this case, within 30 minutes. Reference to steps 5 and 6 in Table 7-1 indicates that $T$ should be assessed as 7 minutes ( 5 minutes per step 5 . a plius 2 minutes per step 5.c). $T_{d}$ is calculated per step 7 , as $30-7=23$ minutes.

Step 8 in Table 7-1 refers the analyst to Figure 7-1 or to Table 7-2 to obtain the estimated diagnosis HEP for the calculated 23 minutes that are available for the diagnosis. Normally, one would prefer to use Table 7-2, as it is easier to read correctly. However in this case, the second footnote to that table refers the analyst to Figure 7-1, as the table has no value for 23 minutes. Using Figure 7-1, the diagnosis HEP for 23 minutes is about .06 . Assume that none of the rules for adjusting this estimate (as stated under step 8) are relevant to the problem.

Step 9 in Table 7-1 refers the analyst to Table 7-3 to estinate the HEP for the one critical post-diagnosis action. Assume that a moderately high stress level is assessed. Therefore item 3 in the table results in an assessment of .05 as the HEP for the critical post-diagnosis action of interest.

Figure 7-2 shows an HRA Event Tree as one method of analysis per step 10 in Table 7-1. (For a description of this type of event tree, see "HRA event tree" in the prefatory section on "Definitions of Technical Terms.) In the figure, "F7-1, 23 min" refers to Figure $7-1$ and its HEP value for 23 minutes. "T7-3 \#3 refers to Table 7-3, item 3 . These are typical abbreviations used in HRA event trees.

Finally, the estimated total failure probability, $F_{T}$, of .1 is entered into the appropriate place in the system fault tree or system event tree per step 11 in Table 7-1. 


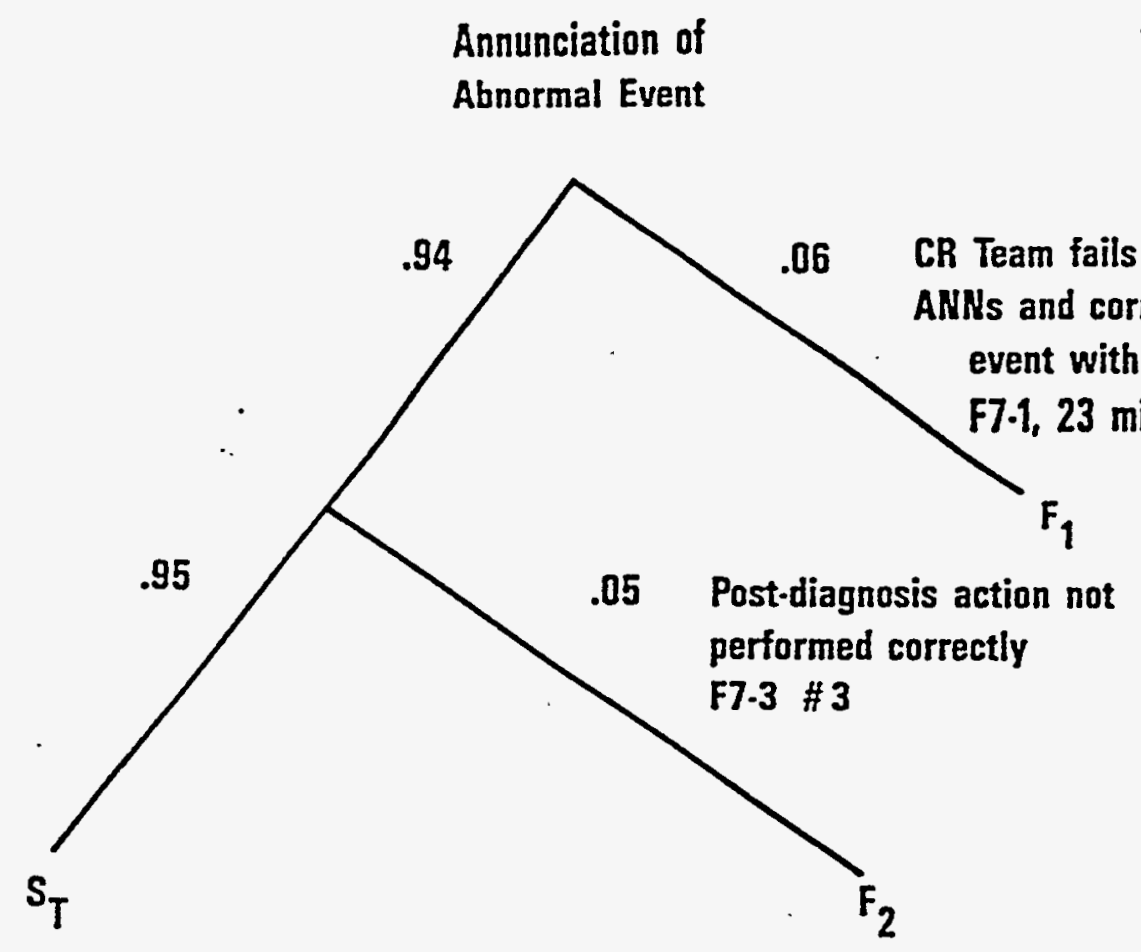

The screening $F_{T}$ is calculated as follows:

$$
\begin{aligned}
& S_{T}=.94 \times .95-.893-.9 \\
& F_{T}=1-S_{T}-.1
\end{aligned}
$$

오

$$
F_{T}=F_{1}+F_{2}=.06+(.94 \times .05)-.107-.1
$$

Following is a check on the correct logic and arithmetic:

$S_{T}+F_{T}$ must equal 1.0

$.893+.107=1.0$

The above illustrates an advantage of not rounding until the final answer.

Figure 7-2 HRA Event Tree for a Hypothetical Post-Accident Screening HRA 
APPENDIX B

Excerpts from NUREG/CR-1278, Handbook of Human Reliability Analysis with Emphasis on nuclear Power Plant Applications: Application of THERP Methodology 


\section{Handbook of Human Reliability Analysis with Emphasis on Nuclear Power Plant Applications}

Final Report

Manuscript Completed: June 1883

Date Published: August 1883

Prepared by

A.D. Swain, H.E. Guttmann

Sandia National Laboratories

Albuquerque, NM 87185

Prepared for

Division of Facility Operations

Office of Nuclear Regulatory Research

U.S. Nuclear Regulatory Commission

Washington, D.C. 20555

NRC FIN A1188 
Ch. 5. A Technique for HRA

Overview; Background of THERP

CHAPTER 5. A TECHNIQUE FOR HUMAN RELIABIIITY ANALYSIS

Overview

This chapter describes a technique for human reliability analysis (HRA) that has the acronym THERP (Techrique for Human Error Rate Prediction) and includes examples from probabilistic risk assessments (PRAs) of nuclear power plants (NPPs) in which this HRA technique has been employed. This chapter is restricted to a discussion of the use of single-point estimates of basic and conditional human error probabilities (HEPs); Chapter 7 shows how distributions of HEPs for a task are handled in a PRA. A graphic method of task analysis called the HRA event tree is presented as a means of diagramming correct and incorrect human actions. For PRA use, the outputs of the HRA event trees are fed into system or functional event trees or system fault trees. For design trade-off use, the ERA outputs are entered into appropriate levels of sys: an or component reliability analyses.

Estimates of basic and conditional HEPs to be used in THERP are compiled in Chapter 20, based on the models and data presented in Part III of the Bandbook. Chapter 6 describes how such data have been derived. This chapter presents the mechanics of incorporating the estimated HEPs into the HRA event trees. For this purpose, an example of an HRA is provided. The incorporation of HRA in design trade-off studies and in PRA is discussed, including the use of sensitivity analysis when data on BEPs are lacking or are speculative. The general form of an HRA for PRA is described, with the note that there are possibilities for different levels of incorporation of HRA results in the PRA. Finally, some comments are made on the validity of. HRA Using THERP.

Background of THERP

In Chapter 2, we defined human reliability as the probability of successful performance of only those human activities necessary for either a reliable or an available system. HRA is a method by which human reliability is estimated. The HRA method described in this chapter is an extension of human reliability studies made at Sandia National Iaboratories (SNL) in the early 1950 s in which reliability analysts estimated the quantitative influence of first-order human failure terms on the reliability of military systems and components. In the early 1960s, the method used in these early HRA studies was expanded and refined to permit more detailed consideration of the human component in system reliability. Subsequent development of the method has included its applications to a large variety of military systems, to the U.S. Nuclear Regulatory Commission's (NRC's) Reactor Safety Study (HASH-1400), and to subsequent human reliability problems in NRC- and ut1lity-supported PRAs of a number of NPPs (Dougherty, 1983; Kolb et al, 1982a; Carlson et al, 1983). 
Most of the applications of TEERP have Involved estimates of the probabilities that system-required tasks will be executed correctly and, in some cases, within specified time limits. Nearly all of the applications have assessed the probability that individuals or teams would carry out specified procedures correctly under varying degrees of stress. The types of . tasks include assembly of equipment in manufacturing processes, calibrating and testing equipment, air crews performing milltary tasks (sometimes under great stress), and the various NPP activities assessed in WASB-1400 and subsequent PRAs of NPP operations. It is only with the most recent.PRAs that the so-called cognitive aspects of behavior have been addressed (Chapters 3 and 12 ).

Since the use of THERP in WASH-1400, there have been some refinements in this method and the data it uses:

(1) The development of several human performance models:

(a) a model of positive dependence

(b) several models for the perceptual and response aspects of hrman activities in KPPS

(c) an interim model to assess comulative probability over time of correct diagnosis of transients and other abornmal events in NPPs (i.e., the "cognitive" aspect)

(d) expansion of the extremely high stress model to include several. other stress leveis

(e) a model for assessing team interaction in NPP control rooms

(2) Use of estimated distributions to permit employment of a Monte Carlo or equivalent procedure for handing distributions of HEPs.

(3) A method of estimating and propagating uncertainty bounds in an HRA.

(4) Partial verification of some predictions of rule-based behavior.

(5) The Handbook 1tself, which brings together the latest developments.

\section{Description of THERP}

At the Sixth Annual Meeting of the Buman Factors Society in November 1962, the acronym THERP was first used to deglgnate the human reliability method developed at SNL (Swain, 2963a). Until publication of the draft version of this Handbook, we used the expression human error rate (HER) interchange:ably with human error probability (FEP). For reasons stated in Chapter 2, we have dropped the term HER in favor of HEP. However, since the acronym THERP is now well established, we retain it despite its use of the term "human exror rate." 
The following is a revised definition of this human reliability technique:

THERP (Technique for Human Error Rate Prediction) Is a method to predict human error probabilities and to evaluate the degradation of a man-machine system likely to be caused by human errors alone or in connection with equipent functioning, operational procedures and practices, or other system and human characteristics that influence system behavior.

The method uses conventional reliability technology with modifications appropriate to the greater variability, unpredictability, and interdependence of human performance as compared with that of equipment performance. The steps in THERP are similar to those in conventional reliability analysis, except that human activities are substituted for equipont outputs. The steps are:

(1) Define the system failures of interest. These pertain to system functions that may be influenced by human errors and for which error probabilities are to be estimated.

(2) Iist and analyze the related human operations. This step is the task analysis described in Chapter 4.

(3) Estimate the relevant error probabilities.

(4) Estimate the effects of human errors on the system failure events. This step usually involves integration of the HRA with a system reliability analysis.

(5) Recommend changes to the system and recalculate the system failure probabilities. (The procelure is iterative.)

The above five steps typify the use of HRA as a tool in system design. For assessments only, Step 5 is not required, and not all tasks will be analyzed and included in the HRA. For PRA purposes, the HRA will include only those tasks that will have a material effect in the system event or fault trees.

In an ERA, the primary interest is in estimating the following parameters:

(1) Task Reliability-Task rellability is defined as 1.0 minus the estimated probability of task failure. For each task to be analyzed, we use Chapter 20 or other data sources to estimate the probability that it will be completed successfully (within some period of time if time Li a requirement).

(2) Recovery Factors--The probability of detecting and correcting incorrect tabk performance in time to avoid undesirable consequences constitutes the recovery factor. In any man-machine system, there are usually several recovery factors, e.g., Inspections that increase the probability of detecting errors before they affect the system. Recovery factors are discussed in Chapter 19. 
(3) Task Effects--This is the probability that unrecovered errors will Iesult in undesirable consequences to a system. A separate calculation is made for each system consequence of interest. Therefore, one may. estimate the effects of the same human error on more than one system outcome. These calculations are usually a joint effort by Bystem and human reliability analysts. For PRA, the system analysts will perform, these calculations.

(4) Importance of Effects-This is the importance of each set of undesirable effects to a system in terms of cost or other criteria. General2y, no attempt is made to quantify this parameter; it is often a value judgment made by persons in authority. In PRAs of NPP operations, a frequently used criterion is avoidance of a core.meltdown.

THERP is used to generate quantitative estimates of the first two parameters based on estimates of human reliability, on the dependences among human performance, equipment performance, other system events, and outside influences. The operator's perception or anticipation of the effects of his tasks (parameter 3) is a potent PSE and is included in formulating the estimates of HEPs in the first two parameters.

\section{Model Versus Method}

In the draft issue of this Eandbook, we described THERP as a human reliability model. - We now think it preferable to restrict the term model to the kinds of human performance models described in Part III of the Handbook. To clarify our position, the following is a quote from an earlier report (Swain and Guttmann, 1975):

The term "model" has several meanings and is used loosely in the behavioral sciences. For our purposes in describing THERP ...., we will use the narrow meaning of "model," defined as "a set of relations and operating principles." Although this may slight some who are interested in theory development, THERP was developed as an applied technique, for use as a fast and relatively simple method of providing data and recommendations to system designers and analysts who require a quantitative estimate of the effects of human errors on system performance.

THERP is not a model in the usual sense of a hypothetical analogy, although it is regarded as a modest form of mathematical (Boolean) modeling, representing behavior variability by simple equations dealIng with.equipment parameters, human redundancy, training, stress, etc. When using this method, we are cognizant of its limitations, but for practical reliability work, these limltations are surprisingly few. The only limitation of consequerice ió the dearth of data on human error rates in many areas. However, the varlables affecting human reliablitty are fairly well understood, and we are expanding the data base for human error rates and the effects of the pertinent performance shaping factors. The method of assessing the effects of errors is well established, both in logic and experfence, 
and, while refinements will continue to be made, it does not appear that any major changes are indicated. Therefore, we suggest that THERP be regarded as a practical method of predicting human reliability rather than as a hypothetical model.

\section{BRA Event Trees}

The basic tool of THERP is a form of event tree called the probability tree diagram (Figure 5-1) in use at sNI since the 1950s (Mililer, 1964). In this issue of the Handbook, we use the new term HRA Event Iree to distinguish our event trees from other kinds of event trees used in PRA. In the ERA event tree, the limbs represent a binary decision process, 1.e., correct or incorrect performance are the only cholces. Thus, at every binary branching, the probabilities of the events must sum to 1.0 . Limbs in the HRA event tree show different human activities as well as different conditions or influences upon these activities. The values asslgned to all human activities depicted by the tree limbs (except those in the first branching) are conditional probabilities. The first limbs may also be conditional probabilities if they represent a carry-over from some other tree. That is, the first branching in an IRA event tree may represent the outputs of another tree.

Table 5-1 presents the symbology used with the limbs of the BRA event tree. Note that a letter can have more than one meaning depending on whether it is in quotes, capitalized, or lower case. In some cases, it is useful to provide short descriptions of system events or human actions along with the symbols.

We use capital letters in quotes to denote tasks and events. A capital Roran letter in quotes denotes a human task, and a capital Greek letter in quotes denotes a system or component event or state. We use Roman letters not in quotes to denote the success or failure of a human task and Greek letters not in quotes to denote the desirable or undesirable state of a system or component. Capital letters not in quotes indicate failures or undesirable states, or their probabilities. Small letters indicate successes or desirable states, or their probabilities. For example, Task "A" in Figure 5-1 might represent the task of a calibration technician setting up his test equipment before calibrating some sensor. The lower case letter a represents the fact that the technician has correctly set up his test equipont and also stands for the probability of correct performance. The capital letter A represents the fact that the technician has incorrectly set up the test equipment and also stands for the probability of incorrect performance.

The letter $b$ represents the fact of correctly performing Task " $B$," the second task performed, and $b$ also stands for the probability of correct performance. Task "B" might be the calibration of the sensor mentioned above. The letter $B$ stands for the Incorrect performance as weil as for the probability of incorrect performance. The dependences between Tasks " $A$ " and " $B$ " are represented by the symbols $b|a, B| a, b \mid A$, and $B \mid A$. Norally the conditional relationships are understood, and the letters $b$ and $B$ are written without the conditional qualifications. 
SERIES

PARALLEL S

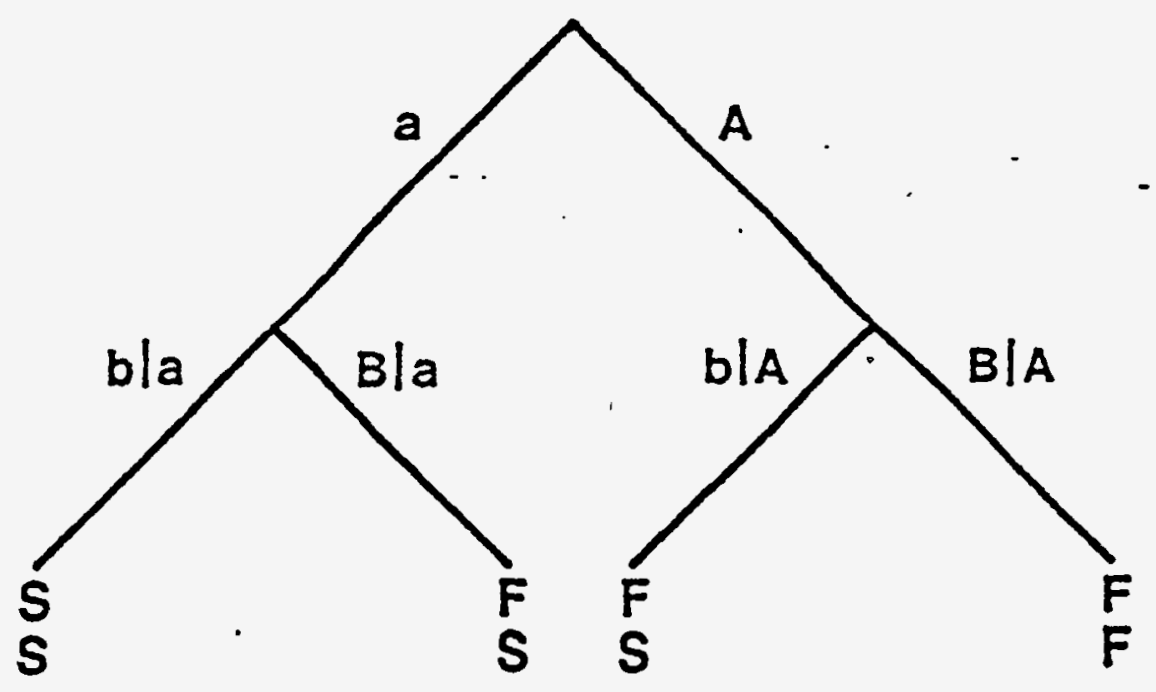

TASK "A" = THE FIRST TASK

TASK "B" = THE SECOND TASK

$a=$ PROBABILITY OF SUCCESSFUL PERFORMANCE OF TASK "A"

$A=$ PROBABILITY OF UNSUCCESSFUL PERFORMANCE OF TASK "A"

bla = PROBABILITY OF SUCCESSFUL PERFORMANCE OF TASK "B" GIVEN a

B/a = PROBABILITY OF UNSUCCESSFUL PERFORMANCE OF TASK "B" GIVEN a

bIA = PROBABILITY OF SUCCESSFUL PERFORMANCE OF TASK "B" GIVEN A

B|A = PROBABILITY OF UNSUCCESSFUL PERFORMANCE OF TASK "B" GIVEN A

FOR THE SERIES SYSTEM:

$\operatorname{Pr}[S]=\mathbf{a}(\mathbf{b} \mid \mathbf{a})$

$\therefore \quad \operatorname{Pr}[F]=1-a(b \mid a)=a(B \mid a)+A(b \mid A)^{\prime}+A(B \mid A)$

FOR THE PARALLEL SYSTEM:

$\operatorname{Pr}[S]=1-A(B \mid A)=a(b \mid a)+a(B \mid a)+A(b \mid A)$

$\operatorname{Pr}[F]=A(B \mid A)$

Figure 5-1 IRA event tree for series or parallel system. 
Capital Roman letter in quotes, e.g., "An

Capital Roman letter not in quotes, e.g., A (except $F$ and $s$ )

Capital letter $F$ at the end of a path through an HRA event tree

Capital letter $S$ at the end of

Lower case Roman letter, e.g., $a, b$, etc. (except $i$ and $I$ )
Iower case Roman letters, 1 and $r$

Lower case underlined Roman letter, $\underline{\mathrm{n}}$

Capital Greek letter in quotes, e.g., " $\Delta$ " (delta)

Capital Greek letters not in cuotes, $\Delta$

Lower case Greek letters, e.g., $\delta$
1. The human action itself; e.g., Task "A." Note: The expected or required sequence of tasks is designated by the alphabetical ordering; e.g., Task " $\mathrm{A}$ " is the first task, Task " $\mathrm{B}$ " is the second task, etc.

1. The estimated probability of incorrect performance of a human action; e.g., A stands for the probability of incorrect performance of Task "A." This is the usual meaning of $A$.

2. Incorrect performance of a human action; e.g., A stands for the incorrect performance of Task "A."

1. The erid point or end-failure probability for a failure path in the tree.

1. The end point or end-success probability for a success path in the tree.

1. The estimated probability of successful performance of a human action; e.g., a stands for the probability of correct performance of Task A. This is the usual meaning of $a$.

2. Successful performance of a human action; e.g., a . stands for the correct performance of Task "A."

1. ith and rth task.

1. The number of events or tasks in a sequence. Not to be confused with an $n$, which indicates the success (or probability of Buccess) on Task "N."

1. The system event itself, or the equipment state, e.g., Event " $\Delta$. "

1. The estimated probability of equipment failure or of nonoccurrence of some system event (not a human activity).

1. The estimated probability of equipment fallure or of occurrence of some system event (not a human activity). 
Note that the above symbology is presented as an aid only, since It is the one that we have been using. Any symbology can be used as $20 n g$ as it makes the required distinctions. Most analysts will evolve their own "shorthand" as they prepare their HRA event trees; Iigid consistency is not essential. When convenient, we have used other symbols, as in the example in Figure 10-6 rear the end of Chapter 10. In this example, we use a lower case Roman e for equipoent success (the capital Roman $E$ is the same as the capital Greek epsilon). No problems will occur as long as the meaning of the symbols is understood by the users.

In a system, sometimes aII of some set of human activities must be performed correctly for bystem success to be achieved. We call this application a series system. In other cases, a system will fail only if all of the human activities in a set are performed incorrectly. He cald this application a paraliel system.

In Figure 5-1, if we are dealing with a series system, only the completebuccess path, i.e., a(b/a), is designated as ending with 5 , which stands for a success path. All the other paths end In $F$, which stands for faliure. Thus, for a serles system, the only success path is one in which both tasks are correctly cone, $i . e .$, the calibration technician correctly sets up his test equipment and also correctly calibrates the sensor. For other problems, the interest might be in performing either task correctly, .e. a paraliel system, and any path other than $A(B \mid A)$, the complete-failure path, would be considered a success path, as indicated in the figure. For example, Tasks " $A$ " and " $B$ " might represent the restoration of two blocking valves that are in parallel. As long as the operator remembers to restore at least one of the two valves, the system will function properly. It is the system application that determines which paths through the tree are considered success paths or failure paths.

Since the limbs in the tree represent a binary decision process, a $+A$ in Figure 5-1 must equal 1.0 , and $b|a+B| a$ as well as $b|A+B| A$ must equal 1.0. At every binary branch, the probabilities of the two limbs sum to 1.0. In other event trees there could be more than two limbs in a branching to represent different conditions or events, or different levels of correctness or incorrectness, but in all cases, the probabilitles of the limbs in any one branching must sum to 1.0 . In our event trees, we use binary branching even if there are three states to be modeled le.g., three stress levels: very low, optimal, and moderately high). In this example, one could show a binary branching to indicate (1) the probability of very Low stress and (2) the probability of other than very low stress. The limb designated as "other than very low stress" would then be subject to a further binary branching to indicate the probabilities of (I) optimal and (2) moderately high stress levels. The use of binary branching facilitates computer usage. - As with any IRA event tree, the sum of the probabilities at the terminals of all paths also must sum to 1.0. Thus, in Figure 5-1, $(a \times b \mid a)+(a \times B \mid a)+(A \times b \mid A)+(A \times B \mid A)=1.0$.

The limbs in an HRA event tree may represent correct or incorrect human outputs, exrors of discrimination, or mediating processes related to those 
human outputs. Any limb in the tree may also represent correctness or incorrectness of some system-required task or activity or. it may denote some other human task or activity that is not system-required but that has potential for reducing the probability of achieving desired system functions. In the HRAs done for WASH-1400, for example, besides depicting the selection of certain correct switches, tree limbs depicted the selection of nearby switches that could cause serlous problems if inadvertently selected (see Problem 2, Chapter 21). Thus, limbs in HRA event trees can be used to represent plausible and important extraneous actions. Of course, not all extraneous actions can be identified in advance. Although most wuch actions are unimportant in terms of system consequences, it is always possible that some important extraneous action will be overlooked in an HRA. The more detailed the task anaiysis behind the IRA event tree, the greater the likelihood of identifying the important, plausible extraneous actions. The identification of extraneous acts resulting from incorrect interpretation of signals is very difficult and speculative. For PRA purposes, however, it is often sufficient to estimate the probability that some small set of correct actions will be taken and to designate any other action as system fallure. Therefore, although the prediction of errors of interpretation is often speculative, it is often the case that considerable latitude is allowed the analyst.

Once the HRA event tree is properly orawn, the mathematics are simple. When the estimates of the conditional probabilities of success or failure of each limb in the tree have been determined, the probability of each path through the tree is calculated by multiplying the probabilities of all limbs in the path. This does not correspond to the simple multiplicative model, that is, the multiplication of task probabilities without the assurption of any task dependence. The use of conditional probabilities takes into account the interdependence between the limbs in the tree, and no errors will result from the use of this simple mathematical approach. Errors arise from incorrectly estimating the HEPs for the tasks represented by a limb.

\section{Event Trees Versus Fault Trees}

The HRA event tree starts with any convenient point in a system procedure and works forward in time. The level of detail depends on the parpose of the analysis; for PRA, the level of detall in an ERA is generally less than when the HRA is being cone as part of design trade-off studies. The topdown procedure enables the user to analyze what leads to what and allows him to ldentify the important events affecting human performance. It follows the same sequence in time as the underlying task analysis and facliltates showing in graphic form those parts of the task analysis relevant to the BRA.

In the fault tree approach, one starts with some fault and vorks backwards in time (Vesely et al, 1981). As with fault trees, boxes with short descriptions of events may be used in addition to symbols in an HRA event tree to assist the reader. Also, as with fault trees, one 1 imb in an HRA event tree may stand for another entlre tree. Nielsen (1971 and 1974) has 
Nomiral, Basic, Conditional, and Joint Probabilitles

developed a combination of event trees and fault trees called Cause/Consequence Diagrams; this combination has some of the advantages of both scheEatic techniques.

It is more difficult to represent dependence among human actions in a fault tree than in an event tree. In the latter, the conditional probabilities are shown directly following the events or actions that generated the conditionality. In fault tree modeling, the dependence may show up in different boxes of the tree or in different fault trees altogether. However, if great care is taken, human dependence can be represented in fault trees, and one should get the same answer to a human reliability problem regardless of the graphic method employed.

The event tree format presented in this chapter is the one we used for the HRA in WASH-1400 and in the Arkansas Nuclear One Unit 1 PRA (Kolb et al, 1982a). In WASH-1400, the system analysts used a different format for their event trees, in which the progression is from left to right, and in each branching, the lower limb is the fallure limb (Figure 5-2). Variations of this event tree format have been used by Dougherty (1983); by Barrington (in Cook et al, 1981), whose format is called the Operator key Action Event Tree; by Erown et al (1982) and Brinsfield et al (1983), who use the term Operator Action Event Tree; and by Wreathall (1981, 1982) (see also Hall et al, 1982), whose format is known as the Operator Action Iree system (OATS). Full descriptions of these alteinative graphic methods are found in the referenced articies. Which format is used for an event tree is a matter of convenience for the analyst. If used correctly, any format will provide the correct answer.

\section{Nominal, Basic, Conditional, and Joint Probabilities}

Use of the HRA everit tree is based on the assumption that the estimates associated. with the limbs are conditional probabilities. Considerable error in estimating the probabilities of paths through the tree can occur unless conditional probabilities are used. If independence of acts is mistakenly assumed, the fallure contributions of people to systems can be significantly underestimated.

For convenience, we repeat some definitions of different kinds of HEPs from Chapter 2. The nominal HEP is the probability of a given human error when the effects of plant-specific PSFs have not yet been considered. The basic KEP (BEEP) is the probability of human error without considering the conditional influence of other tasks. The conditional HEP (CHEP) is a modification of the BHEP to account for influences of other tasks or events. The joint HEP (JHEP) is the probability of human error on ald tasks that must be performed correctly to achieve some end result. There are also basic, conditional, and joint human success probabilities (HSPs), but usually ve speak only of the HEPs. To avoid excessive use of abbreviations, we will generally write out the words "conditional" and "joint" in association with HEPs, but BHEP will be used frequently.

To illustrate these IEP terms, let us take the tree in Flgure 5-1 and assume a paraliel system, $1 . e .$, one in which all of the human activities 


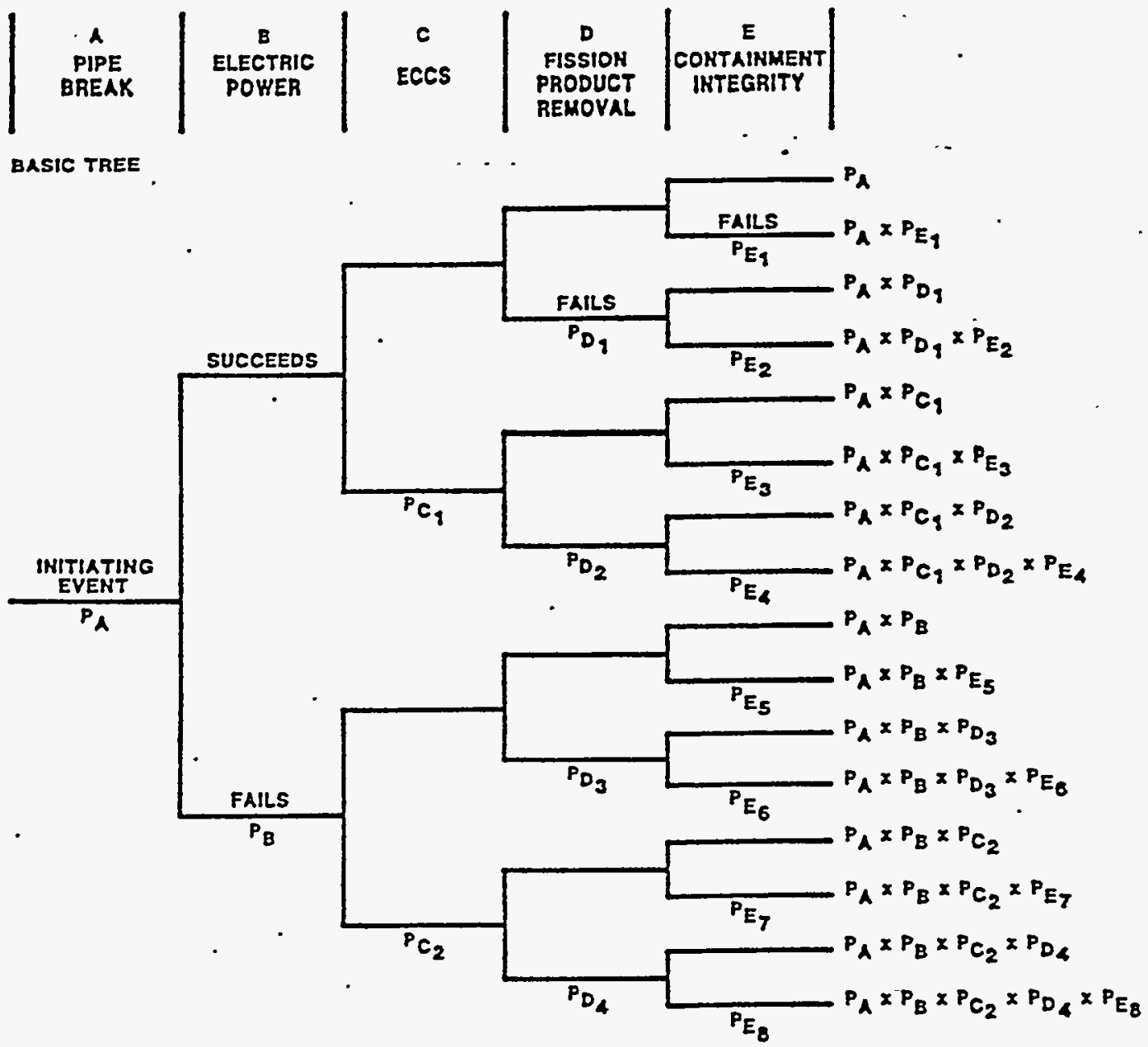

REDUCED TREE

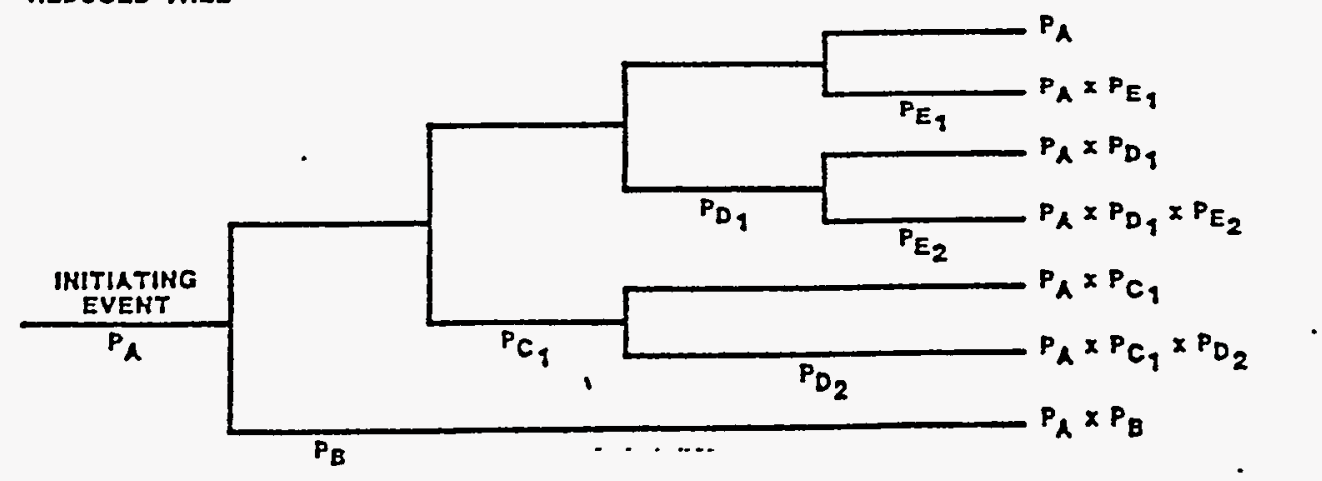

MOTE - SIKCE THE PROBAEILITY OF FALLUE, P. IS OEHERALLT LESE THAN 0.1. THE PROBAEILITY OF sUCCESS (T - P) IS ALWAYS CLOSE TO $\%$. THUS. THE PROEABILITY ASBOCIATED WITH THE UPPER (SUCCEBS) INAHCHES IN THE TREE IS ASSUMED TO $B E$.

Figure 5-2 simplified event trees for a large LOCA (from
Figure $4-4$ of the Main Report to WASH-1400). 
Example of an HRA

must be performed incorrectly for the system to fail. The only failure path is the joint HEP, $A(B \mid A)$, i.e., fallure occurs only if rasks " $A$ " and "B" are both performed incorrectly. All the other paths lead to system success. Assume that Tasks " $A$ " and "B" are the opening of two valves after maintenance and that the system will function properly if either valve is opened. Farther assume that the valves are next to each other, so that if the operator forgets to open one valve, he is 1008 sure to forget to open the other valve, $1 . e .$, there is complete dependence between the two acts. Also assume that the BHEP of forgetting to open a valve of this type is $10^{-2}$. If we mistakenly assume independence between the opening operations for these two valves, we will get an unfealistically low joint Hep estimate of $A \times B=10^{-2} \times 10^{-2}=10^{-4}$. However, if we correctly assign the conditional HEP of 1.0 to $B \mid A$, our estimate of the joint BEP is $A(B \mid A)=$ $10^{-2} \times 1.0=10^{-2}$. This example 112ustrates the importance of incorporatIng dependencies among the events in an HRA event tree. Chapter 10 presents the dependence model in detail.

\section{An Example of a Human Reliability Aralysis}

To illustrate the use of HRA event trees, Figure 5-3 is based on a case study described by Bell (1983) in which she ldentifies the major human activities and errors in the establishment of the appropriate steam generator feed-and-bleed procedure following a loss of both normal and emergency feed to the steam generators in a pressurized water reactor (PWR). The loss of all feedwater results in failure to maintain cooling of the nuclear reactor core unless the operating crew establishes feed and bleed. The tree represents the activities of a team of three Iicensed reactor operators, one of whom is the shift supervisor.

In this chapter, we use the tree merely to fllustrate the mechanics of the logic and calculation of the overall system failure probability based on single-point estimates of HEPs. In Appendix $A$, we expand this tree and add uncertainty bounds fOI each HEP to lilustrate the handing of distributions and a method of propagating uncertainty bounds through an BRA. A similar tree is also used in Problem 1 in Chapter 21 to provide a complete example that ties together models for dependence, diagnosis, and other human performance. considerftions, lncluding the use of the tables of estimated IEPs in Chapter 20.

For this example, we have arbitrarily omitted some recovery factors and have defined six end-failure terms in the tree. In the real-world, some failure paths would be Insignificant because of system recovery factors. The reader is asked to accept the estimated HEPs without question since the example is given for purposes of 1llustrating the ERA event tree structure only. In Chapter 21, the derivation of each estimated HEP is explained fully.

The sequence of events is presented at the bottom of the figure. The letter A stands for the jolnt HEP of all three people failing to initiate some kind of action after turning off the auditory and flashing signals from some annunciators (ANNs). An estimate of .00008 is assigned to this 
)

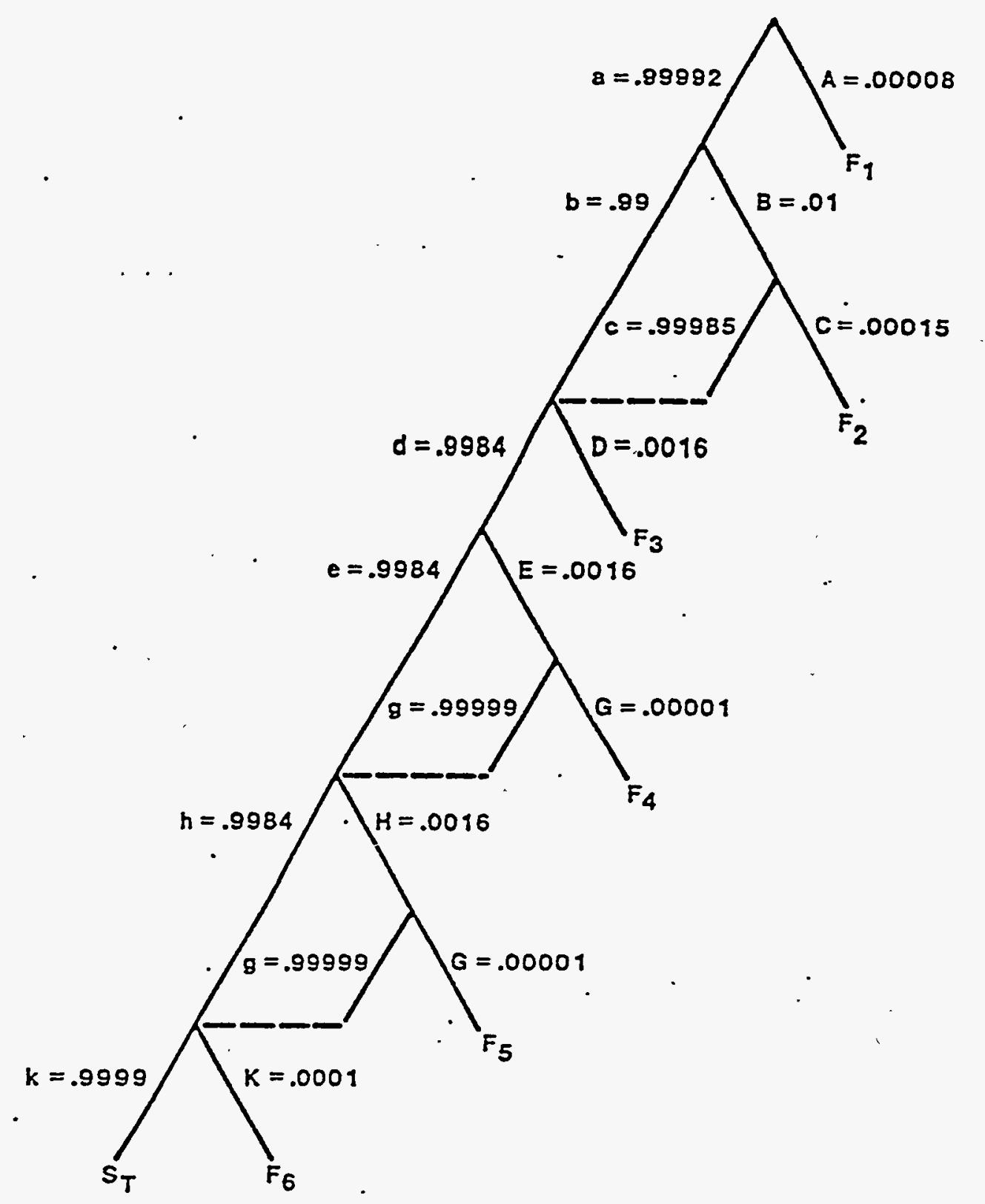

\begin{tabular}{|c|c|c|}
\hline JHEP: & EVENTS & JOINT HEP F FOR 3 \\
\hline A & FAIL TO INITIATE ACTION TO AHNE* & .00008 \\
\hline 8 & MISDIAGNOSIS & .01 \\
\hline c & FAIL TO INITIATE ACTION TO AKM & .00018 \\
\hline D & OMIT STEP 2.4 & .0010 \\
\hline $\mathbf{E}$ & OMIT STEP 2.5 & .0018 \\
\hline a & FAIL TO INITIATE ACTIOH TO AHK & .00009 \\
\hline H & OMIT STEP 2.8 & .0018 \\
\hline $\boldsymbol{x}$ & FAIL TO INITHATE HPI * * & .0009 \\
\hline
\end{tabular}

Figure 5-3 HRA event tree for loss of steam generator feed. 
joint HEP. As shown in the tree, if A occurs, the system will fail. There are no recovery factors for this joint error.

At this point, a word of explanation is in order regarding such a small number as .00008 . Obviously, the data for IRA are not so accurate that the number $8 \times 10^{-5}$ can be regarded as "right on." We could round this number to $10^{-4}$. However, the practice we follow is to postpone rounding until the final answer to a problem is obtained.

$B$ stands for the joint HEP of .01 of misdiagnosis by the three operators of the pattern of annunciators. Note that there is a recovery factor (Task " $(")$ of a special ANN to show that the margin to saturation in the steam generator has exceeded tolerable 2imits. C stands for the failure of all three to be cued properly by this AkN. If $B$ and $C$ happen, the system will fail.

However, if $c$ occurs, the crew has been cued and will proceed to the next sequence of activities. Note that in the tree, the end of the path $a-B-C$ leads back to the main success path in the tree. Thus, in this tree, the path $a-B-c$ is equivalent in terms of success, not of probability, to the path a-b. One could repeat the tree beginning at the branching for rask "D" so that it would begin following $c$. This repetition is unnecessary; the dotted line means the same thing.

$D$ stands for the omission of an important step in the written procedures, which we designate as a first-order human failure term. E Is a similar error of omission, but there is a recovery factor, Task "G," consisting of the cueing by an AN of the loss of feed. If $g$ occurs, the dotted line shows that the path $E-g$ is equivalent in terms of success to the limb $e$. If stands for another error of amitting a critical step in the procedure, with the same recovery factor as for $E$. Finaliy, $X$ stands for fallure to initiate high-pressure injection (HPI) by the use of the proper feedand-bleed method.

To arrive at the overall failure probability, the exact failure equation involves suming the probabilities of all failure paths in the tree. There are 17 failure paths, which are listed below with their probabilities:

A

$\mathrm{aBC}$

aBCD

$\mathrm{abD}$

abdeg

abdEgRG

abdEghx

abdEgHgK

abdeEg
.00008

.0000095

.000016

.0015839

$\sim 10^{-8}$

$\sim 10^{-11}$

$\sim 10^{-7}$

$\sim 10^{-10}$

$\sim 10^{-8}$ 


$$
\begin{aligned}
& \text { abdeHgk } \quad \sim 10^{-7} \\
& \text { abdehk } \quad .0001 \\
& \text { aBCdEG . } \sim 10^{-10} \\
& \text { aBCdEgHG } \quad \sim 10^{-13} \\
& \text { aBCdEgHgK } \sim 10^{-12} \\
& \text { aBcdeHG } \sim 10^{-10} \\
& \text { abcdeligk } \sim 10^{-9} \\
& \text { aBcdehk } \sim 10^{-6} \text {. } \\
& \simeq .00178 \simeq .002 \text { (rounded) }
\end{aligned}
$$

When all the HEPs are .01 or smaller, the exact fallure equation can be approximated by suming only the primary fallure paths, Ignoring all the success limbs. There are six primary fallure paths. Thus, an approximation for the total failure term, $F_{T}$, given each HEP $<.01$, is $F_{P} /$ HEPS $<.01=A+B C+D+E G+H G+K$

$$
\begin{aligned}
& =.00008+(.01 \times .00015)+.0016+(.0016 \times .00001) \\
& +(.0016 \times .00001)+.0001=.0018=.002 \text { (rounded) }
\end{aligned}
$$

The rounded values of the approximate and the exact equations are the same. The accuracy of the approximation decreases as the number of terms or the values of the HEPs increase.

Another way of working the problem is to use the exact success equation:

$$
\begin{aligned}
S_{T}= & a(b+B C) d(e+E g)(h+H g) k \\
= & .99992 \times[.99+(.01 \times .99985)] \times .9984 \times[.9984+(.0016 \times .99999)] \\
& \times[.9984+(.0016 \times .99999)] \times .9999=.9982188=.998
\end{aligned}
$$

As a final check on the logic and arithmetic,

$$
F_{T}=1.0-.9982188 \simeq .0018 \simeq .002
$$

The above HRA event tree and the calculations are typical of the use of this approach for single-point estimates. However, for most RRA work, each human activity is characterized by a distribution of HEPs. The HRA event triee will be the same, but the total-fallure term will be expressed as a distribution of HEPs. This method is described in Chapter 7 and Appendix $A$ and provides an example of these points, using an expansion of this tree. Examples of HRA event trees to illustrate dependence and exrors of diagnosis are presented in Chapters 10 and 12. 
Use of ERA Outputs

\section{Use of HRA Outputs in System Reliability Studies}

The outputs from the HRA will consist of estimates of success and fallure probabilities of human actions or tasks that can be used in design tradeoff studies or in PRAs. Application of HRA to these two areas and the use of sensitivity aralysis for both are described below.

\section{Design Trade-Off Studies}

In systems under design and development, there are often reliablifty goals set by system reliability specialists. "Tolerable failure probabilities" are set for different subsystems or functions so that their sum will not exceed 1 minus the total system reliability goal. A particular subsystem may consist of several items of equipment, each of which is allocated a tolerable fallure probability. This process is called reliability allocation. The human contribution to the tolerable fallure probabilities may occur at the component level or at some higher level. Calculation of the estimated human error contribution at any level can be used to determine if that contribution 1tself 15 tolerable. If the human contribution to the failure probability is too large, some change is necessary. This application of ERA falls within the latter steps in the man-machine systems analysis (MMSA) described in Chapter 4. As noted in step 9 of the MMSA (Table 4-1), changes are proposed, and the estimated effects of these changes are analyzed in an iteration of the MSA (Step 10). Historically, most applications of THERP preceding the WASH-1400 safety study were in this azea of application.

\section{Probabilistic Risk Assessment}

In a PRA, the ERA is used to estimate the human error contribution to the fallure of system components or functions. If the contribution is too large, presumabiy someone will be directed to do something about it. If PRA is done as part of the NRC Iicensing process and if the PRA ylelds results that are not tolerable, corrective actions are appropriate if the plant is to continue in operation. In Chapter 21, Problem 3 describes an informal study in which it was judged that the probability of plant personnel coping successfully with a design-basis loss-of-coolant accident (IOCA) was not high enough, and changes in written procedures and training vere necessary for the plant to continue in operation.

In a PRA of an NPP system, the estimates of human reliability can be included in system or functional event trees or in system fault trees, provided that the dependencies between human tasks are also incorporated. Thus, the outputs of the HRA are estimates of the human component rellabli1ty and can be handied just like estimates of the reliability of other syster components.

In Fash-1400, for example, the fault tree shown as Figure II 5-45, p II-303 in Appendix II, Indicates that an operator might forget to open a 
motor-operated valve (MOV-1B66E) after a monthly Elush of the High Pressure Injection System (IPIS.) discharge lines. The estimated probability of an unrecovered human error $153 \times 10^{-4}$. If that human error occurs, or if any: one of three mechanical failures occurs, the BPIS will fail to deliver sufficient water through the HPIS discharge 1 ine.

To arrive at the $3 \times 10^{-4}$ error probability estimate in the fault tree, we could have constructed an HRA event tree to ensure consideration of all the events related to the failure to open NoV-1866E. Bowever, as often occurs, this failure event was so simple that a tree was not necessary. For the error to occur, an operator has to fail to initiate the task of reopening the MOV or fall to operate the MOV switch correctly, and someone else has to fail to inspect the switch or fail to note that it is closed when he makes the inspection.

The estimated $3 \times 10^{-4}$ unrecovered error probability was derived by using . the $3 \times 10^{-3}$ estimated probability of an error of omission for items that are embedied in a procedure (Table III 6-1 in FASE-1400). This estimate was modified by assuming a $10^{-1}$ probability that either the inspection would not be carried out or the inspector would fail to notice that the switch was in the incorrect position. Thus, PI [F] $=3 \times 10^{-3} \times 10^{-1}=3 \times$ $10^{-4}$. The $10^{-1}$ estimate included the dependence between the operator and the inspector.. For the WASh- 1400 analysis, this gross estimate was adequate.

For plant-specific analyses, more precise estimates can be obtained by performing a detailed task analysis of each specific task, constructing one or more HRA event trees to indicate the success paths and the plausible failure paths, and assigning the appropriate estimates of conditional probabilities. of success and failure to the branches.

The most obvious sources of information for the ㅍRA event trees for the NPP tasks to be performed are the written procedures for the tasks themselves and the plant's operating rules for verifying the correctness of the tasks performed. However, basing the tree solely on written procedures and plant operating rules may not result in a complete and accurate picture of the human actions. It is necessary to follow up the study of the written materlal with observations and interviews, as described in the preceding chapter.

Once an HRA event tree has been constructed, any potential system failures resulting from a single human failure will be obvious. For example, if an auxiliary operator has to reopen a critical valve, if no one checks his work, and if there are no other recovery factors in the system, that error alone could result in system failure. Such errors represent first-order human fallure terms. An advantage of the BRA event tree is that these system-critical errors become obvious when the tree is drawn.

The HRA event trees also help the analyst identify possible common-cause fallure events where the common-cause is the human error. An example is 
the comon-cause failure potentiality in the misadjustment of the test equipnent used for calibration of sensors, described in the discussion of Figure 5-1.

Sensitivity Analysis

Because of the uncertainty associated with most of the data on human performance that is expressed in probabilities, it is often useful to perform a sensitivity analysis in which the estimated HEPs, dependence levels, stress levels, or other indices of human performance are systematically varied to determine the effects of such variation on system outcomes. In the performance of an HRA, insufficient information may be avallable for one to be certain whether the estimated HEP for a certain system-critical task is .003 or .01 . One approach to this problem is to perform relevant parts of the HRA twice, using both estimates, and to note if it makes any difference to the overall system analysis. If it does not, it will be adequate to use the .01 estimate. If it does make a difference, additional information should be obtained to emable a more accurate estimate to be made of the HEP.

Two types of sensitivity analysis have been used in ERA by the authors. One is the familiar worst-case analysis, in which highly pessimistic estimates of hePs are used in assessing the impact of human errors in a system. In design trade-off work, we have used a $10^{-1}$ HEP for all tasks involved in some assembly or test procedure to see if the system could tolerate a consistently high HEP. If the system has sufficient redundancy and recovery factors to tolerate the worst case, no detailed HRA may be required; the design may be judged adequate without further analysis.

The opposite case is the best-case analysis, in which highly optimistic estimates of HEPs are used in assessing the impact of human exrors on a system. In one such application, we wanted to find out if the addition of new equipoent to a system would be much better than merely retraining operators in the existing system and providing better procedures. In the existing system, several tasks were accomplished by clerical personnel. Even though their exror rates were low, those uncaught errors that did occur were very costly. It was possible to purchase a modification to the system that would accomplish the same functions performed by humans, but the modification involved a substantial one-time cost. After a task analysis of the operations performed manualiy, we determined that some improvement could indeed be made but without considerable study, data collection, and analysis, it would be difficult to arrive at accurate estimates of how much improvement could be achleved by retraining and the use of bettex designed procedures.

We therefore decided to use a best-case analysis in which we assumed that retraining and new procedures would result in an IEP of $10^{-4}$ for each relevant task. There are human activities that have HEPs that low or lower, but it would be unrealistic to think that all activities in the job could be performed with such accuracy. 
An HRA event tree was drawn using $10^{-4}$ for each fallure limb, and the total failure probability was calculated. The result was clear. Even assuming superaccurate humans, the old system would be much less reliable than the modified. system. The cost of the new system was justified. Had the comparison gone the other way, we would have had to perform adiitional analysis to derive more realistic estimates of HEPs.

Another form of sensitivity analysis is called a bounding analysis, In which both the worst-case and the best-case analyses are used to establish boundarles of the estimated influence of human performance in a system. The same HRA event tree is used, but two sets of total failure probabilities are calculated using two different sets of HEPs, one based on the worst-case HEPs and the other on the best-case HEPs. The former is said to define the upper bound of the total fallure probability and the latter the lower bound. This type of bounding analysis will usually result in extremely wide bounds. A different type of bounding analysis based on characteristics of distributions is described in Chapter 7.

A type of worst-case analysis often used early in a PRA reduces the amount of analysis necessary. Upper bounds or high values for failure probabilities are assigned to equipont and human events for initial screening. In the HRA, for example, rather than use the best estimate for each HEP, one uses a screening value that may be the best estimate multiplied by a factor of 2 or more. The idea is to see if a task with a high HEP will affect the system analysis. If it does not, the task does not have to be analyzed further. The major caution to be observed in using screening values in a PRA is to ensure that all task dependences are taken into account. Screening HEPs for rule-based tasks and for cognitive tasks are discussed in Chapter 12 .

\section{- General Form of an HRA" for PRA}

In the PRAs of NPP operations that have been done to date, the general approach used for HRA has been to identify, analyze, and to estimate EePs for human tasks that system analysts and human reliability analysts detersine could have major impact on system criteria of interest. This section escribes the approach to HRA used by SNL human reliability analysts as part of the Interim Reliability Evaluation Program (IREP). The SNI HRA is based on the use of the Handbook as the major source document and on THERP (including task analysis) as the major analytical tool. Except for minor changes to figure numbers and references and the underlining of some terms, the remainder of this section is a quote from Bell (1983).

Figure 5-4 shows the four phases of an HRA. In the first phase, famillarization, the hum reliability analyst is in the process of gathering plant- specific and event-speciflc information. The former he obtains from actually visiting the plant (if he is not already quite familiar with it) and becoming aware of the PSFs peculiar to it. He should at this time evaluate the plant's administrative control system and its test, maintenance, and restoration policies. The latter (event-specific) information can be obtained 


\section{FAMILIARIZATION}

- INFORMATION GATHERING

- PLANT VISIT

- REVIEW OF PROCEDURESIINFORMATION FROM SYSTEM ANALYSTS

- DETERMINE PERFORMANCE REQUIREMENTS

- EVALUATE PERFORMANCE SITUATION

- SPECIFY PERFORMANCE OBJECTIVES

- IDENTIFY POTENTIAL HUMAN ERRORS

- MODEL HUMAN PERFORMANCE

- DETERMINE PROBABILITIES OF HUMAN ERRORS

- IDENTIFY FACTORSIINTERACTIONS AFFECTING HUMAN PERFORMANCE

- QUANTIFY EFFECTS OF FACTORSIINTERACTIONS

- ACCOUNT FOR PROBABILITIES OF RECOVERY FROM ERRORS

- CALCULATE HUMAN ERROR CONTRIBUTION TO PROBABILITY OF SYSTEM FAILURE

\section{QUANTITATIVE ASSESSMENT}

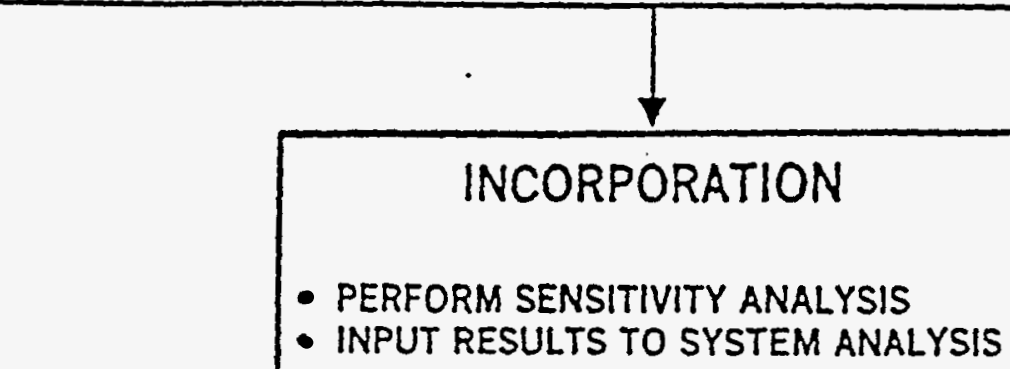

Figure 5-4 Four phases of human rellablilty analysis. 
at this time by the human reliability analyst if the scenarios to be evaluated have already been identified by the oystem analysts. If such is the case, the human rellability analyst is able to conduct on-the-spot task analyses of the events in question (part of phase 2). If this is not the case, he can gather information sufficient to allow him to complete his analyses at a later date by referring to them.

The second phase, qualitative assessment, involves preliminary analyses of the performance situations to be included in the HRA portion of the PRA. The human reliability analyst performs a rough task analysis of the actions required of the operators in responding to each situation. That is, he breaks down the operator actions into tasks and subtasks based on the action characterizations found in NUREG/CR-1278. It is not necessary for him to determine the motivation behind every operator action, but rather for him to be able to identify the most likely operator activities.

For each of these activities or tasks that the human rellability analyst identifies, possible human exrors must be pinpointed. In assessing the actual performance situation, the human reliability analyst decides which potential errors are likely. Each of these errors is included in the model of human response that is then developed. This model is a representation of the quality of the human/system interface in that from it certain system deficiencies can be detected.

The third phase of HRA, the quantitative assessment, involves developing a probabillstic statement of the likelihood of each system outcome as defined in the model constructed in phase 2. In other words, the human reliability analyst makes estimates of the probabillties of the human errors listed in the model. These estimates could be based on data stores, expert prediction, or extrapolation of existing data from similar actions. The effects of any factors acting on the situation that might alter the probabilities of the identified human errors must $a 150$ be quantified at this time, along with the probabilities of any possible recovery factors. Finally, the results of the quantified model can be applied to the definition of system fallure as established by the system analysts to determine the contribution of the probability of human error to the probability of system failure.

The fourth phase, incorporation, deals with the use of the results of the HRA. Sensitivity analysis can be performed in which the assumptions made in the original analysis are modified, and the analysis 1 tself 18 repeated to see what impact these assumptions had on the probability of system fallure. The results themselves are then input to the PRA.

The level at which incorporation occurs is a point of controversy in the current state of PRA. If this incorporation is performed correctly, there should be no numerical difference in the resulting 
"Validity" Of HRA Using TKERP

probability of system failure (see Figure 5-5). Bowever, there are more subtle implications of the level of incorporation chosen. It may be that the "higher" in the system model the HRA appears (the closer it is input to the system rather than to the component level), the less likely it is that important human-caused system interactions will be overlooked. For example, dependence between operators may link their manipulations of items of equipment from operationally dissimilar systems. This dependence may not be included in the system models as represented by the system analysts because of this operational alssimilarity. The controversy over the preferred level of incorporation of hRA into PRA continues. One method of incorporation is discussed in Bell and Carlson (1981). Resolution of the problem should not materially affect the performance of the actual HRA, but rather it should affect the emphasis placed on various parts of it.

Figure 5-6 shows a block diagram of one possible ordering of the basic steps of HRA as specified by THERP. This figure is reproduced from the December 1981 draft of NUREG/CR-2254 (Be1l and Swain, 1981a). It depicts the procedure followed for some of the IREP PRAs. The procedure is by no means static nor is it rigid. There are in practice several feedback loops that operate during the. course of the BRA. These are not reproduced here in order that the simplicity of the procedure may be more easily explained. The steps do not necessarily have to be performed in this exact sequence, although performing them out of sequence may lead, at least for the novice human reliability analyst, to inadvertent deletion of important aspects of the analysis. The steps in the procedure are discussed at length in NUREG/CR-2254 and summarized in Bell and Swain $(198 \mathrm{ib})$; this discussion will not be repeated here.

\section{"Validity" Of HRA Using THERP}

The quotation marks around "validity" are deliberate. There has been no real validity test of our predictions using TEERP. One's predictions are valid if they are borne out by real-world events. The majority of the applications of THERP since 1961 have been to military systems, often as part of system reliability studies that estimate probabilities of extremely improbable events or of events that would occur onjy in combat. Consequently, evidence to support our predictions in such studies is usually unavailable.

There have been a few occasions on which our estimates of HEPs could be verifled up to a point. Two of these are described. Both occasions dealt with the estimation of probabilities of error in assembing components for military systems.

One IRA involved predicting the probability that a system would fall because of unrecovered human errors during the production process (swain, 1980b, pp 104-5). One of the authors of the Handbook visited the

.j production plant and performed the usual task andysis. During the visit, 
Figure 5-5

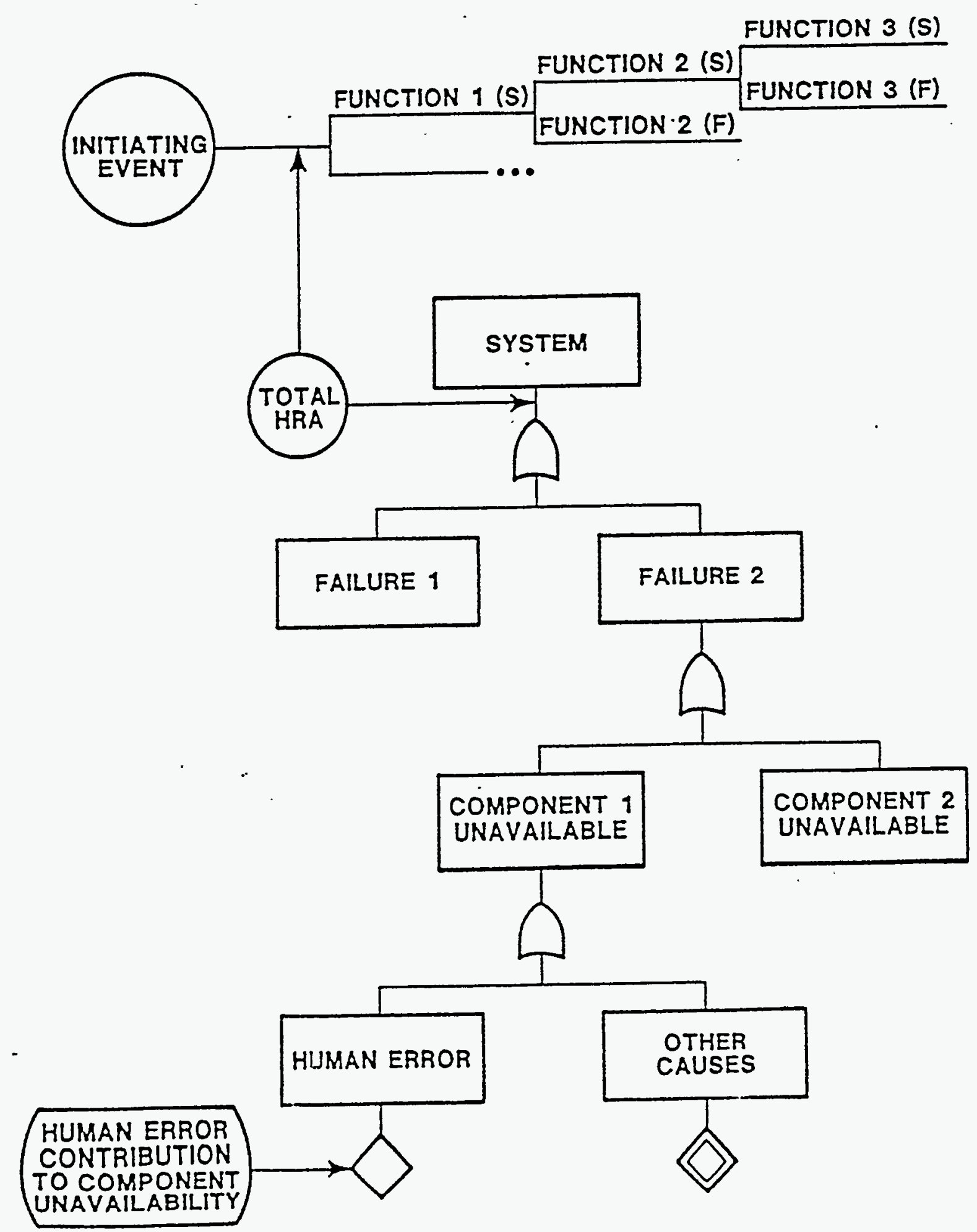

Figure 5-5 Two options for incorporation of HRA Into PRA. 


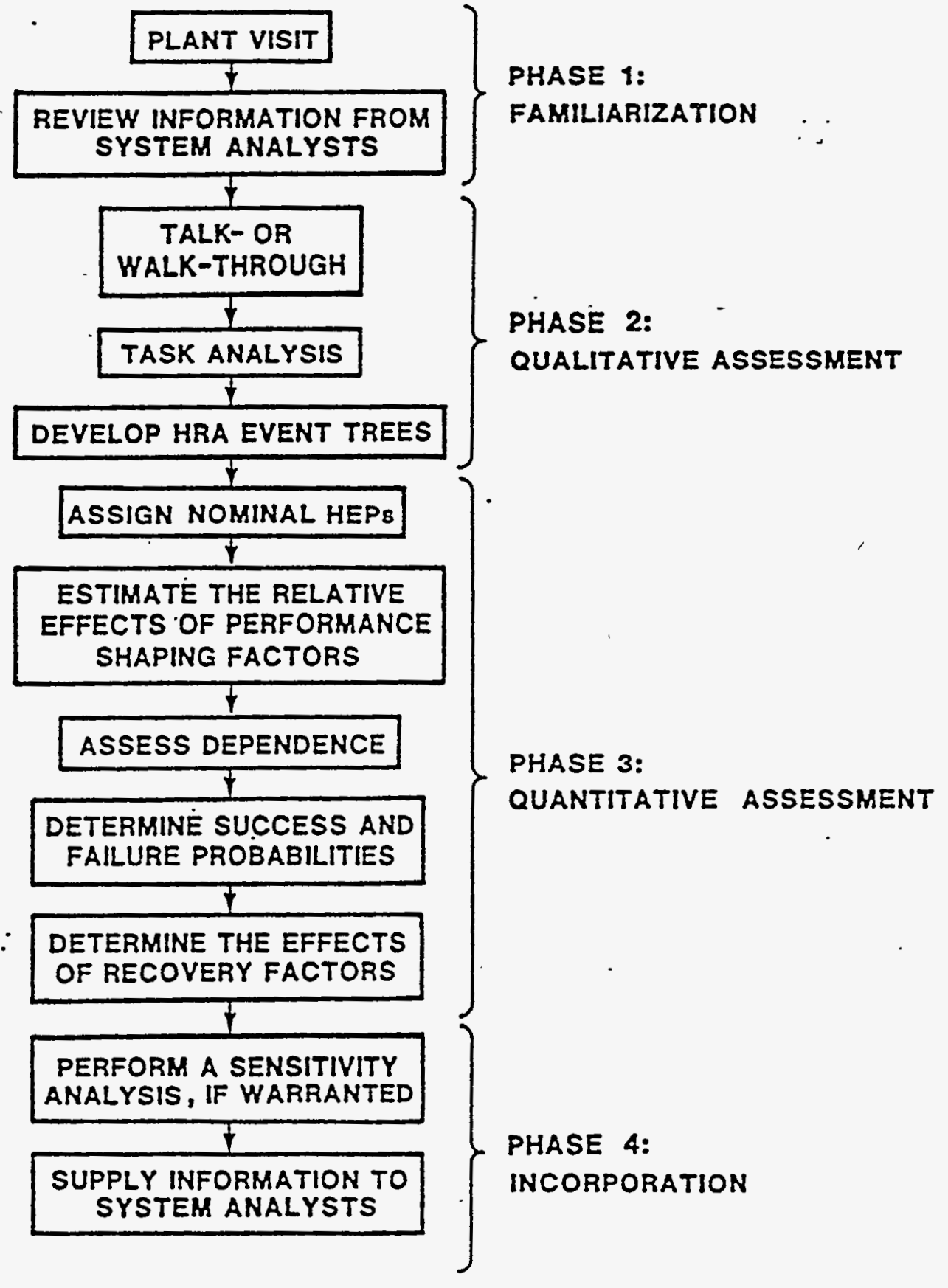

)

Figure 5-6 outline of a THERP procedure for HRA. 
he intervlewed workers, inspectors, foremen, and manufacturing engineers and observed all of the operations being performed. Using the information obtained by this analyst, the avallable paper work, and a working model of the equipment to be produced, both authors independently performed an BRA using the HRA event tree method.

There was considerable agreement between the two analysts in most of the HEP estimates. The few disagreements that occurred were resolved by asking a third member of the human. Ieliability staff to provide an independent estimate. In general, a voting concensus was used. On this basis, a composite estimate of fleld failure due to production errors was made.

The system was produced in quantity and fleld tested. Although fallures occurred, none could be ascribed to unrecovered production errors. Our estimate of production errors was within the 90 f confidence interval.

The other occasion for verifying our estimates of Heps has been reported (Swain, 1982a). Two hundred and eighty-four electronic components were installed in major systems. During a random check of one of the major systems, it was discovered that one of the two connectors in the component had a defect that resulted in a significant loss of reliability for that system. One of the authors of the Eandbook visited the plant, performed the task analysis (Including an interview and talk-through with the person whose error resuited in the defect), and generated the HRA event tree. He then showed the tree (without the estimated HEPs) to two other SNI human reliability analysts and described the results of his interview and talkthrough. The three analysts then independently evaluated the tree and assigned the appropriate HEPs. The estimated end-failure terms of the three analysts differed by less than a factor of 2. After discussion, the consensus estimate of the production error probability per component was .004 .

Subsequent to the analysis, 64 additional major systems were disassembled to check for similar errors. None were found. The analysis in Swain's paper shows that if the true probability of the error per component is .004 , the probability that a sample of 65 will have at least 1 bad component is .23. There is blas in the statistical test since the one failed unit was used in calculating the probability of at least one bad component. However, the bias is toward rejection of the assessment, which was not done, so the conclusion of an assessment of .004 is valid.

Although the verifications described above do not coristitute a complete validity check, they do provide some confidence in our estimates of HEPs when using THERP and the data in this Handbook to perform an HRA of procedure-based routine human performance in a well-structured manufacturing complex. In both instances, the estimates of the different analysts 
"Validity" of HRA Using. THERP

were in close agreement, and the composite estimates were not significantly different from the data that were observed subsequent to the estimates.*

The above examples 1liustrate another aspect of TrERP that has not been discussed thus far. There is room for a certain amount of subjectivity in arriving at exror probability estimates, and it is valuable to obtain independent estimates when available. The most difficult part of the job is the gathering of the basic information--the interviewing, the observing, and the filtering of all the avallable information. This "legwork" requires a degree of acumen that develops only with experience in the actual conduct of onsite task analyses.

Those interested in the history and use of THERP can refer to Rook, 1962, 1963, and 1964; Swain, 1963a and b, 1964a and b, 1967a.and b, 1969a and b, 1971, $1974 \mathrm{a}$ and $b, 1976$, and 1977a and $b, 1980 \mathrm{~b}$ (Ch. VIII); Rigby, 1967; Rigby and Edelman, 1968a; Rigby and Swain, 1968; Swain and Guttmann, 1975; and "Human Reliability Analysis," Section 6.1, Appendix III - Fallure Data, 1975, KASH-1400; Bell and Swain, $1981 \mathrm{l}$ and 1982; Bell and Carlson, 1981; Kolb et al, 1982a; Bell, 1983; and Bell and Kolb, 1983.

\footnotetext{
"It is perhaps fitting, or inevitable, that a paper on the "validity" of a technique to estimate human errors vould include a major human error. The equation for the significance level (SI) in Swain's paper left out the combinatorial term. The correct equation 15 as follows:$$
S I=\sum_{x=1}^{n}\left(\begin{array}{l}
n \\
x
\end{array}\right) p^{x}(1-p)^{n-x}=1-(1-p)^{n}
$$

where $n=$ sample size, and $p=$ assessed fallure probability.
} 


\section{APPENDIX C}

Explanations of THERP trees and Calculation Sheets

Contained in Chapter 6, Figure 6-17 through

Figure 6-20 


\section{C.1 THERP tree Results and Input Data Sheet}

This section refers to Figure 6-17 and Figure 6-18. The left (or results) side of the THERP tree and input data sheet contains the following:

\section{C.1.1 Human Event Designator and Title Section}

This section provides a four alpha-numeric designator, and the title of the human event corresponding to the title in the Human Sequence and Error Modes data sheet. The first two through four places of the designator represent the building location (e.g., Hot Shop, Hot Cell). The number (e.g., 01, 02) represents the numbered human event for that building area. An alpha following the number indicates a truncation of the human event because of options available to the performer either in an initiator or mitigator role. Base Case THERP trees for each event are presented first along with their failure path calculations sheets, followed by Best Case trees and failure path calculations sheets.

\section{C.1.2 Left or Results Side of THERP tree Data Sheet}

Human Event Designator and Title

Left or results side of the THERP tree Data Sheet:

THERP tree Cum Prob Median HEP Error Factor

Main PathsP(f) EF TotalP(f)

C.1.2.1 THERP tree presents the graphic description of the human event and error modes. Breaks in the alpha sequence of the left slanting axis indicate recovery is possible between error modes. The Technique for Human Error Rate Prediction (THERP) methodology used in this HPA (as described in NUREG/CR- 
1278) does not use the letter alpha " $\mathrm{f} /$ " $F$ " for a success/failure path since it is used later to designate the composite human failure probability (HEP).

C.1.2.2 Cum Prob presents component probabilities as they are combined to achieve the composite probability presented under Main Paths TotalP(f), and are the main contributors to the TotalP(f).

C.1.2.3 Cum Probs are the component HEPs for individual human error modes whose basic or nominal HEPs have been adjusted for impacts of human causal factors (HCFs), recovery potential, and dependency. Therefore, individual Cum. Probs. can also be used to support the NFF hazards and accident analyses.

NOTE: If an individual (component) HEP is used without regard to its recovery potential, its Median HEP value should be used in lieu of its Cum Prob.

C.1.2.4 Median HEP presents component probabilities derived from the right side of the data sheet impacted by HCFs and dependency, but not for recovery potential. Median human error mode HEPs and there recovery HEPs are multiplied to achieve a Cum. Prob. when there is a recovery potential. In cases where a recovery potential does not exist, the Median HEP and Cum. Prob. are the same number.

C.1.2.5 Error Factor presents component error factors derived from the right side of the data sheet for use in calculating the THERP tree.

C.1.2.6 Main Paths TotalP(f) and TotalP( $f)$ are the composite HEPs computed from the THERP tree. The Main Paths TotalP( $f)$ is the summation of Cum Probs. presented in the THERP tree Data Sheet. The TotalP $(f)$ represents the summation of all possible combinations of success and failure paths represented 
by the THERP tree (except for failure path probabilities less than 1E-06. This latter Total (f) represents the composite HEP for the THERP tree. The difference between the TotalP(f) and the Main Paths TotalP(f) represents a residual, that is, the contribution of tertiary paths computed as part of the THERP tree calculation.

C.1.2.7 $\quad E F$ is the composite error factor computed from the THERP tree. For the Base Case, the composite EF is the largest component error factor entered into the THERP tree. For the Best Case, the composite EF is the largest component error factor divided by 2 . Rounding where necessary is always to the next larger and more conservative number. 


\section{C.1.3 Right (or Input) Side of THERP tree Data Sheet}

\section{Human Event Designator and Title}

Right (or input) side of THERP tree Data Sheet:

$\begin{array}{llll}\text { Basic HEP } & \text { Basic EF } & \text { Basic HEP } & \text { Error Factor } \\ \text { SBS/DYN } & \text { HCF Modifier } & \text { HCF Method } & \text { Dependency }\end{array}$

C.1.3.1 Basic HEP presents the HEPs derived from the Accident Sequence Evaluation Program (ASEP) screening procedure described in NUREG/CR-4772.

C.1.3.2 Basic $\boldsymbol{E F}$ presents the error factors derived from the Accident Sequence Evaluation Program (ASEP) screening procedure described in NUREG/CR-4772.

C.1.3.3 SBS/DYN indicates whether error modes within a human event occur sequentially (SBS), or dynamically (DYN). Error modes for which recovery is possible are considered to be dynamic.

C.1.3.4 HCF Modifier is a number ranging from 1 to 10 . A score of 1 indicates a Best Case in which all of the HCFs are optimized (error is least likely). A score of 10 (shown as a 0 ) indicates a Worst Case (error is most likely). For initiator and mitigator human sequences, each of the five HCFs used in the HPA were allocated 2 points. These included training, procedures, oversight, experience, and Human Factors Engineering. Task Difficulty, a sixth HCF, was taken into account in selecting Basic or nominal HEP values using ASEP. See Figure 6-14 and Figure 6-15, and Appendix $A$ of this Course Text for a description of ASEP. Recovery was taken into account by assigning failure to 
recover values ranging from .001 through .5 to individual error modes. Dependency impacts were taken into consideration also using ASEP.

C.1.3.5 Source indicates from whence the Basic HEP and Error Factors were derived. For NFF, all Basic HEPs and Error Factors were derived using the ASEP procedure.

C.1.3.6 HCF Method indicates the method used to achieve the HCF Modifier score. For TEEN, given its Hazard Category 2 classification, a modified verification procedure (Pver) for training, procedure, oversight, experience, and human factors engineering (HFE) was used. See HCF Modifier discussion above.

C.1.3.7 Dependency indicates degree of dependency or conditionality between error modes in the THERP tree. For NFF, almost all THERP trees involved error modes having ZD (zero dependency).

\section{C.2 Failure Path Calculation Sheets}

This section refers to Figure 6-19 and Figure 6-20. A single or multiple page failure path calculation sheet is provided behind each THERP tree Results and Input Data Sheet. The purpose of the failure paths calculation sheet is to provide a computational audit trail for the HPA.

Failure Path

Calculations

Median/Mean 


\section{C.2.1 Failure Path}

The failure path indicates the combinations of THERP tree branch and slope entries whose numeric values are multiplied together, and whose products are combined to produce the composite HEP TotalP(f).

NOTE: A computer program HEPGen, developed by the Idaho National Engineering Laboratory was used for this HPA. HEPGen does not print out THERP tree branch/slope failure path combinations that achieve products less than 1E-06.

\section{C.2.2 Calculations}

The calculations indicate the product of the numeric values for individual failure paths.

\section{C.2.3 Median/Mean}

The median/mean presents the calculated median and mean human error values for individual failure paths.

NOTE: Median values are the focus of the HPA since they were being used for overall NFF hazards and accident analyses calculations. 